\title{
I am undone by these women: Identity and change in a feminist domestic violence organisation
}

By

Ruth Weatherall

\begin{abstract}
A thesis
Submitted to the Victoria University of Wellington

In fulfilment of the requirements for the degree of

Doctor of Philosophy
\end{abstract}

Victoria University of Wellington

2018 


\section{Abstract}

The six words of the title, 'I am undone by these women', embody the interconnected dimensions of this thesis. Simultaneously, this thesis is a personal transformational project (the 'I am'); a series of theorisations of the relationship between identity and change in the context of the community sector (the 'undoing'); and a textual space through which I share the working lives of my participants and victims of violence (the 'these women').

My experiences as a volunteer ethnographer sit at the heart of this thesis. The ethnographic project was undertaken in the community sector, with a feminist domestic violence organisation in Aotearoa New Zealand. Through this project, I became committed to the social justice cause of my colleagues and participants: ending violence against women. My thesis aims to (re)create the textures of the working lives of my colleagues and participants. To represent these textures, I suffuse emotions and contradictions into this thesis through writing personally and subjectively and through adopting a rhizomatic (non-linear) structure in order to foster affective connections between the reader, the writer, my colleagues, and victims of violence.

The 'undoing' in this thesis relates to how my theorisations developed over this project through a mixture of my own emerging understandings of identity, reflections on my ethnographic experience, and on issues salient to the working lives of my colleagues. My thesis traces the lines of my thinking about the relationships between identity and change in the context of the community sector, showing how they shifted before, during, and after my ethnographic experience. My thesis is structured into five parts. Each part acts as a semiindependent node of thought; following similar lines about identity and change but flourishing in different intellectual territory. This rhizomatic structure emphasises how feeling identity during my fieldwork changed how I thought about identity for my thesis. Or in other words this structure maps how my thinking became 'undone' and the relevance of this undoing for understanding identity and change.

Initially, I map my thinking about the concept of identity as situated in the Critical Management Studies literature, particularly in relation to the work of Judith Butler and narrative theory. In the further parts of the thesis, I follow some of these initial lines of thought, but circle away from others. One part contributes to the literature about alternative organisations. In this part, I argue that strong emotions are important for fostering collective responsibility in alternative organising - here for victims of violence. Another part 
contributes to the literature on the gendered body. Here, I argue that gender identity becomes unsettled through the body in domestic violence work because of repetitive exposure to gender violence. Accordingly, both celebrating and reconsidering gender identity in domestic violence work can help to achieve change for all women subjected to violence. In a further part, I contribute to literature on the micro-politics of identity. I argue that storytelling about feminist identity can help to foster solidarity in the context of the community sector. Ultimately, this thesis puts the emphasis on the different ways identity and change are interlinked; there is no centre point to the argument.

In the vein of autoethnography, the 'undoing' and 'these women' are also understood through an exploration of who 'I am' as a scholar. I understand the thesis to be a formative process through which the doctoral student learns what it means to be a researcher in their field. I map how my identity as a researcher was unsettled as I came into contact with domestic violence work and workers. In this way, I also explore what is learnt about identity and change on a personal level. 


\section{Acknowledgements}

As with any project of this nature there are many people to whom I owe my sincerest gratitude:

My first thanks must go to the wonderful women I was lucky enough to volunteer alongside and who form the heart and soul of this work. Thank you also to all my other participants for taking the time to share your passion for making our country a better place.

To those at my university:

Thank you to the three people I was fortunate enough to have as my supervisors: Sarah, Todd, and Deborah. Sarah, thank you for your invaluable guidance in the early stages of my thesis and for finding the perfect balance between letting me explore and helping me find my way. Thank you for your continued interest and feedback on the late stages of this thesis. Todd, thank you for joining my supervision team and helping me to find my voice. Thank you for the faith, the enthusiasm, and for being an endless source of inspiration. Deborah, thank you for all your immense support throughout my time at university, and especially across the whole $\mathrm{PhD}$ process. Thank you for always making my work richer and encouraging me to think deeper, and for your invaluable passion and encouragement. Thank you to all the academic and administrative staff at my university that supported me through my PhD, with especial thanks to Dr Sally Riad, Dr Noelle Donnelly, Carine Stewart, and Megan Key. Thank you to my various office mates over the years: Dominik, Hongxia, Sandra, Geoff, Bernhard, Avigail, Rebecca, and Esme. Thank you for all your support. And thank you to the other members of our $\mathrm{PhD}$ and Masters cohort for our forums, our symposium, and for sharing stories of our mutual journey. It's been a pleasure to get to know you all. Thank you also to Victoria University of Wellington for the scholarship without which this research would not have been undertaken.

To those outside of my university:

Thank you to my family for your love. To my grandparents who I wish could see me graduate, to my Mother and Father for their unquestioned belief in my ability and their endless support, to my siblings Eva and Paul for being all the best parts of me, to my Aunt Ann and my cousin Helen for their love and interest, to my Uncle Ian and Aunt Sharon for hosting me during my time in London. 
Thank you to all those who supported me in developing my work. Particularly: to Ang for seeing the value in my research, to Natalie for the solidarity and study dates, to Jo and Eda for helping me at the outset of the writing process, to the members of my writing group, especially Claire and Ellie for the solidarity and feedback, and to the wonderful folk I met during my summer in the UK for making our conferences and summer schools an unforgettable experience.

Thank you to all my friends outside my university. Particularly: to Kathy for the long walks and many cups of tea, Maggie for tennis and dinner, Brittany for our ramblings in St. Albans, London, and Cambridge, and to Rachel for the music which kept me sane. My especial thanks to Alex for being close when you were far away and for always sharing my good days and my bad days, and to Nina for making it feel like we weren't the world apart and for always inspiring me to be better and do more. 


\section{CONTENTS}

$\begin{array}{lr}\text { PrefaCe } & 4\end{array}$

$\begin{array}{lr}\text { SETTINGS } & 5\end{array}$

I. THE INTRODUCTION 6

II. THE THEORETICAL QUESTION

III. THE KEY CONCEPTS $\quad 8$

$\begin{array}{ll}\text { IV. THE ETHNOGRAPHY } & 10\end{array}$

V. THE FIELD OF CRITICAL MANAGEMENT STUDIES 11

VI. THE WRITING 13

Part I: Beginnings

$\begin{array}{lr}\text { THEORETICAL BEGINNINGS } & 18\end{array}$

$\begin{array}{ll}\text { Theorising identity: A starting point } & 19\end{array}$

Situating the identity literature in the CMS context 24

Initial theoretical frameworks 28

Theoretical beginnings in brief 35

Contextual Beginnings $\quad 38$

Community organisations in the organisational literature $\quad 38$

The community sector in Aotearoa New Zealand 42

Contextual beginnings in brief 46

$\begin{array}{ll}\text { Methodological BeginNings } & 47\end{array}$

$\begin{array}{ll}\text { Feminist orientations } & 47\end{array}$

$\begin{array}{ll}\text { An ethnographic approach } & 50\end{array}$

In the field: Gathering and analysing empirical material 64

BEGINNINGS IN BRIEF: WHERE TO FROM HERE?

PART II: TIES THAT BIND; TIES THAT BREAK

A familiar tale of the community sector 79

Alternative understandings; alternative organisations 85

On emotion and organisation $\quad 89$

Emotion in alternative organising $\quad 97$

$\begin{array}{ll}\text { Ties that bind; Ties that break } & 117\end{array}$ 
Domestic violence (DV) and identity in the literature 123

In the lunch room: The body and gender identity 127

LGBT+ identity and domestic violence $\quad 134$

Radically unsettled identities $\quad 146$

Gendered bodies at the intersection of DV work 154

Part IV: A Multiplicity OF Feminisms 158

Social justice identities and change 161

Giving an account of feminist identities 166

Organising for solidarity through a multiplicity of feminisms $\quad 182$

Organising from different directions 196

$\begin{array}{ll}\text { PART V: ENdings } & 200\end{array}$

$\begin{array}{ll}\text { APPENDICES } & 210\end{array}$

REFERENCES 


\section{LIST OF TABLES}

TABLE 1. First PHASE PARTICIPANTS

TABLE 2. EXAMPLE QUESTIONS FIRST PHASE INTERVIEWS 66

TABLE 3. EXAMPLE THREE ROUND INTERVIEW QUESTIONS 
There must always be

A first victim. Maybe not the very first, But the one that shocks. The one that says: 'hey, look'. The one we can't let go.

The more I came to know my colleagues, the more details of their stories would come back and replay in my memory: Evelyn's ${ }^{1}$ mother shaking her and screaming at her when she was 7 years old, blaming her behaviour for the sickness in her family; Tia's mother being chased around a car with an axe in a childhood described by Tia as devoid of domestic violence; Kimberley feeling uneasy around locked doors because they bring back debilitating memories of rape; Ava's lonely childhood being told that she should be seen but not heard; Emily relapsing into substance abuse because of overwhelming feelings of being unworthy, which were compounded by an experience of sexual violence; Jen lying in hospital as a demonised teenage mother and not being able to hold her newborn for ten days. I sometimes see this when I look at these women; I see the hurt, the vulnerability, and the violence.

Sometimes I would look at them and see a diverse group of professional women bound together by a passionate anger against a system that condones violence against women. I would see Evelyn valuing all of her past life relationships, and seeing every man, woman, gang member, abuser, and victim she knew as worthy of support; Tia pushing for a practical approach to getting things done, stoically listening and caring about everyone as people; Kimberley using her keen sense of humour and absolute talent for her work to share it with others; Ava drawing on her need for connection to frame a collectivist approach to relationships in the office; Emily embracing her vulnerability to put herself forward and to take all the criticism she was given on board to improve the quality of her work; Jen mixing a tangible aura of no-nonsense strength, acute professional intelligence, and a deep-felt compassion to ceaselessly advocate to the government for improved care for abused women. I see the potential they hold, individually and together, for making the world a better place.

I am undone by these women.

\footnotetext{
${ }^{1}$ All names are pseudonyms.
} 


\section{SETTINGS}




\section{Setting: The introduction}

The sense of unfamiliarity on opening a thesis as a reader can be very similar to the unfamiliarity of walking into an organisation for the first time. In a new organisation there is a sense of strangeness as the space and faces blur around you. You're desperately trying to remember all the names of the people you meet so as to keep track of who they are and what they represent; you are introduced to an abundance of knowledge - some of it new, some of it well-known; and you're trying to get a sense of the purpose and how all the pieces fit (or don't fit) together to fulfil a certain goal. You probably also have a lot of questions like: "What will working here be like? How am I to understand this organisation? What are we going to achieve?", and expectations that over time the unfamiliarity will dissolve into an intimacy with the daily workings of the organisation.

Thankfully, when you walk into most organisations you have a guide who will give you a whirlwind tour of the key aspects of the organisation, so that you can orient yourself and find your feet. The 'Settings' section offers that guide for you for this thesis. You've already met the most important aspect of the thesis, the women I worked with during my fieldwork. The women you met will begin to take on increasing fullness and complexity in the empirical parts (Part II, III, and IV) of this thesis. The other 'Settings' will provide you with the rest of an orientation, so that the blurry unfamiliar will start to take shape, and that some of your questions will be answered (at least initially). In the 'Settings', I briefly introduce you to the theoretical question at the heart of this thesis, the key concepts that I will develop, the academic field within which I situate this research, and the writing and structure of the remainder of the thesis.

After this whirlwind tour of the key aspects we move to developing an intimacy with the minute workings of this thesis in Part I - Beginnings. 
II. Setting: The theoretical question

My thesis explores the various ways in which identity becomes unsettled in the context of social justice community work, and argues that in this context remaking our identities by drawing on lived experience in and beyond the organisation is an essential part of catalysing change. The research question that this thesis addresses is:

In which novel ways can identity be understood to act as a catalyst for change in the context of the community sector?

'Beginnings' (Part I) provides some of the theoretical foundations for answering my central question, but it is in the empirical parts - 'Ties that bind; ties that break' (Part II), 'Vulnerable bodies' (Part III), and 'A multiplicity of feminisms' (Part IV) - of this thesis that I develop multiple perspectives on the relationships between identity and change. Emotions, bodies, and feminisms are the subjects of the empirical parts of the thesis respectively. In the empirical parts of this thesis I address additional questions that were formed through my experiences in the field. 


\section{Setting: The key concepts}

Identity is the central concept of this thesis. I understand identity broadly and define it as 'a sense of self'. I approach the concept of identity from a post-structuralist perspective, and understand identities as social constructions that are fragmented, multiple, and constituted through discourse (Hall, 1996). Significantly, I understand identities to be constructed through fields of power which shape and constrain how identities are understood and which identities are valued. I develop and discuss the concept of identity throughout this thesis, but the background to my understanding of identities from a post-structuralist perspective can be found in 'Beginnings' (Part I).

The ways in which identity is tied to change is the locus of the thesis. I understand change as occurring at multiple and interconnected levels of personal change, organisational change, and social change; which although not wholly divisible are usefully analytically separated. Identities are part of the continuous process of co-constitution between individuals, organisations, and society. A person's identity is shaped and constrained by their organisational and social context. If people move between different organisations and social contexts their identities also shift and change. People can also enact their identities in new ways which can shift power relations and, because they are intertwined, they can catalyse organisational and social change. My initial theoretical background for understanding the relationships between identities and change can be found in 'Beginnings' (Part I), and the remainder of the thesis develops novel perspectives on understanding the relationships between identities and change.

The empirical parts of this thesis, 'Ties that bind; ties that break' (Part II), 'Vulnerable bodies' (Part III), and 'A multiplicity of feminisms' (Part IV), develop an understanding of identities and change in direct reference to catalysing change that will help to end violence against women in Aotearoa New Zealand ${ }^{2}$ (NZ).

The community sector and community organisations are the final key concepts embedded in this thesis. This thesis is based on an ethnography that I conducted with a domestic violence organisation in the community sector in Aotearoa New Zealand. The community sector, sometimes called the third sector, is a vast and loose collection of organisations that are not-

\footnotetext{
${ }^{2}$ The use of the name Aotearoa New Zealand includes both the Māori and English names for our country. This choice is a political position which is discussed further in the 'contextual beginnings' and 'methodological beginnings' sections of Part I.
} 
for-profit, involve a meaningful degree of voluntary participation, and are separate from the government (J. Sanders, O'Brien, Sokolowiski, \& Salamon, 2008). I focus specifically on social service community organisations with social justice missions. In 'Beginnings' (Part I), I introduce theorising around community organisations and the context of the community sector in Aotearoa New Zealand. The discussion in 'Beginnings' (Part I) acts as a frame for a more detailed and localised discussion of the community sector in 'Ties that bind; ties that break' (Part II). 


\section{Setting: The ethnography}

An ethnography sits at the heart of this thesis. I undertook a yearlong field study grounded in a feminist ethnographic methodology in the community sector in Aotearoa New Zealand. My ethnography was separated into two phases. In the first phase I engaged in interviews with 15 experts whose work intersected with social justice community organisations. In the second phase of my field study, I became a volunteer in a domestic violence organisation for eight months and worked for the organisation while also engaging in participant observation and interviews with the members of the organisation. I refer to my field site simply as 'the organisation' throughout the text. I discuss my research design in depth in 'methodological beginnings' in 'Beginnings' (Part I). The preface of this thesis introduced you to my colleagues and some of the details of their lives. In the empirical parts of this thesis I tell more stories of day-to-day working life in the organisation, recount conversations, observations, and stories from my voluntary work, and give more depth to the lives of my colleagues.

Fundamental to this thesis are the ways I became emotionally involved in social justice work relating to domestic violence. My strong emotional investments in my voluntary work were central to the development of the theoretical contributions of this thesis. As I go on to explain in 'Setting VI', the structure and writing of my thesis refracts my strong emotional investments and my experiences in the field. 


\section{Setting: The field of Critical Management Studies}

Engaging in 'critical' research about organisations within the field of Critical Management Studies (CMS) signifies a dedication to questioning mainstream knowledge and theorising surrounding business and organisation, and a thorough consideration of the ways in which power shapes relations between socially diverse people and patterns of organising (Alvesson, Bridgman, \& Willmott, 2011). Such research is often sceptical of the concept of management and is critical of the application of regimes of managerial control which perpetuate suffering, particularly of already marginalised groups in society (M. Parker, 2002). My research contributes broadly to this project by continuing to question mainstream theorising around identities, and giving thorough consideration to the ways in which certain kinds of organising - namely feminist organising and community organising - are overlooked and undervalued within critical research.

There are many contemporary considerations of what CMS is and does (e.g., Alvesson et al., 2011; Malin, Murphy, \& Siltaoja, 2013; A. Prasad, Prasad, Mills, \& Mills, 2015; Pullen, Harding, \& Phillips, 2017b) as well as now 'classic' texts about Critical Management Studies (e.g., Alvesson \& Willmott, 1992). However, although there is, generally, a strong sense of what CMS is against, there is less agreement as to what CMS stands for, and which ethical and political organisational practices it wishes to promote (M. Parker, 2013; Pullen, Harding, \& Phillips, 2017a). What CMS is against tends to include capitalism, profit maximising activities and ideologies, social inequalities such as racism, environmental irresponsibility, and neo-liberal practices (Pullen, Harding, et al., 2017a). Establishing a politics of what CMS is for tends to be less well fleshed out, and many studies seem to move from strong critical theorising, to a weaker set of vague ethics and politics about what is to be done (M. Parker, 2013). In particular, there have been strong feminist critiques of CMS (Pullen, Harding, et al., 2017b) that argue that CMS continues to reify gender, race, and postcolonial (among other) inequalities it purports to dismantle thereby undercutting the potential of CMS to foster sustained change. I engage with these debates later in 'Beginnings' (Part I). Throughout this thesis I situate my research in relation to the ethical and political imperative of ending violence against women and how patterns of organising assist (or constrain) this endeavour. Situating organisational research in relation to the sub-discipline of Critical Management Studies is not necessary to engage in critical or political research. It is, however, useful for providing a context to the debates with which my research engages, and the currents of 
politics that underpin both the motivation behind the research and the shape of the discussion.

Consequently, I have situated my research within CMS and engage with several contemporary debates about a political and ethical imperative for critical work throughout this thesis. 


\section{Setting: The writing}

I engage with ideas about writing differently throughout this thesis. Writing is a central concept to the PhD thesis, as Kamler and Thomson (2006) note:

What writing [a thesis] creates is a particular representation of reality. Data is produced in writing, not found. And the data and subsequent texts that are written are shaped and crafted by the researcher through a multitude of selections about what to include and exclude, foreground and background, cite and not cite (p. 4).

Thesis writing has, however, generally followed a very normative and scientific pattern, with a linear orthodox structure of 'introduction - literature review - methods - results discussion - conclusions' (Honan \& Bright, 2016). Although scientific writing has benefits for demonstrating the mastery of certain research concepts expected through a $\mathrm{PhD}$, it is also constraining of novel ways of creatively engaging with conceptual and empirical material. Part of my interest in writing differently derives from my background in the field of English Literature. Writing and reading matter to me deeply as an endeavour to understand what it means to be human, imagine different ways to be human, and to expand the possibilities of being human. Carefully considering how my writing was contributing to my understanding and the reader's understanding of what it means (or could mean) to be human in the context of this thesis is, therefore, a central concern.

Moreover, writing has become an increasing focus in Critical Management Studies, with growing arguments for writing in less scientific ways (C. Grey \& Sinclair, 2006) and in ways that explore the possibilities of more feminine writing (Pullen \& Rhodes, 2015) to open up the critical and creative potential of critical research. The setting of writing for my thesis is therefore particularly significant as one of my central aims was to critically and creatively explore novel ways of theorising identities. Experimenting with different ways of writing the thesis can support this endeavour. I will here briefly outline writing strategies I used which will frame the style and structure of the thesis. Significantly, my writing strategies engage with some of the key dimensions of my ethnographic experience including, emotion, messiness, violence, and the variety and complexity of the identities of my colleagues.

The first key writing strategy is to write in, rather than out, the emotional dimensions of my ethnographic experience (and those of my colleagues) and maintain a personal tone throughout the thesis. My first writing strategy aims to add to what we feel as well as to what we know (Rhodes, 2015). Secondly, I have reshaped the structure of the thesis (discussed 
below) to emphasise that knowledge is not total, linear, or neatly ordered. Writing in this way helps to counter the feeling of deadlock in specific ways of knowing (Steyaert, 2015).

Thirdly, I oscillate between theory and empirical material throughout the thesis, refusing the impulse to reorder my thesis to put the most salient theoretical material up-front. Doing so creates a stronger dialogue between the lived experiences of my colleagues and the theoretical material. My final writing strategy aims to recreate the textures of our experiences and our lives in ways that are consistent with our complexities as people (Lorde, 2007). The writing and structure of my thesis works with, rather than against, the emotional, messy, and complex experiences of fieldwork and research.

The structure of this thesis plays with the orthodox format. Instead of a linear series of chapters that separate out the findings, discussion, and conclusions and foreground these with a holistic summary of relevant literature, each part of this thesis is more self-contained. I've called this thesis structure 'rhizomatic' and discuss this structure thoroughly at the outset of 'Beginnings' (Part I). In this thesis instead of 'chapters', I have opted to structure this thesis in five 'parts'. For me, chapters imply a succession of linear thinking that follow on from each other sequentially to form a 'whole'. Alternatively, the concept of parts that I've used to structure this thesis refers to different aspects of a more ambiguous process that represent a series of partial attempts to understand social phenomena. Knowledge is not so total, conclusions are not always neat, social phenomenon do not necessarily become clearer through rigorous study (Pullen \& Rhodes, 2008).

I have several reasons for structuring my thesis in this way. Firstly, the (seemingly) total integration of the literature into the beginning as a frame serves to provide an unwarranted perception of wholeness of research. Writing 'literatures' up-front locks us into particular ways of knowing and operates to fix certain understandings of theory. As Kondo (1990) argues: "the structure of conventional ethnography sandwiches the 'data' in the body of the book, leaving 'theory' for beginning and end... [alternatively, we can understand that] 'theory' lies in the enactment and in writing strategies, not simply in the citation and analysis of canonical texts" (p. 304). Avoiding this " "straightforward' track of the genre of linearity" (Steyaert, 2015, p. 164), can help us to open up the possibilities of thinking differently about theory, and about how we amalgamate theory to the lifeworlds of our participants, colleagues, friends, and family. The structure of my thesis experiments with ways of amalgamating theory and empirical material, as well as attempting to break with an orthodox structure by producing a less linear thesis. 


\section{PART I: BeginningS}


'Beginnings' (Part I), maps multiple beginnings of this thesis. I weave through three traditional beginnings of academic research: theoretical beginnings embedded in various 'literatures' considered relevant to the project; contextual beginnings embedded in various empirical settings in which fieldwork is carried out; and the methodological beginnings embedded in the methodological literatures and the research activities in empirical settings. Although 'Beginnings' (Part I) introduces important theoretical, contextual, and methodological material influential to this thesis - and in particular influential to the research design - the remainder of the thesis does follow on from this material directly. The structure of 'Beginnings' (Part I) and the structure of the remainder of the thesis is rhizomatic, in that the structure is non-linear and new lines of thought are introduced throughout the thesis that circle away from what is found here in Part I.

In Thousand Plateaus: Capitalism and Schizophrenia, Deleuze and Guattari (1987) suggest that the structure of a book (or in my case a thesis) could take inspiration from the rhizome. A rhizome is a type of plant that instead of having a singular root, consists of multiple, semiindependent nodes that follow the same line, but which grow and spread in their own way. As they describe: "any point of the rhizome can be connected to anything other, and must be. This is very different from the tree or root, which plots a point, fixes an order" (p. 7). Through this conceptualisation they suggest non-linear or hierarchical ways in which research, argumentation, and concepts could be structured. Structuring writing in a rhizomatic way means that there is no 'root' from which all branches and leaves bud and develop, but there are ceaseless connections formed in semiotic chains, overlapping lines are followed rather than fixed points, there are multiple entryways, and there are multiple points of breaking and reconnecting. My thesis does not radically apply the concept of the rhizome, but I take inspiration from the metaphor for structure and research. 'Beginnings' (Part I) is not a 'root' but circles of overlapping lines that now spread and grow in new directions.

Rather than fixing our writing and research as hierarchical, linear, and rooted, we can think of our writing and structure as a multiplicity which occurs along multiple, overlapping and divergent axes (Steyaert, 2015). Deleuze and Guattari (1987, p. 11) argue that we should take inspiration from:

The wisdom of plants: even when they have roots, there is always an outside where they form a rhizome with something else... follow the plants: you start by delimiting a first line consisting of circles of convergence around successive singularities then 
you see whether inside that line new circles of convergence establish themselves, with new points located outside the limits in other directions.

In Part I, I wander through three circles of theoretical convergence: identity theory, the community sector, and ethnography. The literature that encompasses each of these broad topics is presented as a 'beginning' of my research. In other words, each 'beginning' maps my thinking about these respective topics which informed my research design and understanding of my key concepts before I engaged in my fieldwork.

In 'Theoretical beginnings' I discuss the identity literature in Critical Management Studies. I map two of the key themes of the literature - identity regulation and identity work - and discuss how they contribute to our understanding of identity and change in organisational contexts. I then situate the identity literature in the broader context of the politics of CMS, highlighting how the power relations within CMS have shaped the theorisation of identity and the currents of interest. I conclude my discussion of the identity literature by outlining three theoretical frameworks that were influential to my thinking at the outset of this project. Subsequently, 'Contextual beginnings' discusses the context of the community sector both within the literature and within the empirical context of Aotearoa New Zealand. I extend my critique of the identity literature by drawing on some of the central themes in the community sector literature. Finally, in 'Methodological beginnings' I delineate the methodology of my project and introduce my engagement with the community organisation at the heart of this thesis. Rather than 'Beginnings' (Part I) being a 'root' from which all the branches and leaves of this thesis bud and develop, the remainder of the thesis develops in a non-linear way. Each subsequent part acts as a semi-independent node that grows and spreads in its own way; connected to the lines of 'Beginnings' but flourishing in new fields of thought. I come back to this point at the close of 'Beginnings' and discuss how the thesis develops from the material covered here in Part I. 
Part I: Beginnings

\section{Theoretical beginnings: Contours and possibilities of identity in Critical Management Studies}

I started this project by developing my understanding of how scholars in organisation studies think about identity. In 'Theoretical beginnings', I trace some of the central debates in the identity literature situated in Critical Management Studies that formed part of the impetus for my study. In all of my discussion of the identity literature, my focus is on research that intersects in some way with fostering change. A primary motivation for this project was to consider novel ways that scholars could help to address social inequalities and (as I go on to illustrate) I saw the identity literature, with its contributions to understanding power and resistance in organisations, as a useful body of literature for aiding in this endeavour. As I have already highlighted in my overview of the rhizomatic structure of the thesis, the identity literature discussed in 'theoretical beginnings' does not neatly anticipate later parts of this thesis. Research is a messy, emotional, and dirty process, and writing strategies can productively evoke vagueness, incompleteness, and uncertainty by refusing the impulse to tidy up and order (Pullen \& Rhodes, 2008). In this section I therefore offer an incomplete and untidy map of thinking about identity, rather than re-tailoring the literature to foreshadow a forthcoming analysis of my colleagues' identities.

Additionally, what I discuss here is focused primarily on what I thought about identity during the initial phases of this research. In the later parts of this thesis I focus more on the interrelationships between how we think about identity and what we feel about identities. As Campbell (2013) argues, becoming emotionally involved with a research project can shift how researchers engage with a problem. In her case, the confronting dimensions of research surrounding rape that she felt, changed how as a researcher she thought about the problem. Similarly, my engagement with my colleagues shifted my understanding of the relationships between thinking about identities and feeling identities in relation to domestic violence. In order to explore how to creatively interweave theory and practice and how we can more effectively communicate how we feel identities as well as think about them, I engage with the most salient literature around identities in the community sector as it becomes pertinent in the empirical parts of this thesis. In 'theoretical beginnings', it is nonetheless useful to cover what I thought about identity, as it informed my research design and formed the foundations of my interest in feminist and post-structuralist perspectives on identity. 


\section{Theorising identity: A starting point}

Identity research situated in Critical Management Studies has established that the concept of identity is a valuable way of understanding power and resistance in organisations (Alvesson, Lee Ashcraft, \& Thomas, 2008). Central to critical approaches to identity in organisations has been a reactionary concern to positivist approaches to identity. Positivist identity literature tends to build from two dominant perspectives, one grounded in an approach from sociology called social identity theory which characterises identity as a positive or negative belonging to a social group (Tajfel \& Turner, 1979), and the other in an approach from psychology termed identity theory which characterises identity as sets of social roles from which individuals derive personal meaning (Burke \& Stets, 2009). The aim of most positivist literature is to understand the possibilities of overlap between an individual with a unique identity and her/his identification with the organisation which may increase (or decrease) organisational performance, motivation of employees, and the efficacy of management practices (Albert, Ashforth, \& Dutton, 2000; Ashforth, Rogers, \& Corley, 2011; Ashforth, Schinoff, \& Rogers, 2016). Positivist perspectives assume that identity is separated into discreet, but interrelated, levels of individual, group, organisational, and industry (Ashforth et al., 2011; Ramarajan, Berger, \& Greenspan, 2017); relates to what makes an individual unique from the social surroundings (Ashforth, Harrison, \& Corley, 2008); and is a root concept necessary to understand how to effectively manage individuals in an organisational context (Albert et al., 2000).

Critical scholars have a common twofold critique of the positivist identity literature. The first is a criticism of the values of functionalist approaches which attempt to utilise identities for (typically commercial) organisational ends. Positivist studies tend to assert that 'managing' (or controlling) identities of organisational members is necessary for fostering ideal workers who support a managerial agenda. Statements such as "increasingly, an organization must reside in the heads and hearts of its members" (Albert et al., 2000, p. 13) are common justifications for scholarly explorations of identity, but are incredibly problematic as they assume that managerial control over individuals is necessary and positive. Organisational control mechanisms regulate the identities of organisational members and influence them into adopting organisational values and norms. Examining how organisational members resist such mechanisms is therefore essential for critical scholars (Fleming \& Sewell, 2002; Fleming \& Spicer, 2004). How individuals can contest and challenge organisational practices 
that constrain the possibilities of identities remains a central concern for many critical scholars.

Both bodies of literature that positivist studies build from are rooted in an assumption of the separation of the individual from the organisational and the social, and the assumption that identity is an internal and (mostly) unchanging essence that makes someone 'who they are'. For organisational scholars sceptical of the theoretical foundations of positivist approaches, there are multiple alternatives to theorising identity (Alvesson, 2010). I focus here primarily on critical perspectives that are founded in post-structuralist and psychoanalytic contributions to understanding the self. Post-structuralist and psychoanalytic perspectives have enhanced organisational scholars' comprehension of identity as a discursive construction (rather than a pre-determined essence) and have given insight into how identities are formed, maintained, and regulated in organisational contexts (Knights \& Willmott, 1989; Kondo, 1990; R. Thomas, 2011). Such approaches to identity, in nuanced ways, argue that identity is not an internal essence, but a discursive construction of subjectivities shaped by uneven power relations (Knights \& Willmott, 1989).

The concepts of the 'subject', 'subjectivity', and 'discourse' have frequently been used in post-structuralist and psychoanalytic explorations of identity. Focusing on the concepts of subject, subjectivity, and discourse, rather than a monolithic construct of identity, has assisted scholars in highlighting how identity is not an internal essence but a discursive construction (Hall, 1996). Foucault's (1981) conceptualisation of discourses as sets of social interactions, embedded in power, which operate to construct objects and subjects at certain points in history, has been very influential for understanding identities in organisations as social constructions (R. Thomas, 2011). The 'subject' and 'subjectivity' are broadly understood to refer how an individual is produced through discourse and comes to occupy positions carved out in society (Thiem, 2008). Building on post-structuralist and psychoanalytic approaches, identities are therefore understood as fragmented, multiple, constituted within discourses, and constantly shifting and changing (Hall, 1996). Throughout this thesis I draw on the language of the subject and subjectivity, and my focus remains on the constructed 'sense of self' that is identity.

The influence of anti-essentialist theorisations of identity within organisation studies has been significant. Founded in the critiques of positivist approaches to identity, there is now a substantive body of literature that both provides a critique of positivist approaches to identity 
and offers alternative critical theorisations that foreground issues of power, resistance, and control in organisations through the concept of identity. Within the body of critical identity literature there have been two central themes: identity regulation and identity work. I discuss these themes below, focusing on how the insights of this research have been relevant for understanding the relationships between identities and change in organisations.

The critical literature about identity regulation is a diverse set of approaches that critique positivist thought about identity and organisational practices which promote managerial control (R. Thomas, 2011). Identity regulation refers to the organisational practices and processes which promote certain identities that increase managerial control or benefit managerial objectives (Alvesson \& Willmott, 2002). Earlier critical studies of identity regulation tended to be almost totalizing in their conceptualisation of managerial control of employees' identities (e.g., Alvesson \& Willmott, 2002; Casey, 1999; Humphreys \& Brown, 2002), positioning individuals as primarily passive receptors of organisational discourses. Importantly, the debates around the degree of domination managerial control regimes exercise over workers is related to the amount of agency - the capacity of an individual to influence or act (R. Thomas, Mills, \& Helms-Mills, 2004) - ascribed to organisational members. In response to the more deterministic accounts of identity in organisations, scholars have developed approaches to identity regulation that focus on how people resist identity regulation and open up the possibilities for challenging or subverting managerial control. Identity regulation studies that explore how workers can, and do, contest organisational control mechanisms, emphasise that resistance is complex, fluid, and generative ( $R$. Thomas \& Davies, 2005a; R. Thomas et al., 2004). Micro approaches to identity regulation, those that focus on the individual level, have therefore been influential in developing understanding of how people contest the dominance of regulating managerial practice (R. Thomas et al., 2004). Adopting a micro approach to identity regulation nevertheless maintains the emphasis on the efficacy of managerial control mechanisms. R. Thomas and Davies (2005a), for example, follow a micro approach to examine how resistance to managerial control mechanisms involves both challenging organisational discourses and opening up alternatives, and simultaneously reifying organisational discourses. They conclude that when exploring identity in organisations, identity scholars should not romanticise the possibilities of resistance, but nor should they position organisational members as passive recipients of discourse. A generative approach to resisting managerial control, however, makes it difficult 
to ascertain how people can effectively challenge organisational discourses; a point of sustained contention in the critical identity literature.

Identity work is the second central theme of the CMS identity literature. Identity work refers to the processes of formation of a sense of self and how individuals in organisations negotiate discourses to construct identities (Brown, 2015). Conceptualising identities as socially constructed, through discourse or through narrative, highlights how identities are subject to power relations, and thus poses problems for understanding how identities are formed, maintained, or changed within organisational contexts (Nentwich, Ozbilgin, \& Tatli, 2015). Unlike identity regulation studies, however, in which the focus is on the efficacy of power relations, identity work studies place weight on the negotiation of organisational discourses. Studies that focus on identity work examine how people in organisations actively and critically interpret discourses to construct and maintain a sense of self.

Identity work has been conceptualised as a struggle over multiple possible meanings of identities in organisational contexts that individuals negotiate to construct and maintain a sense of self (Sveningsson \& Alvesson, 2003). Two influential perspectives have informed identity work literature: either understanding identities as discursive formations that are constantly (re)constructed through local discourses (Hall, 1996) or as narrative formations which are complexes of in-process stories that are suffused with power (Brown, 2006; Rhodes \& Brown, 2005). Exploring identity work in organisations therefore gives scholars a sense of how identities are constructed at work from a non-essentialist perspective (Watson, 2009), and offers a strong framework for understanding how identities can affirmatively draw from, as well as be regulated by, organisational processes (Brown, 2015). The variety of theoretical approaches to identity, however, means that there are multiple ways of exploring how people construct their identity at work; not all of which are sit within the frame of 'identity work'.

Post-structuralist and psychoanalytic perspectives don't often neatly fit into the literature of 'identity work', particularly as (from these theoretical perspectives) the notion often places too much importance on a 'heroic individual' (Alvesson, 2010). Alternatively, poststructuralist perspectives tend to place more emphasis on the interrelations between the individual, organisational, and social. Nonetheless, post-structuralist and psychoanalytic perspectives have broadly informed the debates about the negotiation of individual identity in organisational contexts. Post-structuralist perspectives have underscored that although all 
organisational members construct their identities through uneven matrices of power, it is nonnormative identities that require more negotiation to be viable in organisational contexts

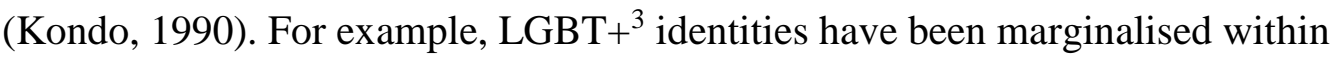
organisational contexts, and LGBT+ individuals must engage in concerted identity work in order to construct or maintain a sense of self as an organisational member and as a member of the LGBT+ community (Rumens \& Kerfoot, 2009). Beyond negotiation post-structuralist perspectives provide nuanced understandings of the interrelations between power and identities in organisational contexts.

One crucial reason for utilising post-structuralist perspectives on identities, is that understanding the interrelations between individuals, organisations, and society is productive for understanding how identities can catalyse change in organisational contexts (Parsons \& Priola, 2013). Studies that explore the relationships between identities and change have noted that in exploring localised constructions of identity, there is a great deal of potential for understanding how individuals can effectively challenge managerial control practices (R. Thomas \& Davies, 2005a). Organisational members have the potential to challenge and change organisational practices that open up possibilities for new ways of being in organisations. However, as Schilt and Connell (2007) have noted, performing identity work is not always sufficient to challenge organisational norms in order to promote change because of powerful social norms which shape the construction of identity. Furthermore, Nentwich et al. (2015) illustrate that the capacity for change does not solely rely on the individual but is connected to the interrelation between the social, the organisational, and the individual. Thus, post-structuralist perspectives offer strong avenues of insight into how identities can both be a catalyst for and/or constrain change in organisations. For my thesis, therefore, I became interested in the potential of post-structuralist perspectives on identity for advancing our understanding of the relationships between identities and change.

As mapped above, the identity literature has put substantial intellectual energy into critiquing positivist literature and establishing alternative ways of understanding identities. These endeavours provide a series of solid foundations for scholars to examine how organisational members might challenge organisational practices to foster change. However, a large proportion of the identity literature has focused on examining and critiquing power relations through identity regulation and identity work, at the expense of sustained exploration of how

\footnotetext{
${ }^{3}$ The expression 'LGBT+' draws both on the classic term for non-heterosexual orientations and non-binary gender identities, and indicates the multiple possibilities of identifications beyond these boundaries.
} 
identities can contribute to organisational and social change. Advancing approaches to understanding the relationships between identities and change is therefore important for resisting and changing regulatory and exclusive organisational discourses.

As post-structuralist perspectives on identities have demonstrated, however, grand notions of 'resistance' overlook the subtle and complex ways in which power and identities are interrelated. Developing novel ways of understanding the relationships between identities and change must, therefore, focus on the intricate interrelations between the social, the organisational, and the individual in ways that the identity regulation literature and identity work literature have often under-examined. Situated within post-structuralist contributions to understanding identities in organisations, this thesis therefore set out to contribute to debate around the theoretical relationships between identities and change, by developing these concepts in the context of the community sector.

\section{Situating the identity literature in the CMS context}

Having developed a critique of the critical identity literature, I want to now reflect on my critique of the literature in relation to the context of Critical Management Studies. As discussed in 'Settings', CMS is the field within which I situate this research. In this section I discuss some of the overarching trends in the critical management literature in order to both scrutinise why there has been less examination of the links between identity and change despite the political imperatives of CMS, and to further explain the motivation for my interest in the theoretical frameworks which I engaged with at the outset of this project. I touch on some of the central debates and critiques around the politics of Critical Management Studies. I cover both the inward facing critiques - those which stress the political production of knowledge within research - and the outward facing critiques that question the relationship between CMS and social change more broadly. Ultimately, I conclude with the implications of the production of knowledge in CMS for my research and the framing of social change.

CMS has received sustained critique that it does not sufficiently engage in performative activities that will foster the political changes it purports to seek (Bridgman \& Stephens, 2008; M. Parker, 2013). Partially, this lack of engagement is attributed to the antagonistic history of CMS which has prioritised critique of institutions over performing change activities (S. Parker \& Parker, 2017). In response, there has been increased current attention 
given to how CMS scholars might engage in 'critically performative' research, or research that attempts to extend the ways in which critical research can actively address its core political purpose: mobilising meaningful change (Spicer, Alvesson, \& Kärreman, 2009, 2016). Ideas of critical performativity have been usefully applied to identity studies to examine how identity research can be productive of change (e.g., E. Bell \& King, 2010; King \& Learmonth, 2015; Knights \& Clarke, 2014), as well as in CMS generally (Spicer et al., 2016). Prominently, Spicer et al. (2009) have stated that for CMS to have serious social impact it must focus on the efficacy of its political engagement, and to "attempt to create social change [critical research should] involve a range of more pragmatic encounters that might take place through the research process" (p. 555). They argue that critical scholars should seek to alter managerial power relations, but they claim that critical studies have become tied up in minute theoretical concerns that do not pay sufficient attention to how change can actually be achieved in organisations (Alvesson \& Spicer, 2012; Spicer et al., 2009, 2016; Wickert \& Schaefer, 2015). The lack of attention on meaningful change in CMS generally is a partial explanation of why there is less critical research on the specific topic of the relationships between identities and change.

Although mostly scholars laud attempts to make critical research more politically engaged, several are critical about the approach taken by Spicer et al. (cf. Cabantous, Gond, Harding, \& Learmonth, 2016; Fleming \& Banerjee, 2016; Swan, 2017a). Two of these critiques are significant here: that they overlook the nuances of the theories that they use, which forestalls their political potential (Cabantous et al., 2016), and that feminist and queer theories have long engaged in the project of critically engaging with meaningful identity issues to promote change that Spicer et al. (2016) characterise as 'recent' (Pullen, Harding, et al., 2017a; Swan, 2017a). These critiques are exemplary of the wider debates over the role of theory in research and over the power relations of CMS which operate to exclude feminist and queer theories. I attend to these critiques here to situate this thesis within CMS, as well as to explain my motivation for the theoretical and methodological approaches I used throughout this thesis.

Cabantous et al. (2016) express concerns that the work of critical performativity exemplified in Spicer et al. (2009) misinterprets the fundaments of performative theory with which they engage. They argue that overlooking some of the important theoretical insights of performativity undermines the political potential of the concept, which would therefore actually inhibit rather than promote change. Cabantous et al. (2016) specifically refer to the theoretical groundwork established in the identity work and identity regulation literatures to 
argue that critical scholars must work through the complexity of theory in order to benefit from its political potential. Spicer et al. (2016), however, assert that the concerns of Cabantous et al. (2016) are regressive and conform to a 'comfortable formula' that develops workplace dynamics but is primarily concerned with theories only a narrow sub-set of people will understand and appreciate. Correspondingly, on the one hand Cabantous et al. (2016) argue that a greater engagement in theory is necessary to realise its political potential, and on the other hand theory is presumed to be distant form organisational life and therefore needed to become more pragmatic in order to engage managers in effective critique and foster change (Spicer et al., 2009, 2016). At the heart of the debate is conflict over the relationships between theory and change in organisations. Accordingly, work is needed to progress debates around this tension and to think through how scholars can effectively promote meaningful change.

The debate over critical performativity also exemplifies a wider debate within CMS on the role and relevance of critical theory. Critical theories are often criticised for being too obscure, or at least written about in a way that is too obscure, to have meaningful relevance to people in organisations (Bridgman \& Stephens, 2008; C. Grey \& Sinclair, 2006).

Nevertheless, there is a consensus that Critical Management Studies needs to do more work to engage more thoroughly with the potential of fostering change in organisations (Contu, 2017). The debate between Cabantous et al. (2016) and Spicer et al. (2016) points to two pathways for engaging the political potential of critical research. The key problem is to find ways to develop theory that are more politically relevant to organisational life in ways that can foster change. My thesis acknowledges and engages with aspects of this debate, and experiments with different ways of exploring how theory and organisational life are intertwined in ways that can be productive of fostering social change. As I go on to discuss below, however, the presumed 'distance' of theory from organisational life and the claim of 'recent developments' of research that takes political change seriously, overlooks the key contributions of political work that has always harboured social change at its core.

Critical Management Studies has been critiqued for being unreflexive, in that it often reproduces the power relations that it intends to critique and challenge (de Souza, Brewis, \& Rumens, 2016; Just, Muhr, \& Burø, 2017; Swan, 2017a). Although Spicer et al. (2016) characterise the turn to critical performativity as 'recent', within Critical Management Studies there are multiple projects - including feminist, queer, anti-racist, intersectional, postcolonial and many others - that have engaged in prolonged and substantive attempts to dismantle 
contemporary power relations in organisations. Feminist and queer theorists and theories, for example, have made "significant in-roads into [understanding] the marginalisation of the lived experiences of non-normative populations" (Pullen, Harding, et al., 2017a, p. 2) and have been fundamental in developing a sustained agenda for identity politics and change (Pullen \& Thanem, 2010). Feminist contributions to critical perspectives of identities have been essential to understanding relationships between power, subjectivity, and resistance, and provide nuanced understandings of the interdependencies of individual-level identities, and social and organisational discourses for fostering change (R. Thomas \& Davies, 2005b; R. Thomas et al., 2004).

Yet, despite the extensive contributions of feminist theory to Critical Management Studies, and the political possibilities of feminist and queer politics for fostering change, feminist theories remain underutilised and consistently situated at the margins of CMS (Ashcraft, 2015; Harding, Ford, \& Fotaki, 2013; Pullen, Harding, et al., 2017a). Exclusion of feminist and queer theories from 'mainstream' CMS work (such as the vast majority of debates of critical performativity) can be attributed to power relations which reproduce the dominance of white, masculine, middle class perspectives, and perspectives from the Global North within CMS (Ashcraft, 2015; Swan, 2017a). For the political aims of the CMS which seeks to challenge contemporary power relations that marginalise women, people of colour, LGBT+ people (and others), unreflexively marginalising theories and work that locate organisational and social change at their core is extremely problematic.

The lack of examination of the relationships between identities and change can therefore be located as a twofold problem. Central attention has historically, within the organisational literature, been given to critiquing conventional practices and establishing a body of critical theory that provides both an impetus for conceptualising identities alternatively and for challenging managerial practices. The attention on identity regulation and identity work has formed a strong base for understanding how identities are experienced in the workplace. Despite this, much less thought has gone into developing the relationships between identities and change. Consequently, refocusing the identity literature around the political potential of critical studies has experienced a resurgence.

However, contemporary power relations within CMS marginalise feminist and queer contributions to advancing the theoretical conceptualisations of identities and change. Despite claims to the 'recent turn to critical performativity' that "starts from the point of addressing 
and critiquing organisational issues" (Spicer et al., 2016, p. 226), feminist and queer theories have long fought to effectively understand the relationships between identities and change in nuanced theoretical ways that pay close attention to the lived experiences of marginalised people. Therefore, this thesis contributes to addressing both these problems; advancing identity theorisation to further examine how we can understand the relationships between identities and change that resonate with lived experience, and continuing to draw attention to the politically transformational potential of feminist and queer theories of identities that continue to be neglected in CMS.

Within the context of identities in Critical Management Studies I set out to ask the question: In which novel ways can identity be understood to act as a catalyst for change in the context of the community sector?

\section{Initial theoretical frameworks}

In this section, I cover the basic tenets and contributions of two influential bodies of theoretical work that underpin substantive explorations of identities in organisational studies. Specifically, I focus on the work of Judith Butler and on narrative theory. I highlight how these bodies of work have contributed to the theorising of identity in organisational contexts and examine their potential for developing our understanding of the relationships between identity and change. I also briefly discuss the influence of the work of Bourdieu on this project; specifically, why Bourdieu's work contributed to the initial frame for the thesis, and why the influence of his work is less prominent in subsequent parts of the thesis.

\section{Judith Butler and examinations of identity in organisational studies}

Judith Butler's work has been extremely significant in feminist scholarship, and is described as providing one of the most thorough and rigorous contemporary frameworks for understanding identities (Hall, 1996). As well as inspiring contemporary feminist thought, Butler's work has also been instrumental in developing queer theory (M. Parker, 2002). Her influential books Gender Trouble (1990) and Bodies that Matter (1993) outlined her fundamental premise about gender identity: that "identity is performatively constituted by the very 'expressions' that are said to be its results" (Butler, 1990, p. 25). Our actions, language, 
gestures, and narratives do not express some underlying reality of identity. Instead our dayto-day embodiment of these things is our identity. Subjects are not presupposed but come into being through the (re)citation of discourse. Identities are fragile and contingent, and we therefore need to continually maintain them through (re)citing discourses. Butler follows a Foucauldian understanding of discourse and power as simultaneously forming and regulating one's identity (Butler, 1997). Identities are limited by culturally sanctioned social norms. These social norms restrict which identities are considered liveable, possible, or acceptable (Butler, 2006a, 2006b).

Most importantly, however, Butler's conceptualisation of identity does not lead to a deterministic account of identities. She argues alternatively that the imperative to (re)cite discourse in order to come into being is both constraining and harbours the potential for radical (re)imaginings of the possibilities of being (Butler, 1993, 1997). Through people 'troubling' social norms by (re)citing discourses in subversive ways, different identities are made possible (Butler, 2006a). Individual performances are not enough to incite social change, however, and sustained sets of actions and audience sanctification are essential at the collective level.

Her more recent works, including Notes Toward a Performative Theory of Assembly (2015), Precarious Life: The Powers of Mourning and Violence (2006b) and several shorter works (see also Butler, 2010; Butler, 2011a, 2011c) have focused on putting her earlier conceptualisations of identities and discourse into practice to understand how social norms can be challenged collectively. In Notes Toward a Performative Theory of Assembly and Precarious Life, Butler draws together several of her earlier key concepts of performativity, precarity, and power to offer a political and ethical framework for collectively working together to dismantle power relations which unevenly attribute bodies with the 'right to live'. Her later work emphasises political and ethical imperatives to challenge discourses which limit the possibilities of identities and make certain lives more precarious than others.

Within CMS, Butler's work has had a long presence; particularly as an influential figure for post-structuralist thought (Gherardi, 1995; Knights, 1992, 1997). Her work has become increasingly important as a feminist gender theorist and for non-essentialist understandings of the self and subjectivity (Borgerson, 2005). However, there remains a lot of potential to develop the use of her work in CMS (Harding et al., 2013). Primarily, her work has been used to understand how genders are 'done' and 'undone' at work (e.g., Hancock \& Tyler, 2007; 
Kelan, 2010; McDonald, 2013b) but there are a growing number of studies that use Butler's work to understand other identities and other related aspects of organisational life. For example, Harding, Lee, and Ford (2014) draw on Butler's understanding of performativity to understand how the identity of the 'middle manager' is constructed, and Kenny (2010) draws on Butler's conceptualisation of the ek-static to understand ethical identities in community organisations. Additionally, Butler's work has been built on to understand the political potential of identities at work. For example, Rhodes (2017) draws on Butler to critically assess the business case for diversity at work and argue that the instability of concepts in organisations can be harnessed for political potential. There is, therefore, a lot of potential for addressing the relationships between identities and change in Butler's work.

There have been critiques (even by those who draw on her work) that Butler's work is too complex and theoretical to be utilised effectively in organisational studies (e.g., Morison \& Macleod, 2013). Other scholars (both in and beyond organisational studies) have also claimed that there are other substantive difficulties in applying Butler's work, including that it is too abstract for feminists or other change agents to utilise effectively and take directive, intentional action (McNay, 2000; Spicer et al., 2016). Such critiques are, however, usually derived from misunderstandings about the nature of post-structuralist theory or shallow interpretations of her work and detachment of concepts from their feminist foundations (Borgerson, 2005; Harding et al., 2013). Butler's work remains one of the richest and most comprehensive bodies of feminist post-structuralist thought, of which there are persuasive examples of the value of application in organisational studies for understanding a variety of phenomena (cf. Harding et al., 2014; Johansson, Tienari, \& Valtonen, 2017; Rumens, 2017). Nonetheless, scholars who use Butler's work are still wary of the 'translation' of her work in organisational settings. Kenny (2010), for example, concludes that although Butler's work provides a powerful framework for understanding the complex affective attachments in community organisations, there are constraints of Butler's theory for certain types of questions, such as 'big picture' questions of power versus resistance (Kenny, 2010, p. 15). Research that draws on Butler's work must remain attentive to the theoretical complexity of her work and its foundations in feminist post-structuralist thought in order to develop nuanced understandings of concepts - such as identity - in organisational contexts.

Recently in organisational studies, feminist and queer scholars have made positive steps to developing frameworks for the application of Butler's work in organisations. Riach, Rumens, and Tyler (2016) draw from Butler's work on narrative (Butler, 2005) and performativity to 
conceptualise how her ideas might work in an organisational context to change the normative conditions of organisations. They argue that doing so will provide the foundations of a critical and political approach to dismantling organisational norms that marginalise certain groups of people (such as queer people or women). Likewise, de Souza et al. (2016) develop Butler's work in organisational contexts, and seek to understand how scholars can disrupt their research processes to dismantle naturalised notions of gender and sexuality. They argue that doing so can aid us in dismantling the power relations within research, as well as external to research projects. Both approaches demonstrate that careful attention to the theoretical richness of Butler's work can provide solid foundations for politically performative research in organisation studies.

The body of Judith Butler's work therefore offers a lot of potential for understanding organisations from multiple perspectives, as well as that of gender. As yet, however, the vast majority of research in organisational studies has focused on using Butler's work to understand gender in organisations. Her more recent material (e.g., Butler, 2006b, 2015) offers a broader examination of political and ethical frameworks for dismantling harmful social norms. Studies which draw on more contemporary aspects of her work such as Kenny (2010) drawing on the ek-static (Butler, 2006b), Riach et al. (2016) drawing on giving an account of oneself (Butler, 2001, 2005), or Rhodes (2017) drawing on Butler's conceptualisation of the politics of de/humanisation (Butler, 2006b) have been few. Nonetheless, these studies exemplify some of the radical possibilities of a political understanding of identities; possibilities that this thesis builds upon. This thesis therefore contributes to these projects by developing our understanding of how Butler's work can be politically relevant to organisations, and how it can help us to conceptualise the relationships between identities and change in an organisational context.

\section{Narrative identities in organisation studies}

The second body of theory I engaged with early in this project was the critically orientated literature about narrative identity. Within critical traditions, narrative identities are understood as "complexes of in-progress stories and story-fragments, which are in a perpetual state of becoming, and suffused with power" (Brown, 2006, p. 732 - emphasis in original), and are crafted within fields of power and through discourses which shape how and why certain narratives are told (Kondo, 1990; Tamboukou, 2013). For the aims of this project, I 
found the concept of narrative identity especially attractive because it is conceptualised in such a way that encapsulates how people can give a simultaneous account of their sense of self-continuity and their sense of self-transformation over time. Additionally, narrative identities are considered to be situated, temporal, and grounded in lived experience; thereby embedded in the organisational and the social. For understanding how change can be achieved, I saw the concept of narrative identity as holding potential to explore how people could creatively and reflexively (re)story their identities in specific contexts in order to catalyse social change. Below, I outline the influence of narrative in organisational studies and how narrative identities and change are seen as interlinked.

As a concept, narrative has been widely utilised in organisational studies, as it has been across the social sciences; an interest that has been characterised as a 'turn to narrative' (Andrews, Squire, \& Tamboukou, 2013; Hyvärinen, 2010). Narrative is used both as a theoretical approach as well as a methodological one. Within organisational studies, particularly influential theoretical perspectives have included the notions that organisations are storytelling systems (Boje, 1991, 1995), that narrative is a process of knowledge creation and communication (Gabriel, 2000), and that narratives are a process of organisation and simultaneously make organising possible (Czarniawska-Joerges, 2003). Methodologically, narrative has also been an influential approach to studying organisations, with many wellestablished methods for understanding texts as having a narrative form (Czarniawska, 1998; Riessman, 2008). Studies of narrative identities are thus drawing on a rich and wellestablished tradition in organisational studies that has strong theoretical and methodological bases.

Importantly, narrative identities are understood as powerful mechanisms for achieving change in organisational contexts (Gherardi \& Poggio, 2007). The potential of narratives for change is embedded in the characteristics of narrative. Constructing a narrative involves a process of (re)storying the self, embedded in lived experience, that is both transferable and malleable across time (Ricœur, 1988). Importantly, individuals' narratives are intimately interconnected with collective narratives (Brown, 2006); and thus by re-storying the self, wider change can be engendered (Wolgemuth \& Donohue, 2006). The transferability and simultaneous malleability of identity in narrative, and the embeddedness of narratives in the collective are understood as two central characteristics which offer novel possibilities of understanding identities. In (re)telling the stories of ourselves we can produce new meanings, new assumptions, and new ways of organising that challenge or reposition dominant ones 
(Gherardi \& Poggio, 2007). These characteristics make narratives valuable for understanding how identities and change are interlinked.

In CMS there has been substantive consideration of the ways in which narrative identities and change are interlinked (cf. Lapointe, 2013; Maclean, Harvey, Gordon, \& Shaw, 2015; Murgia \& Poggio, 2009; Riach et al., 2016). Two broad claims across the range of studies include:

(1) in sharing our narratives we open up the possibilities of others becoming aware of marginalisation or mobilised into action, and (2) (re)storying our identities involves a process of critical reconsideration of our lived experiences which can engender alternative possibilities. Importantly, critical studies pay careful attention to how narratives are subject to power relations and thus are constrained by the social conditions of their production.

Gherardi and Poggio (2007), for example, highlight that gendered norms are reproduced through narratives by interweaving cultural norms into personal identity narratives. The discursive conditions through which narratives are constructed are therefore an important aspect of theorising how identities and change are linked. Thus, although many proponents laud the possibilities of narratives for fostering change, any exploration of identity narratives also needs to explore how narrative identities are crafted and constrained within local fields of power.

Narrative identity studies tend to focus on how narratives are artefacts of identity work and operate as resources for change within certain fields of power (e.g., Lapointe, 2013; Maclean et al., 2015; Murgia \& Poggio, 2009; Parsons \& Priola, 2013; Wright, Nyberg, \& Grant, 2012). The politics of the form, structure, and order of narrative (as well as the content) has received significantly less attention in organisational studies. Queer and feminist perspectives on narratives focus on how the form, as well as the content, of narrative needs sustained critical attention in order to open up the possibilities of transformation (Warhol \& Lanser, 2015). For example, Kondo (1990), in her study of the interconnections between gender and artisanal identities in Japan, emphasised the importance of form, structure, and order for maintaining gender hierarchies that marginalised women in the workplace. She argues that the forms of narrative identities are political as they are infused with power which is embedded in broader cultural and social norms and meanings. Certain forms of narrative identities are more privileged than others, which has political implications for change in that non-normative structures and orders may struggle to dismantle dominant ones. 
Narrative identity research both has the potential to explore the lived experiences of organisational members and to develop an understanding of the form of narratives that is necessary to be recognised as a subject. At the outset of this project, therefore, I was interested in developing a feminist perspective on narrative identities that focused on the importance of form, structure, and order for understanding the political potential of identities for change. Over the course of this project, the body of literature on narrative identity became less prominent as I became more interested a specific theory of narrative identity that resonated closely with the specific story-telling practices in the organisation. I retained my interest in developing understanding of the form, structure, and order for narrative identity but this interest became less rooted in narrative identity and more situated within broader post-structuralist theories of identity. The body of work on narrative identity was nonetheless influential in developing my research design and my approaches to analysis - which I discuss further in subsequent sections.

\section{Using Bourdieu to think about social inequality}

At the outset of my thesis, Bourdieu played a central role as one of my key theorists and I was interested in what his work might add to understanding relationships between identities and change in an organisational context. I was especially interested in the ways in which he frames the relationships between social inequalities, identities, and political systems; which had distinct relevance to my interest in organising for social justice. Bourdieu has gained increasing prominence in organisational studies (Sieweke, 2014). In their discussion of the contribution of Bourdieu to management Tatli, Ozbilgin, and Karatas-Ozkan (2015) highlight that Bourdieu's recognition of "the intrinsically political nature of our scholarship is at the heart of the potential contribution of Bourdieu's sociology to the development of organisation and management... [which helps us to battle] the neo-liberal, individualistic, and depoliticising tendencies in our discipline" (p. 1).

Indeed, Bourdieu's extensive focus on how social inequalities are inherited, and how we might engage in collective political action to dismantle contemporary inequality (Bourdieu, 1991, 1992, 2002; Bourdieu, Loic, \& Farage, 1994) offers potential for a rigorous analysis of social systems and a framework for how scholars can effectively engage with communities. Bourdieu also offers a strong framework for understanding identities through his interrelated concepts of capital, the field, and the habitus. Rather than presupposing the essence of 
identities (particularly class identities), Bourdieu explored how identities are constructed, maintained, and infused with inequalities. Importantly, his rigorous framework offers much potential for understanding how symbolic power is circulated and what the material effects are of social inequalities related to identities.

Over the course of the project, however, I found that continuing to incorporate Bourdieu in a sustained way was beyond the scope of the thesis, and I began to feel an incompatibility with the theorisation of his central concepts and the empirical setting of my research. In terms of scope, the use of Bourdieu's framework is theoretically demanding as his body of work places extensive emphasis on the importance of attending to the interconnections between broad social patterns and individual experience. To carry out this sort of analysis effectively would have consumed more space and resources than the limitations of a thesis allowed and my interest in engaging with multiple frameworks offered. Rather than offer a shallow interpretation of his work for one dimension of my empirical material, I opted to place his work aside for this thesis. Relatedly, I found that Bourdieu's work was less relevant for my research because his concepts bring a lot of structure to complex social systems. As part of the aim of my research became to preserve the mess, ambiguity, and fluidity of the research setting and of social justice work, continuing to draw on Bourdieu's concepts took the focus away from the messy elements of my ethnographic experience.

Nonetheless, I used Bourdieu's central triad of concepts early in my analysis to explore the relationships between the community sector, the state, and the identities of my participants. The rigorous theoretical framework helped me to map the interrelations between the community sector and the state, and develop an understanding of the inequalities between the state, private, and community sectors in Aotearoa New Zealand. As Bourdieu was an initial theoretical inspiration for the project, traces of his work can still be identified in the remainder of the thesis; principally in the understanding of the relationships between the community sector, the state, and communities in Aotearoa New Zealand found in 'Ties that bind; ties that break' (Part II) and 'A multiplicity of feminisms' (Part IV).

\section{Theoretical beginnings in brief}

'Theoretical beginnings' has mapped my thinking about identity before I engaged with my fieldwork. To summarise: the identity literature within the context of Critical Management 
Studies formed the impetus for this thesis. The central debates around identity in CMS have rotated around how identities are negotiated in workplaces, and how managerial regimes of control are resisted. The theme of change underlies both identity work and identity regulation, but it has far less frequently been an explicit aspect of theorisation. I suggested that there are two central reasons for the deficit of exploration of the relationships between identities and change. The first reason is that an initial aim of critical studies was to establish strong foundations of alternative ways of understanding identities in organisations. There is now a substantive body of critical literature that provides these foundations, and more recently scholarly attention has been directed toward how we can mobilise this knowledge for change. My research is part of this surge of interest in how identities can be productive of change in a variety of organisational contexts. The second reason I gave for the lack of sustained attention intersects with power relations within Critical Management Studies. The repeated exclusion of projects outside of mainstream CMS - including feminist, queer, decolonial and others - has precluded a thorough application of these projects insights into the relationships between identities and change. Continuing to challenge the exclusion of feminist and queer work is a necessary part of fostering change for marginalised groups in organisations.

From the foundations of the identity literature I introduced the three bodies of work that were influential in my initial thinking about how identities and change are related. The work of the feminist, queer scholar Judith Butler has been increasingly influential in organisational studies but more labour needs to be done to engage with the richness of her work for identities in organisational contexts. I outlined how her work was influential to this project and delineated several potential avenues for developing her work in an organisational context. I then introduced narrative identity as a second initial framework. Narrative theory has been widely influential from a variety of positions, including feminist and queer, and has been extensively utilised in organisational studies. Nonetheless, developing narrative identities in ways that respond more carefully to issues of power, form, structure, and politics is needed to progress understandings of how narrative identities and change are related. I finally, albeit briefly, discussed the importance of the work of Bourdieu to this project. Although his influence is less salient than the other theoretical frameworks throughout the remainder of the thesis, he formed an important and incomplete part of this research, particularly in developing my research design. 
From here, I move to introducing the context of my research - the community sector in Aotearoa New Zealand. I begin by discussing the theoretical foundations of the community sector. This discussion extends the critique of the critical identity literature. The vast majority of the literature mapped above is situated in commercial contexts. Next, I examine how this is problematic for projects that seek social change, and discuss how the context of the community sector shapes the theorisation of identity work and regulation. 


\section{Contextual beginnings: A note on communities}

Up until this point, I have only briefly mentioned the specific context of my project: the community sector in Aotearoa New Zealand. In this section I want to introduce the community sector literature by discussing some of the focal trends and theoretical debates. Firstly, I provide an overview of the nature of community sector research focusing on debates around definitional issues of the community sector. The definitional issues of the community sector frame how almost all community sector research is undertaken. Secondly, I discuss how these debates about community organisations relate both to identities and to change. Ultimately, I argue that the community sector literature provided a strong basis within which to explore the relationships between identities and change.

In the initial stages of this research, I understood the community sector as a relevant site for my research, but not as a central locus of identity. As I explore in 'Ties that bind; ties that break' (Part II), my understanding of the centricity of the community sector to identities and change shifted as I become increasingly engaged in my fieldwork. In 'Ties that bind; ties that break' (Part II), I explore the shape of the community sector in Aotearoa New Zealand more deeply and connect with the literature about alternative organisations. Here, I outline my understandings of the community sector that shaped my research design, focusing on definitional issues and gathering together some background information about the community sector in Aotearoa New Zealand.

\section{Community organisations in organisational literature}

Community organisations occupy a contested conceptual space (Corry, 2010). There is sustained disagreement as to how scholars should conceptualise the community sector and community sector organisations. Principally, the disagreement stems from a vast range of terms (such as not-for-profit, NGO, or voluntary organisations) used for very similar concepts (Corry, 2010), and only relatively recent interest in organisational studies in theorising the community sector (Hull, Gibbon, Branzei, \& Haugh, 2011). Numerous scholars argue that the prolific range of conceptualisations of what a community organisation is, and absence of clarity around the use of terms, hinders a substantive exploration of challenges within community sector organisations (Knutsen, 2013; Sama, 2010). Other scholars see the lack of clarity as unavoidable, as community organisations are so diverse that a term wide enough to 
encompass them would be meaningless (Corry, 2010). Consequently, other scholars argue that we should select a term that best suits the aims of the specific research project (Lorentzen, 2010). For example, choosing the term 'charity' emphasises the absence of commercial aims, and 'voluntary association' emphasises the voluntary and participative characteristics of the organisation. I have thus chosen to use the terms 'community organisations' and 'community sector' for this thesis. The interconnections between staff and volunteers, the organisation, and society are fundamental to this project, and emphasising the interdependency of community organisations and the communities they serve is imperative.

Another significant dimension of the conceptual debate is whether community organisations are unique organisational forms. Most of the literature operates from a conceptual understanding of community organisations deriving from economic definitions, which conceptualise community organisations in contrast to a 'pure' state-market system in which they fill the 'gaps' (Corry, 2010; Powell \& Steinberg, 2006). The conceptual dependency on a relational definition to the public and private sectors has supported many scholars in their assertion that the community sector has no unique identity. They claim alternatively that we should understand community organisations as hybrids of public and private organisations (Knutsen, 2013; Maier, Meyer, \& Steinbereithner, 2016). The increasing push that community organisations face globally toward embracing 'business-like' behaviours, and the private and public push to adopt socially responsible practices (such as environmentally friendly practices), have seen the lines blur (Knutsen, 2013). As a consequence of this ambiguity, however, the community sector has been identified as a key area in which to study identities, as conflicting pressures make the tensions of identities salient (Glynn, 2000; Kreutzer \& Jaeger, 2011). Thus, at the outset of this project, I understood that for enquiry attending to identity, the community sector offers a relevant and dynamic site for conducting research.

Although there are many claims that the community sector has no distinctive identity, many scholars continue to seek to conceptualise community organisations as having unique characteristics, even if those characteristics are increasingly blurred and contested. An influential global definitional project was conducted by Salamon and Anheier (1997) who sought to define community organisations by what they were rather than what they were not, and to thereby create a lasting set of criteria from which to build research about community organisations. Their criteria outline that community organisations are: 
- Formal or institutionalized to some extent;

- Private-institutionally separate from the government;

- Non-profit distributing;

- Self-governing; and

- Involve a meaningful degree of voluntary participation. (Salamon \& Anheier, 1997)

The definition is still widely used, but since its inception, their project has been met with multiple critiques; including that it excludes forms of community organising, such as mutual aid organisations, that have been historically significant (Morris, 2000); that it can struggle to respond to contemporary policy and ideology changes surrounding community organisations, particularly in terms of recent neo-liberal policy changes in the Global North (Milbourne, 2013); and that it is not always relevant to local populations, for instance that Māori ${ }^{4}$ have a conceptualisation of 'voluntary' which does not fit within that framework (J. Sanders et al., 2008). Although definitions such as the one provided by Salamon and Anheier (1997) are limited, they do provide a useful basis for conceptualising community organisations as social formations with distinctive characteristics. Any project involving community organisations should, however, maintain an awareness of the loose, ambiguous, and malleable dimensions of the community sector.

Consistently within the debates there is a strong sense that the community sector is difficult to define and dependent on other areas of society in ways that private sector organisations, in particular, are not (Corry, 2010). Explorations of community sector organisations in the organisational literature therefore tend to treat ambiguity, contingency, and conflict as founding concepts. Where most studies understand these notions as self-explanatory and largely negative, there has been increasing attention in critical work given to these concepts as having political potential (Bernal \& Grewal, 2014; Hull et al., 2011). Looser organisational structures, flexible forms of working and/or volunteering, and the possibilities of organising around localised social missions offer a lot of political possibility for social change. Conceptualising community organisations as sites of malleability and flexibility can be, therefore, extremely valuable for critical scholars.

\footnotetext{
${ }^{4}$ Māori are the indigenous people of Aotearoa New Zealand. The term is also used to refer to something done in a Māori way (i.e. in line with Māori values or ethos).
} 
The political potential of community organisations because of their malleability is not, however, as self-explanatory as many studies depict. The conditions of the community sector are not inherent but, as with all social phenomena, are localised, contextual, and shaped through power. Critical perspectives on community organisations understand the conceptualisation of the community sector between the state and the market as extremely significant, as the sector, and the people who work or volunteer there, will always be shaped by market and state discourses (Hull, 2011). Neo-liberal policy reforms, for example, have unequivocally shaped how community organisations are structured, and shape community organisations by privileging market based practices and risk-taking behaviours (Bernal \& Grewal, 2014). The pressures on community organisations to conform to neo-liberal policies have moulded how relationships between the state, private sector, and third sector play out in the UK, and throughout the Global North (Milbourne, 2013). Critical studies therefore seek to interrogate discourses that produce conditions of ambiguity and tensions between social and economic goals.

A further significant consideration for understanding community organisations from critical perspectives is that, as well as being subject to changes in political regimes, community organisations themselves are also political actors. E. L. Kirby, Koschmann, and Dempsey (2012) point out that community organisations constrain and regulate the identities of their employees, present partial versions of their communities to funders and to the public, and have uneven relationships with corporations as societal 'watchdogs' and/or as 'partners' (Dempsey, 2009; E. L. Kirby et al., 2012). As a consequence of complex accountabilities community organisations have to their multiple stakeholders, Carey (2008) argues that community organisations may also inadvertently reinforce neo-liberal control regimes sometimes to the detriment of communities the organisation serves. She emphasises, however, that we should adopt a relational view of power that examines how community organisations both harbour the potential for change, as well as for reinforcing contemporary power relations (Carey, 2008). Accordingly, although community organisations can, and do, have the political potential to foster social change, this potential is still problematic and must always be subject to interrogation.

Despite the potential of community organisations as sites for social change commensurate with the social justice goals of Critical Management Studies (Haugh, Branzei, Gibbon, \& Hull, 2011), the community sector has received less attention than the private sector within critical scholarship (Hull et al., 2011). There is, therefore, a lot of opportunity to develop 
theoretical contributions about how scholars can foster change in community contexts. The exploration of the possibilities of change through community organisations, however, ought to take into consideration their complex accountabilities and the proposition that community organisations are political actors. Critical studies of community organisations therefore have manifold opportunities to theorise how alternatives arise, as well as interrogating constraining and exclusive practices (Haugh et al., 2011). Drawing from conceptualisations of the community sector as both a site of politics and of ambiguity, exploring identity in this context offers the possibilities of understanding both the political potential of identities for change, and how they are shaped in localised organisational contexts.

Within CMS there has been significantly less investigation of identity in community organisations than in private or public institutions, which is a significant omission because of the role that community organisations can play in achieving change. The CMS identity literature frequently assumes that individuals' interests and desires are, to a degree, at odds with organisational goals. In community organisations, however, resistance to and alignment with organisational goals is complex; as individuals might have passionate attachments to the goals of the organisation but not necessarily to the types of action being taken. Studies that have focused on identity in community organisations from a critical perspective note that there are different dynamics to identity work and regulation than in corporate or public institutions (Dempsey, 2009; King, 2017; M. L. Sanders \& McClellan, 2014). Kenny (2010), for example, notes that identity regulation was complex because organisational identities were premised on feelings of friendliness and warmth, and organisational members had strong personal attachments to the goals of the organisation. From the outset of this project, I therefore expected my thesis to build on perspectives of identity in community organisations from a critical perspective.

\section{The community sector in Aotearoa New Zealand}

The vast majority of academic research about community organisations comes out of either the US or UK context, and these contexts form the basis of conceptualisation of most research into community organisations. The US context has primary concerns about the relationship between the private sector and the community sector, as the basis for funding is usually philanthropic (James, 1989). The community sector in Aotearoa New Zealand also receives a high degree of philanthropic funding compared with the global average (J. Sanders 
et al., 2008), and the relationships between community sector and commercial partners are of increasing interest to scholars (Eweje \& Palakshappa, 2009, 2011). Alternatively, the UK context is embedded in UK charity law which both allows organisations to be recognised for their work and to receive social benefits (such as being tax exempt) but also constricts which organisational forms can be recognised as charities (Milbourne, 2013). The relationships between the community sector and the government are therefore the primary concern (Corry, 2010; Milbourne, 2013). The community sector in Aotearoa New Zealand, as a former British colony, is likewise embedded in the same charity law (Poirer, 2013). Consequently, the forms of many community organisations have followed similar patterns to that of the UK including the formation of many charities, unions, and clubs (Tennant, O'Brien, \& Sanders, 2008). Thus, the community sector in Aotearoa New Zealand bears closer resemblance to the UK context than the US context, but also has some distinctive features.

The influence of the UK and US models in Aotearoa New Zealand means that local experiences are likely to resonate with those in other countries throughout the Global North. Additionally, the community sector in Aotearoa New Zealand shares similar socio-political environments and policy-making and receiving environments to countries such as Australia and the United Kingdom; in particular that the sector has been shaped by neo-liberal policy reforms and the dominance of capitalism as the hegemonic ideology of the market (Laurie \& Bondi, 2005). Nevertheless, the community sector in each country has specific characteristics that shape everyday working life. Below, I go on to outline the specific characteristics of the community sector in Aotearoa New Zealand.

The Aotearoa New Zealand community sector is dominated by cultural, recreation, civic, and advocacy organisations; and small community organisations make up about $84 \%$ of the sector (J. Sanders et al., 2008). With such diversity, it is difficult to get a sense of the contribution of the sector to Aotearoa New Zealand. Economically they contribute 5.3\% to GDP and employ $4.4 \%$ of the workforce in NZ (McLeod, 2017), with over 130,000 paid staff and 1.2 million volunteers (Statistics New Zealand, 2015). Despite the economic significance and large role the community sector plays in the working lives of millions of people in Aotearoa New Zealand, research in general has tended to overlook the community sector (Szabo, 2010). Consequently, there is much less exploration of the specific issues in the workplace that members of community organisations negotiate. 
Moreover, the economic contribution is not seen to be the most significant aspect of the community sector. It is the social impact of the community sector that is adding most to the lives of people in Aotearoa New Zealand (Neilson, Sedgwick, \& Grey, 2015). Social service community organisations in Aotearoa New Zealand play an important advocacy role (Erakovic \& McMorland, 2009) and work closely with the government to tackle social issues (Shaw \& Allen, 2006; Tennant, Sanders, O'Brien, \& Castle, 2006). Significantly, community organisations also offer a range of vital social services in response to pressing social problems including homelessness, domestic violence, and mental health issues (McLeod, 2017; Neilson et al., 2015). They also provide intangible contributions to the social fabric of the country which can promote positive social change and strengthen communities (Nowland-Foreman, 2016b). The close interrelationships between social service organisations, the government, and local communities result in a high degree of potential political influence. Alongside the political influence of their embeddedness in the community this makes community organisations in Aotearoa New Zealand an interesting and valuable site for research about change.

One additional fundamental feature of the community sector in Aotearoa New Zealand is the importance of Tangata Whenua ${ }^{5}$, and Māori models of community organising. The nation of Aotearoa New Zealand is purported to consist of two founding peoples, the indigenous Māori and the white British settlers, Pākehā ${ }^{6}$ (A. Bell, 2006), and the relationship between them was codified in Te Tiriti o/The Treaty of Waitangi in 1840. Nevertheless, the rights of Māori were violated by the Pākehā settlers in many ways; including confiscation of Māori land, attempts to abolish Te Reo (Māori language), and the displacement of many Māori from their iwi (tribe). Throughout Aotearoa New Zealand, Māori have engaged in a long, ongoing struggle to achieve recognition of their rights as indigenous people by government and community, their status as traditional custodians of the land, and their rights to self-determination; partly through the medium of Te Tiriti/The Treaty (Tauri \& Webb, 2011; Walker, 2004). However, Tiriti/Treaty relations between Māori and Pākehā continue to be contentious, and have been claimed to mark a cultural and political divide in contemporary Aotearoa New Zealand (Crocker, 2014).

\footnotetext{
${ }^{5}$ A Māori term for the indigenous people of Aotearoa New Zealand which literally means 'the people of the land'.

${ }^{6}$ Pākehā is used contemporarily as the term for white New Zealanders. I identify as Pākehā, with both British and Dutch ancestry.
} 
Te Tiriti/The Treaty is important for the operation of community organisations in Aotearoa New Zealand (Community Sector Task Force, 2006) and is especially important for community organisations that engage in the social service group of the community sector. As a result of historical (and contemporary) injustices, Māori are disproportionally represented as users of community social service organisations (Tennant, 2005). Additionally, many community organisations founded in Pākehā values, understand that they have a responsibility to engage with Te Tiriti/The Treaty (Margaret, 2016). Community organisations have responded to this responsibility and have initiated greater engagement with kaupapa Māori ${ }^{7}$ (Spelman, 2013) with some organisations initiating practices to share power equally (Huygens, 2001). Integrating Māori kaupapa is essential for social service organisations whether they are 'by Māori for Māori organisations' or non-Māori organisations that engage with Māori (Rawiri Waretini, 2012; Tennant, 1989).

Māori kaupapa has been fundamental to the forms, practices, and political influence of community organisations. Early community organisations often excluded Māori (Tennant, 1989, 2005). By Māori for Māori organisations therefore were fundamental in tackling intersecting social issues and institutional racism thereby promoting social change for Māori. Although eventually by Māori for Māori community organisations became recognised and celebrated, the struggle with neo-liberal policies had disproportionally adverse effects on by Māori for Māori community organisations (Came, 2012; Spelman, 2013; Waldegrave, 2009). Nonetheless, forms and structures of Māori organisations have been influential on the structure of the community sector generally (J. Sanders et al., 2008) and continue to be important for everyday practices in community organisations.

The significance of Tangata Whenua in Aotearoa New Zealand is located within the context of indigenous peoples globally, who are involved in the ongoing resistance to the impacts of colonisation and imperialism. The practical and intellectual endeavour to celebrate and make visible the knowledge and practices of Māori is embedded in this global struggle of indigenous peoples for self-determination (Henry \& Pene, 2001). Hence, consideration around issues of power sharing, the significance of the Māori worldview to community organising in Aotearoa New Zealand, and the importance of Tangata Whenua for fostering

\footnotetext{
${ }^{7}$ Kaupapa Māori refers to approaches that are founded on the knowledge, skills, attributes, and values of Māori. Kaupapa is a term now integrated into everyday use in Aotearoa New Zealand by non-Māori to refer to a 'value base'.
} 
change are all concerns embedded in this thesis. Additionally, this thesis uses Māori concepts and language. These are defined and explained as they arise.

\section{Contextual beginnings in brief}

In summary, the context of the community sector for this thesis is significant. The dynamics of the community sector have received less sustained investigation in critical research than private or public institutions; which is lamentable as the goals of social justice organisations often align with the goals of critical research. Community organisations play a significant role in achieving social change but are constrained by the power relations through which they operate. The uneven power relations community organisations are subject to are exemplified in the debates surrounding the theorisation of the community sector. The terminology associated with the community sector underscores the intimate ways in which the community sector is conceptualised in relation to the private and public sectors. The multiple, complex accountabilities that community organisations experience is intertwined with this conceptualisation. Exploring identities in community sector contexts is therefore important as the tensions and interdependencies between the community organisation, the communities they serve, and the public and private sectors make identities increasingly salient and significant for their work. Moreover, identities in community organisations have been pinpointed as having different dynamics to identities in corporate contexts, because of the frequent alignments between desires of organisational members and the goals of the organisation. Situated in the community context, this thesis set out to contribute to our understanding of the dynamics of identities in community contexts.

From here, I move to introducing the methodological beginnings of my research. I begin by discussing the feminist and ethnographic approaches of this research. The ethnographic approach draws strongly on the community context of the research. I explore the challenges of conducting research in the community sector in Aotearoa New Zealand, and the ethics and politics of this thesis. 


\section{Methodological beginnings: The formation of a research project}

The account thus far in 'Beginnings' (Part I) has provided an overview of the theorisation of my key concepts, the field of my research, and the context of my study. As well as giving insight into my thinking at the outset of the project, I have provided this account to map the theoretical foundations that contributed to the development of my research design. In this section, then, I consider the methodological beginnings of my project. To briefly summarise: I undertook two phases of fieldwork embedded in a feminist post-structuralist ethnographic methodology. The first phase involved interviews with experts from the community sector and the second phase involved 8 months of ethnographic fieldwork during which I was a volunteer in a domestic violence organisation in Aotearoa New Zealand. In methodological beginnings, I discuss my conceptualisation of ethnography and provide an initial account of my fieldwork.

\section{Feminist orientations}

Non-positivistic ways of carrying out research have developed into a flourishing body of methodology literature (Denzin \& Lincoln, 2005; A. Prasad \& Prasad, 2002). In part, these non-positivistic methodological traditions have grown from unsettling conventional assumptions about the nature of knowledge (epistemology) and the nature of reality (ontology) that underpin traditional positivist inquiry. Positivist approaches assume that social research can create objective knowledge about an extant and knowable social world, in a similar vein to traditional research in the sciences (Denzin \& Lincoln, 2005; A. Prasad \& Prasad, 2002). However, there are now a variety of positions that question the possibility (or desirability) of an objective researcher and a separate social reality, and in differing ways usually assume that reality is socially constructed and knowledge is partial and subjective. Although in many spaces in organisational studies positivistic approaches to research remain dominant, many non-positivistic methodologies are acknowledged as having strong theoretical foundations and as negotiating some of the limitations and failings of traditional positivist methodologies (P. Prasad, 2005).

The proliferation of non-positivistic methodologies has resulted in a plethora of possibilities for critical management scholars for crafting research in line with their epistemological and ontological commitments (Kelemen \& Rumens, 2008). My research is underpinned by a post- 
structuralist feminist epistemology and ontology (Kelemen \& Rumens, 2008) which has shaped the orientation and commitments of this research. The second tradition that I follow is feminist ethnography (Skeggs, 2001) which shaped the form and aims of my fieldwork. In this section I outline my research approach which derives from feminist post-structuralist principles, and the foundations of my fieldwork which were oriented by my understanding of feminist ethnography.

Feminist research and feminist methodologies have roots in feminist movements that fought to increase the recognition and valuing of women's lives, experiences, concerns, and reduce gendered inequalities that were the result of subjugation and oppression. As with feminism itself, feminist research can never be narrowed to a small subset of concerns or perspectives but is a fluid and dynamic range of ideas, principles, and actions aimed (broadly) at understanding, challenging, and/or rectifying gendered inequalities (Hesse-Biber \& Leavy, 2007). What is clear, however, is that feminist research has invariably deepened and expanded our understanding of a range of issues, usually intersecting with gender and related to social inequalities. Insights from feminist research have come from a range of disciplines, and thus feminist methodologies and approaches are often a compilation of insights from scholars from as wide-ranging fields as anthropology, philosophy, and cultural studies. Within organisation studies - and specifically CMS - feminist research has produced numerous insights into the working lives of women, how organisations and organising are gendered rather than gender neutral, and the various ways in which gendered inequalities are perpetuated and/or resisted in organisations (Pullen, Harding, et al., 2017b; R. Thomas \& Davies, 2005b). Despite the significance of feminist research and feminist methodologies, often feminist research remains at the fringes of some disciplinary fields (as earlier in Part I, I highlight was the case in CMS). This is particularly true of feminist research that has more radical philosophical underpinnings or explores the intersections of gender with other social categories such as race or sexual orientation (Moraga \& Anzaldúa, 2015; Pullen, Harding, et al., 2017b).

Feminist research methodologies, broadly speaking, are social justice oriented and argue that knowledge is socially constructed in ways that benefit certain political interests over others; namely masculine interests over feminine interests (Hesse-Biber \& Leavy, 2011). Feminist methodologies typically situate the socially constructed notion of gender as the primary orientation of analysis, but they have been developed to explore issues of power and 
resistance (usually intersecting with gender) in workplace contexts more generally (Kelemen $\&$ Rumens, 2008). Approaching research from a feminist orientation therefore assumes that knowledge and reality are contextual, situated, and subjective, that gender is a significant point of analysis, and that uneven power relations are an inevitable dimension of research. Responding to the challenges of power involves feminist researchers acknowledging and exploring their personal, professional, and structural positions (Naples, 2003). Clearly positioning the researcher in the text and exploring intersecting issues of gender, power, and subjectivity are essential because as Calàs and Smircich (2009) note: "even in its tamest forms, feminist analyses are concerned with social change" (p. 246). As such, I understand that I am an active participant in the construction of the 'reality' of my research, and the claims I make are not some objective truth but are always partial, situated, and embedded in power. The impetus of social justice is at the heart of my research, and I assume that all research has a political dimension.

More specifically, my research is embedded in a feminist post-structuralist epistemology and ontology. Post-structuralist traditions, like many of the 'post' traditions, are extremely diverse and contested (P. Prasad, 2005). Generally, post-structuralist perspectives are located in an anti-essentialist, anti-foundationalist, and anti-totalising theory and politics that questions the conceptualisation of the individual as separate, unified, and rational (Kelemen \& Rumens, 2008). Importantly, post-structuralist perspectives are sceptical of any grand theory that presents itself as essential truth, alternately assuming that social phenomena do not have essential properties but are socially constructed through shifting, and relational, fields of power (P. Prasad, 2005). All knowledge is thus contextual and partial, embedded and constructed through shifting fields of power. Post-structuralist perspectives offer a nuanced understanding of power; which is not held by any one entity but enacted in the construction of social phenomena in ways that privilege partial interests over other (also partial) interests. In Critical Management Studies, post-structuralist perspectives have been influential and have shaped the development of the field as a whole, particularly in promoting and in opening up new ways of thinking about ideas of language, power, and resistance (C. Jones, 2011).

Post-structuralist thought and feminist thought intersect as both share points of interest in questioning and deconstructing seemingly 'common sense' categories and exploring how contextual power relations marginalise certain interests over others. Both also share a common concern with how power operates and shapes contextual experiences, in ways that 
question a seemingly total and coherent social order (Leavy, 2007). Post-structuralist perspectives contributed to a rethinking of essentialist notions of gender and identity, and to developing an anti-essential politics for social justice and gender equality (Kelemen \& Rumens, 2008). The influence of post-structuralist perspectives in feminism have been controversial however, particularly in reference to the political impetus of feminism. The advances of feminism in the second wave movement ${ }^{8}$ were often attributable to raising awareness about an 'essential' experience of women. Deconstructing the category of 'woman' and questioning the universality of 'women's experiences' through poststructuralist insights was considered to pose a threat to the gains feminism had made in social recognition of women's equality (Leavy, 2007). Without an essential or common experience how could 'women' continue to make collective claims for equality? Advocates of poststructuralist feminism maintain however, that recognising multiple voices, and the diversity and fluidity of the concept of 'woman' does not preclude it being used politically (R. Thomas \& Davies, 2005b). I also maintain that questioning and acknowledging the fluidity of the category 'woman' can deepen our understanding of being, knowing, and power in ways that provide multiple forms of localised resistance that can be extremely effective in reducing social inequalities.

\section{An ethnographic approach}

Building on the foundations of a post-structuralist feminist epistemology and ontology, my research took an ethnographic approach. Commonly, ethnography is understood as a holistic research approach to understanding the everyday practices, customs, and cultures of individuals in social contexts with an emphasis on understanding the social context from the perspective of an insider (Hesse-Biber \& Leavy, 2011). There are wide-ranging implications in assuming a feminist post-structuralist epistemology and ontology for understanding ethnography. Traditional ethnographic accounts, which were understood to be objective representations of culture, were met with increasing criticism from the 1980s onwards (Schrock, 2013). In Writing Culture (2011 - originally published 1986), James Clifford and

\footnotetext{
${ }^{8}$ Feminism is sometimes divided into broad 'waves' of activity and change. The second wave movement typically refers to social movements in the global north over two decades starting in the 1960s which made significant gains for women in terms of equal pay in the workforce, increased social recognition of domestic labour, and establishing laws to combat rape and domestic violence (including, for example, recognising rape in marriage).
} 
George Marcus (and the authors in their collection) drew on post-modern and poststructuralist insights to challenge ethnographers to reconsider 'objective' and 'representative' ethnographic accounts. Ultimately, their collection argued that ethnography was always partial, subjective, embedded in power relations, and inseparable from textual practices. In a similar vein, Rosaldo (1989) argues that ethnographers needed to reflexively reconceptualise their role in the construction of culture and the political implications of ethnographic accounts. He argued that ethnographers needed to reflexively reconceptualise the place of emotion, relativism, and politics of constructing ethnographic accounts and positioning the ethnographer in the text. The reconceptualisation of ethnography through post-structuralist theory is therefore incredibly significant to the understanding of what ethnography is, and the position of the researcher in constructing an ethnographic account within an organisational context.

Notably absent from Writing Culture was an exploration of the importance of feminism and feminist ethnography to textually innovative ethnography that engaged with post-structuralist and post-modern ideas. Behar and Gordon (1995) coedited a collection of essays entitled Women Writing Culture which focused on the missing feminist strands from Writing Culture and outlined the significance of feminist ethnography to ethnographic traditions. In particular, they highlighted that feminism is essential to 'post' ethnographic traditions as it aims to decentre categories of analysis and engage critically in processes of writing, representation, subjectivity, and power. Additionally, overlooking the contributions of feminist ethnography is significant because of the political implications of feminist ethnography. Feminist ethnography seeks to emphasise the politics of the writing of the text, the politics of reading the text, and the politics of the reproduction of ethnographic texts (Behar \& Gordon, 1995, p. 11). Feminist ethnographies therefore both engage with post-structuralist insights to develop methodologies that are creatively anti-essentialist and anti-totalising, as well as aiming to foster social change (Schrock, 2013). As a researcher interested in how people in organisations foster social change, feminist ethnographic traditions offered rich possibilities for my research.

Many feminist scholars have, however, questioned the possibilities of feminist ethnography for being compatible with social justice and the privileging of women's experiences. Stacey (1988), for example, showed how the researcher is almost always in a position of power and thus representing women is not as 'empowering' as a naïve view of ethnographic representation would suggest. Nonetheless, feminist ethnographies have grappled with the 
challenges of power and representation in ways that provide possibilities of engaging with and giving voice to typically silenced members of society (Schrock, 2013). A feminist ethnography, therefore, is not necessarily a unique conceptualisation of ethnography itself, but one that rigorously attends to ethical and political questions about voice, position, and emotion (Skeggs, 2001). Orienting research through a feminist ethnographic approach requires considerable negotiation of key concepts (such as writing, voice, and positioning) in order to open up pathways to social change. I move to these key concepts shortly, but first I introduce the importance of ethnography to organisation studies to frame the conceptualisation of the key concepts.

\section{Ethnography in organisational studies}

Recently in organisation studies there has been renewed interest in ethnography as valuable for research involving organisations (e.g., Brannan, Rowe, \& Nocker, 2014; Neyland, 2008a; Yanow, 2009). However, despite the extensive debates in anthropology and sociology over the criticism of positivist perspectives, often organisational ethnographies continue to follow positivistic assumptions about the benefits of 'thick description' for representing organisational life and the potential of ethnography for providing insights for managerial control (Fine, Morrill, \& Surianarain, 2009). In fact, engaging with the insights of poststructuralist and feminist approaches (and other non-positivistic approaches) can be difficult in organisational studies which generally continues to promote ideals of objectivity, neutrality, and researcher control for organisational ethnographers (Gilmore \& Kenny, 2015). Consequently, the insights of the political potential of ethnography can be difficult to apply in organisational settings, especially as access is often dependent on perceived alignment with managerial goals (Cunliffe \& Alcadipani, 2016).

Thus, although new approaches and ways of conceptualising ethnography in organisation studies are gaining a stronger foothold (Brannan et al., 2014), there seems to remain an attachment to the "the single-site, year in the field, one-tribe-one-scribe, objectivist or Godtrick model" (Van Maanen, 2006, p. 17). Gilmore and Kenny (2015) argue that while organisational ethnographers have become more reflexive, issues of emotion, ambiguous power relationships, and the shifting ethnographic self in fieldwork have been underexplored in organisation studies - much to the detriment of rich understandings of ethnographies of organisations. Delineating my relationship with some of the key concerns within 
organisational ethnography is therefore essential in order to consider how a methodology which considers issues of emotion, power, and the self in research can contribute to theorising about identities and change in an organisational context.

\section{Key concepts in ethnography}

In this section I outline some of the central debates in ethnography over key concepts. The 'crisis of representation in ethnography' (Denzin, 2002) stemmed from uncertainty about what possible truth ethnography could now hold, and how accounts of people's lives could be communicated, in the wake of the revelations associated with post-modernist and poststructuralist thought. No longer could ethnographers stand firm on a cultural landscape of concretely defined methods, strategies, and concepts. As James Clifford so beautifully summarised: "we ground things, now, on a moving earth" (Clifford \& Marcus, 2011, p. 22). Furthermore, the increasing attention on the necessity of confronting intersectional issues of racism, sexism, colonialism, and heterosexism (among others) in ethnography makes a careful theorisation of key concepts imperative (Behar \& Gordon, 1995). Ethnographers need to embed their work within the debates, while maintaining an awareness that social concepts are endlessly malleable and suffused with power. I cover here five key concepts: the colonial and imperialist roots of ethnography, voice of the researcher and the participants, position of the researcher in ethnography, emotion in ethnography, and the role writing in ethnography.

\section{Postcolonialism}

The roots of ethnography and ethnographic methodologies are firmly situated within a legacy of imperialism and colonialism (N. Thomas, 1994). The work of the postcolonial theorist Edward Said (Said, 1993, 2003) has particularly contributed to our understanding of how colonial domination is perpetuated through narration of the lives of peoples. Although Said focuses primarily on fiction as a mode of narration shaping and sustaining colonial encounters (2003), he argues that the influence of colonialism and imperialism takes many forms of narrations of peoples, including ethnography (1993). Processes of orientalism operate to produce an 'othering' of non-Western people; creating binaries of the people of the West 'us' and the Rest 'them' (Said, 2003). Traditionally in ethnography, the former was surveying the culture of the 'other', thereby establishing a hegemonic gaze from 'West' to 
'East' and producing Eurocentrism. The 'west to east' gaze can be a form of domination through interpretation and representation, perpetuating harmful stereotypes about the 'orient' (Krumer-Nevo \& Sidi, 2012) and about indigenous peoples (Smith, 2012).

Said's ideas about colonialism and imperialism have been influential for ethnographers taking a postcolonial stance (e.g., Krumer-Nevo \& Sidi, 2012; Manning, 2016; Smith, 2012; Wong, 2002). Additionally, in certain branches of anthropology (and increasingly in other disciplines such as organisational studies in which ethnography is an established methodology), other postcolonial perspectives have become increasingly recognised. The possibilities of perpetuation of harmful colonial and imperialist discourses have considerable importance for my research because of the status of Aotearoa New Zealand as a former British colony and the consequent extensive impacts on Tangata Whenua. Consequently, developing an ethnographic approach involves considering the historical legacy of colonialism in my contextual setting and the representation my participants and their work (Smith, 2012). For this project, this includes writing ways that enable contextualisation, and historisation of my colleagues, participants, and their working lives (Krumer-Nevo \& Sidi, 2012), reflexively situating the researcher and writing against the 'authoritative' and 'objective' stance of the researcher (Manning, 2016), and acknowledging and examining my place as a Pākehā woman working with Tangata Whenua (Huygens, 2011). These ideas about writing, voice, and position of the researcher central to this stance are developed further below.

\section{Voice}

The possibilities of providing 'voice' to marginalised people was seen as one of the primary possibilities of ethnography for feminist scholars (Lather, 2001). By closely engaging with women considered 'outside' the mainstream, there was a hope that social justice could be achieved by the researcher offering their stories to a wider audience. The naïve attribution of 'voice' however, was rapidly subject to criticism by feminists who were concerned that unproblematically assuming a researcher could 'speak on behalf' of the 'voiceless' was more exploitative than objective and neutral ethnographies (Stacey, 1988). Feminist ethnographers who engaged with the implications of post-modern and post-structuralist perspectives for understanding power developed new ways of reflecting on the possibilities of circulating marginalised voices, without assuming that doing so was an exercise free from power and 
politics (Lather, 2001). Feminist ethnographers who grappled with questions of power and politics in their research alternatively attempt to foster more balanced power relationships surrounding researcher and researched that acknowledges agency and the politics of 'voice' (Davids \& Willemse, 2014). Ideas about promoting social justice through circulating marginalised voices remains central to feminist ethnography, but there is no neutral way of 'representing' them.

Consequently, I do not understand my ethnography to give an objective and apolitical 'voice' to the women I worked with. Manning (2016) suggests that in order to negotiate the issue of 'voice' in a feminist and postcolonial ethnography, an ethnographer should start from understanding participants "as women accentuating their own agency and exploring their own understanding of their organized existence” (p. 100). Manning offers three suggestions for conceptualising feminist ethnography and voice: research is one of many platforms for marginalised women, ethnographic knowledge and voices are co-produced by researchers and participants, and ethnographers should not claim to have complete knowledge but recognise participants as complex and multifaceted people. In order to engage with these understandings of 'voice' a feminist ethnographer should ensure that their ethnography "decentres and deconstructs authorial "presence"” in the text (Lather, 2001, p. 207). Following these perspectives, I argue that my ethnography does not (and cannot) offer the 'voice' of participants, but is a platform for circulating subjective, momentary, and complex understandings of organisational life that might not otherwise have textual presence.

\section{Researcher position}

Acknowledging the authorial presence as inevitable, but needing to be decentred and deconstructed, relates to another central concept of ethnography: the positioning of the researcher in the social context they study. My understanding on the position of my self, and the selves of the researcher generally, changed and developed over my time in the field; a subject that I explore closely in 'Vulnerable bodies' (Part III). Since developing ways of understanding how ethnographers affect the field, and how the field affects ethnographers (Coffey, 1999), there has been increasing interest in how organisational ethnographers can reflexively locate themselves in relation to those that they study (Gilmore \& Kenny, 2015). Organisational ethnographers increasingly acknowledge that part of the process of gaining access, maintaining access, and participating in the organisation involves reflexively 
negotiating the positioning of the researcher in relation to their participants, and in relation to the social context of the study (Cunliffe \& Alcadipani, 2016). As ethnographers continue to grapple with the implications of the impossibility (and often undesirability) of an objective, neutral researcher who observes those around them in a scientific fashion, new ways of engaging with communities have been developed.

As I was going to be engaging with the community sector, I approached my position in this context through the concept of the volunteer ethnographer. A volunteer ethnographer is a unique position within social justice organisations which Garthwaite (2016) explains as a researcher who has both a formal voluntary role and commitment to the organisation, as well as a role as a researcher and a commitment to their research. O'Connor and Baker (2017) also argue that a volunteer ethnographer has an emotional commitment to the social justice work. Consequently, the positioning of researcher and volunteer are not neatly divisible for volunteer ethnographers. Within the organisational contexts they study, they express a formal commitment to the social justice goals and thus can be understood as both 'working with' and 'working for' the organisation (O'Connor \& Baker, 2017). I set out to position myself as a formal member of the organisational context, thereby aiming to acquire access as an insider, while also maintaining my commitment to research.

In developing the position of the volunteer ethnographer, Garthwaite (2016) highlights that although volunteer ethnographers are in a unique position to understand their organisations as insiders, there are complexities with both working for and with the organisation. The formal commitments pose challenges for volunteer ethnographers in writing about their colleagues who are often seen as friends. These challenges are marked when engaging in critical work, as volunteer ethnographers develop strong emotional attachments to their colleagues and do not want to damage the organisation's reputation or their social mission (Garthwaite, 2016). O'Connor and Baker (2017) suggest that volunteer ethnographers should engage in ongoing dialogue in the field to negotiate their dual roles. Understanding the position of the volunteer ethnographer as shifting between expressing and engaging in primary commitment as a volunteer, and primary commitment as a researcher is therefore vital for volunteer ethnographers (O'Connor \& Baker, 2017; Tinney, 2008). Ultimately, the challenges mean that the position of a volunteer ethnographer shifts and changes over the course of the research. Certain commitments remain, however, including that a volunteer ethnographer directly contributes to the organisation and their social justice goals, they embrace 
subjectivity and acknowledge an emotional commitment to the organisation, and they maintain a formal role in the organisational context.

\section{Emotion}

My positioning as a volunteer ethnographer within the organisation raised a specific set of challenges relating to emotion in ethnography. Emotion in organisational ethnography has been a theme that has been overlooked (Brannan, 2011) and organisational ethnographers have been slow to take up insights from the related fields of anthropology and sociology as to the centrality of emotions in ethnographic research (Gilmore \& Kenny, 2015). Within these related fields, however, emotion has been recognised as being essential to ethnography. Rosaldo (1989) establishes the importance of both the emotions of ethnographers for understanding the cultures they engage with, and the emotions of the communities for being central to cultural practices. He argues that emotion is essential to theorising, rather than being contrary to knowing. Similarly, Coffey (1999) argues that attention to emotion in ethnography is essential for understanding the relationships between the ethnographic self, and the other 'selves' involved in the research. Emotion, therefore, is an essential, albeit overlooked, aspect of ethnography particularly as it pertains to understanding identities in organisational contexts.

Furthermore, strong emotions are related to the political potential of research. Whiteman (2010) suggests that strong emotions can help us move beyond 'calm and neutral theorising' and help us to both acknowledge our assumptions about organisational realties and embrace the political potential of organisational research (p. 335). Additionally, Van Maanen (2010) notes that ethnographers have the unique potential of asking the reader of ethnographic texts to identify with those studied, the field-worker, or with the social cause. Emotions are central to engaging this political potential. Thus, emotions were a point of concern for me from the outset of the project, particularly since Garthwaite (2016) reasoned that volunteer ethnographers in community organisations need to pay specific attention to their emotions and the emotions of others because of the social justice context. As I was engaging in social justice community work, emotions were central to my conceptualisation of ethnography. This theme increased in salience during my fieldwork, and in 'Ties that bind; ties that break' (Part II) I explore the topic of emotion in relation to the community sector and identities in detail. 


\section{Writing}

Writing is fundamental to ethnography (Behar \& Gordon, 1995; Clifford \& Marcus, 2011). In more traditional styles of ethnography the writing is seen as a vital mode of representation and communication (Neyland, 2008a). In fact, traditional ethnographies tended to see writing as imperative for producing 'thick description', or long and extremely detailed accounts of cultural practices that were the marker of a rigorous scientific study (Rosaldo, 1989). There are, however, multiple alternatives for understanding the significance of writing for ethnography. Non-positivist scholars have long argued to reconsider the writing of ethnography on the grounds that scientific styles of writing reproduce hegemonic ways of knowing (Manning, 2016) and that writing produces culture rather than representing it (Clifford \& Marcus, 2011). The practices of writing are therefore especially important for ethnography that has a political impetus (Behar \& Gordon, 1995). As Denzin (2002) argues, "theory, writing, and ethnography are inseparable practices... we change the world by changing the way we make it visible" (p. 483). Developing writing strategies that are different to classic scientific standards is an important element of producing novel insights into identity theory and understanding the social worlds of those who are part of our research.

Earlier I discussed some of the writing strategies I experiment with throughout this thesis. These are woven together with my understanding of the importance of writing ethnography for undoing power relations which marginalise women's (and other minority) experiences. Behar and Gordon (1995) note that often when women write their ethnographies, they oscillate between the authorial anxiety of crafting texts of full, complex (often marginalised) people, and the primary importance of circulating tales of marginalised people that would otherwise be excluded. My writing is infused with both concerns. The writing strategies I outlined in 'Settings' emphasise the salience of developing alternative ways of writing for fostering social change to this thesis. Regarding the specific implications for ethnography, I also acknowledge that my writing is inevitably partial and that in my choice of writing strategies, other ways of knowing have been marginalised. The tension between authorial anxiety and the imperative to 'change the world' through writing is a necessary one to avoid positioning oneself an omnipotent ethnographer, and thus is one I embrace throughout this thesis. 


\section{Ethics and politics of ethnography}

As Murphy and Dingwall (2001) argue, "the ethics and the politics of ethnography are not clearly separable" (p. 339). For ethnographers, questions about the right way to treat the communities we work with are interlinked with issues of epistemology and ontology (Murphy \& Dingwall, 2001). As discussed above I take the perspective that all ethnographic knowledge is subjective, localised, contextual, and embedded in power relations which unevenly distribute value. When making considerations about the ethics of engaging with communities and representing them in writing, I consider that ethnographers can never offer objective 'representation' and the voice of participants is always filtered through the researcher (Van Maanen, 1988). Thus, all ethnographic writing has a political dimension as the production of knowledge about a group of people can operate to create and sustain dominance of certain groups over others (Manning, 2016). Consequently, when engaging with a group of people typically excluded from dominant ways of knowing - including women and indigenous people - careful consideration needs to be given to what knowledge is produced and how it is circulated.

Ethnographic research therefore must at all times uphold the dignity, safety, and privacy of participants (Madison, 2005) and reflexively locate the researcher in the study and consider the political implications of ethnographic work for participants (Manning, 2016).

Additionally, all ethical considerations must be located and contextual. In Aotearoa New Zealand two important concerns for research are the small size of the population which makes it difficult to protect individuals' confidentiality, and the rights of Tangata Whenua (Tolich, 2001). I used a duel set of ethics to frame this project. One set of ethics derived from the university ethics procedure and shaped the formal ethical guidelines of the project, including matters relating to consent and confidentiality. In line with my methodological commitments to feminist ethnography, I also drew on a framework of researcher ethics outlined specifically for engaging in research with the community sector in Aotearoa New Zealand. When conducting research with the community sector, the Tangata Whenua, Community and Voluntary Research Centre (“TWCVRC”) suggests that four key principles should guide the research: participation, empowerment, social justice, and moral responsibility (Tangata Whenua: Community and Voluntary Sector Research Centre, 2007). Their framework incorporates the local interests of Aotearoa New Zealand and its people, as well as the specific context of the community sector. Below I outline each of these principles and explain how they applied to the project, and how I adhered to these principles. 
For 'participation' the TWCVRC suggest that the researcher should discuss the research with the community organisation to ensure that the research is wanted by the community and is appropriate for them, ensure that the unique status of Tangata Whenua is acknowledged and that their rights as indigenous people are respected, and that the research spans beyond the timeline of the project to ensure the researcher is embedded in the community. I contacted the organisation initially with a letter and explanation of the project and arranged a meeting with the organisation to discuss the possibilities of volunteering for their organisation. Through this process, I explained the value of the research and additionally offered my skills as a researcher to benefit the organisation. Furthermore, all those who self-identified as Māori are acknowledged throughout the thesis. In the first phase 'by Māori, for Māori organisations' were specifically invited to participate in the research, and all first phase interviews included a discussion of the unique contributions and rights of Tangata Whenua in the community sector. In the second phase of the research half the participants of the interviews selfidentified as Māori and the other half as either Pākehā or other white. Additionally, I retain the use of Te Reo Māori by my participants throughout the thesis. Finally, I remained in close contact with the organisation after the fieldwork was officially completed. All sections of the thesis were discussed with my colleagues as they were developed.

For 'empowerment' the TWCVRC suggest that the researcher must protect and use knowledge in a way that is in line with the community's perception of care and nurturing, that research should enact the concept of koha (reciprocal contribution) ${ }^{9}$, and that the research helps to build the community in the future. The empowerment of women was central to the organisation and acknowledging the power and agency of women was imperative. My thesis aims to emphasise the agency and power of women by always acknowledging their fullness and complexity as people with multiple interests, experiences and knowledge (Manning, 2016). As part of this aim I always refer to them as my 'colleagues' (rather than participants) to indicate their interests, experiences, and knowledge embedded in their context. I also refer to all my colleagues with pseudonyms to retain their fullness as people and maintain a sense of their complexity. Additionally, my volunteering for the organisation was part of the reciprocation to the community, offering my skills in return for the exchange of knowledge. Presenting my ideas and findings to the organisation was also part of the reciprocity. Finally, my research is aimed at understanding how identities and social change were interrelated,

\footnotetext{
${ }^{9}$ The Māori term 'koha' is an offering or contribution, especially one that is maintains social relationships and has connotations of reciprocity.
} 
thereby aiding the organisation in strengthening their work in combating violence against women.

For 'social justice' the TWCVRC suggests that the community should be the first and foremost beneficiary of the research, that collective and individual confidentiality is taken into account, and that the research has layers of ownership. Decisions related to confidentiality and maintaining the dignity and safety of the organisation were always put before the detail included in the thesis. There are many instances in the thesis where details were omitted for the collective confidentiality of the organisation and preserving the dignity of the members of the organisation. Finally, the research always belonged first and foremost to the organisation. Any decisions of inclusion of material rested on the permission of the organisation and its members. Interviews were always provided to the individuals for comment, and all parts of the thesis were available to participants for comments. The core principles of the organisation as serving women and children who are subjected to violence always remained at the core of every aspect of the thesis.

Finally, for 'moral responsibility' the TWCVRC suggest that there is accountability between all parties (preferably in a written agreement), that ethical approval is sought both from the researcher's institution but also in line with the community's own ethical standards, and that the values of the community are understood and nurtured. Ethical approval was sought and obtained from the Victoria University Human Ethics Committee. First phase participants were provided with an information sheet (Appendix A), signed a research agreement (Appendix B), and were invited to ask questions about the research. For the second phase, I obtained a written agreement for my volunteer work, provided the organisation with information and confidentiality forms verified by my university, and obtained individual permission to both interview and observe them. One consent form was used for the organisation (Appendix C), which was signed after consultation about the project (Appendix D), and all participants in the interviews had separate consent forms (Appendix E). These were supplied alongside an information sheet about the project (Appendix F) and participants were invited to ask questions about the research. Additionally, all research forms included space for the organisation and individuals to add their own ethical standards. Finally, I engaged in research of the organisation's history, values, and philosophy before contacting them and integrated their key principles into the ethical touchpoints of this research. Namely, this research operates on an anti-racist, anti-sexist, anti-colonial, and anti-heterosexist basis. 
I met with several direct ethical challenges in my fieldwork which I will briefly cover here, particularly as they are significant for the degree of specificity in this research. As a volunteer I was encouraged to participate in activities that involved interaction with external agencies on a regular basis. Although my knowledge gained from these events has implicitly informed my understanding of the organisation and the identities of my colleagues, I have excluded all mentions of members of the community sector outside of my organisation unless express permission was gained to include mention of specific incidences in this thesis. Additionally, the research I engaged with on behalf of the organisation is excluded from this thesis. The knowledge I gained through participating in the associated activities has likewise implicitly informed my understanding of the organisation, its members, and the issue of domestic violence.

Maintaining the confidentiality of the organisation and my colleagues was a specific ethical challenge. Our organisation was small, and it is likely that my colleagues who read the thesis in detail will be able to identify other members of the organisation. In order to negotiate this challenge, I attempted to put the dignity of my colleagues first when presenting any details of their lives, experiences, and opinions. In the information sheets it was clearly defined that anyone who knows a person well may be able to guess the identity of a participant. I excluded any material that I was concerned may negatively impact the reputation of any of my colleagues. Additionally, maintaining a clearly defined position of a subjective, involved researcher- rather than an objective, neutral expert - also helped me to navigate the complexities of discussing organisational events and the lives of my colleagues. At times I write explicitly from a personal viewpoint in an attempt to mitigate the ethical challenges of presenting material in which my colleagues were emotionally invested. Finally, the confidentiality of the organisation was paramount, and I have attempted to balance sufficient detail for the reader to understand the context, while not providing identifiable details of the organisation.

\section{Domestic violence and the organisational response}

Having delineated some of the debates in ethnography that were central to this project, established a position among them, and outlined the ethical frame that informed my fieldwork, I now move to discussing the methods I used in the field. Before describing the methods and analysis I undertook in the field, however, it is worth pausing to contextualise 
the organisation I carried out my fieldwork with, and the form of social justice that they sought. The particular nature of the organisational work with domestic violence influenced the degree to which I participated in the organisation and was important in shaping the analysis of the empirical material. Confidentiality of the organisation is necessary - as highlighted above in the ethics section - and so I only give a brief outline of their activities and scope.

The organisation I volunteered with specialised in domestic violence. Aotearoa New Zealand has the highest rates of violence against women in the developed world, with one in three women experiencing physical and/or sexual abuse from a partner, and one in two women experiencing psychological and/or emotional abuse (Fanslow \& Robinson, 2011). The likelihood of experiencing violence is also tied to other identities, for example Māori women are twice as likely as Pākehā women to experience domestic violence (Te Puni Kōkiri, 2010) and bisexual women are most likely of all women to experience sexual violence from a partner (Dickson, 2016). There has been a prolonged voluntary led response in Aotearoa New Zealand, with many networks of women emerging from the women's liberation movements in the 1960s and 70s (Else, 1993). Various voluntary groups have come a long way in shifting public attitudes about domestic violence which were once extremely hostile to women's groups (Connolly, 2004) and domestic violence against women is now a widely recognised social issue and one of the government's priorities (Ministry of Justice, 2016). However, the onus for fostering social change, and assisting and supporting women who are subjected to violence still largely remains with advocacy and support community organisations. In the context of this thesis, therefore, social change is always located around reducing violence against women in the context of the community sector.

The organisation that I volunteered with for this thesis was part of the response to domestic violence. The organisation operates throughout the country and provides both services and advocacy for women and children who are subjected to domestic violence. Their workforce consists of a mix of staff and volunteers. Most staff members had training in social work. I volunteered with the 'backstage' workers of the organisation. The reasoning for this was twofold: firstly, engaging in sustained direct work with clients would have added layers of ethical and practical complexity to the project, and would have required training in social work. The contact I did have with clients in my volunteer work is excluded from this thesis. Secondly, I was primarily interested in how at the interfaces between the community sector, government, and the individuals' identity and change were related. The 'backstage' office I 
worked in consisted of approximately 20 people who were a mix of part-time and full-time workers. Some had more sustained contact with frontline staff and clients, and others worked only backstage. Their roles ranged from finance accounting, contract monitoring, research and policy, human resources, to media and public relations. All my colleagues' roles rotated around serving, supporting, and strengthening the frontline staff and the organisation.

\section{In the field: Gathering and analysing empirical material}

In this section I outline the methods I used to gather my empirical material. Overall, my field study was separated into two phases. The first phase involved a series of interviews with experts from the community sector. The second phase involved establishing myself as a volunteer in a single organisation and engaging in participant observation, interviews with my colleagues, and secondary material collection. Once I have discussed the methods used in both phases, I move to discussing the analysis and interpretation of the empirical material

\section{Phase 1: mapping the community sector}

The first phase was intended to map some of the narratives and discourses that constitute the community sector in Aotearoa New Zealand. I conducted a series of expert interviews with a range of people involved with social service organisations in the community sector. The experts were 'boundary-spanners', or people who unite contextually related opinions and knowledge across a range of areas (Tushman \& Scanlan, 1981). The aim was not to gather a representative sample, but to explore how multiple voices constructed the idea of the community sector. I made a list of prominent groups involved in social service organisations and contacted relevant organisations via email or phone. Additionally, during a presentation to the community sector about my research I was also approached by several people interested in participating and was given the suggestion of including social workers as an important group in social service work. Ultimately, the interviews were conducted with 15 different experts, from a range of areas including volunteering, philanthropic funding, senior management of social service organisations, umbrella organisations, social workers, and government departments (Table 1).

Table 1. First phase participants 


\begin{tabular}{|c|c|c|c|}
\hline Pseudonym & Organisation Type & Scope & Age bracket \\
\hline Adam & Volunteering & Sector Wide & $30-39$ \\
\hline Shiner & Volunteering & Social Services & $60+$ \\
\hline Nick & Volunteering & Sector Wide & $50-59$ \\
\hline Jane & Philanthropy & Social Justice Organisations & $50-59$ \\
\hline Brian & Philanthropy & Sector Wide & $40-49$ \\
\hline Michael & Service Provider & Social Services & $40-49$ \\
\hline Phillip & Service Provider & Social Services & $40-49$ \\
\hline Robin & Service Provider & Social Services & $30-39$ \\
\hline Himene & Kaupapa Māori & Social Services & $40-49$ \\
\hline Calvin & $\begin{array}{l}\text { Umbrella } \\
\text { Organisation }\end{array}$ & Sector Wide & $60+$ \\
\hline Kara & $\begin{array}{l}\text { Umbrella } \\
\text { Organisation }\end{array}$ & Sector Wide & $60+$ \\
\hline Abigail & $\begin{array}{l}\text { Umbrella } \\
\text { Organisation }\end{array}$ & Social Services & $50-59$ \\
\hline Tamara & $\begin{array}{l}\text { Umbrella } \\
\text { Organisation }\end{array}$ & Social Services & $50-59$ \\
\hline Elisabeth & $\begin{array}{l}\text { Government } \\
\text { Department }\end{array}$ & Sector Wide & $50-59$ \\
\hline Kelly & $\begin{array}{l}\text { Government } \\
\text { Department }\end{array}$ & Charity & $40-49$ \\
\hline
\end{tabular}

I decided to use semi-structured interviews as they allow for participants to expand on answers and include what information they perceive as relevant, while still providing guidance (Cassell, 2009). All the interviews lasted about an hour. Questions followed an 
interview schedule (Appendix G) and included key issues facing the community sector, the unique value of the community sector, and its relation to the private and public sector (Table 2).

Table 2. Example questions from first phase interviews

\begin{tabular}{|l|l|}
\hline Area & Sample Questions \\
\hline $\begin{array}{l}\text { Describe the } \\
\text { nonprofit sector }\end{array}$ & $\begin{array}{l}\text { How would you describe the nonprofit sector? } \\
\text { What are its unique characteristics? }\end{array}$ \\
\hline $\begin{array}{l}\text { Role of the } \\
\text { nonprofit sector }\end{array}$ & $\begin{array}{l}\text { What role do you see nonprofit organisations playing in Aotearoa } \\
\text { New Zealand? } \\
\text { How would you characterise the relationship between the nonprofit } \\
\text { sector and the community? }\end{array}$ \\
\hline Treaty of Waitangi & How do nonprofit organisations respond to the Treaty of Waitangi? \\
\hline $\begin{array}{l}\text { Achieving } \\
\text { 'success' }\end{array}$ & $\begin{array}{l}\text { What sorts of characteristics do nonprofits need in order to be } \\
\text { successful? }\end{array}$ \\
\hline $\begin{array}{l}\text { Government } \\
\text { relationships }\end{array}$ & $\begin{array}{l}\text { How would you describe the attitudes of the government toward the } \\
\text { nonprofit sector? }\end{array}$ \\
\hline Key challenges & What are the key challenges facing the nonprofit sector? \\
\hline
\end{tabular}

\section{Phase 2: Ethnographic fieldwork}

As I reached the end of the first phase of my field research, I began to prepare to contact an organisation to arrange access for ethnographic fieldwork. Gaining and maintaining access to organisations is complex and is not simply an issue of practicality. In fact, as Cunliffe and Alcadipani (2016) argue, it is an ongoing process embedded in power relations that shapes the research. As my aim was to become a volunteer ethnographer, I was asking for the opportunity to work for the organisation, as well as with them. The nature of the relationship I was seeking with the community organisation could therefore be classified as what Cunliffe and Alcadipani (2016) call a 'relational approach'. A relational approach is about 'the mutuality of researcher-research participant relationships and influence, and requires researchers to be sensitive to the nature and agency of the researcher-research participant relationship" (Cunliffe \& Alcadipani, 2016, p. 543). The negotiation of access was, therefore, not a one-off process at the opening of fieldwork but was an ongoing discussion between me and my colleagues.

Initially, my primary supervisor contacted the organisation to lend legitimacy and support to the process of gaining access (E. Bell \& Thorpe, 2013, p. 14). Through this process I was put in touch with one of the senior managers in the organisation and arranged a meeting to 
discuss the possibility of doing my research with the organisation. Before our meeting I sent through a letter outlining my interest in the organisation, the proposal of my project, and several shorter pieces that I had written on the organisation and their work. I was offered a voluntary role in the organisation after our first meeting and was asked to start within the week. One of my primary concerns as a feminist researcher was engaging in a mutual exchange of knowledge, as well as ensuring that my research was ultimately beneficial for the organisation (Manning, 2016; Schrock, 2013). I was therefore set up to work closely with one member of the office, where my research skills could be best utilised for my colleagues. I also asked for, and was granted, the possibilities of working with each team in the office during my time and to participate in almost all major events that took place in the office. There were, however, events and practices I was not given permission to participate in on the basis of protecting the interests of the organisation.

I undertook my fieldwork with my organisation for a period of 8 months. I started my fieldwork at the beginning of October of 2016 and concluded at the end of May 2017. Overall, I spent an average of 15 hours a week volunteering with the organisation. During this time I engaged in participant observation, "a method in which a researcher takes part in the daily activities, rituals, interactions, and events of a group of people as one of the means of learning the explicit and tacit aspects of their life routines and culture" (DeWalt, 2011, p. 12). I was a 'participant-as-observer' meaning that I participated fully in the ongoing activities of the organisation and all my colleagues knew my identity as a researcher (HesseBiber \& Leavy, 2011, p. 206). My time was unevenly distributed between conducting research on behalf of the organisation, attending meetings with external stakeholders, attending meetings in the organisation, assisting members of the team with their work, participating in lunchtime conversations, attending special event lunches and dinners, attending team-building workshops, attending advocacy training, engaging in advocacy with politicians, and attending an annual organisational conference. Additionally, I had many uncounted informal conversations with my colleagues about their work and encouraged them to expand on any theme that they wanted.

My observations, reflections on participation, and my conversations were recorded in a notebook on the day, and then written up electronically into extended fieldnotes the same day or the day after. The events I attended and time that I spent in the field were recorded on a calendar. My initial process was to write about everything I understood as related to my research topics of identity and change (Hesse-Biber \& Leavy, 2011), but over time in the 
field I narrowed down to focus on more selective areas that were striking or seemed salient to the daily lives of my colleagues. The recording of fieldnotes is itself a form of data analysis, as the researcher is selecting, interpreting, and constructing events and conversations through the process of transcription (Atkinson, 1992). Additionally, I merged together my observations and conversations in field with personal reflections on emotions, reflections, and experiences related to my voluntary work that occurred outside of the time I was physically in the field. Often 'how-to' texts encourage the ethnographer to keep a separate journal which records personal emotional reflections on the time spent in the field (DeWalt, 2011) but as Lofland and Lofland (1995) argue, integrating emotional experiences into fieldnotes of observations and conversations is essential for analysis and provides a deeper of understanding of the social context. Indeed, some of my emotional experiences contributed substantially to the theorising discussed later in this thesis.

I also conducted semi-structured interviews with six of my colleagues. Interviews, both formal and casual, are a key part of ethnographic research (Neyland, 2008b). At a team meeting where everyone was attending I asked for time to talk a bit more about my research and about what the interviews involved. I asked anyone who was interested to either email me or come to talk to me privately, to maintain the confidentiality of my participants. Six of my colleagues came forward interested in the interviews.

The interviews involved a series of three interviews, each with a different focus (Appendix H). Suárez-Ortega (2013) suggests that in order to provide participants with the space for reflexive consideration of their lived experiences and identities, interviews should be conducted in three rounds. These rounds include a (1) a life-history, (2) an expansion on participants' contemporary specific experiences, and (3) a focus on future goals, dreams, and aspirations (Table 3). The three rounds offers space for participants to construct their identities as full, complex individuals, reflect on their lived-experience between interviews, and "makes it possible to know and understand meaningful experiences in women's lives, as they interpret, give meaning to, and explain them" (Suárez-Ortega, 2013, p. 194). My interviews were based on the three-round approach, although I adapted the method to be in line with my feminist post-structuralist orientation. This included embracing ambiguity instead of excluding it, assuming the interviews to be textual constructions of identities rather than representative explanations, and placing more emphasis on the political production of texts. 
In the first interview I asked my colleagues to talk me through their life history. The question was open ended. I took notes and asked my colleagues to expand on certain topics. These interviews lasted between 40 minutes and one and a half hours. In the second and third round of interviews I opened by asking my participants to share any significant changes in the lives in the 3 months since the previous interview. The second interview was relatively more structured than the first, and I asked my colleagues to tell me about their working lives, their relationship with their work, and how it shaped their identities. These interviews lasted between 30 minutes and one and half hours. The third interview followed a similar structure to the second interview but asked questions about my colleagues' future plans, goals, beliefs, and the changes they would like to see in their work and in society. These interviews lasted between 20 minutes and one hour and twenty minutes. The interviews took place over a sixmonth period and in various locations, from meeting rooms in our office, to local cafés. I transcribed the interviews in full and returned the transcripts to my colleagues who were invited to read, comment, or edit our conversations.

Table 3. Example three round interview questions

\begin{tabular}{|c|c|}
\hline Focus & Sample Questions \\
\hline $\begin{array}{l}\text { Life history } \\
\text { (round 1) }\end{array}$ & $\begin{array}{l}\text { - Can you tell me your life history? } \\
\text { - Are there any moments in your life that stand out to you as being } \\
\text { particularly significant for influencing who you are as a person? } \\
\text { - What significant relationships have influenced you? }\end{array}$ \\
\hline $\begin{array}{l}\text { Contemporary } \\
\text { working } \\
\text { experiences } \\
\text { (round 2) }\end{array}$ & $\begin{array}{l}\text { - How did you first become involved with this organisation? } \\
\text { - Are there parts of yourself that you don't express/bring to work? } \\
\text { - Has involvement in the organisation changed the way you think } \\
\text { about yourself? }\end{array}$ \\
\hline $\begin{array}{l}\text { Future goals } \\
\text { and aspirations } \\
\text { (round 3) }\end{array}$ & $\begin{array}{l}\text { - What goals and dreams do you have for the future? } \\
\text { - What would you like to see change in Aotearoa New Zealand? } \\
\text { - How do you see the organisation's goals/mission as shifting over } \\
\text { time? }\end{array}$ \\
\hline
\end{tabular}

\section{Analysis and interpretation of empirical material}

Analysis of qualitative material is an inductive and emergent process rather than a "mechanical process of assembly-line steps" (Lofland \& Lofland, 1995, p. 181). The challenge for critical scholars is therefore to discuss their non-linear and non-neutral modes of analysis in ways that incorporate the ambiguity and intuition of qualitative research, while remaining accessible and sensible (Ashcraft \& Ashcraft, 2014). My analysis was non-linear and involved both spontaneous interpretation of material while in the field and a more 
reflective interpretation of the empirical material outside of the field. The process of analysis was also shaped by my multiple interactions with my colleagues, my supervisors, other members of the community sector, and the theoretical material I engaged with throughout the process. In this section I therefore seek to outline both my more formalised approaches to analysis of the empirical material and map the more spontaneous and intuitive aspects of my analysis.

At the outset of the project I outlined three approaches to analysis of the empirical material that I would engage with to explore what my theoretical frameworks would contribute to an understanding of identities and change. I start my delineation of my analysis from this point before moving to discussing how my analysis developed and shifted over the course of the project as I gathered my empirical material. As outlined above, the collection of empirical material was divided into two phases. Therefore, I subsequently present the analysis of each phase of the empirical material. The analysis of the two phases of collection were not distinct, however, as the primary purpose of the first phase of collection was to map some of the ways of understanding the community sector that shaped the identities of my colleagues on a daily basis. The points of interaction between the first phase material and the second phase material was, therefore, a significant feature of analysis.

\section{Initial frames for analysis of the empirical material}

My first approach drew on my interest in narrative theories of identity. Narrative analysis addresses an important form of social interaction: the stories we tell about our selves (Riessman, 2008). My interest in narrative as a theoretical framework for understanding identities therefore aligns with a narrative methods approach to analysing empirical material. Atkinson and Delamont (2008) suggest that a narrative analysis follows several intertwined steps: understand what form of social interaction narratives accomplish, examine their common properties and features, look at any recurrent structures, and explore what cultural conventions they construct (p. 290). For my narrative analysis I looked across my empirical material as well as examining the interviews as specific examples of narrative texts. Primary among my analytic methods was the process of interrogating how and why narratives are constructed (Riessman, 2008) as well as giving specific attention to the construction of identities through narratives and the social context within which these narrative identities were embedded. 
My second approach derived from the work of Judith Butler; a 'Butlerian' approach. Riach et al. (2016) suggest that for analysis stemming from Butler's work: "the starting point for analysis is a shared understanding of the work we undertake, as organizational subjects, attempting to maintain a performative sense of self that is coherent and viable" (p. 2080). Additionally, a Butlerian approach to the analysis of identities must develop an understanding of the 'breaks', or the moments where identities are reiterated in novel ways that can challenge or change the social norms on which they depend. The points of analysis therefore involved a mixed process of developing an understanding of the conditions of becoming in the community sector, the norms of identities in the organisation, the recurrent performances which construct identities, the instability of identities and the moments of breaking, and an analysis of the form of the work that my colleagues undertook to construct a sense of self.

Although the work of Bourdieu was put aside from the research process a few months into fieldwork, my initial analysis of the first-phase interviews and the first few months of my ethnographic fieldwork still drew on his perspectives. Bourdieu therefore still formed a component of iterative empirical analysis. My third initial frame of analysis was to map the field, habitus, and capital of the community sector. This analysis shaped my understanding of the power relations between the state and the community sector; particularly of the symbolic violence (Bourdieu, 1991) enacted through an uneven distribution of resources and transmission of neo-liberal principles between the government and the community sector (McGovern, 2017; Woolford \& Curran, 2013). Additionally, identifying the salience of 'professional' identities was an initial identity category linked to the work of Bourdieu that shaped my understanding of the community sector. Although these themes are no longer formally developed in this thesis, the echoes of professionalism and inequalities between the community sector and the state derived from this analysis are notably evident in 'Ties that bind; ties that break' (Part II) and 'A multiplicity of feminisms' (Part IV).

\section{Analysis of first-phase empirical material}

My approach to analysing the material from the first phase interviews was undertaken with an aim to explore the ways that my participants talked about the community sector, paying attention to how their constructions would shape identities of community sector members. Reading through the full interview transcripts from my first phase participants, I generated a list of literal (directly from the text) and analytical (developed by the researcher) codes of 
categories related to my central research question (Hesse-Biber \& Leavy, 2011). Additional categories came from the literature. For example, my initial analysis of the literal and analytical categories focuses on the literal category of the importance of the Treaty of Waitangi to identities in the community sector, and the analytical category of professionalism. Categories from the literature included, for instance, the conflict between business and social justice identities. Engaging in this process provided a sort of systematic order to the first phase empirical material that I was able to reflect on during my field study. The categories that I generated based on this process were part of an initial guiding focus in my participant observation.

Throughout my time with my organisation I revisited and reconsidered the importance of these categories to my colleagues. As emotion become more important to me as a salient concept related to identity for my colleagues, I re-read the first-phase transcripts to explore the construction of emotion in relation to the community sector in the first phase interviews. This subsequent rereading of the first phase transcripts occurred after my time in the field was completed and I had gained both more extensive empirical material, and a tacit understanding of the community sector from the perspective of an insider. The aim of the second analysis of the first phase interviews was therefore divided into two distinct foci: (1) the reconsideration of the initial categories as to how they construct the identities of the community sector in relation to my colleagues, and (2) the salience of emotion to the identities of the community sector.

\section{Analysis of second phase empirical material}

During my field research I developed initial points of interest about identity that seemed salient for my colleagues and for daily life in the organisation. My approach to developing the points of interest spanned both my reading in the literature (particularly around the works of Judith Butler and narrative) and my discussions and observations with my colleagues. The longer I was in the field, the more I developed a sense of which aspects of identity were striking, novel, or significant to my colleagues and to their work. These initial ideas were developed into short pieces of writing which I discussed with my colleagues and shaped my interpretation based on their feedback. Analysis through discussing my ideas with my colleagues remained central throughout the thesis, and at each stage of writing the thesis I presented and discussed the development of my interpretation with my colleagues. 
The initial frames of analysis, as I outlined above, continued to be significant in interpreting the empirical material. My fieldnotes from observations, informal conversations, and personal experiences, the formal interviews with my colleagues, the secondary documentation gathered from the field were all analysed through a narrative and a Butlerian frame. For example, the formal interviews with my colleagues were analysed as narratives and I explored their common properties including structure, style, and content, the cultural conventions of storytelling in the organisation, and how identities were constructed in the narratives. Likewise, the formal interviews of my colleagues were analysed for the conditions of becoming in the organisation or what the norms of identity construction were in the organisation, the interviews as examples a performance of identity (Morison \& Macleod, 2013), and the moments of breaking in the interviews where my colleagues challenged or shifted organisational norms.

Further into my analysis I was influenced by Richardson and St. Pierre (2017) analysis technique of writing as a method of inquiry. St Pierre's description of how writing to analyse empirical material is rhizomatic work through which fortuitous and accidental connections form (Richardson \& St. Pierre, 2017, p. 970) resonated strongly with my analytic technique of writing about my colleagues, my experiences, and the organisation and their activities. Richardson further suggests using the metaphor of crystals to conceptualise this analytical method: "crystals are prisms that reflect externalities and refract within themselves creating different colours, patterns, and arrays casting off in different directions." (Richardson \& St. Pierre, 2017, p. 963). From a post-modern perspective she argues that there is no one truth to pursue and so exploring multiple ways of constructing social worlds through writing is a mode of analysis. Refracting social worlds in different ways through writing, like light through a crystal, helps the scholar to construct a deepened, complex, and necessarily partial understanding of the topic.

As Richardson suggests, I employed a mix of creative analytical writing practices in order to develop my analysis of the empirical material. I wrote my empirical material in different ways including a mix of poetry, academic articles, vignettes, descriptive pieces, and reports for my colleagues and participants. I also experimented with writing narratives from my point of view, and from the point of view of my colleagues. Richardson suggests that this form of analysis is extremely useful to "situate your work in contexts, tying what can be a lonely and seemingly separate task to the ebbs and flows of your life and your self. Writing these stories reminds us of the continual co-creation of the self and social science" (p. 975). In exploring 
the relationships between identities, change, and the organisational context, writing as a form of analysis was particularly useful. I incorporated some of the different forms of writing such as poetry in 'Ties that bind; ties that break' (Part II) and vignettes in 'Vulnerable bodies' (Part III) - throughout the thesis, and the analytic processes of writing were fundamental in shaping the exploration of feminist identities in 'A multiplicity of feminisms' (Part IV).

\section{Beginnings in brief - where to from here?}

In 'Beginnings', I have delineated the first lines of thought of this thesis: the circles of convergence of my initial thinking about identity through some of the critical identity literature, the community sector literature, and the methodological literature and the details of my field study. My theoretical beginnings were situated in the critical literature on identity. The critical literature has mapped out various possible approaches to thinking about the relationships between identity and power in organisations. I situated this literature within CMS to emphasise the non-neutral production of academic knowledge, and the power relations within academia that contribute to the formation of research. In mapping the beginnings of the context of my research I discussed various theoretical perspectives of the community sector. Community organisations are usefully conceptualised as being ambiguous, intimately interlinked with the public and private sectors, and as having multiple complex accountabilities to communities and funders. Developing our understanding of identities in community organisations can advance critical scholars' understanding of the relationships between identities and change. In methodological beginnings I discussed my ethnographic approach to my research. I also took the opportunity to discuss some of the more technical aspects of my research project, such as the two phases of collection of empirical material, and my understanding of the ethics and politics of this thesis which aims at respecting and protecting the interests of the community sector, while advocating for social justice.

Although 'Beginnings' (Part I) introduced important theoretical, contextual, and methodological material influential to this thesis, the remainder of the thesis does not build off what is contained in Part I in a linear fashion. In the subsequent parts of this thesis, there are new points located outside the limits of my initial thinking, that spread and grow our understanding of identities and change in new directions. From here, then, the reader moves to the next series of circles of convergence that map the same lines of identity, change, and 
the community sector but grow and spread in novel ways. 'Ties that bind; ties that break' (Part II), 'Vulnerable Bodies' (Part III), and 'A multiplicity of feminisms' (Part IV), rotate around aspects of identity and change that were touched on or framed by my initial explorations of the literature, but did not become salient until my field study. While you may wish to read this thesis in a linear way, moving from 'Beginnings' (Part I) to 'Ties that bind; ties that break' (Part II); the empirical parts could be read in any order. 'Endings' (Part V) includes a reflection on the rhizomatic structure of this thesis, considers how this thesis answered the original and emergent research questions, and discusses which paths forward this thesis opens. 


\section{PART II: TIES THAT BIND; TIES THAT BREAK}


My desire to become a volunteer ethnographer in the community sector in Aotearoa New Zealand was grounded in the concern that, on the whole, the community sector was facing immense contemporary challenges for survival. At the outset of my fieldwork, however, I understood the community sector as an interesting site for my research, but not as one of the core dimensions. As my understanding of the interconnected ways in which identities and forms of organising can catalyse change grew, the community sector and the identity of a 'community sector worker' became increasingly significant. In both my first phase interviews and during my volunteer work, I observed that being part of the community sector was often a deeply cherished aspect of the self. My observations sparked a rethinking of the place of the community sector in my research beyond just a site of research or of working lives, to an important locus of identity.

In the interviews with my first phase participants, I eagerly gathered their perspectives about the community sector. Most of the issues raised by my participants seemed familiar to those I'd already met in the literature or in my previous engagement with community organisations. My participants enthusiastically told me about the immeasurable and positive contributions the community sector made to supporting communities across our country. Kelly described this well to me when she told me:

[In the community sector] it is the people who live in those communities that make the decisions... there is a really personal connection and it is local... I don't think government responds with such heart that the people on the ground actually have, because it is stuff that they care about.

However, tales my participants shared with me were always enmeshed in a palpable concern regarding the prodigious difficulties facing many community organisations in Aotearoa New Zealand. Neo-liberalism ${ }^{10}$, my participants claimed, was continually posing challenges to the sector, and was perceived as threatening the longevity, the impact, and the democratic potential of the community sector. In fact, the challenges of neo-liberalism often became the focal point of discussion, coming to form a frame for understanding the contemporary state of the sector.

\footnotetext{
${ }^{10}$ Neo-liberalism was initially implemented as a set of policies including the 'rolling back' of the welfare state, reducing the size and role of the public sector, and promoting free-market economics, and has been taken up across the globe with considerable variability. Importantly, neo-liberalism has become an ideology that promotes "subjects as self-governing individuals who exercise economic and political choices as citizensconsumers" (Laurie \& Bondi, 2005, p. 5). I discuss my participants localised understanding of neo-liberalism in the subsequent section.
} 
Emerging from my conversations with my first phase participants, I felt I'd received an induction into the sector. As I moved into my voluntary work, I expected my time with my organisation to be enmeshed in many of the same concerns. But I gradually felt that something from my understanding had been missing. It isn't that the frame of neo-liberalism was not important; I reencountered many of the tensions surrounding neo-liberalism and observed and participated in their reconstruction. Once I began my voluntary role, however, I experienced a shift and expansion of my theoretical understanding of the community sector. My colleagues helped me to understand the importance of emotional connections in the community sector. There was something about actually being immersed in the issues and daily activities of a community sector organisation; an emotional dimension that I hadn't fully recognised or appreciated in my initial understanding of the tales of my first phase interview participants. Over time, the role of strong emotions in the community sector became a fundamental conceptual frame connected to identities that I felt could add to understanding how social justice community organisations could achieve change.

I have incorporated this shift in my understanding into the structure of this part of the thesis. I begin by recapitulating the familiar tale of the community sector. In doing so, I draw on elements of realist ethnographic accounts, including presenting a relatively stable, sweeping portrait of the social world through the eyes of my participants (Van Maanen, 1988). Ultimately, in Part II, however, I offer something closer to the genre of ethnographic writing which could be considered to be "constructivist-interpretivist world-making" (Yanow, 2012, p. 33). As an ethnographer, I write to capture the social world of my participants and the ways in which they framed their working selves (Yanow, 2012) in the community sector. Once I have presented this familiar tale of the sector, however, I interrupt the tale by offering an alternative understanding of the same empirical material from the sector that explores the relationships between emotion, identity, forms of organising, and change. After the alternative theorisation, the tales of life in the sector become much more "episodic, complex, and ambivalent" in the vein of impressionist accounts (Van Maanen, 1988, p. 119) as I begin to show how knowledge and experiences of the sector are less neat, total, and clear than the familiar tale would suggest.

My exploration of the community sector, and the emotional ties which bind and unbind us, helps me to answer the foundational questions that guide us here: What is the community sector? How are emotions, organising, and identities intertwined? And in what ways are emotions linked to identities and change? In seeking to answer these questions, I explore how 
our identities are formed through emotional connections to others and how these are periodically done and undone. Which ties bind, and which ties break?

\section{A familiar tale of the community sector}

In an attempt to understand the community sector, I asked my first phase participants to tell me about the sector, the contributions it made to the people of Aotearoa New Zealand, and what it meant to them to be involved with the sector. I encouraged them to share with me how the sector had changed over time. The tales they told felt familiar. There was the initial establishment of the proud history of the community sector, highlighting the benefits for community bonds in Aotearoa New Zealand. This was followed by an invasion of the community sector by neo-liberal ideology, usually pushed by the government, which corrupted the community spirit of the sector. My participants' accounts of the contemporary state of the sector were ambivalent; many of them seemed unsure how to challenge neoliberalism or which elements to embrace to benefit their communities. My ensuing overview of the community sector follows the flow of this tale. The constructions of this tale told by my first phase participants are marked by use of pseudonyms to acknowledge their localised understanding of this history, and I've interwoven their accounts with the literature about the community sector in Aotearoa New Zealand.

\section{History and contribution: Community spirit}

My participants reaffirmed the fundamental accounts of the sector that I had met during the first stage of my research. All my first phase participants assured me of the importance of the bicultural roots of the community sector; the involvement of the sector in diverse aspects of life in Aotearoa New Zealand; and affirmed that the sector contributed to the lives of people in Aotearoa New Zealand and was embedded in the needs of communities. Promptly, however, my participants would put aside these more formalised 'definitions' and move to issues that seemed to lie closer to their hearts: communicating the kaupapa (values base) of the sector. The sector was more than the outcomes it produced; it was a spirit that contributed to social cohesion and empowerment (Neilson et al., 2015). Kelly and Himene both described the sector as something personal and local, something embedded in people's needs. Adam understood it to be a place of democratic renewal through which people developed a sense of 
citizenship. Community organisations were considered by Tamara and Nick to be part of the social fabric of Aotearoa New Zealand. Across my interviews, my participants argued that the sector searched for the common good.

A central emphasis of my participants in communicating the kaupapa of the sector was outlining a set of unique values that they believed were fundamental to community organisations. The values were attached to community organisations that had social justice missions which when followed were argued to help create change in certain directions. Calvin and Adam argued that the community sector valued democratic cooperation. Others, such as Elisabeth, were more sceptical of the actuality of democratic cooperation, but did agree that there was the perception that community organisations provided the possibilities of democratic cooperation toward a shared goal. Abigail highlighted that community organisations valued mutual aid, expressed through the phrase 'aroha tētāhi ki tētāhi' ${ }^{11}$ (let us look after one another). This phrase encapsulates the value of reciprocal care and affection between people in the community sector. Adam similarly stated that the community sector valued work that was "of and for" the community; the work of an 'I' was embedded in a 'we' of the community. Additionally, Kelly explained that her work across the country with a wide range of community organisations had shown her that they uniquely valued the localised and the personal. Importantly, social justice organisations, Shiner told me, were grounded in personal and social transformation. As she said to me, "it isn't just the doing good factor it is... [about] what you might become."

The value set of the community sector was argued to support what my participants understood as the most significant contribution of the sector: fostering and maintaining the social fabric of Aotearoa New Zealand. The sector was perceived by my participants as a place of connection; a tie drawing people together. For my participants, the community sector was about acting together rather than acting in isolation, drawing together people from different parts of society. Significantly, the community sector was thought of as a place through which marginalised community voices could be heard by government and by the public. As S. Grey and Sedgwick (2013a) also found of the community sector in Aotearoa New Zealand, they "perceive themselves as... speaking up for the most marginalised of our society; ensuring that policy meets the real needs of New Zealanders; and ensuring a better society" (p. 4). Being embedded in the community means speaking in a grassroots, honest,

\footnotetext{
${ }^{11}$ A Māori phrase which, literally translated, means 'love is unique to one another'. The sense of the phrase is that we are all reciprocally connected to one another and should therefore look after one another.
} 
and real way; a voice coming from the people (S. Grey \& Sedgwick, 2013a). Fostering social bonds between communities, bringing people together, was perceived deriving from the values of democratic cooperation, aroha tētāhi ki tētāhi, empowerment, and transformation.

The engagement of the community sector with issues surrounding the Treaty of Waitangi/Te Tiriti o Waitangi, demonstrated for many of my participants the way in which they embedded themselves in communities. Calvin explained to me that although the community sector had no formalised responsibility to the Treaty, community organisations were either kaupapa Māori, or were active in their attempts to understand their bicultural role. Tamara similarly noted that community organisations were more interested in considering what biculturalism felt like rather than interpreting policy decisions. Abigail argued that this was because the community sector was open and willing to respond to social issues. Himene highlighted how organisations like hers that were kaupapa Māori, and operated by and for Māori, were foundational to the sector; demonstrating how the response to need was by and for the people. Community organisations had deep rooted ties to their communities which they attempted to respond to the felt needs of the people.

\section{Colliding with the market: The impacts of neo-liberalism}

The critical community sector literature is rife with concern about the collision between neoliberalism and the community sector. In the international literature, neo-liberalism is argued to limit the democratic, localised engagement (Woolford \& Curran, 2013) that was central to the community sector in the first third of this familiar tale. The community sector in Aotearoa New Zealand has also experienced wide-ranging impacts of neo-liberalism that have impacted democracy and shaped the way community organisations operate (Laurie \& Bondi, 2005). The relationship between the state and the community sector had changed during the 1980s after the implementation of neo-liberal policies, and funding became based on the purchase of services through competitive short-term contracts (Tennant, 2006). Importantly, the New Zealand government was seen as pushing neo-liberal ideologies on the sector that were contrary to community engagement (S. Grey \& Sedgwick, 2013b; Neilson et al., 2015). Shiner explained that she noticed an immediate shift from community organisations being groups of common interests and enthusiasm, to competitive organisations that had to jump hurdles of formalities get funding. Generally, community sector organisations were now 
expected to exhibit, as Adam put it, a "neo-liberal spirit" that was enterprising, individualist, and risk-taking (Larner \& Craig, 2005).

My first phase participants primarily understood neo-liberalism as an ideology; focusing less on policy changes and far more on how they perceived the spirit of neo-liberalism to "take away the essence of community", as Shiner noted. Neo-liberalism was usually conflated with community organisations assimilating business-like behaviours. My participants presented a number of different features of neo-liberalism. Kara, Robin, and Shiner felt there were pressures to adhere to bureaucratic and hierarchical organisational structures that promoted tight, centralised control by elite individuals. Jane explained to me that it had become necessary to have "a solid organisation in the style that people, as in the establishment, the government funders, the non-government funders are comfortable with" to obtain funding and therefore survival. Himene and Kelly shared the common concern that community organisations were expected to have a one-size fits all approach to service provision that was prescriptive and directive. Adam and Calvin thought that neo-liberalism constructed individuals as competitive, rational, and independent from the community, and organisations as needing to be entrepreneurial. Ultimately, my participants who held a primarily negative view of neo-liberalism were concerned that it promoted organisational behaviour that was exploitative, oppressive, and contrary to community spirit.

However, some of my participants shared an ambivalence about the effects of neo-liberalism in the community sector. Tamara, for example, thought that the community sector needed to "get over being worried about being managers" in order to effectively govern their organisations, and Phillip was certain that "if you want to run a big organisation you need an IT shop and you need to have an HR shop. It is almost inevitable if you want to be really impactful." There remained, nevertheless, a perceptible sense that there was the possibility of corruption; that by embracing neo-liberal ideology something intangible and precious would be sacrificed. Phillip, for example, was also concerned that by "participating in the machine... somehow the kaupapa seems to get tainted or corporatized". Michael was also concerned about whether it was possible to 'marry' the demands of quantifiably measured outcomes (implemented by funders in a neo-liberal spirit) and social missions. Balance between neo-liberalism and community was considered necessary by those who perceived that neo-liberalism had some positive benefits for efficiency and effectiveness for achieving organisational goals. 
My participants' concern about neo-liberalism was set in contrast to the kaupapa of the sector outlined in the first third of the familiar tale. On the one hand the community sector perceived values of democratic cooperation, orientating around localised lived experience, empowerment of the marginalised, aroha tētāhi ki tētāhi, and transformation as important. On the other hand, the collision of the community sector with neo-liberal ideology had resulted in the promotion of hierarchy, individualism, generic service provision, competition, and entrepreneurialism. Even those who perceived that neo-liberalism had benefits for efficient and effective organisational governance - such as Phillip and Tamara - were hesitant to embrace neo-liberalism whole-heartedly. The foundational values that my participants considered to belong to the sector were in danger of 'corruption' if neo-liberalism continued to be dominant. Community bonds could be put in danger.

\section{Dissolving community spirit?}

The impacts of neo-liberalism were considered by many members of the sector to be taking society down a very dangerous road which threatened the social fabric of Aotearoa New Zealand. Many of my participants could not emphasise enough how intensely they perceived neo-liberalism as a danger to the sector (Nowland-Foreman, 2016b); Adam stressing: "it makes my skin crawl'. In the community sector literature there has been a wide-ranging discussion about whether or not the relationships between the state, the private sector, and community sector have moved beyond neo-liberalism (Larner \& Butler, 2005; Larner \& Craig, 2005; Laurie \& Bondi, 2005; Nowland-Foreman, 2016b). Government models in Aotearoa New Zealand have claimed to have moved to a 'partnership model' based on mutual cooperation, but both scholars and community sector workers have found the partnership model embedded in the same market-driven ideology that was a feature of explicit neo-liberal policies (Larner \& Craig, 2005). Similarly, my participants reaffirmed that neo-liberalism was a continual challenge and that it weakened the possibilities of making a positive contribution to the bigger project of the community sector: to form and maintain ties between different communities in Aotearoa New Zealand (S. Elliott \& Haigh, 2013).

One of the most significant outcomes of the neo-liberal reforms to funding structures was that community organisations became afraid to speak out for or against policy changes (S. Grey \& Sedgwick, 2013b; S. Grey, Sedgwick, \& Commerer, 2015). The perceived need of community organisations to exhibit neo-liberal behaviours in order to gain funding, and their 
dependency on these short-term funding contracts, had made it difficult for community organisations to speak out against the government or other institutions. Phillip explained community organisations did not want to be seen "biting the hand that feeds you". However, Robin considered social change advocacy to be something unique to the community sector, so if this ability was constrained, they would lose an important dimension of their work. Without the capacity to speak out on social issues many felt that community sector organisations were not able to fulfil one of their primary functions; to give voice to the marginalised. Additionally, the rigid focus of the neo-liberal contracts on individual outputs and quantifiable measures is seen as harmful as it excludes the intangible contributions of the sector to communities in Aotearoa New Zealand (Neilson et al., 2015; Nowland-Foreman, 2016a). The tension between neo-liberalism and preserving the community spirit was described as reaching a breaking point; pursuing social justice had become almost unviable for many community organisations (Nowland-Foreman, 2016a).

Overall, the tale emphasised the challenges of neo-liberalism. The 'community spirit' of the sector seemed to be dissolving in an environment of neo-liberal ideology. Neo-liberalism was seen as slowly becoming normative, and the lines between community organisations and private organisations were increasingly blurred (Douglas, 2015). Nevertheless, some of the tales told by my participants would ultimately revert to (re)emphasising the positive contributions of the community sector to Aotearoa New Zealand; coming full circle back to the kaupapa of the sector. Nick's response was fairly characteristic:

The sector shouldn't be overlooked. It is such a powerful force in life. Everyone is part of a community and it is a force. If it is degraded in any way, a lot of life gets lost or isn't going to function as well as it should. You've got to keep that generation of enthusiasm and you can't ever stop.

\section{The familiar tale: The only frame?}

The familiar tale of the community sector in Aotearoa New Zealand is set out above. Significantly, this tale is treated as foundational knowledge in that: it is the dominant frame adopted by members of the sector for understanding community organisations and their activities as part of the market economy, and it is used as a starting point for research about the sector by many scholars (M. L. Sanders, 2015). The tale can be understood as characterised by a binary: 'neo-liberalism'/ 'community'. Neo-liberalism is seen as an 
invasive force that has irrevocably shaped the community sector and situated them in a market economy; whereas community is constructed as the preferred state of the sector that has been corrupted or even possibly lost. Furthermore, neo-liberalism was perceived as the dominant system by members of the sector which governed how they operated. Most of the academic literature about the community sector characterises the sector in the same way; either expressing grave concern about the state of democracy in the sector as a result of neoliberalism (e.g., S. Grey \& Sedgwick, 2015) or advocating embracing market-based principles to enhance the skills and efficacy of the sector (e.g., Douglas, 2015). In both cases, neo-liberalism is the frame for understanding how community organisations operate.

Embedded ways of understanding the community sector direct our focus toward understanding the place of community organisations in the market economy, and how community workers craft their identities in the spaces of neo-liberalism. Scholars and community sector members have gained a deep understanding of contemporary challenges in the sector and how these challenges are negotiated to continue towards their social justice goals. However, dominant ways of understanding aspects of society, such as the tale of the community sector set out above, operate to close-down alternative ways of understanding social systems (Foucault, 1977). Treating 'neo-liberalism' as foundational knowledge can close-down the possibilities of thinking about the experiences of community sector work in different ways. Similarly, treating this tale as foundational knowledge for exploring identities (e.g., Glynn, 2000; Kreutzer \& Jaeger, 2011; M. L. Sanders \& McClellan, 2014), entrenches scholars' understanding of identities in a limited frame. As such, the multiplicity of experiences and dimensions of community sector identities can be overlooked or underemphasised, thereby constraining how the relationships between identities and change can be understood. Accordingly, considering alternative ways of understanding the community sector, which are overlooked or marginalised in this contemporary tale, can help us to think more creatively about how we can catalyse social change in the community sector in Aotearoa New Zealand.

\section{Alternative understandings; alternative organisations}

In order to explore other ways of understanding the community sector, I became interested in the alternative organising literature located in CMS. Alternative organisations are those which attempt to bring new forms of social relationships into being (M. Parker, Cheney, 
Fournier, \& Land, 2014a). Alternative organisations "must encourage forms of organising which respect personal autonomy, but within a framework of cooperation, and which are attentive to the sorts of futures they produce" (M. Parker, Cheney, Fournier, \& Land, 2014b, p. 32). The literature generally recognises that politics, forms of organising, and identities are intimately intertwined (Reedy, King, \& Coupland, 2016) and that there is a pressing need to organise differently (usually referring to different from capitalist or neo-liberal organising) to dismantle social inequalities related to the uneven distribution of wealth, gender and racial discrimination, and an individualism which divides the individual from their communities (Freeman, 2013; M. Parker et al., 2014b). Instead of focusing on the various ways in which capitalism or neo-liberalism manifest and marginalise minorities, the alternative organising literature focuses on how alternative organising processes emerge and can be politically productive (Land \& King, 2014). Focusing on alternative practices of organisations (without assuming they are inherently better) follows the political imperative to engage in affirmative action toward social justice organising, rather than restricting scholarship to a critique of extant practices or resistance to mainstream practices (M. Parker et al., 2014b; Reedy, 2014).

Despite the influence of alternative organisations (such as indigenous organisations, feminist organisations, or cooperatives) globally, the focus on alternative organisations in CMS is relatively recent. Consequently, only a relatively narrow range of themes have been robustly developed. The primary focus in the CMS alternative organising literature has been on what alternatives there are to capitalist organisations, thus taking a labour and production focus (Cheney, Santa Cruz, Peredo, \& Nazareno, 2014; M. Parker et al., 2014b), or on alternative internal structures (such as anarchism) with an emphasis on promoting democracy and providing alternatives to neo-liberalism (Freeman, 2013; Land \& King, 2014; Reedy \& Learmonth, 2009; Sutherland, Land, \& Böhm, 2014). Mostly, the focus has been on alternative organisations that provide alternatives for exchange, consumption, labour, and resources in ways that foster different kinds of social relationships, usually collaborative, inclusive, participatory, and democratic relationships (M. Parker et al., 2014b). The literature argues, however, that alternatives to labour and production organisations, while extremely important, are not the only possibilities that alternative organisations embody. The emphasis in the alternative organisation literature is on imagination; underlining that there are endless permutations of organisational form that could alter our social landscape. Scholars are noted to have much opportunity to learn from alternative organisations, describe how they function, 
and thereby imagine and develop novel ways of conceptualising how organising might shape our social landscape.

The attention to the alternative organising practices of community organisations has been fairly limited in the alternative organising literature. Land and King (2014) contend, nonetheless, that community organisations "offer a particular potential for organizing otherwise due to their explicitly social mission" (p. 930). However, only a small number of studies have focused explicitly on community organisations as alternative organisations. This small group of studies has explored the translation of anarchist practices into the community sector (Jensen, 2017; Land \& King, 2014) and the possibilities of creating spaces of solidarity that allow non-normative identities to emerge and flourish (Reedy et al., 2016). As community organisations are embedded in their communities, alternative organising practices are seen to benefit marginalised people by engaging in collective education (The Trapese Collective, 2014) and social support (Jensen \& Meisenbach, 2015) without embodying market values. Consequently, community organisations have been argued to provide a 'best case context' for alternative organising practices to take form (Land \& King, 2014).

Nonetheless, consideration must still be given to the marketization pressures in the community sector context, if scholars are to understand how community organisations build sustainable models of alternative organising (Jensen, 2017). Therefore, there remains much work to be done to expand on how community organisations can be understood through the lens of alternative organisation.

In the community sector literature, there have also been considerations of how community organisations might embody alternatives to neo-liberal models of organising. The collection of essays edited by Bernal and Grewal (2014), for instance, argue for understanding NGOs as a distinctive form of organising, which differs from market or state organising primarily due to feminist politics. Bernal and Grewal argue that NGOs are shaped, but not governed by, neo-liberalism, and that in their pursuit of change community organisations regularly engage in alternative organising practices. Alongside research situated within the alternative organising literature, Bernal and Grewal's collection indicates that the community sector is usefully understood as a space of alternative organising, as it helps us to understand how community organisations achieve social change. Additionally, much of the literature on the community sector, democracy, and citizenship has been centred on practices which could be understood as 'alternative organising' (e.g., Connor \& Yerbury, 2017; Dodge \& Ospina, 2016; Eikenberry, 2009; Fung, 2003; Kent, 2012). Although linking these literatures is not a 
contribution I offer, it is an important future avenue of research which would usefully expand the alternative organising literature. Nevertheless, the range of perspectives in the community sector literature broadly helps to underscore that framing an analysis of identity through the alternative organising literature is particularly valuable for considering how community organisations might be understood.

My consideration of how some community organisations can be understood as forms of alternative organisation is not to detract from the importance of the impacts of neo-liberalism on the community sector, or to offer a discrete alternative to the binary. My aim in considering how community organisations can be understood as alternative organisations is to draw out more clearly the 'community' side of the binary and explore how these aspects of the tale can contribute to creating the social justice that community organisations seek. As such, describing alternative ways of organising in the community can help us to more effectively imagine how we might tackle social inequalities perpetuated by certain neo-liberal modes of organisation, and, in the case of identity, to foster the conditions which make it possible for non-normative identities to flourish. Moreover, developing understandings of the community organisations as alternative organisations, opens up possibilities for scholars to find novel ways of thinking about how we might understand what it means, or could mean, to be a member of the community sector.

In the context of this thesis, alternative organising in the community sector relates to the 'community' side of the binary; the values that were associated with the sector that were alternative to neo-liberalism. The community sector, according to my first phase participants, actively attempted to provide alternatives to neo-liberalism by offering a space of democratic cooperation, empowerment of marginalised people, transformation of the social landscape and of people's identities, and to promote aroha tētāhi ki tētāhi. In order to enact and embody these values members of the community sector actively attempted to engage in alternative organising practices. One of the central practices of organising alternatively I give attention to here is organising around the emotional bonds between members of the community.

During the first phase interviews I was struck by the passion of my participants as they discussed the sector with me, but it was not until my ethnographic fieldwork that I deeply reflected on the potential of strong emotions for remaking the social and organisational landscape. After learning from my colleagues about what it meant to belong to the community sector, I began to consider the centrality of emotion for making and remaking 
identity in this context. The alternative organisations literature prompted me to rethink how I was interpreting the community sector. Through thinking about the possibilities of imagining alternative ways of organising and considering how the social justice workers organised with an intent on reducing social (particularly gender, racial, and wealth) inequalities, I was now struck by ways in which the community sector was constructed in the first phase interviews as being constituted through the emotional connections between people. Strong emotions, it seemed, were central to the ways in which community workers understood their identity and felt their responsibility to the community.

\section{On emotion and organisation}

\section{Outside of ourselves: The ek-static}

My thinking about the concept of emotion was inspired by my engagement with Judith Butler's work on the ek-static (Butler, 1997, 2006b). In the early stages of this project I had been interested in Kenny's (2010) use of the ek-static to understand the importance of strong emotions like passion in the construction of ethical identities in the context of a community organisation with a social mission. When I reread her paper late in my fieldwork, it resonated deeply with my experience. I felt that likewise in my community organisation, certain strong emotions were particularly salient and had extensive implications for the construction of identity and for organising around social missions. As I began to understand that certain kinds of strong emotions were significant for my participants, I felt that, like Kenny, Butler's conceptualisation of the ek-static was useful for understanding identity in the community sector. In particular, the ek-static helps us to think through how emotions can reify or break social norms and potentially remake our relationships with one another.

Judith Butler's conceptualisation of the ek-static is embedded within her work about identities and change covered in 'Beginnings' (Part I). Through the ek-static Butler offers a way of understanding the emotional dimensions of identities. She argues that there is a "passion and grief and rage we feel, all of which tear us from ourselves, bind us to others, transport us, undo us, and implicate us in lives that are not our own, sometimes fatally, irreversibly" (Butler, 2006b, p. 20). In other words, the notion of the ek-static refers to the emotional state of being beside oneself with a passion, grief, or rage that moves us to form 
ties with others. We become beyond ourselves and can recognise our self in someone else. This connection is not a link between separate individuals, but a binding between and around us, through which a community can emerge (Butler, 2011c). We have passionate attachments to other people that result in our being intertwined with the lives of others (Butler, 2006b). The reverse is also true, we can become undone, our passion, rage, or grief can undo our ties and drive us apart from one another. We have a passionate desire to be recognised by others and legitimated as recognisable human subjects. Our identities are limited and governed by powerful social norms and when we fall outside the norms of recognition, we can experience an abjection; a disconnection from others (Butler, 2006a). Identities that fall outside of these norms are often made particularly precarious, and some identities are targeted with material and symbolic violence (Butler, 2006b). Emotions, therefore, can operate to exclude.

Butler's conceptualisation of the ek-static is useful for exploring how certain emotions move us and operate to 'bind' or 'unbind' subjects and objects. Organising in ways that involve being 'outside of ourselves' in community organisations entails fostering the conditions for emotions to move us. Additionally, the ek-static can offer us insight into the ways in which organising around emotion can reify social norms; the moments when identities are 'othered' in community organisations, as Kenny (2010) demonstrates in her study of the dark side of emotional identification in a community organisation. In short, the framework of the ek-static helps to focus on the significance of particular intense emotions for catalysing change that were salient in my experiences of the community sector.

Here in Part II, I frame my use of the ek-static within the literatures on emotion and affect in organisation studies. Butler's conceptualisation of the ek-static is embedded in these two related concepts. The emotion and affect literatures act as a basis for understanding the role of emotion in organisations, in organising, and for the construction of identity in different organisational contexts. Importantly, I am not purposefully attempting to contribute to either the literature on emotion or affect - rather I am drawing on these literatures to understand the importance of strong emotions for alternative organising in the context of the community sector. From this basis, I return to Butler's notion of the ek-static in order to explore the role of the specific emotions - passion, grief, and rage - in the organisation I volunteered with for alternative organising.

Prior to the explosion of interest in the 1990s, emotion had been treated as an inappropriate or absent dimension of working life (Fineman, 2000b). Since the publication of the works of 
Hochschild about emotional labour (Hochschild, 1979, 2012 - originally 1983), emotion has become recognised as an important part of organisational life both in the conventional literature and in the critical literature - albeit in differing ways (Ashkanasy \& Cooper, 2008; Fineman, 2000b). The conventional literature - which forms the majority of the literature on emotion in organisations - typically treats emotion as psychological: an internal state of feeling, naturally occurring, triggered by the external environment; usually opposing rationality. From this perspective, emotion is seen as something experienced by a worker as a consequence of the organisation, the work, their personality, and their interactions with colleagues (Ashkanasy \& Cooper, 2008). The individual's experience of emotion is therefore seen as related to a raft of dimensions of organisational life including job satisfaction (Hülsheger, Alberts, Feinholdt, \& Lang, 2013), stress levels (Mackey \& Perrewé, 2014), inter-personal relationships with colleagues (Farh, Seo, \& Tesluk, 2012), and leadership (Kafetsios, Athanasiadou, \& Dimou, 2014). Importantly, emotions are perceived to be something to 'control'; regulating emotion - particularly 'negative' emotions such as rage is seen as essential to a well-functioning workplace (Perrewe, Halbesleben, \& Rosen, 2013; Troth, Lawrence, Jordan, \& Ashkanasy, 2017).

Although conventional studies have made the importance of emotion in the workplace mainstream, they tend to share a problematic de-politicization of emotion and minimise or ignore the ways that emotion is emergent and contingent on social and cultural norms. Critical perspectives on emotion have taken up these latter two themes and demonstrate how emotions are political, emergent, and contingent on social and cultural norms (Sieben \& Wettergren, 2010). Most prominently, studies of emotion in CMS have drawn from social constructionist and/or psychoanalytic perspectives (for an overview of strengths, weakness, and similarities of the two perspectives see Ulus \& Gabriel, 2018) to critique conventional perspectives on emotion in organisations and provide alternative ways of theorising emotion.

Social constructionist perspectives largely draw on insights from sociological and anthropological studies of emotion and explore emotion as constituted in social interaction, describing how social contexts shape the experience and expression of emotion (e.g., Fineman, 2000a, 2004; Lindgren, Packendorff, \& Sergi, 2014). Psychoanalytic perspectives on emotion have emphasised how unconscious investments shape collective emotions (e.g., Antonacopoulou \& Gabriel, 2001; Gabriel, 1998; Kenny, 2010). Although the perspectives have different points of focus, they have jointly challenged the individual/social bifurcation of the bulk of the literature; instead emphasising how emotion is emergent and relational. 
Critical studies of emotion have also showed the problematic (political) ways in which emotion is utilised for functionalist ends to regulate employees and maintain social norms (Lindgren et al., 2014); that majority of the literature excludes or marginalises non-Western emotions (Ulus, 2014); and that 'gender blind' studies of emotion can contribute to the (de)valuation of women at work (Knights \& Surman, 2008).

The critical literature on affect has been burgeoning in recent years (cf. Kenny, 2012; Kenny \& Fotaki, 2014; Thanem \& Wallenberg, 2015; Thompson \& Willmott, 2016). The concepts of affect and emotion are usually considered to be related - often positioning emotion as a dimension of affect. There have been recent calls both in CMS (Fotaki, Kenny, \& Vachhani, 2017) and more broadly in the social sciences (Seigworth \& Gregg, 2010) to see affect as a distinct concept worth critically examining. The distinction between 'emotion' and 'affect', however, is not always drawn clearly; and nor necessarily need it be (Ahmed, 2014). Studies that pay particular attention to the concept of affect, nonetheless, highlight the political potential of affect to catalyse change (Fotaki et al., 2017). Pullen, Rhodes, and Thanem (2017), for example, argue that the remaking of organisational practices involves an affective and affirmative politics that challenges the individualistic, competitive, and rational (masculine) norm. Additionally, affect studies point to the possibilities of the concept of affect for understanding how we are 'held together', or in other words the potential of affect for thinking about the shape of our social landscapes and the patterns through which we organise (Michels \& Steyaert, 2017; Thedvall, 2017).

The critical literature on emotion and affect offers a useful intellectual backdrop to draw from in order to explore the relationship between identity, emotion, and change in the context of the community sector. In particular, the literature offers me two key ideas. Firstly, that emotions are a dimension of identity that shapes, and is shaped by, our social landscapes, including organisations. Secondly, that emotions are embedded in our interactions with one another, both forming ties between us, but also having the potential to reify social norms that marginalise groups of people. Although, like Ahmed (2014), I am interested in affecting and being affected; I seek to build my arguments through specific accounts of emotions such as passion, grief, rage, pain, and fear. Accordingly, emotion remains my organising term, and indicates my point of concern.

Within the broader literature on affect and emotion sketched above, I found the work of Sara Ahmed on the cultural politics of emotion to be useful for thinking about the relationship 
between identity, emotion, and change. Ahmed (2014) theorises emotion as a form of 'world making' that involves a process of endowing objects with meaning and value. Importantly in the context of this thesis, Ahmed's theorisation of emotion pays specific attention to how emotions can both reify exclusionary social norms and have the potential to open up different futures. Thus, understanding emotions as a form of world making is particularly beneficial for understanding how emotions operate as alternative organising practices which can remake our social landscapes.

Ahmed (2014) builds from sociological and anthropological traditions of understanding emotions as a form of cultural and social practice. She argues that emotions are produced as effects of the interaction between objects and subjects. Emotions are thus relational; in that they involve a (re)action to objects and an interpretation of whether objects seem to be 'beneficial' or 'harmful' (etc.). Emotions, therefore, involve an orientation of our relationships toward or away from each other, depending on our perception of the meaning and value of our feeling attached to objects. Objects could be a person (or group of people), an action, a text, an image, a practice, or an idea. For example, the image of a starving child can be the object of emotion. We see the image and our interaction with the image shapes the emotion (e.g. compassion) we attach to the image; the object seems as deserving of compassion. Our orientation toward or away from others (e.g. starving children) is shaped by our attachment of certain emotions to the object. The process of interpretation of feelings and the attribution of emotions is embedded in histories of association (such as the perception that children are innocent), and over time certain objects are consolidated as the 'sticking point' of particular emotions.

As well as consolidating or reifying particular orientations to one another, emotions can also involve movement. Emotions, Ahmed argues, are effects of circulation. It is the objects, she contends, rather than emotion itself which get circulated; allowing emotions to 'move' and change the orientation of our relationships with one another (e.g. the image of the child is circulated as an object of compassion). A change in the interpretation of our feelings, or a displacing of the object as the 'cause' of particular emotion can therefore remake the orientations of relationships with one another. Additionally, a change in our interaction with objects - such as a change in the types of actions we engage in - can also shift how we understand objects. In other words, emotions are implicated in the creation of objects and involve the repetition of certain actions rather than others, which can change our orientation to the object. Emotions, therefore, can also remake our social landscapes. 


\section{Alternative organising, emotion, and the community sector}

Understanding emotions as a form of 'world making' (Ahmed, 2014) underscores that emotions are not erased or caused by certain modes of organising, but that the making of emotions is implicated within forms of organising. Hence, we can understand that emotions are shaped by capitalist ways of organising. For instance, the exploitation of certain kinds of emotional labour (particularly of women) to financial ends evidenced so strongly by Hochschild (2012 - originally 1983) is a dimension of capitalist organising. Neo-liberal organising in the community sector also shapes emotion. Pedwell (2012) highlights that in international aid organisations, neo-liberalism promotes the commodification of compassion as a useful 'tool' for workers to enterprisingly employ to achieve their goals. She argues that this has the problematic effect of ultimately 'fixing' the people that the organisation seeks to help as the object of compassion and other (usually privileged) people as the subject or the distributors of compassion. Emotion as world-making underscores, however, that if we are made through processes of organising emotion, we can also be remade. There are alternatives. The possibilities of organisations which foster different emotional relationships are evidenced by feminist or women's organisations that take the localised emotional bonds between women as their core organising practices (e.g., Burstow, 1992; Else, 1993; Hanisch, 1970), thus increasing their sense of responsibility for one another in an attempt to engender change. Emotion is, therefore, an important dimension of organising and has significant potential to remake our social landscapes.

In light of the ways in which various modes of organisation are intertwined with emotion and identity, emotion must be a consideration in the study of organising alternatively; particularly, in the context of this thesis, in relation to identity. Deliberately considering the types of future that organisations wishes to produce can involve centring emotions, and emotional connections between people, as important for how we organise. The significance of emotion in community organising is not a new concern, and it has long been recognised that in various ways emotion is particularly salient and significant in these contexts (Goodwin, Jasper, \& Polletta, 2001; Mason, 1996). Additionally, emotion is often seen as fundamentally linked to achieving social justice in community organisations, in that organisations should seek to promote empathetic identification of the workers or donors with marginalised people (Pedwell, 2012). Emotion, in the community context, can therefore be located as a potentially significant dimension of organising alternatively to remake our social landscapes. Below, I go on to explore how the tale my first phase participants told me can be 
understood through the perspectives of emotional bonds as the locus of alternative organising in the community sector.

My first phase participants emphasised that they perceived emotion and the emotional bonds between members of the community as fundamental for social justice work in community organisations. Tamara explained that in the community sector "people really care about what they are doing, they are enthused, they are energetic and committed. And there is a lot of energy and, sort of, passion." What differentiated the sector for Kelly was that "uniquely this [is a] sector that people give their time to. Because of their passion they give up their weekends or their nights, they go to meetings and they don't get paid for it. There is something else there that feeds them." The 'something there else that feeds them' is similar to what Tamara was trying to communicate; that there were emotional bonds that were central to how community organisations were organised. The emotional energy of the sector was founded in a sense of commonality; shared interests, kaupapa, philosophy, or passion. An emphasis on emotional bonds and organising to embrace emotion drew them together as communities, as community organisations, and as a community sector.

In all my first phase interviews, emotion was not just present; it was an active way of thinking about community organisation's actions and social relationships. Phillip explained: "I think that the most important thing is that we are a sector in that our coming into existence and our passion and energy for our continuing existence comes from a set of values." These values were the community values of democratic cooperation, empowerment of marginalised people, transformation of the social landscape and of people's identities, and aroha têtāhi ki têtāhi. Abigail considered the community organisations she worked with to organise around their passions both "physically and spiritually"; Jane simply called this way of orienting work "the love factor". The emotions seen to be prevalent in community organisations were linked to these values. As Shiner explained: "The impetus is not just the passion... but the flexibility, the freedom, the enthusiasm". For Shiner, the emotion of passion was fundamentally linked to the ways the community sector organised. Nick emphatically described how the community sector changed the social landscape: "we are talking to each other and getting to know one other, something happens, something dissolves." The community sector was constructed as centred on these emotional connections; as Calvin noted, “you [will always] still find a group of people who say, look I'm really feeling whatever, keen on something or other, and why don't we get together and do something about it?" 
Not all emotions were positive or had positive effects in this tale. Just as emotions were the ties between members of the community that formed the community sector, they could also keep people apart and cause connections to become unbound, or 'stuck' in particular configurations of social relationships. Elisabeth told me a story of two organisations who provided the same work in the community, just down the road from each other, which harboured such an animosity that they would never work together. Emotional connections can result in exclusions; maintaining boundaries between 'us' and 'them' that can have harmful effects (Ahmed, 2014). Additionally, many of my participants were concerned that the "fire has gone out of the belly", as Tamara put it, as a consequence of movement toward neo-liberal ways of organising, which precluded organising through and for emotional bonds between people. Nonetheless, there was a strong sense that emotional bonds remained the locus of organising and that through negative emotions an affirmative politics could still be maintained. As Calvin told me: "what brings them together in almost every case is some passion, some interest, some ideal, some goal. And that's outside of ourselves."

In drawing attention to the importance of certain emotions, I intended to explore how these emotions were perceived as foundational to the ways in which community workers decided to organise and how they understood their identity. Having established my theoretical framework for understanding how emotion, organising, and identities are intertwined, I now seek to apply these ideas to the organisation of my ethnography. I am cautious, however, in not generalising that all organising around strong emotions involves alternative organising practices. As both Pedwell (2012) and Brewis (2017) note, emotion that 'fixes' objects and subjects in social norms, by orientating emotion as a tool or the possession of an individual, reinforces harmful neo-liberal models of organising that marginalise non-normative identities. For organising alternatively, the focus must be on how emotion encourages the moving of subjects and objects, and the dismantling of normalised boundaries between 'us' and 'them'. I also do not wish to generalise empirically from the example of my organisation. Instead, I aim to describe how these practices worked in my organisation and thereby offer a way of theorising alternative organising through which scholars can imagine how emotion, identity, and change are linked in other forms of alternative organising.

In order to expand on these ideas to offer a localised exploration of the role of emotion in forming identity in alternative organising, I will draw on Judith Butler's (2006b) conceptualisation of the ek-static within this broader frame of emotion in organisations. I use Butler's work here because she specifically theorises the relationships of emotion and identity 
through three emotions - passion, grief, and rage - which were salient in my organisation, and she focuses on how emotions can remake social landscapes by pushing subjects 'outside of oneself', thereby attempting to avoid 'fixing' subjects and objects. Her work helps me to give an account of emotion that focuses on how we move and what moves us, in ways that open up different kinds of relationships to others that can foster the conditions for remaking our orientations toward non-normative people. In short, Butler's conceptualisation of the ekstatic helps to localise some of the broader ideas I outlined earlier in Part II for my organisation and their specific practices.

For the remainder of Part II, I trace how emotion in my organisation was an important aspect of forming identity that was part of producing distinctive social relationships which attempted to remake our orientation with victims of domestic violence. The ensuing analysis is structured in three sections which explores the relationships between intense emotion, identity, and organising practices in a community organisation. The first section explores how emotion, organising, and the sense of self in the organisation played out in a particular event; underscoring the value of the framework developed above. The second section 'ties that bind' explores how passion, grief and rage formed ties to others by pushing us outside ourselves. 'Ties that break', the third section, looks at the ways in which emotion both encouraged movement by breaking normative ties, as well as sometimes reifying exclusionary boundaries between 'us and them'. Ultimately, I draw the analysis together, reflecting on how these examples can offer a way of imaginatively rethinking the relationships between emotion, identities, and change in the community sector context.

\section{Emotion in alternative organising}

To begin the exploration of the relationships between emotion and identity, I start with a story of an experience at a 'working well workshop' that accentuates these two themes: Some four months in to my voluntary work with my organisation I found out that all staff members were to attend a series of workshops together to help us work better as a team. I was almost absurdly enthusiastic about the workshops and the possibilities of getting to see all my colleagues discuss the purpose of their work together. My eagerness for attending this event was rather unusual for me, given that under any other circumstances I would have been mutinous if someone had tried to get me to attend one of these events. My colleagues were 
slightly sickened at my enthusiasm; at lunch the day before the event it turned out I was the only one excited at the prospect of the afternoon. Emily was appalled she had to attend and was desperately attempting to come up with excuses not to go. Even Ava, who usually took these sorts of things seriously, expressed to me that she was apathetic about attending because she didn't see the purpose behind it. I assumed this was being driven by Jen, but when I chatted to her about it, she didn't seem to want to attend either. The impetus behind this event therefore remained a bit of a mystery.

At 11 o'clock we piled into hired vans to be taken to our destination. I climbed into the back seat with Gracie, Kimberley, and Zoey. Gracie was carrying a giant A3 notebook; an accidentally humorous contrast to my tiny ethnographer's notebook which I was holding in my hands. Gracie told me that the coordinators of these workshops had tried to charge her an extra $\$ 30$ to supply one. This was not something we could afford, and felt like an irresponsible use of our funds. After about 20 minutes in the van joking together, watching silly pet videos on YouTube, and listening to music we arrived at our destination. Almost immediately Anika and Tia went looking for the smoker's area. The rest of us filed into the room marked 'café' and settled to an early lunch together before the workshop started. Emily and I grabbed the vegetarian option and went to sit with Jen and Riley in the sunshine outside.

Our workshop was held in a large, cold room. Four tables were set up and the sixteen of us split into groups of four around them. Inadvertently we ended up sitting in our teams. The administration team, Gracie, Sharon, Diane, and Ava at the table to my right, Tia, Michelle, Riley, and Esther at the table behind them a mix of the media and services teams; the rest of services team, Hayley, Zoey, Kimberley, and Evelyn behind me, and Emily, Jen, and Anika sitting with me. We were restless after our lunch. Kimberley was still eating her pizza in the corner, laughing loudly with Zoey about something. Ava and Sharon were engaged in a quiet intimate, conversation. Jen and Anika, on my left, were talking about work.

The session coordinator, Christine, was a lithe, little woman in formal dress. She had a habit of rocking backwards onto her heels while clasping her hands in front of her. We were introduced to her one by one, and shook hands. Christine had a firm handshake and made a point of looking directly into your eyes for a few seconds before releasing you and repeating your name. The room had been altered in our absence at lunch. The large notebook that Gracie had taken with her had been used by Christine to write inspirational quotes. These 
were now stuck up around the room. They said things like: "be yourself because everyone else is taken" and "courage is not the absence of fear but the admittance of fear". Anika really liked the 'courage' quote and wondered what the translation into Te Reo would be. The one at the front read:

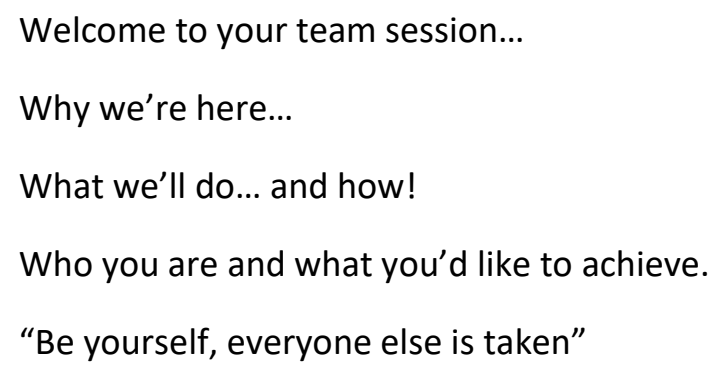

Anika opened our session with a karakia ${ }^{12}$ (prayer), standing above her seat, head slightly bowed, and speaking in rapid Te Reo. At the conclusion, we all echoed with a kia ora (affirmation). Jen then gave a short introduction about why we were there, again standing by her chair, but facing the room. She said that she struggled to explain why we're here but felt that we didn't have enough events for the whole team. In conclusion, Jen noted, she wanted to get a sense of how everyone sees the office and our work. Finally, Christine took her turn to give an introduction. She stood upfront, facing the entire room, and said that we were here to decide: "what is important to 'me' and 'we'”. Christine suggested that first we needed to reflexively examine ourselves before we could understand what we contribute to the "me and we'. We were here, she said, to "build a space of trust" so that we didn't feel that "no one sees me, includes me, understands me, or accepts me".

After a coffee break, we were given a new task: discuss in our groups what we wanted out of these workshops. I found it surprising it took us this long to get to this point. In the earlier session, we spent a lot of time setting 'ground rules' and thinking about our individual identities. Now we were focusing on ourselves as a whole; as an organisation. We had been rearranged into different groups so now I was sitting with Hayley, Gracie, and Esther. The room felt slightly more uneasy after being moved out of our regular teams. There was still a buzz of conversation and several of my colleagues were expressing discontent about not working together as a whole team and a desire to have a "shared end goal" and "clarity of vision". Christine took the floor and explained that we were now going to come to the crux of

\footnotetext{
${ }^{12}$ The Māori term for a recitation of ritual chants to enable an activity to be carried out in union with ancestors or spiritual powers.
} 
the first session. We were to move on to discussing: "the question of the overarching purpose of the organisation" and explain to our group: "how does your role fit into that". We were to bring the 'me' into the 'we'.

Hayley immediately turned to me, Gracie, and Esther, and zealously said to the group that she thought that the role of national office was: "to support [our frontline workers] in succeeding in eliminating family violence”. Gracie nodded her head vigorously at this. Hayley animatedly went on to explain that this meant doing things that frontline staff didn't have time for, like securing them funding and running stakeholder education programmes. Gracie agreed with Hayley and added that she thought that it was this way because our organisation was "not a top down structure" and that our national body was also charged with making policies and making sure that Māori women had equal voice and access to resources. Esther explained how her role in communications was about reaching out to the public, garnering their support, and helping them connect with women and children in abusive relationships.

We were then asked to share our thoughts about our purpose with the room. Echoing Hayley, most of my colleagues said that working at the national body meant working at a national level to promote change for women experiencing domestic violence. Emily added that our job was to "make sure that we are one of the leaders in that" and Jen re-joined humorously: "what do you mean one of?" Hayley then added her mission statement that she had given to us and added that this was "deeply felt". Other people added that we were providing "social commentary and informing the public" and "demonstrating a commitment to [feminism, Tangata Whenua, and LGBT+ women] ". The discussion also seemed particularly affirming, as all my colleagues were sitting up, paying attention, and nodding in agreement with each statement. Even Tia, who until this point had kept her head down to avoid notice, had turned her whole body toward the centre of the room and muttered: "hard out" when Hayley offered her definition.

Suddenly, Jen halted the conversation and turned to the room and asked firmly: "Is this really what you think? I really want to know. Is this what gets you out of bed in the morning? Serious question: Is that why you come to work?" Hayley said it absolutely was. Several other people around the room nodded in agreement. Two comments were then made simultaneously. Gracie said to Jen: "do you know how cool it is to be able to say that you work for [our organisation]? ” but Gracie's comment was drowned out when Riley 
concurrently said loudly: "that isn't why I come to work. I'm contributing my skill set to an organisation that needs it”. Riley went on to say that for her it wasn't about domestic violence; it was the use of her personal talents. Jen went on to say firmly: "that [promoting change] is not actually what [the national body] is charged with doing” it was about "protecting and strengthening the [frontline workers]". Kimberley chimed in: "and keeping them out of the news". Abruptly, the language of our discussion changed. A more sombre discussion ensued. Other words started sneaking into the conversation: "accountability", "funding", "meeting our compliance obligation" and giving "hard lines to the frontline workers".

The atmosphere in the room seemed to shift during this discussion. The discussion had petered out, and an awkward silence was developing. Around the room people were avoiding making eye contact. They seemed anxious and uncomfortable. Christine decided to end the session. To wrap up the session Christine quickly made some half-hearted resolutions that we were going to do before we saw her next. Christine finished with a quote about change and how we could make change happen. With the session wrapped up we headed back to our office. We filed back into the van and sat in silence on the way back. Back at our office people shuffled back to their desks finish off some of their work; I just grabbed my things and left.

Part of my ethnographic enthusiasm for attending the 'working well workshop' was my interest in observing my colleagues discuss together what working for the organisation meant and how they understood their working selves. In the tale above, my colleagues offer two very different versions of what it means to work for the organisation and 'who we are' as community workers. The story also illustrates the ways in which the familiar tale of the community sector plays out in a localised context. Conversations about "who we are and should be' were not ordinarily so explicit, but the subtly informed everyday working life in the organisation. On the one hand my colleagues understand their intense emotions to be foundational to their social justice work, and on the other hand there appears to be a push toward neo-liberal forms of organising. I decided to focus on this particular incident because it illustrated the complexity of attempting to organise alternatively. I wanted to ensure that I did not underemphasise the tensions of community sector work even while drawing attention to the possibilities for organising alternatively and how these possibilities are shaped by emotion. 
In my observations of my colleagues talking about their work, I was struck by the intense emotion they articulated; in particular, their claims to a "deeply felt" passion. Earlier in Part II, I demonstrated that my first phase participants likewise perceived that passion was foundational to community organisations and achieving social justice missions. In the 'working well' tale I recounted how my colleagues understood their work through a collective sense of 'passion' attached to achieving social justice for victims of domestic violence. In being asked to share how we understood our role in the organisation, the description my colleagues gave was oriented around this 'sticking point' of their passion. For example, Hayley understood herself as serving the frontline workers in a way that best supported victims, and Esther understood herself engaging in transformative dialogues with the public. In general, my colleagues perceived that what work was done, how it was to be done, and their relationships with others in the organisation came from their intense passion for ending gendered violence. This certain kind of intense emotion, therefore, informed how my colleagues understood their identity and helped to create shared assumptions of how we ought to work with one another.

Gracie highlighted how the passion was perceived to inform the daily practices of working in the organisation. The passion, she argued, influences how the organisation is structured; that because of their passion the staff members give priority to workers with direct client contact. The 'bottom up' structure Gracie claims the organisation has, implies that preference is not given to managerial work and that hierarchy is minimal in organisation. My colleagues, as the backstage workers, did generally understand themselves to be working for as well as with their frontline counterparts; the "for and of" the community value Adam talked about in the familiar tale. The organisation was thereby described by my colleagues as attempting to function as a collective; equally weighting the input of all staff and volunteers. Attaching passion to their work helped my colleagues to create shared assumptions of how we should interact with one another to embody the values of 'community' organising; for instance, by prioritising empowerment, transformation, and aroha tētāhi ki tētāhi. Although in daily life my colleagues were more sceptical of the successes of collective organising than they appear in this tale, the important perspective expressed by my colleagues is that passion was perceived as fundamental to the attempt to organise.

Passion also was perceived by my colleagues as shaping their identities. Hayley, Gracie, and Esther took great pains to articulate that their passion shaped how they understood their identity and their responsibility to others. The identities of my colleagues were shaped by the 
centring of passion; framing their identities as community workers as 'servers'. My colleagues' construction of an identity as community workers as a 'server' can be seen as a subversive alternative to the pressures of neo-liberal ideologies to act as 'service providers' to clients. The other salient identity implicated in the locus of passion was the identity of being a 'social change advocate'. Esther in particular emphasises how she understands her identity as an advocate for social change for victims of violence. Similarly, to the identity of 'server', the identity of 'social change advocate' is shaped by the intense emotion of passion. Esther, for instance, sees her passion as foundational to her construction of her identity as a social change advocate. Seeing herself in this way, she argues, is important for ending gendered violence. Both server and social advocate identities are subversive to neo-liberal positioning of subjects as entrepreneurial individuals (Laurie \& Bondi, 2005) and operate to increase the intensity of my colleagues sense of responsibility to victims of gendered violence.

The passionate attachments to victims of violence were disrupted after Jen and Riley questioned the relevance of passion in our backstage work. The neo-liberal-like position put forward by Jen and Riley for understanding our identity as community workers dislocates intense emotions like passion, and instead individual skill sets and the use of these to ensure a well-functioning organisation are positioned as valued aspects of community worker identity. The identity of my colleagues shifted from servers or social change advocates, to needing to act as 'managers' and 'service providers' to keep the frontline workers 'in-line' and to meet compliance obligations. As the understanding of identity shifts, so to do the shared assumptions of how we work together and the type of responsibility we hold for victims of violence. The longevity of the organisation, and efficient and effective organisational governance become the primary responsibilities of community workers. Although Jen and Riley's perspective can be understood as important for the latter, the dislocation of intense emotions, and the promotion of a different emotional orientation, reinforce conventional modes of organising and inclined my colleagues to reposition their identity as community workers. The social change dimensions of the work become less central to the identity of my colleagues.

Although in this instance passion was dislocated, my discussion underscores that paying attention to the role of intense emotions in shaping identity and organising practices is, nonetheless, a useful way to understand the relationship between identity and change. The analysis of this event demonstrates that intense emotions - in this case passion - was an important part of identity and could help to stimulate a different set of assumptions about 
how we organise and our responsibilities to each other than with neo-liberal organising. Intense emotions like passion were perceived as foundational to social change work, and these emotions shaped my colleagues understanding of their identity as social change advocates or servers. The dislocation of intense emotions, and the promotion of other emotional orientations, highlighted that it was difficult to organise alternatively; particularly when the 'familiar tale' formed the frame for understanding the community sector. Overall, the story of the 'working well workshop' underlined that intense emotions shaped identity and the shared assumptions of how we should work together. I now turn to drawing out some other intense emotions in greater depth, to explore the ways in which intense emotions increased my colleagues' feelings of responsibility to catalyse change for victims of gendered violence.

\section{Ties that bind: Emotional attachments}

Having set the scene looking at the example of passion, I argued that paying attention to emotion in alternative organising can help us to understand identity and how community workers create shared assumptions of how we should work with one another. This section deepens this argument by looking at how the specific emotions of grief, passion, and rage shaped how my colleagues perceived their relationships with victims of violence. In particular, this section focuses on how these emotions operated to increase the intensity of feelings of responsibility toward victims of violence.

Communicating the intensity of the emotions my colleagues oriented their work around is difficult, and thus I have opted to illustrate the emotions I discuss here through poetry. Using poetry as a method of presentation of material can offer a deeper sense of emotion because "poetry is felt as well as read" and "poems concertize emotions, feelings, and moods, and thus recreate experience itself to another person" (Sayers \& Jones, 2015, p. 107). Writing through poetry offers a way to explore events without reducing them to rationality (Kostera, 1997), and can aid in communicating with a simple force how the self is constructed (J. Kirby, 2011). Additionally, I wanted to avoid offering 'thick descriptions' of emotion that privileged breadth over depth. The emotion I discuss here was felt and interpreted in a variety of ways, but the intensity of grief and anger I observed lends itself more to communicating the 'simple force' of emotions in certain cultures (Rosaldo, 1989), as the "deeply felt" 
attachment to ending gendered violence was usually expressed by my colleagues simply and directly.

My first poem was written after an interview with Emily who explained to me the intensity of her commitment to engaging in advocacy - such as writing submissions or research - for victims of violence:

"I write."

Emily tells me. "I write from the position of anger, and sadness, and passion.

What is the injustice here? What makes me most angry about this bill?"

She pauses. Contemplates.

"Great. That makes us sound like a happy bunch.

We are passionate, sad, angry people."

She looks at me. I laugh.

"Is this the point where I am supposed to deny that?" I ask.

Here, Emily highlights how she perceives a collection of intense emotions, namely anger, sadness, and passion as foundational to her social justice work. She describes the emotion as a 'position', an occupied space through which she carries out her social justice work specifically in this case engaging in political advocacy work. Importantly, Emily doesn't see her position in emotion as static, but as a kind of moving investment in victims of injustice which makes change possible (Ahmed, 2014, p. 172). The intense emotions seem to make her identity malleable, as she notes there are different orientations that shift her relationships with 
victims of violence. All her emotional orientations locus on the undoing of injustice, for her the 'sticking point' of emotion in her work. Emotion is implicated in creating change and addressing our social landscapes which condone injustice. The result of taking emotion as an organising principle is that Emily can orient her work toward transformation and aroha tētāhi ki têtāhi. Taking her emotion as her starting point of advocacy results in Emily forming the basis of her work as providing mutual aid and pushing for social change.

From Emily's perspective, these emotions are collectively felt as a 'we'; implying that as she perceives these emotions as foundational to her work, so too do the "bunch" of colleagues she works alongside. By emphasising that the emotions are collectively experienced, Emily also indicates the importance of emotion for fostering identities as community workers and as an organisation. In particular, Emily sees these intense emotions as fundamental to her work for social justice, helping her to direct her attention to changing social norms as a social justice advocate. The emotions of passion, grief, and rage, in Emily's view, shape the shared assumptions of her and her colleagues. The intense emotions are a tie that binds her to her colleagues, and to the work that she undertakes. For the organisation to achieve justice for victims of violence, Emily perceives that passion, grief, and rage are important in how she organises and what work she undertakes. By connecting emotion with ideals of social justice and social change, the identity of being a social change advocate is strengthened, and the organisation as a space for advocacy is legitimated.

Feelings of anger or rage were commonly circulated by my colleagues in everyday working life. I remember one particularly striking instance of expressed anger, which came from Ava who otherwise was a soft-spoken woman:

Ava seems to me like a fine bone china

Delicate and smooth

I handle with care

But when we talk of abuse

Women and children

Broken, smashed, fractured 
"Militant", she tells me, "really militant"

"I would march for the cause."

She is unbendable iron.

Intense anger was particularly salient in our organisation. Anger was 'stuck' to the notion of women's oppression; the notion of social norms which devalued women thereby making them vulnerable to domestic violence. The emotion of anger shaped my colleagues consideration of what one should not do (Ahmed, 2014); namely be violent (physically or symbolically) to women under any circumstances. Ava, as an example, highlights how deeply felt the anger was in our organisation. Noticeably, Ava's articulation of her anger rests on several key interlinked points. She implies that anger involves movement ('marching'), solidarity ('the cause'), and the need for organised, efficient, and fierce opposition to violence against women ('militant'). The movement evoked, being 'stuck' to the system, implicates the need for a collective action, tied to one another by an anger against gendered violence (Butler, 2006b). In short, shaping her understanding of her work through anger aided Ava in organising with democratic cooperation and to prioritise transformation related to social justice.

Anger also shaped the social relationships between members of our organisation. The work was framed as 'the cause' (as noted by Ava). Social norms that marginalised women were variably recognised as sexism, racism, and heterosexism which precluded women from living full lives and made them more precariously vulnerable to violence. As such, my colleagues attempted to enact practices in service of marginalised members of our community, such as evenly sharing resources and leadership positions with Māori kaimahi ${ }^{13}$; providing flexibility for women with children, such as allowing children to come to work regularly and having a room in the office dedicated for them; or regularly promoting discussions throughout the organisation on the impacts of homophobia and their contribution to violence against women. These daily practices were constructed in opposition to marginalising social norms; the anger that prompted my colleagues to shape their shared assumptions of organising around what they should not do to groups of marginalised people. Anger, therefore, encouraged my

\footnotetext{
${ }^{13}$ A Māori term for worker or staff member.
} 
colleagues to (re)consider which identities were marginalised by oppressive systems, and consider 'the other' compassionately both in general and as individuals (Brewis, 2017). As with Ava, generally anger aided my colleagues to enact the values of democratic cooperation, attached to one another as women impacted an oppressive system in the spirit of aroha tētāhi ki tētāhi, and toward a future without gendered violence.

One striking emotion that was not raised in my first phase interviews, but suffused daily life in my organisation was grief:

Kim reads about the women and the children and the details of

Tearing, throwing, starving, hitting, raping, spitting, slapping, beating, battering, bruising Daily in the data base that she so passionately maintains.

One day when I'm standing next to her desk, she tells me the number, a black and white number

Of women and children and details.

I try to make this number real

Thinking about every woman I've walked by on the street, stood behind in line, or have ever seen.

And when I fly above my city and see the tiny homes stretch from coastline to coastline I imagine that every single one of those houses and buildings and cars

That I'm trying to hold in my view are filled with women and children and details.

Bringing myself back onto the solid ground

I see Esther standing in our office tentatively asking us to confirm

That she isn't crazy,

She is not crazy when men keep emailing her saying 'wrong' and telling her 
To listen, that she needs to get her facts straight, that she is spreading lies.

Just another woman violently spreading lies about men.

“And I just think" Esther tells us,

"if those men are right, where are the bodies? There would be a body count to match."

Like all of those bodies of women and children and details.

In the example above, grief shapes the ways we organise and our identity as social justice advocates. In everyday working life, grief was commonly interpreted as 'stuck' to the abused bodies of women. The emotion was outwardly inflected, in that it sought to unite people in a condemnation of violence as a collective responsibility, rather than individualising this responsibility (as would be the case with neo-liberal oriented organising). Kim, in her work with the records and data bases, explained her intense devotion to her work through her feelings of grief over the sheer volume of records. For her, grief furnished a sense of political community (Butler, 2006b); the work of the organisation was focused on reducing the need for grieving because of the destruction of so many lives. Similarly, Esther, in her media and public engagement work, focused on fostering a sense of political community through grief; frequently engaging in discussions with the public through our social media that emphasised the relational ties between abused women and our communities. She would engage the public in discussions about sexism in judicial decisions, the death of women at the hands of abusive partners, and the devastating impacts of prejudice against victims of violence in our communities. An attachment to abused women was understood through grief, and organisational practices attempted to bring our current social landscape to the fore by highlighting how domestic violence against women is minimalized or marginalised in Aotearoa New Zealand. Importantly, grief also fostered a sense of community and aided my colleagues in organising for social transformation.

Although grief for another person, or for groups of people, can make bind us together and show us the ways in which we are implicated to others (Butler, 2006b), there is also the risk of 'fixing' some bodies as the object of grief. For example, fixing the boundary between members of the organisation (the helpers) and their clients (the abused) in a way that resulted in 'othering' of victims of violence by fixing them as objects of grief. In order to aid my colleagues in organising alternatively, grief would need to orient the social relationships of 
my colleagues toward seeing the ways in which we were implicated and undone by each other. Generally, I observed that grief was dislocating rather than fixing. Grief, as expressed by my colleagues, usually carried a sense of personal location; that we grieved for abused women because violence had been launched at our own bodies, and the bodies of our intimate friends and family. We also grieved because violence had happened to us and our community; grief helping to orient organising around lived experience. It was common practice to situate the stories of clients in relation to personal grief of our own stories of domestic violence, rape, or sexual assault, as well as less (physically) violent stories of sexism or demands of emotional labour; grieving simultaneously both for our own bodies as well as those of clients. Grief for the bodies of women, including our own, thus shaped my colleagues' perceptions of their responsibility to victims of violence. We were not free until all of us were free.

Emotion accentuates our connections with one another in ways that recognise the need to value and protect others who are marginalised (Butler, 2006b). In my organisation the intense emotions of passion, grief, and anger informed how my colleagues decided to organise and how they understood their identity as community workers. Above, I illustrated how the intense emotions of anger, grief, and passion tied my colleagues together in a way that helped them to embody values of democratic cooperation and aroha tētāhi ki tētāhi. Passion, grief, and anger were all outwardly inflected, implicating my colleagues in the lives of others. Intense emotions also shaped how my colleagues understood their identities. Rather than fixing identities of themselves as 'helpers' and others as 'victims', through emotion my colleagues sought to bring out the relational ties with their own identities; thinking about the ways that their own identities as women were implicated in systems of violence. These intense emotions shaped the intensity of my colleagues' feelings of a collective responsibility for improving the lives of marginalised communities.

\section{Ties that break: Being beside oneself}

In my theorisation of emotion, I developed the idea that while emotions can bind us together, they also involve a 'breaking' and a ‘boundary setting'. Importantly, Ahmed (2014) highlights that emotion can involve a moving away, as well as a moving toward, thereby involving a reifying of boundaries between groups of people. Emotion can be exclusionary. These exclusions are not necessarily negative; anger stuck on white supremacy, for example, 
can lead to the exclusion of white supremacist identities. The processes of moving away, therefore, could be affirmative, a dislocation from identities that were perceived as contributing to oppression. Butler (2006b) notes that this 'breaking', being beside oneself, is essential for moving away from normative identities and fostering the conditions that make it possible for non-normative identities to flourish. Focusing on ties that break also helps me to explore more fully how emotion can remake our identities in ways that that encourage the creation of new patterns of social relationships. However, breaking ties with others can also result in the exclusion of groups of people and the maintenance of social norms which condone physical or symbolic violence targeted at marginalised groups. In this section, therefore, I want to draw out the processes of breaking as it related to how emotion moved my colleagues, particularly focusing on how their identity as community sector workers was shaped by how they perceived their ties to abused women. I begin with a story about Indian migrant women that illustrates how emotion moves us but can also operate to fix identity in exclusionary and possibly harmful ways:

I entered the presentation late and the speaker - a young Indian woman called Disha - had already begun her talk. There were only a few empty chairs in the middle of the room, so I sat on a doorstep at the edge of the dim space. Disha was telling the audience about her experiences growing up in India, highlighting the static gender roles through the story of her first marriage to an older man who refused her many freedoms, including preventing her from eating until all the men had finished their meal. After divorcing her first husband (to the shame of her family), Disha became free to work and travel. Her new-found freedoms made her even more aware of the extent of abuse against women in India. In one particularly striking anecdote, she started telling us about the 'burning brides'. They are newly-wed women who are doused in kerosene and set on fire by their husbands, so that the man can take control of the dowry and marry another woman for her money. The deaths are labelled 'kitchen accidents'. At one hospital where Disha worked, there were over 100 women in one month who died in this way.

Disha then moved to telling us about her work with Indian migrant women in Aotearoa New Zealand. She told us that although 'burning brides' were less common, they still occurred in Indian communities in this country. The more common types of abuse, Disha told us, were emotional and economic abuse by in-laws - a dynamic of abuse seldom considered - and the impact of Indian community leaders who encouraged women to stay with their abusive husbands, so as not to bring shame to their community. The women sitting around me had 
intense responses to Disha's stories. Several women were openly crying in grief, and throughout the presentation there had been repeated pained gasps around the room.

Disha took a few questions from the room. The first question came from an older Pākehā woman who wanted to know how Disha had "escaped the cycle" that Indian women were trapped in. The next woman simply stood up and told Disha: "you are an amazing woman of courage and strength" and explained that she was shocked at the extent of violence that Indian women suffered. The final question came from a Māori frontline worker who told Disha that her eyes had been opened, particularly because there was a large Indian community near to their workplace. This woman now felt better equipped to engage with Indian women. Zoey, who was sitting near me, said to me while we were applauding Disha, "I know it sounds bad, but it is because I've travelled a lot, but I don't find it [the abuse of Indian women] that surprising". She told me she thought it strange that women who work with abuse everyday should be so shocked by Disha's stories and didn't know what Indian women went through.

Grief was the most salient emotion attached to the migrant women in Disha's stories. The revelations of her stories about Indian migrant women involved challenging our understanding of domestic abuse and our affective relationships to those who are targeted with extreme violence. The intense emotion of grief that Disha's talk encouraged, implicated the people in the room with the lives of Indian migrant women. The three questioners all acknowledge the way that grief has moved them; pushed them beside themselves to see how their lives and their work were implicated in the lives of Indian migrant women. The final questioner, in particular, highlights the 'breaking' she experienced through grief. Her now 'opened eyes' have involved movement; from a state of being unaware of our indebtedness to Indian women, to a recognition of Indian women in her community as victims of a particular kind of violence. The movement grief involves in this case - attaching the grief to Indian women - makes our fundamental dependency and ethical responsibility to the lives of each other salient. Feeling this responsibility as community workers demonstrates how attaching the emotion to the suffering of others can translate into physical support for our lives (Butler, 2006b). Here the intense emotion of grief that makes us beside ourselves opens up the possibilities of forming different kinds of attachments with others, thereby helping to organise alternatively for aroha têtāhi ki têtāhi. 
Grief shaped our identity as social justice advocates for the Indian migrant community and helped to create shared assumptions of how we should work together. The mobilisation of emotion through Disha's talk is, however, problematic. In order for grief to shape alternative identity and organising, grief must encourage movement and operate to undo normative relations. In this context however, grief appears to be uni-directional, passed from privileged subjects and fixed on 'third world' practices in a way that reifies contemporary geo-political hierarchies (Pedwell, 2013). Unlike earlier examples I gave where grief was localised and personalised, as well as outwardly inflected, here the 'breaking' seems to both involve a movement toward responsibility for Indian women, but also fixes Indian women objects of grief in a way that they, and the violence they suffer, is othered. Disha herself is understood as an object of compassion by two of the questioners - someone who suffered based on her Indian identity. In this way Disha is separated from others in the room who experienced violence, her identity as Indian is 'sticking point' of grief. To aid in organising alternatively, grief must operate to foster spaces of aroha tētāhi ki tētāhi and democratic cooperation. Grieving for Indian women must involve, as the final speaker suggests, a change in practices to include and engage with the community.

Disha's presentation was an example in which she directly set out to challenge our current social landscapes and promote a reorientation of our work through emotion to form different patterns of social relationships with 'other' women. Although presentations like Disha's were fairly common events - I observed several other similar presentations over my time with the organisation - being moved and moving with emotion were also common features of daily organisational life. My colleagues frequently shared personal stories related to moments of 'breaking', linked these moments to their identity as community sector workers and social justice work of dismantling harmful social norms and practices. One of Tia's moments of 'breaking' occurred in her first months of working for the organisation. We were talking about how she felt about becoming involved in domestic violence work, and I asked her if anything stood out for her in her first few months of working. Initially, she told me about how she felt out of her depth in the first few months, not having the business skills to efficiently do the work. Then she paused, reflected, and told me a story that changed her:

Violence and abuse, we knew it growing up, there were times and that we were exposed to it and felt the impact of it and stuff like that. But as an adult and coming face-to-face with that first woman lying in a hospital bed. It's just. Fuck. That stands out. Anyone who works in this field, or anybody who has that first experience, can't 
say that it doesn't stick. It did. I was just fucking standing there at the bottom of the bed and didn't know whether to walk out or just. I just thought that actually I was waiting for her eyes to open. But they were already open. But I just couldn't see them because they were so fucking bruised and shit. That was something that stood out.

The grief that Tia brings attention to in her story involves movement. The grief that she feels is interpreted as 'sticking' to that first moment in the hospital where Tia was confronted with the extremity of violence. The 'sticking' involves a movement from her understanding of childhood violence, to the victims of abuse she works with in the organisation. Dislocated from her original understanding of violence, Tia became beside herself with grief. The moment of being beside herself with grief fostered transformation rather than dissociation, as Butler (2006b, p. 28) puts it: from the "experience of loss and fragility, however, the possibility of making different kinds of ties emerges". Tia comes to understand her identity as a community sector worker through grief and she becomes implicated in the lives of abused women. Importantly, Tia highlights that 'anyone' in this line of work, or anyone who has a lived experience of the extremity of violence, is moved by grief. The movement invoked by Tia implies that all our colleagues who work with victims have all been pushed beside themselves through this grief, and that through circulating these experiences others can also be moved. Emotion that involves movement, therefore, is essential for social justice organising and remaking our connections with one another.

Tia also explicitly connected her 'breaking moment' to the depth of her attachment to her identity as a community sector worker. Tia felt that the community sector was the best place for victims of violence to engage with social support. Tia described to me how she understood her identity as a community sector worker and the nature of the community sector to achieve justice for victims. She contrasted our open and autonomous work with the "bureaucratic bullshit that every [government] client has to go through to either access them or have their services imposed upon them" and is proud that "[community organisations] are not dictated to by legislation and/or government policy". The perception of the community sector expressed by Tia here is understood through intense emotions and her anger attached to harmful organising practices. Her arguments here reflected a wider attitude in the organisation: that women who have violence imposed on them by an intimate partner should not then have symbolic violence of the state or other institutions imposed on their bodies. The grief attached to the bodies of abused women, for Tia, created shared assumptions among 
community workers in our organisation that we should organise around lived experience and empower women to make their own decisions.

Personal stories from my colleagues also demonstrated that intense emotion could also result in exclusionary practices and the 'fixing' of certain identities. Evelyn, for example, was becoming increasingly disillusioned with the approach of some members of the organisation toward Tangata Whenua. One story she told me illustrated how she became beside herself with anger, being moved to break ties with some of her colleagues and shift the 'sticking point' of anger to the organisation rather than to systems of racism. One story she told me was about how she felt members of the national body were not respecting kaupapa Māori processes:

[Some members of our office] went to a board meeting [of a member organisation] uninvited and it caused a lot of shit. With kaupapa Māori services it has to be in agreement before hand and let them know. That is respect regardless. They took offence to it, and all sorts of other things. Anyway, it was my turn to go up there and do an audit and Michelle [a Pākehā colleague] was coming with me. [The member organisation] wanted to clear the air of all the stuff that had happened and wanted to do a mihi whakatau - a kind of ceremonial blessing of her as a manager and me as worker going on there, onto their space. Levelling out the energy around it the incident] is a good way to explain it. Going in to talk to Michelle about it, her door was closed, and she suggested that we should go out and get pissed the night before because she doesn't give a fuck about their mihi whakatau. Didn't care if we went there smelling like alcohol. I was pissed off because this is them holding out an olive branch; you don't shit on that. But that is the attitude that it was. I lost so much respect.

The story above illustrates how Evelyn was moved by anger to breaking ties with colleagues, and that a colleague's anger involved exclusionary practices that reified boundaries between Pākehā and Māori identities in the organisation. Michelle ${ }^{14}$ had remarked before how angry she was at what she felt were discriminatory or racist practices toward Pākehā organisational members. The anger, for Michelle, was stuck on Māori organisational members, and she reified boundaries between Pākehā and Māori organisational members through practices such

\footnotetext{
${ }^{14}$ Michelle's perspectives, it must be noted, were contrary to the vast majority of the organisation. Almost all my other colleagues actively embraced and celebrated the central place of Māori and kaupapa Māori in our work.
} 
as those outlined in Evelyn's story above. Anger that fixes identities can be harmful and exclusionary. In Michelle's view, the work of the organisation was giving unnecessary priority to Māori and that our service provision should be the same for everyone regardless of ethnicity. Michelle's practices, therefore, tended to embrace notions of individualism and generic service provision. In Evelyn's story, Michelle's orientation around her anger therefore operates to reify the boundaries between Māori and Pākehā in a way that Evelyn understands as contrary to social justice.

Evelyn's anger moved from being 'stuck' on systems of racism to being stuck on the organisation. Her story above was illustrative of her feelings about how some members of the organisation treated Tangata Whenua. The moment of 'breaking' for Evelyn, unlike for Tia, involved a moving away from the organisation and their practices. She felt that these practices were reifying racism in our organisation; and her colleague's actions were a form of symbolic violence that excluded and devalued Māori identity; including her own.

In order to dismantle harmful and exclusionary social norms, social justice work must alter the social landscape and remake our connections with one another. Above, I explored how remaking of the social landscape can involve an emotional breaking of our attachments to social norms. Emotion moves us. My colleagues consciously reflected on the place of emotion in informing their identity and shaping their assumptions about how they should organise. In order to organise alternatively for self and social transformation, empowerment of marginalised people, and for aroha tētāhi ki tētāhi, intense emotion that involved movement were significant for bringing these practices into fruition. My examples illustrate that processes of movement were complex and messy. Breaking normative ties by being beside ourselves with grief remade connections to Indian women and other women who are victims of violence but emphasised that these practices could not be static. Grief and anger could also operate to set boundaries between us; breaking ties of solidarity and resulting in othering groups of people, thereby devaluing their identities. Emotion in alternative organising must involve movement in order to push us 'beside ourselves' and foster new identities and new patterns of social relationships with one another. 


\section{Ties that bind; ties that break: Identity, emotion, and alternative organising}

Before I started my interviews and my ethnography in the community sector in Aotearoa New Zealand, my understanding of the sector was embedded in the extensive debates in the community sector literature about the tensions between social missions and neo-liberalism (M. L. Sanders \& McClellan, 2014). These tensions are salient and have been important for deepening scholarly understanding of the nature of community sector work and the limitations community organisations face in achieving social change. The familiar tale is not, however, the only way to understand community organisations.

The problem with the familiar tale, I have argued, is that it positions neo-liberal modes of organising in the community sector as inevitable; a mode of organising to be either embraced or resisted. Drawing on the alternative organising literature, I contended that the perceived inevitability of neo-liberalism is problematic; there are alternatives. In fact, the alternative organising literature has determined that community organisations regularly attempt to engage in practices that are alternative to neo-liberal modes of organising (Jensen, 2017; Land \& King, 2014; Reedy et al., 2016). With an explicit focus on social missions, community organisations are argued to be an important site for identifying and describing modes of alternative organising and thereby imagining other ways of being, doing, and creating our social landscapes (Land \& King, 2014). However, only a handful of studies have directly engaged in understanding community organisations as alternative organisations, and thus much work remains to be done in understanding what alternative organising practices have emerged in the context of the community sector.

Herein lies the primary contribution of Part II to the alternative organising literature. My central proposition has been that paying attention to how certain kinds of strong emotions such as passion, anger, and grief - shape identity is important for understanding how alternative organisations can remake our social landscapes. In my rereading of the community sector, I argued that intense emotions were perceived as foundational to the ways in which community workers decided to organise and how they understood their identity. Celebrating and circulating these intense emotions was perceived by community sector workers as helping to create a social landscape based on the values of democratic cooperation, empowerment of marginalised people, transformation of the self and the social norms, and aroha tētāhi ki tētāhi. The explicit focus of community organisations on building and maintaining emotional bonds between members of the community opened up the 
possibilities in engaging in affirmative action toward achieving their social justice goals. Intense emotions informed the shared assumptions of how we should work together.

In reference to my organisation, I drew out aspects of emotion, arguing that intense emotions deepened community worker's commitment to social justice and encouraged community workers to form new patterns of attachment and responsibility to marginalised people. I insisted, however, that intense emotions could preclude as well as catalyse change. Emotion that operated to 'fix' people as objects or subjects of particular emotions often reified harmful social norms. Taking Butler's conceptualisation of the ek-static as my starting point, I argued that emotion only promoted social change if it also operated to break our normative ties to patterns of social relationships and aid in forming different types of ties to other people. The 'breaking' process associated with emotion was messy and complicated, but it opened up the possibilities of fostering new connections between community workers and victims of injustice.

I also suggested that understanding community organisations as alternative organisations had implications for answering the overarching research question of this project: in which novel ways can we understand identity and change to be related in the context of the community sector. Following Reedy et al. (2016) who argue that forms of organising, politics, and identities are intertwined, I argued that understanding community organisations as alternative organisations influences our understanding of community sector identities and change in two key ways. Firstly, that emotion is an important dimension of how identities are formed in community sector work. Secondly, that forms of alternative organising in the community sector promote the valuing and protecting of non-normative identities; fostering the conditions that allow them to flourish. I reflect on my arguments on these two points in turn.

Drawing on the works of Sarah Ahmed (2014) and Judith Butler (2006b), I argued that identities and emotions were intertwined in community sector. As emotions are implicated through forms of organising, how my colleagues understood their identities as community sector workers was tied up with emotion. I suggested that intense emotion, specifically passion, shaped how my colleagues understood their identities as social advocates and servers. In the attempts of my organisation to remake our social landscape in a way that reduced gendered violence, understanding community identities as social advocates was central to orienting their work around practices related to social justice. Butler's conceptualisation of the ek-static supported me in developing insight into how the 
relationship between emotion and identity is significant in alternative organising. Kenny (2010) has also utilised Butler's work on passionate investments community sector workers have to their identities - although without focusing on alternative organising. Her focus has been on how passionate attachments operate to maintain boundaries between groups of people and reify social norms (Kenny, 2010, 2012). My work here has been on the drawing out the affirmative ways in which passionate attachments operate to shape how community sector workers - such as my colleagues - understand their identities, and how intense emotions can create shared assumptions of how we should work with each other that are alternative to neo-liberal modes of organising or relating to one another.

My second central claim about identities and emotion is that organising around emotion can promote affirmative attachments to non-normative identities. Through my exploration of how emotion pushed my colleagues beside themselves and implicated them in the lives of others, I argued that intense emotions can deepen community workers' feelings of responsibility for improving the lives of victims of violence. Although organising around emotion can also operate to reify boundaries between people, I argued that when intense emotions promote movement and undoing normative ties to one another, change was possible. I also demonstrated through my colleagues' experiences that intense emotion shaped how they engaged with their work and decided to organise. The intense emotions of passion, grief, and anger were perceived as foundational creating shared assumptions of how we should work together in ways that exemplified the values of democratic cooperation, empowerment of marginalised people, transformation of the self and the social norms, and aroha tetāhi ki tētāhi. 


\section{PART III: Vulnerable BOdIES}


Kimberley and I were chatting together one lunch time, sitting on opposite sides of the lunch table. She was buoyantly explicating her views on the relationships between gender identity and violence, and I was listening intently, intrigued to hear her latest opinions on the subject. I had the opportunity to work closely with Kim during my time volunteering - assisting her in her work and talking with her regularly in our breaks. She's a young, educated, selfproclaimed "urban Māori" who loves debating with her colleagues, myself included, about gender identity, violence, race, and politics. Our lunchtime conversation today has been about whether or not it is actually possible to end gendered violence. Kim argues that it isn't possible, not with contemporary gender identity dualisms. She tells me that until we can imagine a third possible gender, consistently and coherently, there is always going to be a violent fight for the masculine to be dominant over the feminine. She laughs and summarises: "basically, every time I think about gender equality, I just think it's never going to happen”.

Kim then asks me what I've been working on recently. I explain that I've been doing some reading about violence, particularly thinking about the necessities of violence for forming identities (Bergin \& Westwood, 2003) and I've been particularly interested in the idea that becoming something involves violently foreclosing the possibilities of other ways of being. Kim is particularly enthusiastic about the idea, linking it to her interests in how making some aspects of violence visible - "hypering" she calls it - invisibilises other kinds of violence. Hypering the idea that it is possible to end gendered violence invisibilises the ways that gender inequality perpetuates, she argues. Kim has been interested in the notion of the 'undertow' of gendered violence; all the complex and subtle ways that people unconsciously revert back to harmful gendered norms.

My lunchtime conversation with Kim left me, as it usually did, unsettled in my ideas about the relationships between gender and violence, and the relationships between gender identity and the possibilities of achieving social change for victims of gendered violence. I didn't agree with Kim that it was impossible to end gendered violence, but my conversations with her were helping me to expand and challenge my own thoughts on the relationships between gender identity and domestic violence work.

The interest in gender identity was widespread in my organisation, with all of my colleagues, like Kim, interested in regularly discussing what it meant to be a woman, and what specifically it meant to be a woman working in domestic violence. My colleagues, generally, perceived their identities as women to be marginalised and targeted with physical violence in 
a society that perpetuated gender inequality by devaluing and attempting to control women. Nevertheless, my colleagues frequently attempted to celebrate 'being women', by encouraging and supporting each other to openly discuss their bodies and their experiences as women. My own observation of my colleagues was also that gender identity seemed central to domestic violence work and the possibilities of ending gendered violence. Over the course of my time with the organisation, I learnt from my colleagues that celebrating, examining, and remaking our identities related to the gendered body is fundamental to work with domestic violence, and the possibilities of the reduction of gendered violence.

In starting my fieldwork, I did not consider myself to be an object of study or anticipate the radical ways in which my sense of self as a researcher or woman would be unsettled by my ethnographic work. Although I'd considered the ethics of my project and thought about the implications of ethnography along various lines (as I discuss in 'Beginnings'), I had not deeply considered the possibilities of learning from how I was marked by my prolonged engagement in the field. The more engaged I became with my colleagues' questioning of their own identities, however, the more acutely I felt how I was becoming unsettled at my own intersection between gender, domestic violence work, and identity. From my colleagues, I learnt that I was implicated in systems of violence. In several extremely confronting moments inside and outside of the field, I understood what my colleagues were trying to get all of us to understand: that violence is unevenly distributed, but all of us are precarious to violence at the hands of those who are supposed to love us most. I learnt from my colleagues how working with domestic violence marks your body. And most importantly, I learnt how our bodily vulnerability is important for ending gendered violence.

In ethnographic accounts it has become traditional to present both a personal and an authorial voice, although these tend not to coincide (Coffey, 1999). Critically oriented ethnographers have, however, argued that personal and authorial accounts can, and should, be interwoven in order to generate a greater depth of understanding and feeling for our participants (Behar, 1996). One way to interweave personal and authorial accounts with stories from participants is to engage in autoethnography. Autoethnography draws and theorises from the researcher's experiences and connects these to the social and the cultural; aiding in breaking traditionally established divisions between researcher/researched (Boylorn \& Orbe, 2013). In this part, therefore, I interweave aspects of my own gendered identities at the intersection of domestic violence work alongside my colleagues. Reflecting on my own experiences in domestic violence work helped me to more fully appreciate my colleagues' understandings of how 
identities, change, and domestic violence work intersect. Consequently, I draw on autoethnographic material throughout Part III to develop and explore the central theoretical ideas about identities, bodies, and vulnerability.

Ultimately, in Part III, I offer an account of what I learnt from my colleagues about identity, domestic violence work, and social change. I explore the intersection of domestic violence work and identities, emphasising that how we understand our identities through our bodies is essential for understanding 'who counts' as a staff member and shapes who is perceived as a client of the organisation, or more generally as a victim of violence. Before I move to exploring the three central themes that make up the majority of Part III - gender identity, LGBT+ identity, and bodily vulnerability - I discuss the literature that has studied the intersection between domestic violence work and identity. The literature on domestic violence work and identity is slim but it offers a foundation to understand the centricity of gender identity to working with violence.

\section{Domestic violence and identity in the literature}

My own perception that identity was salient, and my colleagues' considerations that gender identity in particular was central to domestic violence (DV) work are well-supported in the interdisciplinary literatures. For different groups of workers who come into contact with victims of violence, including social workers (Goldblatt \& Buchbinder, 2003), therapists (Tyagi, 2006), police officers (Johnson, Todd, \& Subramanian, 2005), and nurses (Goldblatt, 2009), there is a widely acknowledged 'spill-over' of DV work into personal lives. The majority of this literature is centred on the cognitive impacts (like vicarious trauma) and emotional impacts (like compassion fatigue) of working with DV. In contrast there is limited exploration of how working with domestic violence catalyses an unsettling of professional and personal identities (Seymour, 2009). Nonetheless, explorations of identity and domestic violence work have noted that repeated exposure to gendered violence 'floods' the lives of domestic violence workers, blurs the boundaries between personal and professional identities (Goldblatt, Buchbinder, Eisikovits, \& Arizon-Mesinger, 2009), and, in particular, invokes a re-examination of gender identity (Goldblatt \& Buchbinder, 2003; Seymour, 2009).

Women who work in domestic violence are described to feel particularly unsettled, and even disempowered, in their gender identities when repeatedly exposed to gendered violence 
(Goldblatt \& Buchbinder, 2003; Seymour, 2009; Tyagi, 2006). In contrast, DV workers who identify as men tend to find DV work empowering and affirmative (Bailey, Buchbinder, \& Eisikovits, 2011; Seymour, 2009) even while questioning and remaking their gender identities (Bailey et al., 2011). The centricity of gender identities to domestic violence work is argued to be particularly prominent in organisations, like mine, where domestic violence is understood as a gendered problem (Iliffe \& Steed, 2000; Nichols, 2013). Understanding domestic violence as a societal gendered problem recognises that domestic violence is a consequence of systemic devaluation and objectification of women in education, the home, the workplace, and public social life (Nichols, 2014). Women who work in DV and are aware of the systemic nature of the problem can feel overburdened, overwhelmed, and devalued in their sense of self (Seymour, 2009). My colleagues, who generally did understand domestic violence to be a gendered social problem and all (save one) self-identified as women, likewise felt the impacts of domestic violence work on their gender identities; although in more complex ways (as I explore shortly) than typically depicted in the literature.

Although the literature generally acknowledges the impact of DV work on identities, research tends to uphold worker/victim distinctions, in that they presume that workers are not simultaneously victims of violence while working with violence; there is a 'professional' and 'personal' split (e.g., Bailey et al., 2011; Goldblatt et al., 2009; Tyagi, 2006). In the literature there seems to be a widespread silence about workers who consider themselves as victims of violence and work with violence (Ben-Ari, 2008). Studies that take an explicitly feminist approach to researching the intersection with domestic violence and identity (e.g., Nichols, 2011, 2013; Seymour, 2009), however, strongly make the case that women who work in DV are, in fact, simultaneously advocates for ending gendered violence and are victims of societal structures of gendered violence. Additionally, the DV and identity literature tends not to investigate the processes of gender identity construction (see Nichols, 2013; Nichols, 2014; Seymour, 2009 for notable exceptions). Identity categories of 'woman', for example, tend to be assumed rather than analysed (e.g., Goldblatt, 2009) and the connections between being 'female' and having a 'feminine identity' or being 'male' and having a 'masculine identity' tend to be naturalised (e.g., Bailey et al., 2011).

Research of victims' identities, and of identities of non-professional helpers (e.g. victims' mothers) has more thoroughly explored the construction of gendered identities in relation to DV. Gendered constructions of maternal identities, for example, are unsettled by coming into contact with gendered violence, demonstrating that organisational, societal, and individual 
processes of identity construction are interdependent (Gueta, Peled, \& Sander-Almoznino, 2016; Peled \& Dekel, 2010). For example, constructions of the 'good mother' in Western society are troubled when mothers' daughters become victims of violence, impacted by the perception that mothers have individually 'failed' to protect their daughters (Gueta et al., 2016). The perception of the 'bad mother' has implications for the type and extent of help victims of violence receive, and can hinder social change by excluding, marginalising, and devaluing mothers that do not adhere to social norms of the 'good' mother (Peled \& Dekel, 2010). Importantly, therefore, the research that actively examines how gendered identities are constructed in relation to violence, highlights that as well as unsettling identities, the intersection between domestic violence work and identities has impacts for catalysing social change. However, few studies of DV workers draw links between the impacts of DV work on identity and the importance of identities for social change (see Nichols, 2013; Nichols, 2014 for notable exceptions).

My colleagues were particularly cognisant of how domestic violence also impacted other identities, such as lesbian identities, a point on which the literature on DV work and identity is very limited. One particularly important consideration for my colleagues was the inclusion and valuing of LGBT+ identities in their work. The literature on domestic violence and identity is extremely heteronormative, and there has been no extended exploration of LGBT+ identities and domestic violence work, despite the consistent presence and influence of LGBT+ women in domestic violence organisations since the 1970s (Arnold \& Ake, 2013). Studies typically assume that people who work with DV are in heterosexual partnerships (e.g., Bailey et al., 2011; Goldblatt \& Buchbinder, 2003; Goldblatt et al., 2009; Tyagi, 2006) and assume that exposure to DV is so unsettling because of the reflection it causes on (hetero) intimate partnerships external to the workplace. Therefore, there is very little understanding of how LGBT+ identities are impacted by working with domestic violence. Despite this lack of attention there is extensive evidence that in order to create sustainable social change for abused women, including and celebrating women's multiple identities (e.g. black identity or lesbian identity) is essential for achieving change for all women (Macy, Giattina, Parish, \& Crosby, 2010).

In summary, although there is some research into the impacts of DV work on identities, "there appears to be a deafening silence when it comes to the needs of, and accountability to, women as workers in this area" (Seymour, 2009: 260). There is limited literature to draw on to understand the implications of my colleagues' diverse experiences of their identities while 
working with domestic violence. The majority of the literature gives very little consideration to how identity is constructed and to the implications of identity construction for reducing gendered violence. Additionally, beyond gender specifically, there is very little consideration of the intersection of domestic violence work and other gendered identities. Including and celebrating marginalised identities, as I learnt from my colleagues, was fundamental to achieving change for all women. The literature about DV and victim identity, nonetheless, demonstrates that exploring how identity is constructed at the intersections of self and domestic violence is important for achieving social justice for all women who are impacted by domestic violence.

In Part III, I will extend the literature on DV work and identity which has minimal presence in the organisational literature. As a point of comparison, there is some literature on the relationships between identities, organisations, and sexual violence work (e.g., Campbell, 2013; P. Martin, 2005). Sexual violence and domestic violence work share similarities (particularly as sexual and domestic violence sometimes overlap), including the argument that sexual violence is a systemic, gendered problem that unsettles the identities of those who come into contact with it (Campbell, 2013). Domestic violence, however, has other distinctive characteristics that make it different from sexual violence, such as the longevity of the violence, the multifaceted ways in which it manifests (i.e. economic, emotional, or spiritual abuse), and the specific status of the victim and abuser as partners. I therefore treat domestic violence work as having characteristics that make it a distinct form of work from other kinds of trauma work and as a topic that has received little attention in organisational studies (Seymour, 2009).

I develop my account of the intersection between domestic violence work and identity around a dimension that I perceived as important for my colleagues' identity construction: the body. Having a 'woman's body' was an intimate point of concern for my colleagues, and the concern was particularly marked because of the daily exposure to physical and symbolic violence on women's bodies in our work. How we understood our bodies, the vulnerability of these bodies, and how they contributed to our identities as women was negotiated on a daily basis. Research on victim identity has argued that the perceived 'closeness' of women to their bodies has significant impacts on DV victims understanding their identities as women (Wesely, Allison, \& Schneider, 2000). Despite the centricity of the body in domestic violence, there has been no research on how identities, particularly gender identities, are constructed through the body by domestic violence workers. As highlighted by my 
colleagues, as well as the literature, understanding how identities are constructed has implications for understanding how social change for victims of violence can be achieved.

Understanding how the body is constructed in relation to identity and domestic violence work raises several vital questions for catalysing social change for victims of violence. I intend to explore several here including: How is being a woman experienced and constituted through the body when working with domestic violence? Whose bodies are constructed as worthy of protecting, valuing, and celebrating? How can we foster identities that benefit women across multiple intersections of identity in domestic violence work? When we make political claims condemning 'violence against women' on behalf of which bodies are we making claims?

By drawing attention to the performative practices of the body in domestic violence work, I consider three ways in which the body was significant in daily organisational life. I respectively discuss how the identity of 'woman' was constituted through the body, and how experiences of unsettled gender identities in DV work was both constraining and liberating. I then move to exploring how LGBT+ women were constructed in the organisation in relation to the gendered body. I look at how some of the practices of the organisation reinforced a heteronormativity that my colleagues were intent on displacing which meant that LGBT+ bodies were sometimes positioned as less worthy of protection from violence. Finally, I give consideration to a striking formulation of women that my colleagues shared with me: women as vulnerable bodies. To conclude I discuss the implications of the construction of bodies in domestic violence work for achieving social change for victims of violence.

\section{In the lunch room: The body and gender identity}

Lunchtimes were particularly interesting for me as an ethnographer, as I was able to get to know my colleagues and hear about their lives. My fieldnotes often rotated around this daily ritual. Conversations over lunch seemed to provide a platform to discuss common interests. A common focus of discussion over the lunch table that I found to be particularly striking was the interest in the body. In my very first set of field notes this is how I describe the lunchtime conversation: "two of the younger staff members - Gracie and Kimberley - were already sitting chatting about TV shows when Emily and I joined the table. It seemed to be normal to have lunch together, particularly for the younger staff members. There were then four of us at the table, and all of us were under 30. A large number of topics were covered in the hour [including] a discussion of menstruation, abortion, sexual partners, sexual health related 
drugs, [medical disorders] related to the womb or ovaries, marriage, dieting, mood swings, recreational drugs, and flatmates."

I continued to be fascinated by the extensive attention given by my colleagues to describing bodily experiences and discussing topics related to the body. Many experiences related to women's bodies are marginalised in organisations, including miscarriage (Porschitz \& Siler, 2017), pregnancy (Gatrell, 2011b), menstruation (Sayers \& Jones, 2015), and motherhood (Lee, 2017; Riad, 2007). Contrariwise, my colleagues appeared to be comfortable in actively including women's bodies in everyday working life, and frequently celebrated or discussed those bodily experiences. The body seemed foundational for my colleagues in understanding their identities as women. As the DV and identity literature elucidates, however, gendered identities are unsettled by coming into contact with domestic violence (Seymour, 2009). My colleagues' identities as women appeared to be unsettled particularly because of the feelings of powerlessness that working with DV invoked, related to a lack of bodily control. In addition to the celebration of women's bodily experiences, there was a perpetual concern of the abuse of women's bodies by institutions and the constraints of social norms on what women could do with their bodies.

Not all analyses of the body in organisation studies are gendered (see for example: Riach \& Warren, 2015), but there has been extensive development of the gendered body in organisations by feminist and gender scholars (Jeanes, Knights, \& Martin, 2011). A critical examination of how the gendered body is produced in organisations in ways that perpetuate gender inequalities (and how these inequalities can be disrupted) has continually been important to feminist and gender scholarship (Acker, 1990; Gatrell, 2011a; Trethewey, 1999; Vachhani, 2014). The gendered body has been argued by feminist scholars to be shaped and disciplined by normative expectations of which bodies can successfully and legitimately be performed in organisations (Acker, 1990; Gatrell, 2011b; Kenny \& Bell, 2011). Feminist scholarship on the gendered body in organisations has ascertained that, on the whole, women continue to be closely associated with their bodies; which are often framed as needing to be controlled or repressed in organisations (Acker, 1990; Kenny \& Bell, 2011), or disruptive and less valuable than men's bodies (Sayers \& Jones, 2015). In short, feminist scholarly attention to the gendered body has continued to demonstrate that the prevailing notion that men can transcend the constraints imposed by their gendered bodies and that women continue to be constrained by their gendered bodies, remains embedded in organisations (Sinclair, 2011). Women's efforts to disrupt the perception that their bodies are deviant or shameful, therefore 
continue to be important for achieving change toward gender equality (Pullen, 2018; Sayers \& Jones, 2015). Around the lunch table, although my colleagues were acutely aware of the constraints attached to their gendered bodies, they were determined to shift the societal devaluation of women's bodies.

There are a variety of theoretical approaches to understanding the relationships between gender, the body, and gendered identities (Hope, 2011). To understand how the gendered body was constructed around the lunch table, I draw on Judith Butler's understanding of the relationship between gendered identities and the body. Butler argues that the body itself is produced through discourse, rather than being a passive and neutral foundation upon which gendered identities are built (Butler, 1993, 2006a). A gender identity - say that of 'woman' is a "repeated stylization of the body, a set of repeated acts within a highly rigid and regulatory frame" (Butler, 2006a, p. 45), and one that is open to reinterpretation and reformulation by nature of the need for repetition to maintain recognisable gendered identities (Butler, 2004). The constitution of the body through discourse has been a contentious claim for other feminist scholars who are concerned that Butler reduces the body to an effect of signification (Benhabib, 1995), or that her claims limit achieving transformation of gender inequalities grounded in the body (Hope, 2011). The criticisms often fail to recognise that Butler's claim is primarily epistemological, and also as Butler outlines more thoroughly in her later work that her claims tend toward a kind of sociality of ontology (Lloyd, 2015) which situates the body as an important site of interdependency and transformation (Butler, 2006b, 2011c).

Feminist organisational scholars who have utilised Butler's work to explore gendered bodies in organisations have illustrated that her work draws strong attention to how the body is constructed in particular cultural settings as valuable and legitimate (Johansson et al., 2017; Tyler \& Cohen, 2010). Moreover, Butler's work also offers the potential for transformation of gender relations in organisations through remaking the gendered body (de Souza et al., 2016). In reference to transforming gender inequalities through the gendered body, Butler's work attempts to balance two key concerns: the need for personal bodily autonomy that is attached to a sufficiently bounded identity to be recognised in the law and to make collective claims (Butler, 2006b), and the need to unsettle and remake our gendered identities in ways that open up the possibilities for novel and non-normative identities to be valuable and legitimate (Butler, 2004, 2006a). Drawing on Butler's conceptualisation of gendered identities, I explore below how these two key concerns permeated my colleagues' 
conversations around the lunch table and discuss how gendered identities were constructed at the intersection of domestic violence work in ways that attempted to disrupt the devaluation of women and their bodies.

Working with domestic violence positions the body as an important site for the construction and negotiation of gendered identities. The everyday work of my organisation always involved some form of exposure to violence perpetrated against women's bodies. The poster hanging behind my desk was a typical daily reminder of violence perpetrated against women's bodies. The top of the poster had the shape of a roof (indicating the domestic setting), and beneath the roof was a clutter of bold text words about men's violence against women written in the second person including: beating you, raping you, spitting on you, burning you, etc. The consistent reminder that women's bodies, including our own, were vulnerable to violence was unsettling. Moreover, the feminist analysis of domestic violence that my colleagues (on the whole) shared meant that the concern about individual violence against women's bodies was tied up with the perception that there were institutional and societal norms that devalued women and their bodies (Nichols, 2011). To feel confident and secure in our identities as women was, therefore, a difficult task at the intersection of domestic violence.

Our discussions around the lunch table were an important space for picking up on these concerns about women's bodies and negotiating them together to construct our gendered identities. Members of our office would gather together around two wooden tables in a small kitchen at the back of the office almost every day around midday. Attendance at lunch was usually indicative of stress levels around the office, and at times when we were all busy most of my colleagues ate while working. Lunches where at least four or five members of our office gathered together were usually animated affairs. The topics I noted in my first set of field notes turned out to be a common set of themes related to the body that my colleagues returned to many times. Personal bodily experiences, related to being a woman, were seen as inextricable from organisation life.

Most of the construction of our gendered identities at the lunch table was linked to the notion of women lacking bodily control. Around the lunch table my colleagues demonstrated an intimate concern with the ways in which women's bodies were violently limited by institutions, the law, or social norms. Gendered identities were not only constructed through the body; they were also unsettled in relation to the body. The unsettling of gendered 
identities through the body appeared to have significant impacts on my colleagues' wellbeing and shaped their experiences in the workplace. A large part of the discussion about the body oscillated between the personal and social, drawing links between practices that limited personal bodily freedom and that oppressed women socially. To illustrate, I will explore two vignettes of an issue related to women's bodies: reproductive rights. Reproductive rights and capabilities - including abortion, pregnancy, menstruation, and menopause - were often central themes of our lunch time discussions. These reproductive themes were constructed by my colleagues as women's issues, and in particular women's issues related closely to institutional and individual violence:

Gracie was reading an opinion piece in the paper, from a writer arguing that the number of women who experience mental health problems after abortion negated the number who said they would suffer mental health problems if they didn't have an abortion. Gracie started swearing, talking about women's rights, and told us "the only reason that women have to claim to have mental health issues is because abortion is still listed under the Crimes Act! And unlike sticking a huge needle into your stomach and removing some of the embryonic fluid, mental health issues require no invasive medical tests!” Kimberley agreed passionately, saying that the mental health issues were caused by "the absolutely ridiculous bureaucratic system that made women suffer." Kimberley went on to argue that there was a "war between the dichotomies [of male and female]" and that one, men, would always try to keep dominance over the other, women. One way for men to retain dominance over women, Kim pointed out, was to control the body and what it could do.

In this particular lunch time conversation, Gracie draws attention to the notion that our gendered identities of women are tied up with our bodies and how the law, institutions, and social norms shape the possibilities of being a woman. The issues related to the body (specifically reproductive capabilities) are linked specifically to the identity of 'woman', positioning the body as an important dimension of this identity. For Gracie and Kimberley understanding what it means to be a woman involves both a grounding in a (constrained) body, and as an opposite to (unconstrained) men. The topic of abortion is, for Kimberley, related to the distinctions between men and women, in which women have a bodily vulnerability that places their body outside of their control. Gracie and Kimberley both understand women to be situated within systems of oppression that seek to gain and maintain control over their bodies. Abortion was one example of an attempt to divorce from (male) control and gain personal freedom over the body. Kim and Gracie draw connections between 
the bodies of individual women and the institutional norms and regulations that constrain the possibilities of the body. Although Gracie and Kimberley are unsettled in their own gendered identities, this discussion forms the grounds for making claims for autonomy for women.

For my colleagues, the body was, therefore, a salient and significant site of construction of gendered identities. Importantly, work with domestic violence shaped how the body, and consequently gendered identities, were understood. In particular, working with domestic violence made me and my colleagues acutely aware of the lack of bodily autonomy felt by women subjected to gendered violence. The defining feature of domestic violence, from my colleagues understanding, was that violence was perpetrated against women because they were seen in society as 'objects' to be controlled. It was unsettling to be consistently reminded that our bodies were vulnerable to oppression and seemed to represent the limits on our freedom of self-determination. As Lloyd (2015) argues: "one cannot live one's life as one chooses if someone or something else - another person, institution, or state - controls one's body, including both what is done by it and to it" (p. 169). Around the lunch table my colleagues would regularly draw links between their own gendered identities and the institutional and social controls that constrained women's freedom make decisions about their own bodies:

One lunch time, Emily was looking at her phone and came across a news item that she wanted to share with us all around the table. The article was about contraception; about the negative impacts taking the pill had on women's bodies. Emily said that the article showed that medical practitioners had completely different standards when it came to men's and women's bodies and reproductive rights. The article - Emily read us snippets - argued that the negative side effects of taking the pill, including emotional instability, pain, and weight gain, were enormous, and that when men were exposed to similar effects they struggled to cope with the experience. Gracie responded in a sarcastic and irritated tone: "Oh poor men can't handle it, boo hoo hoo" and drew tear marks down her face with her hands. She went on to say that the article confirms her theory that "men are happy to dick around with women's bodies in a way that they wouldn't try with [other] men". Emily fervently agreed saying that men needed to consider the humanity of their treatment of women when making the medication. Michelle added drily: "that's two words I haven't heard together for a while: 'men' and 'humanity.,', 
Emily and Gracie strongly draw attention to the divisions they perceive between the treatment of women by medical institutions, and the treatment of men by medical institutions. The concern about the treatment of women centres on the (violent) misuse of women's bodies. Gracie, in particular, highlights that she understands institutions as placing less value on women's bodies; that somehow women were seen as more disposable and less worthy of protection or care. Gracie and Michelle both draw distinctions between men and women. Men are positioned as passionless, lacking understanding, and in a position of power. Women are positioned as suffering, aware, and subjugated. The distinctions are grounded in a sense of control; who has the power to mark another's body. Women, in my colleagues' construction, lack control over their bodies; both in the sense that institutions preclude women from making their own decisions and in the sense that the individual's body becomes uncontrollable. Gracie and Emily both agree that men have power over women's bodies and abuse them in ways that they would not do to their own or to other men. Around the lunch table, the gendered identities of my colleagues were shaped by a perception of a lack of bodily control and institutions that unevenly distribute value to different kinds of bodies.

My colleagues' construction of gendered identities in relation to the body are notable because of the legitimatisation of bodily experience in the norms of our organisation. The salience of violence toward women in domestic violence work shaped my colleagues' experiences as women in the workplace and positioned the body as central to our gendered identities. As the feminist literature on the body and gendered identities in organisations has established, women are often aware of (and can deeply feel) how their bodies are perceived as a constraint in organisations. In DV work my colleagues' awareness of the constraints of their gendered bodies seemed particularly complex because of the salience of bodily constraints in the context of violence, and simultaneous organisational norms that legitimated, and even celebrated, the body as focal to our work and gendered identities. Although my colleagues were unsettled in their gendered identities at the intersection of domestic violence (Goldblatt et al., 2009; Seymour, 2009), coming into contact with DV had complex and almost paradoxical impacts for understanding gendered identity. The unsettling of my colleagues' (and my own) gendered identities through the body, also opened up the possibilities of establishing a political agenda for change, and for celebrating identities as women.

In both vignettes my colleagues demonstrate an awareness of the constraints of their gendered bodies and the institutional norms which preclude their freedom of choice. Being unsettled, however, opened up the possibilities to remake the meanings attached to the body. 
In both vignettes the discussion of women's bodies both consolidates my colleagues' understanding of their gendered identity and provides a basis from which to make political claims. Drawing connections between personal bodily autonomy and social/institutional norms that constrain the body helped my colleagues to negotiate the context of violence within which they worked. Around the lunch table, meanings that were attached to the body were remade: from a position of subjugation, to a position of political change. The themes of the two vignettes were repeated in other similar situations. For example, in discussing the 'women's march' over the lunch table, Kim, Gracie, Evelyn and Emily agreed that it was necessary to unite together as women against institutional control over women's bodies. Additionally, the themes were attached to other topics related to the body such as food or sex. The body was grounds for the construction of gendered identities and the unsettling of gendered identities in the context of domestic violence.

Working in domestic violence was unsettling for our gendered identities. Although my colleagues did at times feel overburdened or disempowered in their gendered identities, the unsettling of our gendered identities also opened up the possibilities for them to be remade. Constructing our identities through the body over the lunch table provided grounds to negotiate a political agenda for reducing gendered violence through the gendered body. My colleagues were therefore also able to celebrate their identities as women, even while feeling constrained. Although the gendered body did provide this potential, the construction of our gendered identities through the body was also problematic. Our construction of gendered identities tended to rest on the presumption that women had a mimetic relationship between their gender identity and their sex (Butler, 2006a, p. 10) and our lunchtime conversations tended to reproduce these assumptions as natural and even unquestionable. As I move to discussing in the next section, there were negative effects when taking into account other aspects of our gendered identities, namely our sexual identities.

\section{LGBT+ identities and domestic violence}

Recognition and celebration of lesbian identities had been a part of my organisation since its inception; a trend similar to other long running international DV agencies (Arnold \& Ake, 2013). The salience of lesbian identities, Tia explained to me, was partly due to the positioning of organisational members as "tree-hugging, bra-burning, man-hating lesbians" by hostile communities in the 1970s. The public negativity, however, resulted in the creation 
of a political space in which the organisation was determined to break down discriminatory social norms which limited the full participation of lesbian women in Aotearoa New Zealand. Jen, who had been part of the organisation for nearly 30 years, felt liberated by the attention to lesbian identities. Earlier in her life she told me, she knew that she was:

Attracted to girls... but my understanding of what a lesbian was, was this hairy, big, truck driver, butchy jeans and boots... and I knew that wasn't the sort of woman that I wanted to be. Therefore, if I was a lesbian, and I didn't want to be one of those, then I didn't know what I was.

Many years later, Jen was exposed to the possibilities of being a lesbian like she wanted, when she joined the organisation as a volunteer. She described it as incredibly liberating, telling me: "I came out as a lesbian about the same time [as I started volunteering]. That was really quite cool because being a lesbian in [the organisation] in those days was a very... recognised and celebrated thing."

Like Jen, I experienced a feeling of liberation in volunteering with an organisation that actively attempted to celebrate and include LGBT+ identities, and where my identity as an asexual woman was not only recognised by my colleagues, but often openly celebrated as bringing a unique perspective to how LGBT+ women are impacted by domestic violence. The contrast to the compulsive sexual and gender 'neutralisation' of the business school environment (Ozturk \& Rumens, 2014; Rumens, 2016b) in which I was spending the other half of my time was stark. The more accustomed I became to the norms surrounding the enactment of sexual orientation in the organisation, however, the more acutely I felt my exclusion from aspects of organisational life. As McDonald (2016) argues, researchers who hold particular identities, such as LGBT+ identities, are more likely to notice certain organisational norms and thus are in a strong position to more richly theorise those phenomena. Accordingly, reflecting on my experience helped me to understand the theoretical and methodological implications of the construction of sexual orientation in my fieldwork (McDonald, 2013a) and exploring the intersection of domestic violence work and LGBT+ identities became imperative. As I felt the limitations, abjections, and celebrations of LGBT+ identities in daily organisational life, I came to recognise the importance of LGBT+ identities for expanding our understanding of how DV work impacts gendered identities and to feel the imperative of dislocating heteronormativity in order to protect the lives of LBGT+ women subjected to gendered violence. 
Despite the three decades of attention given to LGBT+ identities and issues in the workplace, the construction and experiences of sexual orientation at work has been slow to gain traction with critical organisational scholars ( $\mathrm{Ng} \&$ Rumens, 2017). The case for the need to pay attention to LGBT+ issues in the workplace and in research is, however, clear and compelling. Even in workplaces perceived as 'gay friendly', LGBT + people frequently feel that their identities are silenced or marginalised (Bowring \& Brewis, 2009; Giddings \& Pringle, 2011) and/or face open discrimination from co-workers or third parties (Köllen, 2013; Rumens, 2016a). Consequently, as Colgan and Rumens (2015) emphasise, critical scholars need to explore how "the workplace is sexualised through how sexual orientations are constructed and attributed meaning at work" (p. 1). Organisational scholars can, therefore, learn much from my colleagues' practices of LGBT+ celebration, and from the daily construction of LGBT+ identities at the intersection of domestic violence work.

My organisation had long been aware of the importance of inclusivity of LGBT+ women for tackling gendered violence. When I joined the organisation, a few of my colleagues - Jen and Emily particularly - were beginning the process of changing organisational policies and practices from focusing on lesbian identities specifically, to all LGBT+ women ${ }^{15}$, with an aim to be inclusive of all LGBT+ workers and clients. Although my colleagues espoused their support for providing services and support to LGBT+ women, the notion that lesbian women were to be treated no differently from heterosexual women continued to be pervasive. Tia, for example, told me when I asked her about inclusivity of lesbian women: "what about it? They are everywhere. Who people choose to go to bed with is their fucking business. It is not illegal so what is the problem?" Kimberley had a similar opinion: "I find it fascinating that a women's organisation has [an explicit interest] that is solely around sexuality. I really think that it brings to the forefront of identity that somehow sexuality is a massive part of our identity as an organisation... Really it shouldn't matter what sexuality anyone is."

The perspectives offered by Kim and Tia were regularly expressed by organisational members who identified as heterosexual. These perspectives were, however, problematic and critiqued by LBGT+ members of our organisation:

\footnotetext{
15 The need to move away from lesbian identities specifically was also important in the postcolonial context of Aotearoa New Zealand. There was concern in the organisation that queer Māori and Pasifika women were excluded from Westernised conceptualisations of LGBT+ identities. Elizabeth Kerekere (2015) gives an accessible introductory overview of takatāpui identities and their importance in the Aotearoa New Zealand context for the health and wellbeing of Māori and Pasifika. None of my colleagues identified along these lines and consequently this is not a line of investigation I follow in Part III.
} 
In the second week of my ethnography, Jen was keen for me to attend a series of talks hosted by members of the organisation, held in a sort of conference like environment. My ethnographic enthusiasm was abounding, and I attended excited to see what these women talked about together. I had decided to go and see Sara talk about "heterosexual visibility"; partly because Emily had repeatedly told me that Sara was a fantastic human being and a great speaker. The room was small and slightly dark, and there were about 30 plastic chairs facing a projector screen. The room was fairly full by the time I arrived, and I took a seat near the back where I could see most people. Emily came and sat down next to me, and I saw Jen hovering in the doorway.

Sara started off by welcoming us and saying how nice it was to see all the heterosexual women here. Immediately there was a loud comment from a woman just to my left: "you are making assumptions!" Sara laughed and put her hand over her chest and replied "oh, I know. I know everyone in this room isn't heterosexual - myself included". Sara started by showing us a video about the 'heterosexual quiz' where she went around young people asking them questions like, "when did you first know that you were heterosexual?", "when did you come out to your parents?" and "what do you think made you straight?" There was a great deal of laughter from all of us in the room and from the participants in the video. Most of their responses were just 'common sense' like "I just knew", and "um... when I first took my boyfriend home?" and "you could tell I was straight by the music I listened to" (underneath this comment on the video Sara had posted 'what???' in bold red text).

After the video ended and the laughter had stopped, Sara said "I'm going to get more serious now”. Sara added an apology that she was going to be focusing a lot on the church. She started talking about the continuing violence against the rainbow community, even though, she added, this was much less of a problem in New Zealand than overseas. "A transgender woman is murdered every three days" she told the now quiet audience, "a statistic which does not include self-harm or suicide rates". Sara then showed another video. It was full of very violent images and violent language - often from members of the church. The violent images included a transgender woman being attacked on the street, gay men being forced to rape themselves with glass bottles, and police brutality against peaceful gay rights activists. The violent language included speeches from priests saying that boys who act like girls need to be abused and beaten up in order to make sure they act like men, emails from priests attacking gay men urging them to commit suicide, and slurs against LGBT+ people in 
everyday situations. During this video, many of the women in the room made small exclamations at the violence, and several women started crying.

No one made a sound when the video ended. Sara paused a moment, as if breathing in the silence, and then went on to explain why it was so essential to foster an inclusive society and why it was so important for the organisation to make this a space for women from the rainbow community as well as heterosexual women. Sara then told her own story and explained how when she was abused by her partner the police had classed the incident as 'between friends', and when she separated from her abusive partner she had no legal access to the (non-biological) children she had raised from birth because there was no legislation to support her custody claims. She said how difficult it was for her to get help from anyone, and how most social workers didn't recognise the violence she experienced. She told us: "people think violence between women is less dangerous because we are about the same physical size. But it can be much worse than violence between men and women". At the end of the presentation Jen added, from the doorway, that she knew how powerful Sara's presentation was and concluded "how can anyone think that [being an inclusive organisation] is not relevant?"

Sara's presentation effectively drew the link between heteronormativity and the violent material implications for LGBT+ women. The stories Sara shared underscored the impacts of heteronormativity on the body. Sara dedicated a lot of time to unpacking the meanings people in her tales ascribed to bodies and the violence perpetrated against bodies. Importantly, Sara highlighted that domestic violence work is often saturated by the binary assumptions that a 'female body' will have a 'female heterosexual identity'. Sara's arguments echo broader sentiments in critical studies of LGBT+ identities in the workplace: restrictive social norms surrounding LGBT+ identities are enmeshed in widely accepted binary models of female/male and masculine/feminine (Colgan \& Rumens, 2015). Judith Butler's work developing the concept of the 'heterosexual matrix' has been influential in understanding how heterosexuality is normalised in many aspects of life, including organisations (Rumens, 2017). The heterosexual matrix articulates how a 'female body' is naturalised to be the complementary opposite of the 'male body', thereby making heterosexual relationships appear self-evident and natural (Butler, 2004, 2006a). Heterosexuality is positioned as the norm and homosexual is the 'other' i.e. heterosexuality is 'natural' and homosexuality is 'abnormal'. Through heteronormativity in institutions, social norms, and practices, 
heterosexuality is made to seem coherent and is privileged by being accepted and included in daily organisational practice (Berlant \& Warner, 1998; Rumens, 2015).

The body is therefore central to the construction of LGBT+ identities. The 'female' body is constrained by social norms which posit a 'natural' heterosexuality thereby marginalising women who perform their sexual orientation differently (Butler, 2004, 2006a). As with all of Butler's work around identity, the performativity of identities opens up the possibility for the remaking of identities which, while difficult, can help to displace restrictive social norms. For example, lesbian women can articulate identities which break with the heterosexual matrix but at the risk of abjection, non-recognition, and violence for breaking with powerful social norms. Additionally, lesbian identities are normatively constructed to uphold some of the sex/gender binary and are often expected to fit within narrow legitimated frames of reference, such as butch lesbian identities (Bowring \& Brewis, 2009). As Jen indicated in her story about not wanting to enact a 'masculinised' or butch lesbian identity, the limited subject positions offered to lesbian women appear as constrained possibilities for identities if one is to be lesbian and a woman. Butler therefore offers both an understanding of how heteronormativity is perpetuated through the body, and an account of how the possibilities of the (re)articulation of LGBT+ identities can dismantle heteronormativity.

In relation to domestic violence, the heterosexual matrix has significant implications for both DV workers and clients. Implicit in compulsive heterosexuality is that a 'weaker' female body is seen as vulnerable to violence from a 'stronger' male body thereby assuming that gendered violence results in women being vulnerable to violence from men, but not from other women (Ristock, 2011). Consequently, as Sara highlights, the severity and seriousness of violence in LGBT+ relationships is often downplayed, which means that victims often face additional barriers in leaving violent relationships (Shelton, 2017). LGBT+ victims may not be aware that their experience constitutes abuse (Shelton, 2017), may be reluctant to seek assistance from domestic violence workers (Bornstein, Fawcett, Sullivan, Senturia, \& ShiuThornton, 2006), and may even be excluded from receiving adequate, or even any, assistance (Ristock, 2011). The impacts of heteronormativity, as Sara indicated through her own experience at the intersection of domestic violence and organisations, is that only certain heterosexual identities are legitimated as the objects of organisational inclusion and assistance. 
Accordingly, one important aspect of the project to include and celebrate LGBT+ identities is to destabilise restrictive social norms that preclude LGBT+ identities and experiences from recognition in the workplace and in society (Colgan \& Rumens, 2015; Ng \& Rumens, 2017; Rumens, 2017). Recognising LGBT+ identities in domestic violence work is important for protecting the lives of LGBT+ women. I now move to exploring the construction of LGBT+ identities in my organisation drawing on Butler's understanding of the heterosexual matrix. I start by describing how heteronormativity was perpetuated through the regulation of heterosexuality and the exclusion of LGBT+ identities in daily organisation life. I then explore how these examples had implications for the wellbeing of staff at the intersection of domestic violence. To contrast the practices of heteronormativity, I then move to illustrating the ways in which some of my colleagues attempted to combat heteronormativity in ways that afforded LGBT+ women the possibilities of constructing identities that fall outside the confines of rigid social norms. In destabilising restrictive norms surrounding LGBT+ identities, the possibilities of recognising the unique ways LGBT+ women make meaning of their identities at the intersection of violence is opened up, and we can understand how the construction of LGBT+ identities have implications for the advocacy and service of all women subjected to violence.

To begin, I offer a story of an ordinary lunchtime conversation:

Lunchtime banter about colleagues' sexual activities was commonplace; with some of my colleagues more enthusiastically sharing stories of their experiences than others. Having no interest in sexual relationships and no stories to add to these conversations, my primary interest was ethnographic as I'd come to be aware that sexual orientation was often fundamental to my colleagues' identities as women. Increasingly, however, I'd felt that some stories about sex seemed to be more acceptable to tell; particularly as my LGBT+ colleagues like Gracie, Jen, and Esther appeared to be less engaged in these conversations or only seemed to be comfortable sharing limited aspects of their experience. I felt that there were two options available: engage in detailed, humorous stories about sex with men, or remain silent. Today started off in the usual way.

Riley was really shocked by Emily's admission that she hadn't had sex in six months and said very loudly “why don't you just get drunk and get your hussy on?”. I hate when people get so shocked about this, it makes me feel like my life isn't worth living. It didn't bother Emily as much, and she immediately shared horror stories of the last time she had tried to have sex 
with men. One of the stories was the time Emily had sex with a man who had a foot fetish... which she didn't discover until halfway through and he started telling her that he was imagining her dominating other women with her feet... Riley howled with laughter and asked where on earth Emily found these men. She happily explained that she had sex with many, many different men but had never come across anything as crazy as that. Riley said all you needed to know was that the men had sheets on their bed. Evelyn piped up trying to claim that they at least needed clean sheets, but Riley reassured the table with a wave of the hand that any sheets would suffice.

Several of my colleagues decided that they would help Emily to find a man to have sex with; despite her protestations to the contrary. Esther held out her hand, demanding Emily's phone so that she could 'work' on her profile on social media. Esther claimed that "my friends call me the Tinder whisperer... The key is to be really bitchy, because men really like that". She looked over the profile, sized up Emily with a quick glance, and said that her personal description should be "probably taller and smarter than you". Kimberley laughed and agreed that men really like women being 'bitchy' for some reason. She told the story of how she met her boyfriend on Tinder; where she had a quote from Taylor Swift that read " a nightmare dressed like a daydream". Riley and Esther asked Emily several times if she was looking for a relationship or if she just wanted to "root some dude". These appeared to be the only two acceptable options.

Gracie came to join us at the table just as Riley was telling Emily that she should go out and "hump randoms that you meet in bars. It is tried and true". Riley turned to Gracie and asked when the last time she got laid was. Gracie laughed off the question, and so Riley ignored her. Emily was now adamant that she wanted on her Tinder profile that she was only interested in sex if she was able to change her mind halfway through. Riley was sceptical about this because it might put men off but told us stories of telling various sexual partners to 'get out' (of her and the house) in the middle of sex if it "wasn't working for her". Esther said she had done that as well, spreading her legs and making shooing gestures around her crotch to indicate how she dismissed unworthy sexual partners. Gracie suggested that Emily should write that she was after "hot and consensual respectful dicking" on her profile and joked that Emily should buy a squirty gun to get men out of her bed. My sense was that by this point Emily was extremely uncomfortable. Ava joined in the conversation saying she didn't understand all this modern dating and asked what had happened to emailing men; that was how she met her husband. 
The banter surrounding sex with men was very commonplace in daily organisational life, as illustrated in the story above, and a central aspect of identity for many of my colleagues. Within this vignette, however, there are only limited possibilities of sexual behaviour normatively condoned or celebrated. In this instance, the normative sexual orientation is governed by an engagement in sex with men, limited to a position of desirable and desiring woman, or a woman in a heterosexual, monogamous partnership. Emily, a heterosexual woman, is being policed in her (lack of) activity, and several of her colleagues encourage her to embody and enact a particularly limited sexuality. The conversation in this case is particularly heteronormative, encouraging each other to engage in detailed descriptions of the use of bodies in sexual interactions with men but marginalising or silencing voices that do not adhere to the social norms. Gracie, for example, was actively excluded when she didn't meet expectations by avoiding an answer and had to engage in heteronormative banter in order to be accepted. Esther and Gracie, who both identified as bisexual, only contributed some aspects of their experiences. In instances where Gracie did share stories about relationships with other women, or explicitly talked about her bisexuality, there was a noticeably cooler and less enthusiastic response; even sometimes only acknowledged by a nod of the head and a subsequent change in topic of conversation.

The conversation over lunch highlights the ways in which heterosexual practices were widely encouraged and accepted by the majority of my colleagues. The whole conversation appears to be premised on a (supposedly) mutual recognition of the female bodily desire for the "male body'. The confines of heterosexuality were, moreover, particularly limited. Riley, Esther, and Kimberley constructed quite limited categories of behaviour expected from a heterosexual woman, tied to the way in which the female body was supposed to look and act. Kimberley proposes that women need to make themselves look sexually desirable for men. Esther expresses normative expectations of the appearance of the female body by drawing attention to Emily's height, noting that she is 'probably taller' than male bodies. Esther's formulation posits that Emily might pose a challenge to a masculine body, suggesting that men might like to have the opportunity to defend their masculinity by proving that they are indeed "taller and smarter" than Emily. Gracie and Esther also make reference to the expected sexual characteristics that 'male' and 'female' bodies should align with, through their gestures and reference to 'dicking'. Male and female bodies are naturalised as complementary opposites, marginalising the possibilities of 'male' and 'female' bodies 
having different physical characteristics or that female bodies could desire other female bodies; or not desire at all.

The silence around LGBT+ identities, even when several members of the lunchtime conversation openly identified as LGBT+, echoes the findings of other studies of LGBT+ identities where silence is the predominant mode of marginalisation of LGBT+ women (Bowring \& Brewis, 2009; Giddings \& Pringle, 2011). As Tia and Kimberley noted in their conversations to me, lesbian experience was often classed as "their fucking business" or "it shouldn't matter what sexuality anyone is". But these expressions contrast with the heterosexuality prevalent in everyday conversations. As well as lunchtime conversations there were many other examples of small exclusions of LGBT+ women. For example, Gracie was told by Jen that as a bisexual woman the other lesbian members of the organisation wouldn't consider her "gay enough" to attend a meeting of lesbian women in the organisation; corroborating that bisexual women face discrimination from both their heterosexual and lesbian counterparts (Köllen, 2013).

As well as posing problems for the wellbeing of LGBT+ organisational members, particularly in relation to sharing their experiences of violence, the heteronormativity became embedded in daily organisational activity. Heteronormativity was problematic as it normalised only certain women as legitimate clients. For example, Zoey, in the writing of a policy for guests visiting women in emergency housing, noted that women were not allowed visitors who were men but were allowed women who were visitors between the hours of $9 \mathrm{am}-9 \mathrm{pm}$. This policy is founded on the heterosexist assumption that women will have been in a violent relationship with men but not another woman, and that victims are in danger of violence from men but not from other women. The formulation in the policy accentuates that the concept of 'violence against women' is often constructed as only a particular form of violence from men to women; excluding and marginalising LGBT+ women and experiences. Heteronormative practices thus had serious impacts on which bodies DV workers perceived as legitimate victims of violence and worthy of institutional protection. It was, however, acceptable to challenge the heteronormative assumptions and in suggesting that this policy, and other similar policies, could be negotiated was testament to the possibilities of inclusion.

Consequently, although there were examples of heteronormative practices in the organisation, to paint a portrait of my colleagues as unaware of the dangers of heteronormativity or regularly complicit in excluding LGBT+ women would present a one-sided view of my 
colleagues' attempts at including LGBT+ women. There was a long history of attempting to celebrate LGBT+ women, as Jen illustrated, and there was the space to challenge heteronormative assumptions and open up the possibilities for LGBT+ women to be liberated in self-expression. Therefore, I now want to draw more attention to the experiences of LGBT+ women at the intersection of domestic violence work and identity. I want to highlight how LGBT+ identities were included and celebrated in ways that attempted to shift heteronormativity, explore two examples of how LGBT+ identities were unsettled at the intersection with domestic violence, and finally offer a positive example of how challenging heteronormativity expanded (rather than constricted) the possibilities of who was perceived as a client.

At the intersection of violence and identity, LGBT+ workers in the organisation were clear that working in DV unsettled their LGBT+ identities. Jules explained that working with violence had unsettled her sense of self as a lesbian partner; telling us how after working in DV for several months she had become afraid that her practices of slamming doors and refusing to talk to her partner constituted abuse. Her experiences of working for the organisation prompted her to reflect on and alter her behaviours and attitudes toward her partner. Interestingly, her concern about her own relationship was mixed together with a worry that she was being a 'bad' representative for the lesbian community. With the regular discrimination that LGBT+ woman faced in society, Jules was concerned that if she was seen as violent then there would be repercussions for the LGBT+ community; seeing them as defective or immoral. Another woman who openly discussed her experience of her sexual orientation and violence was Lesley, who worked with the rainbow community. Lesley came to talk to us about her experiences with violence as a bisexual woman and being a victim of violence from one of her woman partners. She explained some of the forms of symbolic violence she experienced that she considered unique to LGBT+ woman. For example, as a bisexual woman she was coerced into changing her self-definition of her sexual orientation (i.e. from 'bisexual' to 'lesbian') because she'd been in a long-term relationship with another woman. As with Jules, this prompted a reflection and a reconsideration of her own sexual identity.

LGBT+ women experienced an 'unsettling' of their identities, with some similar dynamics reflection on partnerships - and some different dynamics - concern about repercussions for the wider community - to heterosexual women. What both Jules and Lesley identified, however, was that in working with violence they felt that they had unique perspectives on 
domestic violence. They both remarked that their identities had been unsettled in a way that made them better partners and better advocates for ending gendered violence against all women. Domestic violence work therefore unsettles multiple aspects of gendered identities. Legitimating and recognising the multiple ways that women may have their gendered identities unsettled in domestic violence work is essential for the wellbeing of domestic violence workers. Additionally, Jules and Lesley highlight how they feel that they perceive the different ways in which violence manifests through their sexual identities, identifying particular areas in which domestic violence work must also seek to change to end gendered violence.

Including and celebrating LGBT+ identities was also important for the ways in which our work as an organisation recognised LGBT+ experiences as legitimate and worthy of protecting. Emily and Jen, in particular, were concerned with ensuring that staff members perceived LGBT+ women as an essential part of anti-violence work. One aspect of our organisational work that I was heavily involved in alongside Jen and Emily was researching the experiences of our clients in order to improve our engagement with victims of violence. Jen adamantly maintained that: "we are not founding our research on those heterosexist assumptions". All surveys conducted by our organisation about their client base attempted to be as inclusive of LGBT+ experiences by removing all gender specific wording (i.e. changing 'was he physically violent' to 'was your partner physically violent') and asking for the gender identity of the abusive partner rather than assuming them to be a man. These attempts by Jen, Emily, and me had implications for which bodies were perceived as legitimate of recognition and protection from violence.

Naturalising heterosexual relationships as the 'norm' of gendered violence has significant implications for both the domestic violence workers and for who the domestic violence workers perceive as their clients. As I have demonstrated, the embedded heteronormativity surrounding domestic violence work had grave consequences for the inclusion or exclusion of LGBT+ women as organisational members. Understanding how heteronormativity marginalises LGBT+ women at the intersection of domestic violence work is, I have argued, a serious concern for any organisation that seeks to catalyse change to end gendered violence. Which bodies were worthy of protecting, valuing, and celebrating, are impacted by heteronormative practices (Butler, 2004). At the intersection of domestic violence work and LGBT+ identities, it is imperative to understand women's diverse experiences with violence and ensure that our advocacy benefits all women, not only a subset of women (Arnold \& 
Ake, 2013). Opening up the space for LGBT+ organisational members to share their opinions and experiences related to the body is important in this regard. Although my colleagues did make substantive efforts to be inclusive of LGBT+ women, heteronormative practices operated to silence and marginalise LGBT+ women on multiple occasions. Nonetheless, when the experiences of LGBT+ women at the intersection of domestic violence were recognised, we gained a richer understanding of how DV work impacts gendered bodies, and the implications of identities for ending gendered violence for all women.

\section{Radically unsettled identities: Women as vulnerable bodies}

The discussion in the previous two sections emphasises that the heightened awareness of the vulnerability of bodies unsettles gendered identities. I now want to highlight how the unsettling of identities was taken in a radical direction by my colleagues: understanding women $a$ s vulnerable bodies. This formulation of women as vulnerable bodies (characterised by an inherent corporeal vulnerability to violence) proved to be extremely unsettling for gendered identities, not only for me and my colleagues, but for other women who came into contact with this formulation when I shared early iterations of this work at conferences and in other academic settings. In particular, this formulation seemed unsettling as it appeared to run counter to the decades of work on women's empowerment and work toward the celebration of women's bodies as powerful and agentic. The centricity of bodily vulnerability to violence in domestic violence work for the women that I worked with, however, was a striking and salient theme.

In my attempts to come to terms with my colleagues' formulation of women as vulnerable bodies, I found Butler's conceptualisation of vulnerability insightful. Butler outlines vulnerability as having a twofold meaning: "vulnerability includes all the various ways in which we are moved, entered, touched, or ways that ideas and others make an impression upon us... [vulnerability] is also a way of indicating one's dependency on another, a set of institutions, or a circumambient world to be well, to be safe, to be acknowledged" (Butler, 2011 b, p. 200). Drawing on Butler's conceptualisation of vulnerability, I interpreted my colleagues as not only trying to recognise women's physical vulnerability to others, but also that they were attempting to underscore that we needed to cultivate the capacity to be moved or impressed on by women subjected to violence. Positioning women as vulnerable bodies accentuated the pressing need to promote institutional and domestic protection of women. 
Throughout my volunteer work, I was moved by my exposure to my colleagues and our work with victims, and eventually came to understand women's dependency on one another and the social conditions that produced women as vulnerable bodies.

In this section I draw on a series of vignettes from my field notes. In these vignettes, I parallel my experience in the organisation with the experiences of my colleagues. I track my understanding of the formulation of women as vulnerable bodies across my time volunteering with my organisation, emphasising how when we come into contact with organisations our identities are altered. An important aspect of understanding women as vulnerable bodies was the recognition that we were all vulnerable to violence at the hands of those who are supposed to love us most. The deep feeling of corporeal precarity as forming our identities, unsettled the boundaries between 'victim' and 'non-victim' in radical ways. Although I learnt from my colleagues the value of understanding women as vulnerable bodies, I also felt the limitations of this formulation.

Emily and I are indulging in our Monday morning tradition of chatting about our weekends over an early morning cup of tea. We're standing in the small kitchen at the back of the office. I'm leaning against one cupboard, my hands clasped around the warmth of cup, listening to Emily talk and watching her bob her tea bag in and out of the mug. Emily suffers from insomnia. In the little sleep she managed to get last night, she tells me that she has been having vivid dreams about guns. People keep threatening her, telling her that if she doesn't comply with what they wanted her to do that they would kill everyone she loved. And then shoot her. Emily explained that she had been working recently with a lot of young women who were forced into sex work. One story was about a young woman whose boyfriend drove her to the middle of nowhere with his friends, took out a gun, pointed it into the small of her back and told her that she was to go have sex with everyone in the car, otherwise he would kill her. Emily throws her tea bag into the bin, smiles tiredly at me, and asks if we should get back to work.

I've just started having these dreams. The dreams are mainly about being beaten by other people, and usually occur while doing some sort of mundane activity. My dream last night was about playing netball. Whenever I did something wrong, or was seen as too competitive, or too clever, I was beaten (typically punched) by someone on the opposing team. The aggressors never had a solid form. It almost was like getting beaten up by your own shadow. 
Something I had read the other day had been haunting me and seems to have slipped into my subconscious. It was a quote from someone on Facebook who was pushing for the domestic violence legislation to be changed. She said: “you don't understand that feeling when someone you love punches you in the face for the first time”. My dreams were not scary, and I felt neither fear nor pain, and so they do not disturb me. I don't understand that pain yet. But so many do.

Before working in domestic violence, I had not given extensive consideration to how vulnerability contributed to constituting my own, and other women's identities as women. I was aware that as a woman in Aotearoa New Zealand I was more likely to experience physical and sexual violence. As a researcher interested in theories of the self, I'd also been interested in the idea that our physical and symbolic vulnerability to violence from other people is a component of constructing and understanding our identities. In forming our identities we necessarily make violent divisions between who we consider to be 'us' and who we consider to be 'them', and what belongs to 'our' experience and what does not (Bergin \& Westwood, 2003). Although I was aware that we all share a fundamental corporeal vulnerability, this did not lead to a reciprocal recognition of the communities who are more regularly subject to violence (Butler, 2011a). I had experienced some sexual violence, but I felt as an educated, middle-class, Pākehā woman, however, such violence had not been central to my constitution of identity as a woman. I maintained a sense of separation between myself and victims of violence, which proposes that there must be something that separates us from someone who has been a victim of violence when we have not been (Campbell, 2013).

The vignettes above contrast my feeling of separation to Emily's recognition of her body as a body vulnerable to violence. In her dream Emily's body is the body of the women that she works with. She appears to share a fundamental vulnerability with her clients, understanding her own body as vulnerable to physical and sexual violence. Emily frames her body in contrast to the 'other' in the dream; the violent men who threaten her. The identity of 'woman' is situated by Emily in relation to being a victim of violence, and in contrast to the men as the perpetrators of violence. There seems to be no separation for Emily between the clients as victims of violence, and her own sense of self. Emily is the women that she works with; in both her dreamscapes and her waking life. 
My dream does not illustrate the same connection. Those who attack me are 'shadows' rather than a definable contrast to my own body; the shadows lack corporeal form. Although I express sympathy with victims of violence in my dream, I am not seeing myself as radically connected to victims of violence in the way that Emily does. My lack of connection is reflected in the way that I describe how I don't understand their pain and suffering. I am, literally, undisturbed by the violence; it has not unsettled my sense of self and I maintain the boundary between my sense of self as a woman and 'other' women who are victims of violence. The dreams I started having in my work were not nightmares in a traditional sense I did not wake up feeling unsettled or scared. It was an apprehension of violence and corporeal vulnerability but not a recognition (Butler, 2006b). At this stage of my ethnography I have apprehended some of the possibilities of violence, but at the intersection of identity and domestic violence I have not been unsettled in the radical way that Emily expresses.

The longer I volunteered for my organisation, the more my understanding of bodies and vulnerability began to shift. I remember one particularly intense moment where I was utterly unsettled in my understanding of what it meant to be a woman. I was sitting in our office, talking with Emily about her victimisation of a recent sexual assault. She turned her whole body to face me, spreading out her arms, palms facing up, as she remarked: "it'll probably happen again, it is what being a woman $i s^{\prime \prime}$. For Emily, her identity as a woman was dependent on the actions of others which limited her corporeal autonomy and, she felt, constructed her body as inevitably vulnerable to violence. Central to much of Butler's work around the body's place in social justice, is the claim that some bodies are made to be more precariously vulnerable to violence in a way that (in part) constitutes their identities (Butler, 1997, 2006b). Emily is pushing this theoretical claim to its far limits by suggesting that the identity of woman is collapsible into a state of vulnerability. Ultimately, Emily claims that to be 'woman' is to be vulnerable to physical and sexual violence.

Evelyn has a remarkably quiet voice. I'm always surprised that whenever she speaks, she doesn't do so with more force. We are having coffee after work, sitting in the back corner of our local restaurant, and Evelyn is telling me why she had to take so much time off working in our organisation in the last two years. She holds out her light brown, rounded forearm to me for examination. It is marked with a long, thick, white scar. The scar was caused by snapping the bone through her skin as she aggressively defended herself when her ex-partner tried to kill her about a year ago. She is calm as she tells me: "I think I've done alright considering they thought that I would never get the use in my hand back. I've had to relearn 
to use it, relearn to write, relearn to feed myself with it. It's still swollen now, a year later." Four months off work, and another three months part-time, she finds it hard to catch up on the work she missed. But still, she reflects in her quiet voice, she feels okay when she remembers what the doctor said to her: "don't underestimate the damage that you did. You are very lucky to still have a hand".

My thoughts are preoccupied today and I walk home with my arms tightly folded across my chest. I always seem to do this whenever work has been particularly confusing or stressful. I must look the grim and grave figure; eyebrows furrowed and legs swiftly dodging people. All of a sudden, a figure comes out of the edge of my vision and jumps up onto the pavement next to me. I panic. I half jump sideways, as if to avoid being tackled by this man. My arms instinctively stretch out as if to push him away. He moves in front of me, probably not even registering my movement. I shake my head, as if I'm being ridiculous. Refolding my arms, I cross the street, just as the man walks around the corner and out of my life.

Evelyn, in particular, helped me to unsettle my normative distinctions between who I perceived as a victim of violence and who was not, and thereby to understand the formulation of women as vulnerable bodies. During one of our interviews about identity in the workplace, Evelyn and I had a long conversation about her experience as a simultaneous victim of domestic violence and worker in domestic violence. As noted, the literature tends to assume that DV workers do not perceive themselves as victims of violence, and even when these distinctions are blurred (Goldblatt et al., 2009; Seymour, 2009), they are rarely collapsed. At the intersection of DV work and identity, however, my colleagues appeared to be marked by a deep feeling of corporeal precarity that unsettled the boundaries between 'victim' and 'nonvictim' in radical ways. Evelyn is a clear example, being subjected to physical violence by an intimate partner while working in domestic violence. My colleagues generally, however, appeared to take it for granted that all women were victims of systematic violence (albeit to differing degrees) that attempted to control and subjugate their bodies in private as well as in public. The stories of victimisation my colleagues shared with one another prompted outrage at the mistreatment of women, but never surprise of victimisation. All women were positioned by my colleagues as vulnerable to victimisation of violence, inclusive of DV workers. 
The second vignette I offer describes an instance which, in reflection, I see myself in the uneven process of unsettling my distinctions between victim and non-victim. My initial comfort in the notion that I was somehow distinct from victims of violence was radically unsettled in the moment when I recognise my gendered body as vulnerable to violence. Reflecting on moments such as the one exemplified in my vignette helped me to understand that for my colleagues, understanding women as vulnerable bodies embedded in systems of violence was essential for recognising and thereby protecting one another as women. For Evelyn, she took the claims about bodies as vulnerability further than the rest of her colleagues. She argued that men were just as precarious to violence - albeit differing forms of violence - as women. Therefore, she claimed, we should recognise our collective vulnerability embedded in systems of violence and work to dismantle "both ends of the spectrum" i.e. the types of violence that both men and women experience. For most of my colleagues, however, it was only women who were constructed as vulnerable bodies. Recognition of our precarity to this violence is unsettling, but, as Evelyn highlighted, can help dismantle normative distinctions between victim and non-victim that engenders a responsibility to protect one another.

I am at our regular Sunday family dinner; a tradition since my siblings and I moved out of home. My family is all gathered around our large dining room table; every seat is occupied. My father sits opposite me at the far end of the table, my sister's partner and my sister on my right, my brother and my mother on the left. We are laughing about something, although I don't know what exactly. In all honesty, I am rather preoccupied with the piece of cake that my mother has placed in front of me. A bowl of fruit sits in the middle of the table and my brother reaches to grabs something to add to his dessert. I turn and laugh at something that my father says. Out of the corner of my eye I see my brother pick up his knife and I choke on my heart. I am frozen in panic. For a painful, paralysing moment I'm convinced that he is going to stab me. I can see the sharp point of the knife glint and I jerk away so quickly I almost upset my glass. No one seems to notice this movement, and my heart beat slows again. My brother slices his fruit in half. A moment later everyone, except me, laughs at something my mother says, all around the table.

The table in Jen's office is large and solid. The three of us - Jen, Emily, and me - only seem to occupy a very small space at the end of the table; a long, unoccupied expanse stretching 
before us. We're talking about the results of recent research we did about perpetrators who abuse women by precluding access to their money. It's all about control, we concluded. It is no wonder that some women attack their abusers. Emily asks us if we heard the story about the woman who after 20 years of horrific abuse, snuck into her husband's room one night and stabbed him with a knife in the chest over thirty times. The woman had been kept under lock and key, Emily explained. In the court system, she couldn't claim self-defence because the abuser hadn't been attacking her at that moment. But, Emily said "when you're in a constant state of hyper-anxiety, you always feel like you've been attacked". Jen followed up with a story of another woman who threatened her abuser with a knife. He impaled himself upon it - "as you do" Jen adds sarcastically. She was arrested for assault. The table stretches before us.

Repeat exposure to gendered violence is unsettling for women working in DV, particularly when they position this violence in relation to powerful social norms that systematically devalue women. Frequently, my colleagues understood themselves as vulnerable bodies. There was no professional/personal 'split'. As women, they were always victims of violence as well as domestic violence workers. My colleagues recognised themselves as constituted as women through the same norms of gendered violence that marked their clients' lives. The formulation of women as vulnerable bodies offered by my colleagues provoked a recognition that helps us to understand our indebtedness to one another, rather than an apprehension of violence which maintained the boundaries of separation (Butler, 2006b, 2011a). Over my time working in domestic violence, I felt how I too came to collapse the professional/personal distinction and (at least temporarily) understand my identity as a woman constituted through vulnerability. These final two vignettes respectively tell the story of one moment where I felt deeply my bodily vulnerability and a moment where I felt the political potential of understanding women as vulnerable bodies.

The vignette with my family highlights a moment where I felt the full force of my bodily vulnerability. The gathering of my family was, at least at the outset of the evening, an easy reproduction of embedded norms of my safety as a sister and daughter. The intense shock of the realisation of my bodily vulnerability to my brother made the dependency of my safety on the norms protecting my gendered identity as a sister suddenly clear to me. Reflecting on this moment, I felt that I had understood the formulation of women as vulnerable bodies. My identity as a woman had been radically unsettled and for the first time I felt the acute force of the possibilities of violence in a domestic setting normatively constructed as a 'safe space'. 
That the feeling of security could be so easily undone, illuminated the social conditions on which I was dependent and the precarity of my position. I felt my self connected to the bodies of other women precarious to violence in domestic settings.

The formulation of women as vulnerable bodies seemed both an attempt to come to terms with the impacts of repeat exposure to violence on identity, and a political position that attempted to catalyse a recognition of the vulnerability of women to domestic violence. Importantly, through the formulation of women as vulnerable bodies, my colleagues understood themselves as making claims on behalf of one another through a sense of shared vulnerability. Butler's sociality of ontology is again useful here for understanding that "the body does not belong to itself and it never can" (Butler, 2011c, p. 385). In her work she outlines that we are constituted through similar discourses and embodied experiences (Butler, 2011c), dependent on each other for recognition and for physical survival (Butler, 2006b), and any claim we make on behalf of our own bodies also resonates with claims for other bodies (Butler, 2011a). Recognising that our bodies are interdependent in a precariousness to violence "binds us to those whom we may well not know, and whom we have never chosen" (Butler, 2011c, p. 384). Formulating women as vulnerable bodies appeared to be an attempt to find 'common ground' from which to make claims for ending gendered violence.

The vignette in which I am sitting at an empty table with Jen and Emily, highlights how we are bound to those we do not know through a sense of shared vulnerability to violence. In this final vignette I'm no longer making clear distinctions between victim and non-victim, and helper and victim. Instead, in this moment alongside Jen and Emily, I was understanding all women as vulnerable to violence. In fact, the stories of the women are centred around the object of a knife which is imbued with the possibilities of violence; just as my story was. Although we do not share an embodied experience (and I am not claiming that I understand their experiences of physical violence) I can understand the embodied experience of the possibilities of violence. Around the table Jen, Emily, and I make claims for the need to protect women from physical and institutional violence on the basis of a shared sense of vulnerability; that women are vulnerable bodies.

That to be woman is to be a vulnerable body can be a problematic formulation. It could be taken to propose a deterministic chain which posits that the norms which unevenly distribute corporeal vulnerability are concrete and indiscriminate. Although the proposition could be taken to be problematic, I argue that this formulation has relevance in the specific area of 
domestic violence work and has useful effects. There are two important points we can take from understanding women as vulnerable bodies in the context of domestic violence. Firstly, domestic violence can radically unsettle gendered identities of DV workers, to the point where women can feel too disempowered to effectively respond to gendered violence. Women as vulnerable bodies underscores the need to address how gendered identities are constructed at the intersection of DV work. Secondly, the distinctions between victim and non-victim can be usefully collapsed to break down our normative expectations of who is perceived as a victim of violence. Breaking down victim/non-victim distinctions can aid us in recognising that violence perpetrated against other bodies also impacts us, and that we have an interdependent responsibility for those bodies.

\section{Gendered bodies at the intersection of DV work: Catalysing change for vulnerable bodies}

At the outset of Part III, I highlighted that the interdisciplinary literature which has looked at DV work and identity has demonstrated that gender identity is unsettled as workers come into contact with gendered violence. This literature is, however, limited in its exploration of how taken for granted identities such as (heterosexual) woman are constructed. Consequently, understanding how gendered identities are important for catalysing change is constrained. In Part III, I offered three different ways in which gendered identities were constructed through the body in domestic violence work. I considered how the construction of gendered identities had implications for staff wellbeing, and also had wider implications for who DV workers perceive as their clients. In this final section I offer some conclusions focusing on my central claim: that celebrating, examining, and remaking our gendered identities related to the body is fundamental to work with domestic violence, and the possibilities of the reduction of gendered violence. I draw together some of the key claims from each of the sections and reflect on the value of Butler's conceptualisation of the body for understanding the experiences of domestic violence workers.

To begin, I share one final vignette to illustrate the implications of understanding the construction of the gendered body for staff perceptions of who 'counts' as a client:

A couple of months into my ethnography I was invited to join a training session, designed to introduce new staff to the work of the organisation. Our training was run by two frontline workers - one young Samoan, heterosexual woman, Sefina, and one older Māori, lesbian 
woman, Jules. Emily, Diane, Esther, Hamish and me from our office, and Helen and Lucy from a nearby university, were participating. We all gathered together in a small room, sitting around in a semi-circle on couches. Sefina is one of the warmest women I've ever met. She has a comforting way of bobbing her head gently forward and saying 'totally' that makes you feel like she really understands everything that you've been through. Jules is an utter contrast; emitting a tough, down-to-earth persona, bursting with dark humour.

We are sharing stories about clients and thinking about matters related to gender. Sefina and Jules use a 'gingerbread person' ${ }^{\prime 6}$ to illustrate some of the different ways in which we might think about the construction of our gender identities. Categories of composition of gender identity included biological sex (from male-intersex-female), gender identity (woman-man), gender expression (feminine - masculine), sexual orientation (hetero-bi-homosexuality), and romantic orientation (women - men). These are depicted as incremental continuums.

Although it is a useful teaching tool and helps us to understand gender is complex, Sefina acknowledges the difficulties with these binary ways of thinking. To illustrate what she means she tells us a story.

She tells us about a client who had come to our organisation looking for help. Sefina was the client's social worker and suggested that the client would really benefit from participating in a 'women's programme' that the organisation runs to empower clients to celebrate their identities as women. The client looked quite uncomfortable and suggested that perhaps that this programme wouldn't be the right fit. Sefina was adamant, explaining that it was a really wonderful experience, and the client would get to sit with a group of other women to talk through her experiences. Clearly still hesitant, this client admitted to Sefina that they didn't identify as a 'woman' but as gender queer. Sefina wasn't sure how to act. She was partly confused because this client had come to an organisation that explicitly defined by its 'woman-ness' in the first place. But something in Sefina told her that it didn't matter that she didn't identify with the category of 'woman', and that this programme still was right for the client.

Sefina turned to the group and asked us what we thought. Emily immediately had an answer. She explained how in her previous line of work they had accepted anyone as a client who “currently or previously identified as a woman". Basically, this excluded only those who

\footnotetext{
${ }^{16}$ The 'gingerbread person' model is a popular model designed to introduce people to concepts about socially constructed gender. Killermann (2018) is a popular resource which discusses the model.
} 
considered themselves men and had always identified as a man. The important defining feature of a client of our organisation, the group agreed, was the experience of oppression and vulnerability. Labels and definitions were important, but they weren't the fundamental factors for deciding who should be included in the service. The idea was strongly received in the room. My colleagues were keen on the idea, particularly as it opened up the possibilities for non-binary people to have legitimacy in accessing our services.

Throughout Part III, I have argued that gendered identities become unsettled when working with gendered violence. Although becoming unsettled can have negative impacts on the wellbeing of DV workers (Seymour, 2009), remaking our identities is also important for change. Importantly, unsettling our understanding of gendered identities is essential for remaking who domestic violence workers consider to be a credible victim of violence worthy of institutional protection (Jeanes, 2007). Examining our gendered identities, as Sefina encourages us to do here, involves a challenging of our normative assumptions of who we perceived to be clients of our organisation. That 'women' are the clients of our organisation is challenged for Sefina by the gender queer client. Her claim that we should still provide assistance to this client is significant. When our institutional networks fail to care for and protect certain lives, we can lose them; both materially and discursively (Butler, 2017). As a potential solution Emily draws on the perspective that women are 'vulnerable bodies' to argue for who she perceives as the client of our organisation.

The story of Sefina and the gender queer client draws together the key concern of Part III: that how we construct our gendered identities through the body has significance for both DV workers' wellbeing and for those who they perceive as legitimate clients of the organisation. Sefina highlights in her story that the organisation has a particular concern with ensuring the celebration of women's identities as women; particularly as gendered identities are unsettled when they come into contact with DV. Assuming a mimetic relationship between 'female' sex and 'woman' gender identity, is problematic, as Sefina draws attention to in her story about the gender queer client. Unsettling the normative formulation of sex / gender / heterosexuality, I have argued, is essential to recognising that vulnerability to violence manifests unevenly, and that some bodies experience different types of violence can help to counter unevenly distributed precarity. At the end of Sefina's story, Emily draws attention to the formulation of women as vulnerable bodies. For my colleagues, recognising a shared bodily vulnerability and dependency on the other was important for dismantling 'victim' / 'non-victim' distinctions. 
I have drawn on various aspects of Judith Butler's work related to her conceptualisation how gender identities are constituted. Butler's early work (Butler, 1997, 2004, 2006a) provides a robust account of how bodies are gendered. Her careful conceptualisation of the sociality of ontology forms a strong basis for understanding how some bodies are produced as 'nonnormative' and thereby made more precarious to violence. In the context of feminist DV work which argues that domestic violence is related to the devaluation of women, Butler's work is well-positioned to provide an analysis of gendered identities of DV workers. Butler's more recent work (Butler, 2006b, 2011a, 2011b, 2011c) pulls together an account of how bodies are interdependent and share vulnerabilities, which can help us to theorise the importance of remaking gendered identities for ending gendered violence. In drawing on Butler's conceptualisation of vulnerability, I argued that my colleagues were both advocating for protection of marginalised identities from violence, and also that they were attempting to foster conditions to be recognised by others.

At the intersection of domestic violence work, gendered identities are unsettled. In Part III, I have proposed that we can productively understand how gendered identities are understood at the intersection of domestic violence work through the body. Celebrating and remaking our gendered identities in relation to the body, I have argued, is essential to change related to gendered violence. Through my own experience, I reflected on how my gendered identities were unsettled in ways that challenged my own distinctions between victim/non-victim and client/helper. The ways in which my own gendered identities were unsettled helped me to appreciate what I had learnt from my colleagues about the centricity of gendered identities and vulnerabilities to connecting with victims of violence. In attempting to catalyse change for all women subjected to violence, understanding how the body both constrains and opens up possibilities of recognition, celebration, and exclusion is essential. 


\section{Part IV: A Multiplicity OF}

\section{FEMINISMS}


It took me a long time to comprehend the sheer force of will and bravery it took my colleagues to stake a claim to a feminist identity in our organisation. Feminism was a dimension of the organisation that I had taken for granted as an integral and celebrated aspect of our work in my early weeks volunteering. Like many domestic and sexual violence associations that grew out of the women's liberation movements in Aotearoa New Zealand in the 1960s and 70s, my organisation was founded on a second wave feminist approach to gendered violence (Connolly, 2004; Else, 1993). This history was still influential, and our organisation continued to express a commitment to feminism in their practices as well as in writing. The organisation was also understood to be feminist by our communities and other community sector organisations. As my voluntary work brought me into contact with a wider range of stakeholders, however, I became increasingly aware of the complexities of identifying as feminist in the context of the community sector. There was the possibility of having our charitable status revoked (M. Elliott, 2016) and the fear of losing government funding for claiming a political status or agenda (S. Grey \& Sedgwick, 2013b). Additionally, my colleagues told me stories of other people and organisations not wanting to associate with us on the basis of our political commitments. For example, a private sector organisation refused to work with us as we were "those bloody feminists" and we received regular backlash online for our feminist stance.

At the same time as I was becoming more aware of the complexities of feminism at various intersections of the community sector, I was engaged in interviews with some of my colleagues. In all the interviews my colleagues shared stories with me about their feminist identities. I was struck by the diversity of their understandings of feminism and the difficulties they expressed in being recognised by their colleagues as feminist. Within the organisation, as well as at the intersections with stakeholders, it appeared that being a feminist was permeated by complexity. As I got to know my colleagues more intimately I recognised, as Kenny (2010) did in her study of a community organisation, that struggle over presumed shared organisational politics was a prominent feature of everyday organisational life. In fact, my colleagues frequently disagreed over their different understandings of what it meant to be a feminist. Jen, for example, conflicted with Esther over their different perspectives of feminism. Jen described herself as a liberal feminist ${ }^{17}$ who worked within systems for change, whereas Esther's feminist politics were embedded in stories of sex-

\footnotetext{
${ }^{17}$ Liberal feminism emphasises women's ability to achieve equality through their choices and actions. See Kensinger (1997) for a discussion of the importance of liberal feminism to early feminist theory and an examination of the politics of a liberal feminist approach.
} 
positive feminism ${ }^{18}$, and radical emancipation from patriarchal ${ }^{19}$ values. The conflict around the variances within feminism is not new. In fact, many feminist scholars have argued that feminism cannot be understood as a singular emancipatory project, but only as an (occasionally) overlapping, evolving, and diverse collection of voices and politics that ultimately aim for equality between genders (Beasley, 1999; George \& Stith, 2014; Kensinger, 1997). The claim about the diversity of feminist voices resonated with me in my reflections on my interviews and in my daily observations: I heard accounts of a multiplicity of feminisms.

Nonetheless, most of my colleagues remained adamant that feminism (in whatever form it took) was both important to their sense of self and fundamental to their social justice efforts as an organisation. Such views are reiterated in parts of the domestic violence (DV) literature which argues that a feminist approach to DV is crucial for achieving social change that will stop gendered violence (Ali \& Naylor, 2013; Hughes, 2017; Nichols, 2014; Pence \& Paymar, 1993). Even with the disagreement over feminisms there remained a sense among my colleagues of a shared responsibility for the lives of abused women and an imperative to catalyse social change to end gendered violence. Rather than asking how we could unite ourselves under a common understanding of feminism, however, my colleagues were more interested in understanding how we could organise through the multiplicity of feminisms to achieve change for abused women. Undeniably there was conflict and contestation between my colleagues over what was 'feminist' and what was not, but there was also a desire for solidarity and celebration of different understandings of feminism. In the context of the community sector my colleagues recognised that there were added complexities in organising for and with feminist solidarity. Which feminist identities were understood as legitimate or beneficial shifted and changed as my colleagues came into contact with multiple stakeholders.

My colleagues' desire for feminist solidarity forms the basis of my exploration in Part IV. In this part, I focus on the relationships between feminist identities and change in the context of

\footnotetext{
${ }^{18}$ Sex-positive feminism emphasises women's freedom to expand sexual diversity and expression, and liberate women from oppressive practices which limit sexual freedoms. See Fahs (2014) for an overview of sex-positive politics.

19 The patriarchy is a controversial concept. The term usually refers to "the systemic and/or systematic organisation of male supremacy and female subordination" (Beasley, 1999, p. 55). Most often the term was used in our organisation to refer to the social practices that ensure male and/or masculine dominance over women and/or the feminine. Sometimes the patriarchy was used to describe unconscious processes, but often it referred to material processes of domination- such as domestic violence.
} 
the community sector. In the following section, I discuss the organisational literature that considers the relationships between social justice identities (such as feminist identities) and change in different organisational contexts. Although this literature provides solid foundations for reasoning that social justice identities are important to achieving change, there has been little investigation of the intricacies of social justice identities in community sector contexts. In response to the limitations of this literature, I develop a framework for exploring the relationships between feminist identities and change embedded in the community sector context. Throughout Part IV, I am guided by several questions derived from my interest organising through a multiplicity of feminisms: How can community sector workers negotiate their identities at multiple intersections in community sector work in ways that maintain social justice identity? How does struggle over 'shared' organisational politics shape social justice identity? And how can telling stories of feminist identity promote solidarity in the context of social justice work?

\section{Social justice identities and change in the organisational literature}

In the organisational literature, studies of the relationships between social justice identities and change often take place in contexts where there is an overt division between social justice and organisational identities of change agents. Creed, DeJordy, and Lok (2010), for example, explore how LBGT+ priests negotiate the contradictions between their LGBT+ identities and their institutional role in the church, and Wright et al. (2012) explore how environmentalist change agents in corporate contexts struggle to make organisational and environmentalist identities coherent. In a similar vein, studies of social justice identities in academic contexts such as those by Meyerson and Scully (1995), Parsons and Priola (2013), and Murgia and Poggio (2009), argue that social justice identities and organisational identities need to be brought in line to promote change. The achievement of change is usually framed through resistance to organisational practices or managerial ideologies (Swan \& Fox, 2010). Nevertheless, there is generally a recognition that organisational subjectivities are not necessarily contradictory to change initiatives. Organisational subjectivities can be understood as important to identities, and even positively in sync with social justice change initiatives (Maclean et al., 2015; Swan \& Fox, 2010). In general, studies of identities in context where there is an overt division between social justice and organisational identities 
propose that in order to achieve change there needs to be more alignment between the organisational and the political within the organisation.

By contrast, in the community sector context social justice identities and organisational identities are generally considered to be aligned (e.g., King, 2017; Maclean et al., 2015; M. L. Sanders \& McClellan, 2014). The constraints on achieving change through social justice identities are usually positioned as external to community organisations i.e. are constrained by ideologies like neo-liberalism or the demands of external stakeholders (M. L. Sanders, 2015; M. L. Sanders \& McClellan, 2014). In the context of feminist domestic violence organisations specifically, there is usually assumed to be no division between feminist and organisational identities (e.g., Hughes, 2017; Reinelt, 1994; Rodriguez, 1988). As well as feminist and organisational identities being coherent, there is often the unexplored belief that there is a stable organisational feminist politics with which organisational members align. The coherence is considered to be beneficial for victims of domestic violence and the potential for change to be catalysed is increased (Nichols, 2011, 2014). The constraints on achieving change are also positioned as external to the organisation (Nichols, 2014; Reinelt, 1994), echoing sentiments in the community sector literature. In light of these claims, research in the community sector context makes a robust case that unpacking the relationships between the social environment and social justice identities is central to understanding the constraints of social justice identities for catalysing change in organisational contexts.

Assuming both a coherent organisational politics or uncomplicated alignment of members with those politics is, however, problematic. As Kenny (2010) demonstrated in her study of social justice identities in a community organisation, even when there is assumed alignment of social justice identities there is still a continual struggle over 'shared politics' in daily organisational life. Furthermore, Kenny argues that individual identities are constrained and policed by people within the organisation, not just those external to it. In a similar vein, Dempsey (2009) also argues that although political divergences and constraints on identities are often positioned as external to community organisations, there are also political divergences within community organisations. She highlights that identities of members of community organisations are both constrained by their multiple accountabilities to diverse stakeholders as well as by localised organisational norms and practices. When exploring the possibilities of change related to social justice identities in community contexts it would therefore be problematic to assume that all constraints to catalysing change come external to 
the organisation. Even when organisational identities are intimately interwoven with social justice identities, struggle over fostering a 'shared politics' occurs at multiple intersections.

Ultimately, the literature on social justice identities and change has emphasised that social justice identities are important for catalysing change. This literature has, however, focused substantially less on the relationships between social justice identities and change in the community sector context where it is assumed that social justice and organisational identities are already in greater alignment. A few studies have recognised, nevertheless, that the struggle over seemingly shared organisational politics in community sector contexts must be taken into account as well as the influence of external stakeholders and communities. In the case of feminist identities in DV organisations, research has not sufficiently interrogated the fluidity and fracture of feminist identity; an omission particularly significant in light of the arguments in the feminist literature about the multiplicity of feminist politics. Part IV thereby offers two central contributions to the social justice identities and change literature: drawing out the complexities of feminist identities in the community sector context at intersections of the individual, organisational, and social; and expanding our understanding of how feminist solidarity can be achieved when organising against gendered violence.

\section{A micro-political approach to identities in the community context}

Given the complexity of the intersections between individual identity, the organisation, and the community sector context, I decided to approach my colleagues' feminist identities from a theoretical perspective that allowed for a varied and detailed analysis of the nuances of identities and change: the micro-politics of identity. As R. Thomas and Davies (2005a) explain, a micro-politics of identity focuses on "the small-scale changes that can have incremental effects, and that can make differences to how women live their lives, and live with themselves" (p. 120). Rather than thinking about change in terms of a "meta-narrative of emancipation' - which can be overwhelming and unhelpful - a micro-politics of identities alternatively involves emphasising the struggles and tensions played out in individual identity texts (R. Thomas \& Davies, 2005a). The micro-politics of identity is extremely useful for understanding change in complex contexts as it provides a model that accounts for the different shades of engagement with organisational practices and norms (Wright et al., 2012), the generative and proactive possibilities of identities (Parsons \& Priola, 2013), and the variegated ways in which organisational members can catalyse change or inadvertently 
reinforce regimes of control (Swan \& Fox, 2010). Overall, it provides a frame to explore how individual identity texts open up spaces that enable alternative subjectivities and meanings to form within organisational contexts, thereby catalysing change.

Typically, the micro-politics of identity has been applied in contexts where there is an overt division between social justice identities and organisational identities. For example, Wright et al. (2012) look at the micro-politics of environmentalist identities in corporate contexts, and Parsons and Priola (2013) look at feminist identities in a hierarchical and masculine academic environment. The aim of scholars who use a micro-politics approach to change is to destabilise and weaken forms of domination, with a long term view of opening up spaces for challenging and changing oppressive practices and subjectivities (Davies \& Thomas, 2004; Parsons \& Priola, 2013; R. Thomas \& Davies, 2005a). In applying a micro-politics of identity in the community sector context I aim to offer a novel understanding of how a micro-political approach might contribute to our understanding of the relationships between social justice identities and change in contexts of assumed organisational/political alignment.

As I noted earlier, a micro-political approach to identities typically applies these ideas to specific individual identity texts ( $R$. Thomas \& Davies, 2005a). In our organisation, there was a distinctive cultural practice of storytelling about feminism. We would share stories with each other that interwove the personal and the political and connect these stories to the project of feminism. For example, Kimberley would tell us how at university she was told that women were 'too irrational' to work in finance, and Esther would tell us how becoming a sex worker had helped her to understand the power and worth of her sexuality. As well as the cultural practice of telling stories about our personal and political beliefs, there were organisational practices that compelled us to tell stories about our identities as feminist. The mandatory introductory training, for example, involved a half-day session on feminism and its importance to domestic violence work, during which we were directly asked to give an account of ourselves as feminist. We were asked to share personal stories of our experiences of being a woman, and then were asked to consider these personal stories in relation to feminism. In my exploration of the micro-politics of feminist identities, I therefore focus on the micro-politics of my colleagues' narratives that construct feminist identities.

As well as being a significant cultural practice in my organisation, constructing narrative identity texts has been argued by scholars as effective for catalysing change in organisational contexts. The construction of narrative identities has been claimed to be effective for: 
stimulating personal transformation (Maclean et al., 2015), mobilising alternative ways of being (Murgia \& Poggio, 2009), raising awareness of alternative ways of acting (Parsons \& Priola, 2013), loosening our attachments to fixed identities (Riach et al., 2016), developing new meanings (Lapointe, 2013), and for giving voice to marginalised people (Gherardi \& Poggio, 2007). In Part IV, I am following Riach et al. (2016) in drawing from Judith Butler's (2005) understanding of narrative identities. Butler's understanding of narrative is framed within the particular context of giving an account of oneself (Butler, 2001, 2005). From her perspective, narrative is not just telling a story about our selves, but a response to requests or allegations which ask us to account for our identities. Significantly, giving an account of oneself is related to the desire for recognition and persuasion that one is a viable subject:

Giving an account thus takes a narrative form, which not only depends upon the ability to relay a set of sequential events with plausible transitions but also draws upon narrative voice and authority, being directed toward an audience with the aim of persuasion (Butler, 2005, p. 12).

Riach et al. (2016) argue that Butler's approach to narrative is important within organisations as "we seek recognition of ourselves within and through organisations, as viable subjects able to 'give an account of ourselves"” (p. 2077). Notably, Riach et al. (2016) argue that giving an account of oneself is particularly relevant for understanding one's relation with social and organisational power relations, and thus can help to develop political approaches that "seek to change the conditions of becoming within and through organisations" (p. 2085). My colleagues were frequently asked to give an account of their identities, conspicuously in relation to feminist identity. Drawing on 'giving an account of oneself' is therefore pertinent as I am seeking to explore how narratives are related to changing the conditions of becoming, and how organisational norms shaped my colleagues' feminist identities. Additionally, Butler offers an understanding of how narrative identities can simultaneously challenge and maintain social norms (Butler, 2005). In a community sector context where the aim of my colleagues was not to disrupt the organisation, but to support some norms while questioning others, Butler's perspective on narrative can be especially productive. 


\section{Giving an account of feminist identities}

I begin by (re)telling the narrative accounts of feminist identities my colleagues. As part of my ethnographic fieldwork, I arranged to interview some of my colleagues in order to deeply discuss various questions about identity and change at the heart of my research. I engaged in three sets of interviews with six of my colleagues during which we discussed different aspects of their organisational experiences. The stories I share below include aspects of each of these interviews but primarily recount our conversations in the second interview when I asked my colleagues to give an account of their feminist identities. In sharing these narratives here, I have opted to place these accounts one after another, in order to accentuate the multiple feminist identities constructed by my colleagues. After sharing the narrative identities of my colleagues, I explore three dimensions of their accounts that build on the concepts of the micro-politics of identities and of 'giving an account of oneself'.

\section{Jen}

Jen's involvement with our organisation stretched over nearly 30 years. Throughout her narrative Jen offered multiple, shifting accounts of her feminist identity at different points in her life and at different times of engagement with our organisation. Overall, her narrative emphasised that she saw her feminism as evolving as she gained a deeper understanding of the intricacies of achieving social justice for women. During her study at university, Jen found that she could never could "get a decent, solid feminist theory... at times [she] could be a Marxist feminist. Then a post-structuralist. Then [she] could be liberal ${ }^{20}$." Different pieces of feminism, Jen noted, seemed to capture different aspects of her experience:

I was in women's studies. I was a lesbian. And in those days if you were a lesbian in women's studies [radical feminism] was your politics... [but my understanding evolved]. I was vicious actually [during my university study] in my critique of some feminist theory that I thought did just as much to damage women as it did anything. Feminism has always been like that. I get really annoyed at feminism when they use

\footnotetext{
${ }^{20}$ Jen was particularly cognisant of the debates over the features and values of feminism. Beasley (1999) gives an overview of the different positions 'within' feminism that Jen covers and positions herself as, at various times.
} 
the great big capital letters and talk about *Feminism*. For you just can't do that. You can talk about feminisms. But they are everywhere. They are huge. It goes on forever.

Establishing the fluidity of her feminist identity was essential to Jen's account of her sense of self, particularly as it became significant in her narrative as a foundation for negotiating the complexities of maintaining a feminist identity at various intersections within the community sector.

Jen was involved from the early days of our organisation, when they were a loose collection of volunteers rather than a formalised workforce. Jen frames her feminist identity at this time as coherent with radical feminist politics. She found the organisation to be an open, accepting space that was aligned with this radical feminism. She felt that: "we [the volunteers] were doing something that was really, really good and useful. Like we were on the side of the angels. The real staunch feminist angels nonetheless.” Jen considers that volunteering with the organisation had immensely positive impacts on her feminist identity and that she saw these radical feminist politics as fundamental to achieving social justice for abused women. She was supportive of the way in which frontline work was embedded in a radical feminism and Jen felt that it was "all coming from that basic place that women deserve just as much as men".

After years of participation in frontline work, however, Jen felt the toll from sustained exposure to domestic violence and decided to take a break from working with the organisation. On her return she went into a managerial role instead of working on the frontline. This experience changed her view on the organisation:

We had full-time staff. We had a manager. We had a budget of a quarter of a million dollars a year... the governance members were all employed people who really didn't want to put, and didn't have much time to put, much effort into [the organisation] ... It was a totally different way of looking at things because the organisation was totally different. In some ways, it was much better. It was much safer for the staff and the volunteers.

In Jen's narrative, we can see that when she comes into contact with different aspects of organisational life her account of her identity also shifts. At the interface between the 'backstage' work, rather than frontline work, the relationship between Jen's organisational identity and her feminist identity change. Rather than expressing feelings of being 'useful' or being a 'staunch feminist angel', Jen now positions her organisational identity as a risk aware 
governance member. The orientation of her work shifts from a sole focus on outcomes for abused women, to incorporating the safety of the staff and the longevity of the organisation. In Jen's narrative we can see how she reframes her social justice identity:

I discovered what I had known all along: that our reputation with government was very poor. That was largely a result of an oppositional and stridently aggressive form of politics that we had been engaging in. I made it my mission to make friends with our stakeholders and work towards developing a partnering approach, if you like, with our funders. I figured that our life was going to be quite limited if we didn't do that. I have done that and I think we have a far more respected place with government. However! That has come at an extreme cost in terms of our position within the sector, shall we say.

The 'extreme cost' that Jen notes here, was that she perceived that other members of our organisation and other community sector organisations thought that Jen was a "sell-out" who had "lost [her] ability to speak for women" and was "in the government's pocket". Jen resists this conceptualisation of her identity and is compelled to give an account of her shifting feminist identity. Jen emphasies that tempering her radical politics was not something that she necessarily wanted: "it [working closely with stakeholders] has been compromising in a number of ways because I find myself having to put aside, on occasion, personal politics and convictions in the interest of something that is bigger." She narrates the change in her social justice identity away from the "screaming activist place" by framing it as harmful to sustaining change for women subjected to violence. Instead, she proposes her feminist identity is in line with liberal feminism which seeks incremental change involving taking a "nibble at the hand that feeds you" rather than to "start barking and tear it off".

In her narrative, Jen stresses that she is not completely comfortable in the shift in her feminist identity, noting that it became "very compromised". In fact, there were times during which "the only way [she] can hold on to the notion of being a feminist is that [our organisation] is inherently doing good things for women". In challenging the 'screaming activist' form of feminist identity in the organisation, Jen maintains that: "I am possibly not as much as a oneeyed supporter of the notion that 'all things feminist are good' as I was". She emphasises the necessity of temperance of feminism in order to effectively achieve change in the community sector because "[government] consider the NGO sector to be lesser, to be inferior" and "regardless of what any idealist might like to think, when you are dependent on the public 
purse for your very existence, yelling and screaming is just not going to help with your funding negotiations." In order to negotiate the tensions between the community sector, the government, and her own personal politics, Jen (re)narrates her feminist identity explaining: "I would probably [be] a liberal [feminist] because I work very much within systems to achieve change". Although her challenging of the systematic perpetuation of domestic violence does involve constructing a feminist identity, at the same time Jen also underscores her temperance, so securing her place within the system.

Jen's narrative offers an account of shifting feminist identities at multiple intersections in the context of the community sector. She underlines that at times the most difficult intersection to maintain her feminist identity was within the organisation. Jen is cognisant of the contradictions and complexities of her feminist identity and she negotiates this by emphasising the variance and fluidity of her feminism early in her narrative. In doing so, Jen attempts to make her organisational identity coherent with her feminist identity. For Jen, this is a struggle, particularly when she comes into contact with external stakeholders. For example, with government Jen constructs a liberal feminist identity in order to maintain her feminist identity while ensuring the longevity of the organisation. Jen maintains that this is to the benefit of the organisation: "we do have a politically and philosophically informed place from which we provide services [to abused women and children]" but "we could be more politically active, we could agitate, we could do all of those sorts of things, but to do that we would have to be non-government funded."

\section{Tia}

When I asked Tia if she identified as a feminist she scoffed and replied, "no. Cos feminism is quite a Western concept. Which I am not.” Tia alternatively carved out a social justice identity embedded in her identity as Māori, which was a fundamental way in which she understood her sense of self. She explained to me that all her work reflected her identity as "Mana wāhine [and] wāhine toa ${ }^{21}$." Mana wāhine is often referred to as a form of Māori feminism. Essentially, mana wāhine seeks to make visible the diverse experiences of all Māori women with a distinct focus on stories and lived experiences. Wāhine toa literally translates to 'strong women'. This was a term Tia used to describe herself and her social

\footnotetext{
${ }^{21}$ Māori concepts about women and their power. See Simmonds (2011) for an overview of both the concept 'mana wāhine' and wāhine toa'
} 
justice practices that supported abused women. Tia was aware that other people, especially her colleagues, might try to position her as feminist, telling me:

Like you can probably say, 'yeah, you are a feminist', but no. I don't carry that mantle. [I am] absolutely independent. [I am] not scared to give my opinion if I think it matters. Those are probably all traits that Western concepts say 'yeah that's feminism' but to me, nah, I don't like the term.

Tia embedded her claim to a mana wāhine identity in her broader orientation of her self around her Māori identity. Her identity as Māori was grounded in a sense of her cultural heritage, ancestors, and language. Being Māori was central to Tia's understanding of her identity, telling me: "it's who you are... [being Māori] is right for me. It is my identity." Mana wāhine was understood by Tia to involve ensuring that every woman had a voice, and that different life experiences were taken into account. Additionally, mana wāhine was embedded in a weaving together of personal and political stories, as Tia explained to me:

Everybody is political. I believe everybody is, especially if it impacts on them personally. The personal is political, the political is personal. You form a political opinion based on something that happens to you... You don't have to be talking to a politician. You could be talking to a mate in a café and have different opinions but they are political opinions.

Mana wāhine, independence, and opinions embedded in personal experience were the locus points of Tia's social justice identity.

Tia had, like Jen, worked for the organisation for a long time, but had only moved into backstage work in the last few years. Since the shift, Tia had increasingly struggled to negotiate her mana wāhine identity and the different organisational identity she was expected to occupy. Tia constructed distinctions between frontline work and backstage work in order to understand her organisational identity. Her description of her work on the frontline emphasised its multiplicity and fragmentation:

With [our organisation] you can't just be data input person. Or 'she who does advocacy' because that is just bullshit and it just doesn't exist. You are forever wearing several caps. You can be the toilet cleaner one minute and then sitting at 
WINZ $^{22}$ supporting and advocating another lady in the next hour. It's always changing.

In contrast, backstage work was described by her as straightforward, simple, and managerial. In fact, Tia saw this backstage work as a hiatus from frontline work, emphasising that since moving into backstage work she felt that she was now able to build a sense of self outside of the organisation.

In her work, Tia was acutely conscious of the need to balance the careful examination of your own identity and the women you are working with:

[Training] is like a preparation sort of space where you have to prepare yourself in order to help and work with other people. That means unpacking your shit and having a good look at it, and trying to sort it out. And/or getting the help to help you sort it in order to be in a better space to help other people.

Although Tia loved her work, explaining: "it's a lifestyle eh? It's not a job", she felt that "the whole kaupapa consumes you." The work took a toll on her mana wāhine identity. These are the reasons she offered for making the change from frontline work:

You become [almost unrecognisable], when you are in it for so long. I found myself getting quite cynical. And not feeling. I remember wanting to say to someone [a client] who I was sitting in front of: 'can you just shut up? I can finish your story.

At the intersection between her identity and her work with clients, Tia felt her mana wāhine identity shifting in ways that she didn't resonate with.

Tia moved into backstage work but continued to work closely with frontline staff. Even after coming to work backstage Tia continued to frame her work in a practical way refusing to respond to "fluffy directions" or "bureaucratic bullshit". Tia's described her new role in the organisation for me:

Assisting the [frontline] to develop their services and to be bloody good practitioners, deliver good services, be compliant in whatever fucking standards of practice MSD $^{23}$

\footnotetext{
${ }^{22}$ Work and income New Zealand. They provide employment services and financial assistance.

23 The Ministry of Social Development. They are a primary funder of social services.
} 
and shit they need to do in order for them to do what they want to do: which is working with our whānau [extended family $]^{24}$.

The movement between the different intersections of frontline work with clients and backstage work with external stakeholders resulted in tensions in maintaining coherency in her mana wāhine identity and her organisational identity. Tia knew "from talking with my sisters in [on the frontline] the perception was that [backstage workers were] sitting in [their] little ivory tower watching all [their] little peasants so to speak". The tension caused from her shift from frontline to backstage meant she spent a lot of time:

Trying to debunk those myths. It looks all this and that but it really is not.

Professionally working with the [frontline] they are like 'can we talk to you about this and stuff' and I'm like 'not really... it's sort of above my pay grade', they're like 'tell us what you think anyway', and I'm like 'okay but it isn't [professional Tia]' telling you. If you want my own personal opinion, then I am happy to give it to you.

For her "it is keeping really clear boundaries" between the different intersections of her work, and her mana wāhine identity.

\section{Kimberley}

Kimberley's narrative clearly distinguished between two distinct understandings of her identity as feminist. She separated her identity into a 'non-feminist pre-rape' self, and her feminist self after she was raped. Until Kim was raped at university, she told me: "my identity was tied up in some Catholic ideal of purity and that women do certain things." These 'certain things' involved living "in a realm of anxiety and ticking boxes" of "married, babies, houses". Kim positions her self during those years as a naïve non-feminist. After being raped, however, Kim felt she became a feminist. Kimberley explained to me that this shifted her identity:

\footnotetext{
${ }^{24}$ The Māori concept whānau refers to: extended family, family group, a familiar term of address to a number of people. Whānau is the primary economic unit of traditional Māori society. In the modern context, the term is sometimes used to include friends who may not have any kinship ties to other members. It is commonly used by Pākehā as well as Māori.
} 
I think that, unfortunately, I had to become a feminist after I got raped. I think before I wasn't really a feminist, back when I was quite slut-shamed ${ }^{25}$ and I was quite green ${ }^{26}$. Then I got raped and I was like 'fuck. This is a really massive injustice. What the fuck?'. Then, of course, I think dealing with the patriarchal type structure like a university and just their stupid bureaucratic non-process around rape, I was just like this is so unfair!

Kimberley positions being raped as an awakening; a consciousness-raising experience through which she became aware of gender inequality. Recognising and fighting injustice against women became central aspects of Kim's feminist identity. She perceives feminism as based on equality between men and women, on the grounds that "I think that you should value women for the things that make them a woman". Essentially, Kimberley is highlighting that she believes that feminism should work to increase the perceived value of the feminine. Kimberley struggled to maintain a coherent feminist identity, however, as she felt that some of her preferences and life-style choices were frowned upon by other feminists:

I do like Justin Bieber, and I do like Kim Kardashian ${ }^{27}$, and I do listen to Chris Brown ${ }^{28}$ music. I don't consider myself any less of a feminist. Some social justice warriors ${ }^{29}$ would say that I'm not a feminist. I don't like post-wave feminism. What do you mean we are done with it? We are not. [I am] probably more of a third wave feminist. Probably within that realm. Probably intersectionalist ${ }^{30}$. I don't have to be a

\footnotetext{
${ }^{25}$ Being 'slut-shamed' refers to the activity of criticising women for their real or perceived promiscuity. See Attwood (2007) for an overview of the use of the term 'slut' and its relevance to feminism.

${ }^{26}$ Inexperienced, naïve, and lacking a critical awareness of politics.

${ }^{27}$ Kimberley's reference to Kim Kardashian and feminism is a significant one. Kim Kardashian is a controversial figure within feminism (A. Jones, 2014; A. Martin, 2017; Ruekgauer, 2017) but some argue that she is an important figure for promoting feminism as her empowerment status on sexuality and her entrepreneurial attitude to beauty and fashion (Jacobs, 2016). Kimberley uses Kim Kardashian to contrast her earlier position on 'slut-shamming'.

${ }^{28}$ The singer Chris Brown was convicted of domestic violence again his ex-partner Rihanna (Bowes, 2009). The case was particularly high profile, and anti-domestic violence campaigners regularly make use of the case in protests (Ryan, 2015).

${ }^{29}$ Social justice warrior is a colloquial term for a range of positions (often feminist) that are variably claimed to damage social causes by being overly dogmatic in their beliefs about social justice causes (Young, 2016) or be insincere and/or hypocritical (Sarkar, 2016).

${ }^{30}$ Kimberley references several feminist bodies of thought here: post-wave feminism, intersectional feminism, and third wave feminism. Post-wave feminism is used to mark a rejection of feminism on the grounds that success in equality is achieved and now must be maintained. Intersectional feminism refers to feminisms that take the intersection of various oppressions (such as race and gender) as their focus. Third wave feminism is a collection of approaches including the two above, but also refers to the need to not present feminism as monolithic. See Evans (2015) for an overview of third wave feminisms.
} 
social justice warrior. I'm allowed to like things that are inherently 'not feminist' and still be a feminist.

Through her narrative, Kimberley is integrating different aspects of herself in an attempt to make her feminist identity coherent. Kim distances herself from a 'social justice warrior' feminism, invoking a negative stereotype of people who disavow women as feminist on the basis of (what Kim sees as) non-essential attributes. In her arguments against post-wave feminism, Kim also distances people who believe we have no more need for feminist activism. Kimberley attempts to balance what she perceives as the contradictions in her feminist identity of liking things "inherently not feminist" and still wanting to construct her identity through the term. In her doing so, we can see how the construction of a feminist identity can resist some subject positions while being generative of alternative ones.

Kimberley argued that her feminist identity was important to her work in our organisation. Unlike Tia and Jen, Kimberley was fairly new to the organisation. As young Māori woman, Kimberley had only worked for one other organisation before joining ours. Kim often felt out of place within our organisation because she felt she didn't quite fit the expectations placed on her. Particularly, she felt she was viewed by the colleagues who had worked on the frontline as 'too soft for this work'. The tension between Kim's construction of feminism as valuing women for what makes them women (the feminine) and her feeling she was positioned as "too weak" in her work, cause a contradiction in her identity which Kimberley struggled to make coherent.

In her narrative, Kim was often critical about what she understood as discriminatory practices against women in the organisation. She explained to me that "for an organisation that is trying to free women and children from violence they have a really great way of controlling, [which is] almost violent." At times she has:

Just been finding work ruthless. It's been ruthless. So ruthless... it is patternistic. It comes in waves... it does feel a bit like you are waiting for a beating or something, you know, from an abusive partner. You can sense it in the waters. I have to keep reminding myself that it is nothing I'm doing. They can't be stopped. I always just relate it to an abusive relationship. There is no understanding it.

Kimberley comments that this has impacted her understanding of feminism: "one thing it has taught me actually is that the patriarchy can be within women... just because I work for an all-female organisation doesn't mean that it is not discriminatory against women". Kimberley 
is referring to the ways in which she understands the organisation as exploiting the emotional labour of their workers, valuing and promoting masculinity over femininity in their workers, and the lateral violence between women. She uses her own construction of a feminist identity as focused on patriarchal structures to critique and challenge organisational practices and open up feminist subjectivities for herself in the workplace.

In response to the patriarchal type of violence Kim perceived as embedded in the workplace, she drew on her feminist identity to advocate for change. She told me: "I try very hard to build up other women, particularly [the frontline workers]. I try to be very positive with them, I try to highlight their strong points... I try and allow for equal opportunities for everyone." Additionally, Kim retained a focus on dismantling patriarchal structures, but directed her gaze internally. She explained to me that in all her work:

I also keep in the back of my mind that the patriarchy is everywhere. It isn't just men... Like when I was [at university], so many girls were like 'I want to work for an all-female organisation'. You all think it is going to [be great]. Doesn't matter. The patriarchy is there.

\section{Ava}

Ava had worked backstage in the organisation as her first permanent job in New Zealand after her immigration from another country in the later stages of her life. She had worked for our organisation for a number of years, through some substantial changes to the operation of the organisation. Overall, Ava felt her work had opened her eyes to the realities of domestic violence against women and also had expanded her awareness of "different personalities" and ways of being a woman: "I've been exposed to a very liberal society here, that was very different from a very Calvinistic, narrow-minded, restricted environment in [my country of origin]. I love it."

When I asked Ava if she identified with the term feminist, however, she didn't provide a definitive answer instead replying: "I have become more aware of feminism as a way of viewing the world and being." As Ava began to unpack her statement, her narrative developed a conflicted position between different aspects of her identity as a wife and mother, and her construction of feminism. Ava explained her introduction to feminism in her childhood: 
It was very much that my mother wore the trousers in the house always. I always looked at my father and thought why don't you stand up to her? ... That was my model of the world. [My mother] was more feminist than I actually gave her credit for. A lot of that rubbed off on me. I feel strongly that I don't need a man to survive in this world. But I do like having a man in my life.

Importantly, Ava's text positions feminism and being a feminist relative to a women's position on the role of men within her life, and within the family unit. In Ava's description, feminism is linked to dominance or assertiveness, and the capabilities to be successful in life without the support of men. Ava described women as being "more passive... in their relationships, or in the home through their father." From the perspective that feminism is related to assertiveness and independence Ava explained why she was unwilling to identify with the term:

I'm not a staunch feminist, but I do have some ideas, shall we say, about being a feminist. I do believe that I have a special role in our marriage and I'm happy to fill that. I also believe that he has a role that he needs to fill. I like to feel secure with him. I'm not that much of a feminist.

In the text we see Ava's negotiation of feminist identity as she initially constructs herself as 'within' the category, holding 'ideas' about being a feminist, and finally as outside the boundaries of feminist identity. Again, we can see how Ava attributes feminism to roles within relationships and when she positions herself as having a 'special role' in her marriage as a wife, the role conflicts with the construction of feminism, and consequently Ava positions herself as outside of the boundaries of the category.

Nonetheless, Ava argued that she is "very passionate about what happens to women in the world.” I asked her why she wanted to work with women:

I guess to liberate them... Liberation and empowerment of women. I guess what I saw were those women who get stuck in a rut, who often later in life, or need to make a life change, and then they don't believe in themselves. Empowering them to selfactualise and to be more what they think they are. We all have limiting beliefs around ourselves... Women are no different. More so than men. Men have got huge egos generally and believe a lot more in themselves overall then women do... That is why I wanted to work with women. 
Contrary to most of my other colleagues, Ava did not see the principles of liberation and empowerment as the defining features of feminism. She centres these within her work, but for Ava she still does not want to identify with the term feminist because of the conflict she perceives it as causing with other aspects of her identity. For Ava, a feminist is someone who is completely independent of men and rejects traditional gender roles. As Ava feels comfortable in traditional gender roles, she is unable to reconcile a feminist identity with her roles as a wife and mother.

Although Ava does not construct her identity through her understanding of feminism, she demonstrates an awareness that in order to be a recognisable organisational subject, she must give an account of her relationship and beliefs about women. Once Ava had managed to construct an identity around assisting women - and not feminism - she became more confident and articulate in expressing her politics surrounding women. In her narrative she notes that women have difficulties in being empowered. She interweaves the difficulties of empowerment within her own personal experiences of divorce, reshaping her life by learning to be a life coach and training in self-actualisation, and her 'breaking of the rut' by immigrating to New Zealand later in her life. Ava thus interweaves her life-history narrative and her politics of the liberation and empowerment of women.

Ava's narrative demonstrates an acute awareness that her positioning as non-feminist is a minority position in the organisation. Ava attributes the tensions with colleagues as stemming from a contrast between her positioning as a woman as 'soft' and 'relational' to other (feminist) women in the organisation who are 'dismissive and hard'. Nonetheless, Ava draws on the locus of empowerment and liberation of women to explain her organisational subjectivities and frames her approach to work in similar relational terms:

I'm often the buffer zone. When people find it really tough they talk to me... I see myself as supporting women in our office in that way. It is about them coming in, in an unresourceful state, they can't function, they are crying or whatever. And then they'd tell me that they feel heaps better.

\section{Evelyn}

Evelyn was relatively new to our organisation but had several years of experience volunteering with other domestic violence organisations throughout Aotearoa New Zealand. 
Otherwise, Evelyn had spent most of her working life outside of the community sector and not involved with domestic violence work. Evelyn had recently managed to leave her abusive partner. Being subjected to abuse was one of the primary reasons she had become involved in domestic violence work. The lived-experience of violence formed an important locus for understanding feminist identity.

For Evelyn, the most significant attribute of her identity was that things had to come from "life experience". Her narrative is peppered with references to being "opened up" to "people from different walks of life". Evelyn's narrative follows her perception of her transition from a narrow-minded Christian up-bringing, through exposure to "different backgrounds and lifestyles", to a revised, open-minded perspective embedded in lived experience. Working in domestic violence had also opened up Evelyn's feminist identity: "my political spectrum has changed and my political understanding has changed." Most significantly, her work as a volunteer with domestic violence organisations shifted her perspective on men:

[Working for a different DV NGO alongside men] introduced me to this different scene that I hadn't known before and it kind of re-established my faith in men a bit; that there is change possible. That they can do this, that they can be trustworthy. That with the right kinds of supports, things can happen. They've been living proof of it for me and I still am really passionate about that. I believe that the change in men is going to be a huge part of the societal change that will eventually, and hopefully, see the demise of [our organisation] as we can reach those younger generations coming up and that we can de-glorify the violence towards women.

Evelyn embeds her narrative in her personal experiences, telling me that even in her "personal life" she is "very into equality" and that "I live, breath, eat, shit, and dream about it [domestic violence work]". Evelyn thus weaves together her personal experience and feminist identity. In fact, Evelyn situates the boundaries of 'good work' around lived experiences, telling me that her biggest frustration is with her colleagues who value 'business' skills over people skills. In her working life Evelyn felt her sense of self was at odds with her colleagues: "I definitely see things differently to other people and even with my close teammates we have different filters on things."

Evelyn constructs part of her difference from her colleagues as related to her perspective on feminism, and she sees her approach as a counter-narrative to "some of the man-blaming ways" that she feels other members of the organisation propagate. Importantly, Evelyn 
contends that: "I would like [our organisation] to include the whole family. I think the feminism [approach of our organisation] needs to be equality. Once you exclude a member of the family it just makes everything worse." Evelyn here constructs 'feminism' as a narrative exclusive of men, which violates what she understands as the core tenets of equality; the fundamental attribute of a feminist in her view. In her account of herself as feminist, therefore, Evelyn constructs her feminism as bounded by the notions of balance, voice, and inclusivity:

I identify with feminism being equality. I know there are different perceptions out there about what [feminism] is. To me that is equality. That is why, as a feminist, I am very passionate about men and all the changes the stuff that they have, and the equality issues that they face. It is not just women that face stuff, there is also an opposite spectrum of what men face. The perceptions of what a man has to be, versus how down-trodden women are. There is also a bit of a misbalance, obviously, which is where the equality comes in. I'm just as passionate for both. I know there are two sides to every story and I know that women can be just as violent as men.

Evelyn's narrative conveys that she has increased her efforts to insert men into the story of feminism and position them as partners for achieving social justice for victims of domestic violence. For Evelyn, it was essential that feminists were inclusive of "people who have beaten their own demons, created their own change, sustainable in that change, their families have qualified them. Those are the people we need. Not the ones who fit 'the box"'. However, resisting the narrative of feminism in domestic violence that focuses on women, makes it difficult for her to feel recognised as a feminist in our organisation. Evelyn explained that she was "disenchanted with the attitude from [some of her colleagues]" and, in a similar way to Kimberley, found that the "patriarchal, the hierarchical, the white privilege, the putdowns, [and] the disempowerment" were prevalent in her organisational experience. Nonetheless, Evelyn argued that: "There needs to be way more support for men to be able to change. Way more. That is the biggest gap. Everything that creates a perpetrator needs to be addressed."

\section{Emily}

When Emily was 17 and her sister told her that feminism was important for women in achieving equality, she responded flippantly: "oh for fucks sake, we [women] have equal 
rights and feminism is just [for] hairy legged lesbians". Emily now laughs at her "shit view" of feminism was she describes as having "fully changed" now that she had gone through social worker training and "learnt about power and structural stuff". Once she moved into sexual violence work, and then into domestic violence work she said that she "became really feminist". For Emily this involved "rejecting a lot of expectations that were otherwise placed on me as a woman, but also recognised the tension between others." Recognising the tensions involved taking a structural view of gender equality, as Emily explained that she saw people "as products of their experiences and their upbringing rather than people just making bad decisions".

In narrating her transition, Emily draws a distinction between attributes she considers 'feminist' and those that do not fall within the boundary. For Emily, feminism involves rejecting gendered expectations, recognising structural inequalities, and focusing on the "intersectionality and a sense of sexual orientation and gender orientation", which she contrasts with her "shit view" of individualist perspectives on choices, and ignoring the role of sexual orientation as an important intersection.

Emily had only worked for the organisation for a short time before I started my voluntary work and was primarily working at the intersection between our organisation, government, and other domestic violence agencies. For Emily, the construction of the organisation as feminist was a significant point of difference in her work:

We are a really strong feminist organisation. A lot of DV organisations aren't. Or they say they are but they only really pay lip service to the principles of empowerment; I guess [we recognise that] ... every woman [is] doing the best that they can and not being instrumental in their own victimisation. Whereas other organisations get really, really invested in the woman's role in stopping violence. That is something that we try really hard not to do.

Through Emily's critique of other organisations which pay 'lip-service' to feminism, Emily indicates that she understands feminism as attached to organisational practices. Emily positions our organisation as having practices which acknowledge the fundamental agency of women. Agency and emancipation from oppressive social structures are central to Emily's construction of her feminist identity. Emily weaves the organisation's practices together with her own desires and beliefs: "[I have] passion about not having violence against women... 
Women blaming really, really pisses me off." Emily engages with organisational norms to construct her feminist self by weaving together organisational practices and personal beliefs.

As well as emphasising the value of the organisation as feminist, Emily describes how working for the organisation has shaped her construction of her feminist self:

[Working for our organisation] has made me really aware of aspects of intersectional feminism. Particularly when it comes to things like [the intersection of gender and race] or grassroots activism, that I'm often not involved in. Working here hasn't made me any less feminist, but it has made me aware of the flaws in my feminism.

Emily positions herself as particularly mindful of the flaws in her own conceptualisation of feminism, particularly in regard to her tendency to overlook the intersection of gender and race. She attributes the flaws to the difficulties in deconstructing her lived experience as a Pākehā woman which she sees as privileged in Aotearoa New Zealand. Emily maintains, nonetheless, that her feminist identity also aids in challenging some of the norms around feminism in the organisation:

I think in the sense of sexual and gender orientation, I've been aware of how, even within [our organisation] that really values [diversity], that really hasn't been emphasised as much as it could have been. That has been kind of reductionist in its way of thinking. So, in a way it has made me really aware of the fact that I do hold that really important... and how easy it is to invisibilise that, even within my advocacy with government.

Importantly, Emily draws a link between her own feminist identity and the possibilities of change at the intersection with government. She highlights that the tensions between her feminist identity and organisational norms are significant because: "my voice is the one that goes to parliament. It really needs to be reflecting the needs of our [diverse] clients and workers". Being aware of the strengths of other feminisms is important for Emily at the multiple intersections with external stakeholders.

One particular point of tension within Emily's narrative is the positioning of men within feminism. Emily explains that:

Working with [our organisation] has made me innately suspicious of heterosexual relationships because it [DV] appears so prevalent that it is difficult to imagine any 
relationship not having elements of that now. It is really difficult not to recognise that in my friends' relationships now, and that is a real pain in the arse.

Emily is again weaving together the personal and political noting that her organisational experiences shape her personal relationships and role in those relationships. However, in Emily's narrative there is a dissatisfaction with how her feminist self has been constituted through domestic violence work to be suspicious of men's place within feminism. Emily further narrates her tension:

As a feminist it's difficult because you really want to embrace the perception of men being equal partners and as having the capacity to be amazing partners. At the same time, you are so surrounded and immersed in work where men are the perpetrators of violence. And just casual sexism that you being to notice in men more so than in women, that you begin to treat that with suspicion.

Emily argues that there is an imbalance between men and women. As this underpins the construction of her feminist identity, and simultaneously her construction of the organisations feminist politics, Emily opts to leave open the possibility of men's participation in our work without making it a priority. Nonetheless, Emily maintains:

I would like to change our beliefs around masculinity, first and foremost... Then obviously violence against women would have a nice flow on effect from the erosion of harmful hyper-masculinity and we could reconstruct gender as being a non-binary thing and also without the gender roles associated with it and then we would be really happy and healthy.

\section{Organising for solidarity through a multiplicity of feminisms}

The sheer multiplicity of positions, tensions, debates, concerns, and complexities of my colleagues' accounts of their feminist identities is exemplary the absence of a singular feminism. As well as offering a multiplicity of feminisms, my colleagues' narratives illustrate the complexity of establishing and maintaining a social justice identity in the context of the community sector. Not only were my colleagues grappling with constraints on their feminist identities deriving from their intersection with the government, other funders, and institutions (such as the Police) but they were also negotiating constraints on their feminist identities as part of their interactions with their colleagues. From their accounts, it is evident that the 
almost utopian ideal of feminist organising grappling predominantly with external constraints (D’Enbeau \& Buzzanell, 2013; Nichols, 2011; Reinelt, 1994) overlooks the complexity of organising through a multiplicity of feminisms within feminist organisations. Examining how my colleagues negotiated their feminist identities in their narrative texts is therefore necessary to reflect on how they successfully continued to practice feminist solidarity through a multiplicity of feminisms at various intersections of community sector work.

In the following sections, I draw together some of the elements of my colleagues' accounts of their feminist identities to explore the constraints and possibilities of organising through a multiplicity of feminisms. The remainder of Part IV is structured like a spiral: starting at the widest point of intersection with external stakeholders, narrowing the focus to within the organisation, and finally looking at the narrative texts themselves. I firstly attend to the context of the community sector to unpack how feminist identities shift and change at various intersections between the organisation and the multiple intersections of community sector work. Secondly, I look at the negotiation of 'shared politics' within the organisation and explore how my colleagues used boundary setting to maintain some organisational norms while challenging others. In particular, my colleagues' narratives frequently asked the listener to direct their attention within emancipatory projects. Thirdly, I look specifically at the cultural practices of telling stories about personal and political identities from the perspective of 'giving an account of oneself'. Ultimately, I draw these sections together to discuss what I learnt from my colleagues about organising through a multiplicity of feminisms for feminist solidarity in the context of the community sector.

\section{At the intersection of self and organisation: Competing claims for legitimacy}

A point of considerable tension evident in the narratives of my colleagues was the intersection between the construction of their feminist self, and the multiple accountabilities of our organisation. In community organisations there is considerable pressure to construct an identity, often through narrative, which is considered legitimate at multiple intersections of accountability with external stakeholders (Gilpin \& Miller, 2013; Herrmann, 2011). For example, King (2017) shows that conflicting demands for accountability operate to transform community organisation workers from 'idealistic dreamers' to 'nonprofit professionals' and M. L. Sanders (2015) notes that tensions between pursuing social missions and meeting accountability demands interdependently produce identities of organisational members in 
complex ways. Although some scholars advocate for embracing the tension and finding ways to make it productive (Dey \& Teasdale, 2016; Tomlinson \& Schwabenland, 2010), others share concerns that the conflicting demands make achieving social justice difficult and can damage social causes (Eikenberry, 2009; Reinelt, 1994). My colleagues likewise faced multiple, conflicting demands at the interface between social justice identities and accountabilities to external stakeholders.

The narratives of Jen, Tia, and Emily, in particular, foreground the intersection between their feminist or mana wāhine identity, and the multiple accountabilities that their work for the organisation required them to navigate. Importantly, the construction of feminist identity was tied to the social justice goals of the organisation. Not only did my colleagues have to negotiate multiple accountabilities and conflicting discourses in order to construct a feminist/mana wāhine identity; but they wanted to do so in order to direct the organisation toward the social change which they thought would best support victims of violence. As King (2017) underlines, although conflicting accountabilities can orient identities of members away from social justice practices, a desire to promote social change is always important to constructing personal and organisational identities in social justice organisations. The narratives of my colleagues were shaped and constrained by multiple accountabilities and conflicting discourses, but their negotiation of the tensions always sought to open up the possibilities of social change. Here, I highlight how at various interfaces Jen, Tia, and Emily produced certain feminist identities in order to negotiate the complexities of legitimacy in order to continue to seek social change.

Jen's account of her feminist identity emphasises the incremental changes in her feminist identity; shaped at various interfaces between self and organisation. On the frontline she was a 'staunch feminist', in backstage work she constructed 'multiple feminisms', and at the interface between the organisation and government she was a 'liberal feminist'. Jen constructs each feminist identity in relation to the social justice mission of the organisation. 'Staunch feminist' is positioned in relation to doing 'good work' on the 'side of the angels'; at the interface of government and the organisation a 'liberal feminist' identity is positioned in relation to ensuring the longevity of our organisation and providing clients with 'the best service'. Jen frames her negotiation of her feminist identity in response to the shifting demands of accountability. On the frontline Jen's primary accountability was to her clients, and thus her feminist identity is framed as a response to the needs of the clients. At the interface between the organisation and government, however, Jen's primary accountability 
has shifted to ensuring that the organisation has a good reputation and a sustainable source of funding. At the multiple intersections of the organisation which Jen comes into contact with, she offers small and incremental changes to her feminist identity.

At the heart of Jen's narrative of her feminist identity is her desire to achieve social justice for women and children subjected to violence. Her feminist identity is, however, constrained by the pressures to construct a legitimate organisational identity from the perspective of various external stakeholders. As her position in the organisation changes to a governance role, for example, Jen constructs a liberal feminist identity which she argues was a way to maintain their legitimacy as an organisation. The imbalanced power relationship between the community sector and the government, Jen notes, is influential in her construction of her feminist identity. In order to continue to help victims of violence, Jen sees a need to offer a more temperate politics at the intersection with government. In positioning herself as a liberal feminist, therefore, Jen seeks to maintain the personal connection to social justice and to secure a legitimate place at the intersection between self, organisation, and government. Parsons and Priola (2013) and Meyerson and Scully (1995) both argue that achieving change within systems benefits from establishing an insider position. Thus, although Jen's position as a liberal feminist at the intersection between the state and the organisation is constrained, there are still benefits that can be gained from orientation as an insider; such as the possibilities of enacting incremental changes.

Tia engages with the organisation at different intersections to Jen. Predominantly, Tia is engaged at the interface between backstage work and frontline work. Like Jen, therefore, Tia has experienced an alteration in accountabilities from a primary accountability to clients on the frontline, to more complex accountabilities to both frontline workers and the state. In frontline work Tia highlights that she was unable to distinguish a sense of self separate to the organisation; she was consumed by the kaupapa. Rather than framing this as positive for social justice, Tia argues that being too immersed in the organisation was actually damaging for maintaining her mana wāhine identity. In changing the intersection of her engagement with the organisation, Tia felt that new possibilities to construct organisational identities were opened up. In backstage work Tia consciously constructs dual identity positions of mana wāhine and organisational member in order to negotiate both her interactions with the frontline workers and the accountability to the state. Tia positions these boundaries between identities as necessary for negotiating accountabilities at multiple intersections. 
Nonetheless, Tia carried over some of the embedded practices of frontline work to continue to construct a mana wāhine identity backstage in our organisation. Tia's construction of mana wāhine as opposing bureaucracy sits within a legacy of domestic violence organisations that identified, and opposed, bureaucratic processes as patriarchal structures that contradict egalitarian social justice goals (Rodriguez, 1988). In fact, Tia links non-bureaucratic practices directly to outcomes for clients, arguing that unlike the government, who damages clients by making them "jump through hoops" for service, our organisation offers a direct link between clients and service. At the interface between self and organisation, Tia interlinks her mana wāhine identity with challenging organisational practices that are understood to perpetuate the conditions of which prevent abused women - particularly Māori women - from being openly supported. Additionally, the construction of a mana wāhine identity challenges organisational practices which embed 'feminism' (in the singular) as offering the 'best' approach to achieving social justice for women. Tia's construction of mana wāhine identity questions the focus on the 'Western' concept of feminism embedded in the organisation as well as at the interface with government. The negotiations her narrative indicates that small changes to feminist identities open up the possibilities of non-Western identities being recognised and valued at the intersections with government as well as in frontline work.

Emily links her feminist identity to changing "harmful hyper-masculinity" and reconstructing "gender as a non-binary thing without gender roles associated". For her, constructing a feminist identity that breaks gender stereotypes is essential for achieving the social justice goals of the organisation. Emily connects the prevalence of domestic violence to societal expectations that women should fill certain roles in the home, with children, and in the workforce. Unsettling societal expectations through non-conventional constructions of gender, Emily argues, will aid in achieving social justice for women. Emily argues that it is essential for her to maintain a "strong feminist" stance in order to sustain organisational practices that she describes as a central point of differentiation between our organisation and other domestic violence organisations. Emily uses other organisations as a point of difference in order to construct what is a 'feminist organisation' and 'what is not'. For Emily, the practices that sit at the heart of feminism are empowerment and ensuring women are not positioned as responsible for the violence. Emily is therefore able to draw on the intersection between self and organisation to provide foundations to her feminist identity and the direction of social justice. 
Emily is determined to "retain [her] idealism" and maintain a coherent identity across the various interfaces between her identity and the organisation. In contrast to Tia and Jen who produce multiple feminist identities at the different intersections between self and organisation, Emily sees it as important to maintain a coherent feminist identity at the level of her sense of self, and at the level of the organisation. She argues that she is aware "how easy it is to invisibilise [the intersection of race and gender], even within my advocacy with government". Constructing a feminist self that incorporates a recognition of marginalisation is therefore essential for her feminist identity, and her role in the organisation. Continually constructing a positive, inclusive feminist identity is difficult for Emily, as she finds it challenging, but necessary, to work to recognise marginalisation associated with race within feminism. At the intersection of self and organisation Emily is compelled to produce an account of her feminist self that incorporates her accountabilities to diverse clients. Thus, we can see that Emily has been shaped by organisational norms of feminism. The tension between her feminist identity at the intersection of the organisation is seen as essential by Emily because her "voice is the one that goes to parliament". The small and incremental changes apparent in her narrative show the expansion of her social justice work at various intersections.

The discussion of the feminist identities of Jen, Tia, and Emily emphasises that at different intersections of the community sector social justice identities shift and change. Some of this negotiation of feminist identities was conscious, such as Emily's reflection on the limitations of her feminist identity as she came into contact with organisational norms of inclusivity of Māori. At other times feminist identities were shaped by the various expectations of stakeholders. Jen's narrative, for example, demonstrated how accountabilities shaped and constrained the construction of feminist identities at different intersections. The small and incremental negotiations of feminist identities underscore that the negotiation of social justice identities in community organisations is too complex to warrant a broad emancipatory approach to social justice; as scholars who take a micro-political focus argue (Parsons \& Priola, 2013; R. Thomas \& Davies, 2005a). Alternatively, exploring the small and incremental changes to feminist identities at multiple intersections, illuminates how narrative identities can help change agents to maintain a social justice focus in complex situations.

Jen, Tia, and Emily all insisted that the 'heart' of their feminist identities remained consistent across various intersections. Feminist identities provided a point of consistency in their narrative identities which helped them to negotiate the competing demands of accountability 
in the community sector. For Jen, the changing intersections between the state and the organisation shaped her understanding of herself as a feminist. Constrained by accountabilities to maintaining perceptions of legitimacy with the state, Jen was oriented toward producing a liberal feminist identity that was productive within systems. Through her construction as an 'insider', Jen is able to exploit this position in order to push for small, incremental changes within the system. Nonetheless, Jen's identity was constrained by the legitimacy pressures, and we can see the shift of her identities over time as her accountabilities change. Although small and incremental changes within the system are beneficial in the community sector (Tomlinson \& Schwabenland, 2010) a reproduction of the system through constructing a liberal feminist identity, may not, on its own, effectively challenge wider systemic issues related to gendered violence. Accordingly, we can see that placing a micro-political focus in the context of broad emancipatory projects is essential for understanding the efficacy of micro-politics within a community sector context.

For my colleagues, retaining their feminist identities was essential for social justice. At different intersections in their work, however, their identities were shaped or constrained. The narrative accounts of their feminist selves helped my colleagues maintain their focus on social justice for abused women even across multiple intersections. Even if they only achieved 'small wins' (Meyerson \& Scully, 1995) within the system, their narratives continued to circulate the value of feminist perspectives on DV and continued to direct their efforts as an organisation toward their broad emancipatory project of ending violence against women.

\section{Negotiating feminist identity within the organisation}

In the previous section, I focused on the complexities of constructing a feminist identity at the shifting intersections between the organisation and various external stakeholders. As I argued earlier in Part IV, the focus in the community sector literature on external constraints has tended to either overlook or underemphasise the importance of negotiating social justice identities within community organisations (for a few notable exceptions see: Dempsey, 2009; Kenny, 2010; E. L. Kirby et al., 2012). Strikingly, my colleagues' narratives give extensive attention to explicating the complexities of having their feminist identity recognised by their colleagues. Struggle within the organisation to maintain social justice identities was not, however, about the legitimacy of feminist identity as it was at the intersection with external 
stakeholders. Alternatively, struggle over feminist identities within the organisation involved negotiation over how we could construct feminist identities in a way that deconstructed our own socialisation which inadvertently perpetuated norms of violence against women (hooks, 1986).

For this section I pay attention to the micro-politics of constructing feminist identities within the organisation. Feminist literature on dismantling oppressive social norms has often stressed that even organisational practices which are supposed to be empowering or transcend power relations can become vehicles of oppression (Ellsworth, 1989; Swan \& Fox, 2010). Consistent questioning of how feminist identities are situated in power relations is therefore necessary if feminist solidarity is to be achieved and multiple intersecting oppressions are to be dismantled (hooks, 1986). The process of questioning and challenging feminist identities was often painful and unsettling for my colleagues. Nonetheless, I contend in line with other feminist scholars (hooks, 1986; Lorde, 2007; Swan, 2017a), that this process is a necessary pain if we are to deconstruct social norms that perpetuate violence against women, and in particular against women of colour. Feminists are constituted within the harmful norms they attempt to change and can inadvertently marginalise other women. To explore how my colleagues established their own feminist identities and challenged the feminist identities of others in the organisation, I draw out several examples from my colleagues' narratives of negotiation what is 'feminist' and what is 'non-feminist'.

To differing degrees, all of my colleagues' narratives gave an account of the times they felt that their feminist identities were questioned or rejected by their colleagues as well as the times when they drew on their lived experience to question or challenge the feminist identities of their colleagues or organisational norms. The simultaneous challenging and being challenged was played out in the micro-politics of their identity texts and is particularly evident in Kim, Ava, and Evelyn's narratives.

Kimberley argues that in order to challenge social norms which perpetuate violence against women, we need to reimagine the value we place on the feminine. Within the organisation, however, Kim found it difficult to gain recognition as a 'feminine feminist', arguing that she was positioned as "too soft" or "too weak" for DV work by her "staunch feminist" colleagues. Kim argues that the devaluation of the feminine in our organisational practices was a part of women's socialisation within the patriarchy, and that we have all 'internalised' harmful norms that devalue the feminine (and by association women). In a similar way, in 
Ava's narrative she highlights her discomfort with the notion of a 'staunch feminism' which she feels as incompatible with her more feminine roles as a wife and as a mother. Like Kim, Ava thinks that her nurturing or caring roles in the office are perceived as less valuable than activist or business-like roles. Other scholars have also noted similar difficulties in ensuring that feminine practices are seen as valuable in organising as these are continually positioned as less valuable than masculine practices (Jeanes et al., 2011). Without challenging the devaluation of the feminine, however, Kim and Ava both argue that it is difficult to empower women and end gendered violence.

Ava challenges the devaluation of the feminine in her narrative through positioning her dedication to empowerment of women as compatible with cultivating a nurturing role in her relationships with other women in the office. Along the same lines, Kimberley argues that her practices of "building up women" also revolve around "valuing women for what makes them women" i.e. supporting other women through feminine practices of nurture and care. Both Ava and Kimberley challenge the devaluation of the feminine that they consider to be pervasive in our organisation. Kimberley, in particular, links the devaluing of the feminine to women's socialisation within patriarchal discourses. In order to dismantle the devaluation of women which contributes to gendered violence, Kim argues that it is necessary to foster nurturing relationships with women which both increase the value attributed to the feminine and to create sustained bonds between the diverse women in social justice work. Through positioning the patriarchy as within the organisation as well as external to it, Kimberly is able to identify and challenge organisational practices which inadvertently devalue the feminine. Both Ava and Kimberley feel devalued in their more 'feminine' identities, but position these identities as a point of possibility for shifting patriarchal norms and fostering feminist solidarity.

Evelyn also constructed the patriarchy and other marginalising social norms as within the boundaries of the organisation. She argued that the organisation engaged in practices saturated with "the patriarchal, the hierarchical, the white privilege, the putdowns, [and] the disempowerment". In order to foster the necessary solidarity to dismantle these complex and intersecting forms of oppression, Evelyn suggested a different approach to that of Kim and Ava. Evelyn was intent that the organisation should be more inclusive of men and work together to dismantle how both women and men were negatively impacted by the patriarchy, hierarchy, and white supremacy. From Evelyn's perspective, her colleagues often excluded men from the narrative of domestic violence; positioning them as disembodied 'perpetrators' 
rather than as men likewise "created" through the negative implications of patriarchy, hierarchy, and white supremacy. In particular, Evelyn connects the exclusion of men from some of my colleagues' feminist identities to a white feminist ${ }^{31}$ narrative on domestic violence. Failing to take into account how violence impacts the whole family including men, Evelyn argues, is exclusive of Māori women's view on wellbeing and safety which tends to understand healing as involving the whole community (Wilson, Jackson, \& Herd, 2016).

Evelyn argues that our organisation would benefit from rethinking our understanding of 'equality' along the lines of Māori perspective on gender equality and gender roles. Mikaere (1994) explains that in traditional Māori society:

Both men and women were essential parts of the collective whole, both formed of the whakapapa $^{32}$ (genealogy) that linked Māori people back to the beginning of the world, and women in particular played a key role in linking the past with the present and the future (p. 125).

Evelyn's understanding of equality was imbued with a similar understanding; that our efforts as feminists needed to pay attention to the 'collective whole' and the intergenerational inheritance of our gendered roles in society. Through this construction of her feminist identity as being for equality, Evelyn argues that permeating our organisational practices with a recognition of parallel harmful social norms that affect men will help to holistically dismantle the social conditions of patriarchy, hierarchy, and white supremacy. Positioning these intersecting oppressions within the organisation, Evelyn suggests that feminist DV organisations need to challenge feminism which excludes or disembodies men within their narratives of violence. In doing so, she contends, we can more effectively catalyse change that will end gendered violence for our communities in Aotearoa New Zealand.

Although the process of questioning feminist identities was often painful and unsettling for my colleagues, it was also necessary. If we are to dismantle the complex social processes which sustain gender inequalities, we must question normative feminist identities in feminist organising. At times my colleagues were challenged by other organisational members to reconsider their own feminist identity and at other times my colleagues drew on their feminist

\footnotetext{
31 'White feminism' has received substantive criticism by anti-racist scholars (Applebaum, 2010; hooks, 1986; Lorde, 2007; Swan, 2017b). As a form of feminist identity, white feminism is seen to focus on dismantling the struggles of white women while simultaneously failing to recognise the distinctive intersectional oppressions of women of colour.

${ }^{32}$ Whakapapa is a scared and significant concept for Māori. It refers to genealogy (and the recitation of genealogy) and is foundational to a sense of cultural connection and wellbeing.
} 
identity to challenge their colleagues and organisational practices. The dissent among my colleagues was not in search of a singular approach to ending violence, but instead with the aim of solidarity to engaging in multidirectional approaches to dismantling our patriarchal, hierarchical, and white supremacist constructions of feminist identities. The micro-politics of the feminist identities of my colleagues within the organisation highlight how the contestation of organisational norms of feminist identities in individual identity texts was necessary to continue to question and find alternatives to oppressive social processes.

\section{Weaving together the personal and political: giving an account of the feminist self}

I now turn to examining the form of the narratives themselves. The specific cultural practices of the organisation asked staff to give an account of their feminist selves. These practices had interesting effects that are important for fostering social change. I look particularly at the accounts of Ava and Tia to examine how accounts of the feminist identity drew on the notion of 'the personal is political' and were compelled to give an account in relation to feminism, even when refusing the term. In many domestic violence organisations that developed in the 1960s and 70s - particularly those that claimed the feminist mantle (to borrow Tia's term) the link between the personal and the work of the organisation was considered essential, as personal experiences of oppression were argued to form the foundations of organising differently in ways that were more empowering to women (Rodriguez, 1988). Weaving together the personal and political has a long history in feminism, with Hanisch (1970) using the term 'the personal is political' to describe how conscious raising groups in the women's liberation movement made connections between personal experiences of being a woman related to need to take collective political action.

The stories that my colleagues considered appropriate to be shared were shaped by organisational norms which, as outlined above, constrained the possibilities of being understood as a viable subject (Butler, 2005). The narrative accounts offered by my colleagues also demonstrate the weaving together of the personal and the political. Kimberley, for instance, directly relates her becoming a feminist with being raped; thereby offering a sequential transition from 'non-feminist' to 'feminist' through her personal stories aimed at persuading the audience that she is a viable feminist subject (Butler, 2005). The use of the personal as a basis for feminist organising is contentious, however, as it can commodify experience, and 'the personal' is always constructed through power relations 
which unevenly distribute social value to experiences (Phipps, 2016). At the same time, however, in giving an account of oneself you have the possibility of reflecting, and thereby reconsidering, moral and political norms (Butler, 2005). In other words, each time my colleagues gave an account of their feminist identity they were offered the possibilities of (re)considering how they understood the importance of feminism for our organisation and constructing new assumptions for how we should interact with one another.

The personal stories woven into the narrative accounts of feminist identity by my colleagues share some similar themes. Most prominently, the accounts contain stories that emphasise gendered socialisation and suffering. Socialisation as women takes the form of stories of upbringing that were perceived to shape my colleagues political perspectives. Ava highlights her "Calvinistic narrow-minded" up-bringing, and Tia shares stories about being raised to be proud of being Māori. Stories of suffering - particularly in relation to violence from men including sexual abuse, sexual assualt, domestic violence, and abandonment - were also often a centre point of accounts of feminism. Ava told the story of her husband abandoning her and Tia shared stories about her childhood exposure to domestic violence. The privileging of these two dimensions can be seen to be related to organisational norms. For example, in the compulsory training sessions we were asked to give an account of our upbringing in the form of a mihimihi ${ }^{33}$ (introduction) and stories of our tūrangawaewae ${ }^{34}$ (standing place), followed by an account of the 'worst things' and the 'best things' about being a woman, and concluded by an account of our understanding and (possible) commitment to feminism in relation to those other things. Organisational practices thus established links between our personal stories and our relationship to feminism, and put the emphasis on certain kinds of stories.

Ava's account exemplifies these storytelling norms. Early in Ava's account she emphasises that because of her "very Calvinistic, narrow-minded" upbringing, the move into our organisation involved unsettling various embedded aspects of her identity. She compares this early mind-set to the "very liberal society" she engages with in our organisation. In this way Ava establishes both a plausible transition toward a feminist politics, but establishes what she perceives as a legitimate reason for feeling uncomfortable with those politics. Her story thus provides the grounds for her to refuse to adopt a 'feminist identity'. Nonetheless, Ava is still

\footnotetext{
${ }^{33} \mathrm{~A}$ mihimihi is an informal introduction. Many different styles are used but usually a mihimihi includes an account of where you are from and your whakapapa.

${ }^{34}$ Tūrangawaewae is most commonly translated as 'a place to stand'. It refers to places where we feel at home in the world and connected to the land.
} 
compelled to give an account of her identity in relation to feminism in order to retain legitimacy as an organisational subject. Instead of positioning herself as a feminist, Ava more hesitantly concludes that she has "become more aware of feminism as a way of viewing the world and being". As Butler (2005) argues: "the 'I' has no story of its own that is not also the story of a relation - or set of relations - to a set of norms" (p. 8). In order to establish an identity in the organisation, Ava must position her self in relation to feminism - even if that position involves rejecting the norms. Her hesistation is indicative that she is aware that her position as a non-feminist is not widely accepted by her colleauges.

From the basis of this sequential transition, Ava weaves together 'personal' stories to establish her 'political' position in the organisation; not in relation to feminism, but in relation to the empowerment of women. In her narrative account, Ava explains that in her work she seeks to liberate and empower women. She embeds this position within her personal experiences. Ava explains that she saw "those women who get stuck in a rut, who often later in life need to make a life change, and they don't believe in themselves". She relates this imperative to her own life-history, in which she tells the story of her husband abandoning her and her children, compelling her to make a substantial change in her life. This story of how to break away from the "rut", forms the grounds of her political commitments to the liberation and empowerment of women. Through her account Ava establishes that in her work she will engage with women in a way that will help them to "believe in themselves" and "feel better" about their work in the organisation. Although Ava doesn't explicitly construct a feminist identity she is still able to construct an identity as a legitimate organisational subject by adopting a 'feminist analysis' which seeks to empower women.

In a similar way, Tia also negotiated the storytelling norms in her account to reject the term 'feminist'. Tia told me explicity that she belives that "the personal is political and the political is personal. You form a political opinion based on something that happens to you." The 'personal' for Tia was rooted in her Māori identity. Tia told me that growing up:

We knew exactly where we were from and who our ancestors were... we would go home and feel like we owned it because we were part of it... our dialect in Te Reo was important... it has always been important for us to keep in touch withour cultural identity. 
The importance of her Māori identity was something that Tia was adamant that she passed on to her children. The account that Tia gives of her personal identity as Māori is woven into her political position. She explained to me that although: "I'm not one of those activisting Māori and don't believe that what is right for Māori is right for everybody" that she was "becoming aware of Māori issues" and in her practice she would use "Māori models of practice as opposed to Western [models]”.

The stories of her Māori identity in Tia's account formed the grounds for the rejection of the term 'feminist' as a "Western concept". Tia weaves the personal stories of learning about the importance of being Māori in her childhood to her current identification with mana wāhine identity. Through her account Tia also links stories of her childhood to her feeling out of place or limited as a young Māori woman. In this way Tia's account draws on organisational norms to offer a viable account of her identity as mana wāhine in relation to feminism. She thereby establishes new assumptions for how we should interact with one another from the perspective of mana wāhine. She acknowledges that her position is one among many different positions one could take to promote change for victims of violence, but through her account establishes mana wāhine as a legitimate identity from which to advocate for social change. The contrast of mana wāhine to feminism also challenges the exclusions of indigenous ways of being from conventional feminist identity in our organisation.

Even in narratives where my colleagues did not identify as feminist, my colleauges were still compelled to give an account of their identity in relation to feminism. In doing so, my colleauges had to reflect on the value of feminist identity for working with their colleagues and for working with domestic violence. In this way, colleauges who did not express alignment with 'feminism' still considered their own political position in relation to parts of the project of feminism; such as empowerment of women. Organisational storytelling norms promoted the understanding that in some way our socialisation as women was linked to suffering, and that the opposition of suffering was connected to the project of feminism. In this way organisational norms established a mechanism for feminist identity to be seen as a legitimate political position for opposing harmful social norms and for reducing suffering. Feminist identity was therefore associated with assumptions about how we should act to reduce suffering; including dismantling harmful social norms that perpetuated violence agianst women. 
The shape of these accounts thereby promoted feminist solidarity. The personal stories accentuated that members of our organisation came from a variety of different cultural backgrounds but that it continues to be important to share these stories and connect them to how we intended to interact with our colleagues and with clients. As the accounts of Ava and Tia demonstrate, however, these norms could also be exclusive, and for those who identified as other than feminist a plausible account of their non-feminism had to be given.

\section{Organising from different directions: Feminisms and social justice}

At the outset of Part IV, I explained that my inspiration for this investigation had come from my colleagues' desire to organise through a multiplicity of feminisms to negotiate the complex accountabilities of their community sector work and to also promote feminist solidarity within the organisation. Domestic violence workers aiming for a singular, coherent 'feminism' - as many studies of domestic violence organisations either problematically presume (Hughes, 2017; Reinelt, 1994; Rodriguez, 1988) or advocate (Nichols, 2011, 2013) was not only impossible but also undesirable. Singular, often utopian, critical projects overlook the complexities and nuances of power relations which make any emancipatory project necessarily local, contextual, and contested (Ellsworth, 1989; Phipps, 2016). We should not, however, abandon feminist identities. Instead we must acknowledge the contradictions and challenges within feminism (Hemmings, 2012). In testament to acknowledging the complexities of feminism my colleagues expressed a desire to organise through a multiplicity of feminisms for feminist solidarity.

In the context of the community sector, my colleagues' narratives demonstrated the complexities of maintaining a feminist identity at the intersection of the self, the state, other community organisations, clients, and funders. The pressures of constructing 'professional' identities for community workers are intense (M. L. Sanders \& McClellan, 2014) and these pressures constrain the possibilities of social justice identities in community sector contexts (S. Grey \& Sedgwick, 2013b, 2015). Nonetheless, maintaining social justice identities is essential so that community workers can establish and maintain their agenda for social change. Identities in community organisations are therefore more than just a process of legitimation (Gilpin \& Miller, 2013), they aid organisational members in establishing and maintaining a direction for their social mission (Herrmann, 2011). My colleagues' narratives emphasised, however, that pressure to embody certain identities came from within the 
organisation, as well as from external stakeholders. Acknowledging and exploring the exclusionary practices within community organisations is essential to understanding how social justice identities are established and maintained (Kenny, 2010).

A micro-political approach to feminist identity has proven to be extremely useful for my analysis; foregrounding the shades and nuances of change in the community sector context. Studies of the micro-politics of identity have typically focused on how organisational members challenge specific disciplinary practices (R. Thomas \& Davies, 2005a), attempt to challenge institutional practices (Parsons \& Priola, 2013), or challenge corporate practices (Wright et al., 2012). In the context of the community sector, however, my colleagues supported the mission of the organisation and, by and large, were supportive of organisational practices which did often align with their perceptions of their social justice identity. Therefore, in the case of a social justice organisation, I have argued in Part IV that a micropolitical focus can be usefully applied to explore how the micro-politics of identity operate to intentionally embed specific organisational practices while simultaneously questioning others.

In order to achieve a social justice mission, it is important for community workers to retain a sense of themselves as advocates for social justice. A micro-political focus helps to examine how community sector workers negotiate multiple layers of (often conflicting) accountabilities to both maintain legitimacy with external stakeholders and a social justice focus. The small changes in narrative accounts demonstrated how my colleagues maintained social justice identity at multiple intersections in many different ways. For instance, Jen tempered her social justice identity to secure an 'insider' position whereas Emily attempted to maintain a coherent feminist identity across intersections so that systemic issues were always central. The incremental changes in their narratives illustrated how conflicting accountabilities shape identities and that in the negotiation of these conflicts, small changes can continue to be made in order to promote social justice.

Additionally, I followed the lead of other studies of the community sector (e.g., Dempsey, 2009; Kenny, 2010, 2012) which have explored how pressures on social justice identity also come from within the organisation. By turning a social justice focus internal to the organisation, my colleagues were able to question organisational practices that they felt precluded social change. Ava and Kim, for instance, questioned the devaluation of the feminine by their colleagues, arguing that this was an extension of patriarchal devaluation of 
women. Through challenging such practices through their narratives, Ava and Kim created alternative assumptions of how we ought to behave toward one another that they perceived as being integrated into their organisational practice. I argued that although this process was sometimes unsettling or painful for my colleagues, it was a necessary pain in order foster feminist identity that catalysed multi-directional approaches to social justice.

The narratives accounts of feminist identity themselves seemed particularly salient in my organisation, as the storytelling norms of the organisation compelled members to give an account of their identity in relation to feminism. Importantly, the organisation had specific norms for the shape of these accounts involving articulating social situation, telling stories of suffering, and linking these to feminism. In this way feminist identities were constructed through weaving together the personal and the political. Each time my colleagues gave account of their feminist identity the opportunity for reconsidering the value and meaning of feminism was opened up. My colleagues thus frequently considered the qualities and relevance of feminism to domestic violence work. Even in cases where my colleagues did not identify as 'feminist', they still constructed their accounts in relation to feminism. The practice of giving an account of feminist identity thereby created shared assumptions about how we should interact with one another, what practices we should engage in, and how we understood these to be beneficial for ending gendered violence. This promoted solidarity among my colleagues as it accentuated our differences and how our lived experience could contribute to the project of feminism.

Although the layers of self, organisation, and social context have been usefully analytically separated here, they are, of course, concurrent. At the same time as being compelled to give an account of feminist identity, my colleagues were attempting to deconstruct their own harmful practices, and were also under pressure to construct an identity perceived as legitimate by external stakeholders. The micro-politics of my colleagues are, therefore, essential for understanding the complex negotiations of the multiple layers of the construction of feminist identity. In the context of the community sector, constructing and maintaining social justice identity is a messy endeavour. The community sector literature has primarily turned its gaze 'outwards' (i.e. the social environment), but as I've demonstrated in this part, also turning the gaze 'internally' to community organisations can highlight important practices of constructing and maintaining social justice identities. Uniting under a shared politics seems unfeasible in the context of the community sector where multiple 
Part IV: A Multiplicity of Feminisms

accountabilities mean that it may be useful, and even necessary, to engage in a multidirectional approach to social justice. 
Part V: Endings

\section{PART V: Endings}


In the final pages of this thesis, I am put in mind of Kamler and Thomson's (2006) argument that the process of writing a thesis "creates the scholar who at the end of writing is different from the writer who began" (p. 16). I am a different scholar from the one who started this project. In this thesis, I have argued that the changes to my identity spreading around my ethnographic experience and from my development as a scholar over the course of this project have been central to the development of my theoretical contributions. As Behar (1996) argued: "what happens within the observer must be made known... if the nature of what has been observed is to be understood" (p. 6). I have interwoven my ethnographic experience into the structure of this thesis. In this way, I have developed my thinking rhizomatically. Simply put, my thesis structure was non-linear. Each part acted as a semiindependent node of thought which flourished in different intellectual territory. I wrote in a rhizomatic way in order to resonate more closely with the unsettling, emotional, and violent aspects of my research. By suffusing aspects of my ethnographic experience in the structure of my thesis, I have demonstrated how my thinking about the relationships between identity and change shifted before, during, and after my ethnographic experience.

In the opening section of this thesis - 'Settings' - I argued that my thesis was written differently from a conventional thesis in order to think more critically and creatively about the theorisation of identity. I have engaged with ideas about writing differently throughout this thesis. Here, in Part V - 'Endings' - I continue along the lines of this theme. As I argued alongside Pullen and Rhodes (2008) in 'Settings': knowledge is not so total, conclusions are not always neat, and social phenomena do not necessarily become clearer through rigorous study. I do not, then, offer a singular conclusion to this project here in the final pages or extensively recapitulate the contributions I made throughout the thesis. Alternatively, I dedicate this space in 'Endings' to a reflection on three important points. Firstly, I make explicit my reasons for developing the conceptual and empirical material in a rhizomatic way. Secondly, I return to my original research question and argue for the value of my rhizomatic structure for answering it. Thirdly, I consider the unanswered questions of this thesis and argue for valuable directions of future research.

The questions surrounding the theoretical links between identity and change had, for me, always been connected to helping to oppose continued (and even mounting) social inequalities in and beyond organisations. Going into this project I was concerned by the stubborn persistence of gender inequalities in Aotearoa New Zealand despite decades of sustained social justice work. Furthermore, I was aware that marginalised communities 
continue to grapple with the realisation that even 'safe' or 'welcoming' spaces can perpetuate the very inequalities that they purport to dismantle. An interest in providing a contribution to social justice projects - particularly to reducing gender inequality - was one of the fundamental motivations behind my research. In light of these issues, I situated my research within the academic field of Critical Management Studies. I perceived CMS both as having the potential to catalyse change to disrupt these inequalities and as one of the 'safe' spaces which inadvertently reifies the same inequalities.

Taken as a field of the production of knowledge, CMS tends to marginalise or exclude the contributions of feminist and queer research. Nonetheless, in 'Beginnings' (Part I), I articulated my position as aligning with feminist and queer scholars who had long been engaged in the project of conducting research to actively address social inequalities. The political imperative of my work, I concluded, was to contribute to scholarly understanding of how identity and change were interlinked from a feminist post-structuralist perspective. My research aimed to provide both an account of the regulation of identity and an affirmative account of how identity could be productive of change, drawing on a rich history of socially transformative feminist thought. In addition, I argued that the community sector had been overlooked as a research site in CMS, and that this neglect was chiefly a consequence of an antagonistic history that centred on critique of harmful business practice and management ideology. Critical scholars could learn much about achieving social change, I argued, by engaging with community organisations that were actively addressing social inequality.

Had I adopted a conventional thesis structure, from this point I would have gone on to demonstrate how I used my empirical material to contribute to the select debates I outlined in the previous paragraph. My theorisation of the empirical material would have remained rooted in the debates I outlined in 'Beginnings', and I would have produced a consistent and linear thesis. When I began my more formal writing process after completing my ethnography, I did not, however, decide to write my thesis in a conventional way. After 'Beginnings' the narrative of my thesis shifts and the debates in the literature I engage with through my empirical material changes. In this vein, at the opening and close of 'Beginnings' I summarised how I had drawn inspiration from Deleuze and Guattari (1987) and had opted to structure my thesis rhizomatically. Although I drew from the material I engaged with in 'Beginnings', in the subsequent empirical parts I primarily introduced new conceptual material as it became salient to my ethnographic material. Additionally, the new conceptual material I introduced was given equal weight; there was no 'centre point' of my argument. 
I feel the same way as Kondo (1990), who wrote on her use of a non-conventional structure: "what and how I write is no mere academic exercise; for me it matters, and matters deeply" (p. 302). My ethnographic experience volunteering and the changes to my identity as a scholar became indivisible from my theoretical understanding of identity and change. Additionally, as I moved through the project I found that some of my initial frameworks, the work of Bourdieu for instance, became less relevant and I became interested in other literature, such as the alternative organising literature, that more adequately addressed the issues arising during my ethnography. I could have reordered my thesis to reflect these changes, but I acutely felt the significance of Denzin's (2002) argument that: "theory, writing, and ethnography are inseparable practices... we change the world by changing the way we make it visible" (p. 483). Thus, I adopted a structure that allowed me to develop, through my own experience, my central theoretical claim that identity becomes unsettled when you work for a social justice organisation. For scholars to find new ways of contributing to social justice projects we must change the ways we make our research visible through our writing.

In short, I argue that a rhizomatic structure has opened up possibilities of critically and creatively exploring novel ways of theorising identity that resonated closely with my ethnographic experience. Theorising my material in a rhizomatic way allowed me to contribute to several of the wider debates in CMS. Writing in emotional and subjective experiences contributed to circulating 'feminine writing' (Pullen \& Rhodes, 2015) in organisational studies and contributed to how scholars feel about social justice work as well as what they know about it. A non-linear structure helped to break the 'deadlock' of knowing about identity and to creatively theorise identity in novel ways. Additionally, oscillating between empirical and theoretical material throughout the empirical parts contributed to new ways of amalgamating theory to empirical material which maintains theoretical complexity while resonating closely with lived experience. The rhizomatic structure mattered deeply as a dimension of my social justice aims, and acted as a vehicle to privilege the lifeworld of my colleagues and what their knowledge can add to academic knowledge.

The rhizomatic structure of my thesis had extensive implications for how I answered my original research question. At the outset of this project I asked the question: "In which ways can identity be understood to act as a catalyst for change in the context of the community sector?” In 'Beginnings', I considered that my answers to this question would contribute to the debates in the critical literature about how identity and change were interrelated in 
organisations and to debates about the value of feminist perspectives of identity.

Additionally, I considered that this thesis would contribute to the debates surrounding the community sector's potential as a research site for critical scholars to engage in effective critique. Adopting a rhizomatic structure meant, however, that my contributions also circled away from these initial debates. The rhizomatic structure opened up the possibilities of answering emerging research questions as I moved between different bodies of literature. As I went through the project, I found that what I learnt from my colleagues' work in domestic violence had a lot to add to the literature on emotion, alternative organising, the body, and the micro-politics of identity. Accordingly, in each empirical part I engaged with these bodies of literature and I entered into different debates in CMS to respond to my emergent research questions. This thesis, then, put the emphasis on the ways of understanding the relationships between identities and change. As I draw this thesis to a close, it is worth reflecting on the 'ways' I answered my original research question as well as the different debates I contributed to in each empirical part.

The salience of strong emotions in the empirical material I gathered from the first phase interviews, and my subsequent engagement in volunteer work, inspired me to reconceptualise the community sector. In 'Ties that bind; ties that break' (Part II) I argued that community organisations were usefully conceptualised as alternative organisations. Through the alternative organising literature I repositioned my interest in the community sector through the concept of emotion. I drew on examples from my ethnographic study to illustrate how strong emotions in social justice work contributed to my colleagues' understanding of their identity as community sector workers. Strong emotions were seen by my colleagues as an essential part of social justice work as they increased our emotional attachment to protecting the lives of abused women. In Part II, therefore, I answered my original research question by arguing that in alternative organisations strong emotions shape our relationships with one another and can change the intensity of community sector workers' feelings of responsibility for improving the lives of marginalised communities. I also contributed to the alternative organising literature arguing that emotions, forms of organising, and identity were intimately intertwined and in order to understand how alternative organisations can remake our social landscapes we must pay attention to how emotion shapes identity.

I engaged with ethnographic and autoethnographic material about the gendered body in domestic violence work in 'Vulnerable bodies' (Part III). I argued that domestic violence work should be understood as a specific form of work and demonstrated that the gendered 
identities of women become unsettled through the body in domestic violence work. In order to answer my emergent questions about the role of the gendered body in domestic violence work I drew on the feminist literature about the body in organisations and the critical literature about sexual orientation at work. I highlighted that gendered violence is related to the devaluation of women's experiences and the positioning of women as controllable 'objects'. Through my analysis I demonstrated that in DV work heterosexual bodies were legitimated as objects of organisational inclusion and LGBT+ identities and experiences were devalued. In Part III, therefore, I answered my original research question by arguing that remaking and celebrating our gendered identities in domestic violence work is essential to disrupting the devaluation and objectification of all women. Additionally, I contributed to debates on women's bodies in organisations by arguing that domestic violence work made women acutely aware of constraints on their bodies but that these constraints could be used as points of political action. I also developed the sexual orientation literature by showing how LGBT+ identities were attributed meaning in domestic violence work through the gendered body.

I centred the stories that my colleagues told me about their feminist identities in 'A multiplicity of feminisms' (Part IV). I wove together the literature on the micro-politics of identity and Judith Butler's account of narrative identity; 'giving an account of oneself'. In the context of social justice organisations, I argued that a micro-political approach is usefully applied to how identities can intentionally support some organisational practices while simultaneously challenging others. I drew on the perspective of 'giving an account of oneself' (Butler, 2005) to argue that a post-structuralist account of narrative identities can assist in understanding how feminists negotiate a multiplicity of feminisms and maintain solidarity toward large scale emancipatory projects. To answer my initial research question in Part IV, I thereby argued that 'giving an account' of social justice identity helps social justice workers to negotiate multiple accountabilities in the community sector context while maintaining a commitment to a social justice change agenda.

A consistent thread that runs through the contributions of the empirical parts of my thesis is the salience of domestic violence work and workers as an important dimension of my research. At the outset of this project I had no specific intentions to include domestic violence work as a key aspect of the project. Here, in 'Endings', as I reflect on the project as a whole I now argue that my thesis brings the project of domestic violence to feminist research in CMS. My position is now that feminist research located in CMS can contribute to ending gendered 
violence by examining how patterns of organising can assist and constrain anti-violence social justice activities. In this thesis, I have made a contribution to this project by arguing that forms of alternative organising (such as feminist organising) can contribute to ending gendered violence and that understanding the dynamics of DV work as a unique form of work is useful in striving toward social justice goals. I also argued that domestic violence work can contribute to our understanding of gendered issues at work. For instance, in 'Vulnerable bodies' (Part III) I demonstrated that domestic violence work was a site where issues around women's bodies were particularly salient and relevant to improving the lives of women. Furthermore, through my thesis I have also made a potential contribution to the literature on domestic violence work by examining how feminist identities are constrained both internal to the organisation, as well as external, and arguing that feminist solidarity should be the aim of feminist DV work.

Overall, this thesis has developed aspects of feminist post-structuralist approaches to identity to argue for multiple 'ways' that identity can act as a catalyst for change in the context of the community sector. I propose that the rhizomatic structure of my thesis was important for developing the answers to my original research question. As I outlined in 'Beginnings' (Part I), one of the aims of the project was to experiment with different theoretical perspectives to develop critical and creative thinking about identity theory. The rhizomatic structure called attention to and acted as a vehicle for this process. I was able to draw on aspects of different literatures to intersect with my ethnographic experience, which opened up the possibilities for me to creatively amalgamate theory to my empirical material. Additionally, I was more effectively able to 'layer' the different dimensions of my ethnographic experience and accentuate that there are always multiple ways of approaching the same phenomena. I wrote without the intention of creating a 'centre-point' in order to demonstrate that all of the layers had simultaneous relevance for the working lives of my colleagues. Ultimately, my general theoretical approach emphasises that the relationships between identity and change should be understood as multi-directional.

As well as strengthening the contributions of this thesis, the rhizomatic structure also opened up numerous directions for future research. The first direction of future research grows out of the empirical context of this thesis and involves writing a feminist analysis of DV work in CMS. My thesis highlighted that forms of alternative organising can be useful for contributing to large scale emancipatory projects like ending gendered violence. Future research on alternative organising could focus on how different kinds of organisations 
provide alternatives to individualistic or hierarchical organisational norms which perpetuate the conditions of violence against women. Valuable examples flagged by my research would include women's organisations, feminist organisations, and indigenous organisations. There is also value for organisational scholars to understand domestic violence work as a specific form of work (see Part III). Unpacking the dynamics of DV work for different communities of workers - such as indigenous workers or LGBT+ workers - can help to flesh out the norms that need to be disrupted in and beyond organisations to reduce violence against marginalised communities.

I noted in 'Ties that bind; ties that break' (Part II) that although there is significant overlap between the community sector literature and the alternative organising literature, these literatures have not yet been brought together in a sustained way. Future work could bring these literatures together to expand knowledge in the alternative organising field about which practices community organisations already engage in that could strengthen our knowledge about different patterns of organising. In reference to the alternative organising literature, I also argued for the importance of understanding how emotion works in community organisations. Certain kinds of strong emotion - such as passion, anger, and grief - were salient in community organisations and perceived as foundational to the ways in which community workers decided to organise and how they understood their identity. Future projects could explore which emotions are important in other forms of alternative organisations - such as anarchist organisations - and how these shape (and reshape) our social relationships with one another.

My exploration of the gendered body in 'Vulnerable bodies' (Part III) demonstrated the value of domestic violence work for generating further insight to understanding how perceptions of the gendered body impacts women's experiences in the workplace. Domestic violence work itself is also a useful research site as experiences of the body are particularly salient as a result of the daily exposure to (gendered) violence against bodies. Future research can focus on how people with other gender identities (such as non-binary people or transgender folk) construct their gendered identities and are impacted in relation to the body in DV work. Additionally, in 'Vulnerable bodies' I have only scratched the surface of how LGBT+ identities are important for catalysing change for all women in domestic violence work. Future research can give more attention to how LGBT+ workers experience domestic violence work in different ways (beyond the gendered body) and how they disrupt heteronormative practices. Additionally, I flagged takatāpui identities (Māori queer identity) 
as important in domestic violence work in the context of Aotearoa New Zealand. Another trajectory of LGBT+ research would be to explore how takatāpui identities are attributed meaning in the context of domestic violence work or in other forms of work. Such research would give insight into how non-Western LGBT+ identities are experienced in the context of work and thereby counterbalance the current sexual orientation literature which focuses primarily on Western understandings of LGBT+ identities at work.

In 'A multiplicity of feminisms' (Part IV) I drew on two theoretical perspectives that can add more to our knowledge about identity and change in organisational studies. I demonstrated that the literature which develops the micro-politics of identity had a lot to add to understanding the change efforts of social justice workers. Future research could expand the use of a micro-political framework for deepening our understanding of how community workers can negotiate the multiple accountabilities of community sector work. In particular, other social justice identities - such as environmentalist identities - could be examined to explore the micro-politics of their interactions with stakeholders (such as corporations). I also drew on the concept of 'giving an account of oneself' to explore the storytelling norms of my organisation which involved directly asking organisational members to give public accounts of their identity in relation to feminism. Other research could ask which other contexts promote similar storytelling norms of giving accounts of oneself and what impacts these practices have on patterns of organising. Additionally, 'A multiplicity of feminisms' highlighted that feminist identities are an important dimension of achieving and maintaining feminist solidarity. Future research could ask questions about the role of feminist identity plays in achieving solidarity in other feminist projects like sexual violence or pay equality.

Finally, I want to close by underlining my investments in the interconnected dimensions of this thesis. The stories I shared of the social justice work done by my colleagues points scholars toward learning more from people deeply involved in social justice projects and to learning more from the ways in which they organise in an attempt to catalyse social change. The community sector in Aotearoa New Zealand remains, for me, a space of critical and creative potential for learning from social justice work and workers in order to create change for our communities. Critical work should engage more extensively with organisations that can act as allies rather than limiting critical research to critique of harmful business practices. My thesis has also underlined that organisational scholars still have much to learn from feminist and queer scholars that dedicate their time and energy to thinking of ways to highlight and reduce social inequalities. The ways I employed feminist and queer theory to 
understand identity demonstrated that there is multi-directional potential in feminist and queer theory for understanding how identities are made and remade in organisations in ways that can simultaneously reify or remake social norms. I also continue to see CMS as a space of potential for improving the lives of marginalised people, if we can continue to challenge our own exclusions and consciously conduct research to open up new possibilities of thinking and engagement. My thesis has, in particular, illustrated how writing differently can help us to think differently about our role as scholars in catalysing change. Above all, I always circle back to what I learnt from my colleagues. They showed me that our identities are unsettled when we work for social justice organisations, and that remaking and celebrating our identities, even in the face of horrific inequalities, is essential for catalysing change. 
Appendices

\section{APPENDICES}


Appendix A: Information sheet for first phase participants

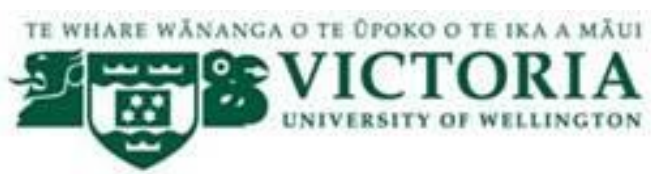

\section{Identity as a catalyst for change: Theorising identity in the nonprofit sector}

\section{EXPERT INTERVIEWS: ABOUT THE RESEARCH}

This research project studies the nonprofit sector and nonprofit workers. I am interested in how people can achieve social change, and am using nonprofit work and workers as an example. I am looking to find out how people involved in the nonprofit sector understand, engage with, and talk about the sector in Aotearoa New Zealand. This involves looking at: the key characteristics of the nonprofit sector, what role the sector plays in Aotearoa New Zealand, the goals and ideologies of the sector, and the key challenges facing the sector.

In this phase of the research I am asking a range of people with various expertise in the nonprofit sector to help me develop a big picture of the sector and nonprofit work. I am talking to people who have a broad, inter-organisational perspective, and are engaged in a range of aspects of the nonprofit sector; including nonprofit workers, government agencies, nonprofit research groups, and funding bodies. In later phases of the research I will engage in a longterm study of a nonprofit organisation to explore how these issue play out on a day-to-day basis. The project is based at the Victoria University of Wellington, and is being conducted as part of $\mathrm{PhD}$ in Management.

I plan to conduct a series of interviews with experts who have a 'big picture' perspective of the nonprofit sector. These interviews will be semi-structured, last about one hour, and ask questions about your ideas, experiences and opinions on the nonprofit sector and nonprofit work. The interview will be recorded. The recordings and transcripts will be kept confidential to the researcher and the supervisors of this project. The names of any interviewees will not be used nor will the names of their organisations. I will not use any quotations in such a way that participants or their organisation can be publically identified. You will be provided with a copy of your interview transcript and can give comments and feedback if you wish.

Participants can withdraw from the research project at any stage before data analysis 
December 2016, without having to give a reason. All information will be kept securely for a period of up to five years after the project December 2023, and will then be destroyed.

After the expert interviews and other data are analysed the findings may be used for academic publications, conference presentations, and public reports. The findings of these interviews will be used for a $\mathrm{PhD}$ thesis that is publically available.

\section{What does this mean for you?}

- I am asking you to participate in a single, one-hour semi-structured interview

- I will be asking you about your ideas, experiences, and opinions on the nonprofit sector and nonprofit work

- You will sign a consent form

Please do not hesitate to contact the researcher or supervisor if you have any questions.

Approval for the research has been granted by the Victoria University of Wellington Human Ethics Committee with approval number 0000023194 
Appendix B: Research agreement for first phase interviews

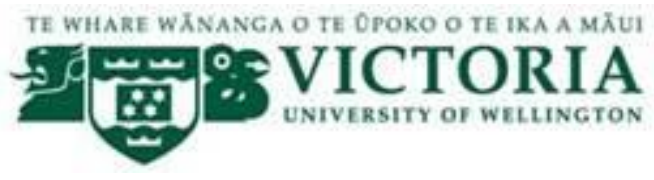

Identity as a catalyst for change: Theorising identity in the nonprofit sector

\section{EXPERT INTERVIEWS: RESEARCH AGREEMENT}

I have read the Participant Information Sheet and understand the nature of the research. I have had the opportunity to ask any questions and have them answered to my satisfaction. I understand that I can ask further questions at any time.

I agree to take part in one audio-recorded semi-structured interview.

I understand that:

- My participation is completely voluntary. My name will not be used in reports, nor will any information that could easily identify me.

- I may withdraw from this study before data analysis begins [December, 2016] without giving an explanation, and any information that I have provided will be returned to me or destroyed.

- The data will be securely kept for a period of up to five years after the completion of this project [December 2023] and then destroyed.

- No-one will have access to the recordings or any notes expect the researcher and supervisors.

- I understand that the results will be used for a $\mathrm{PhD}$ thesis, and a summary of the results may be used in academic publications, conference presentations, and public reports.

- I will receive a copy of my interview summary, and a copy of the final report for the project

- I understand that I am free to decline to answer any question during the interview if I prefer not to provide an answer. 
In publications and presentations, I would like to be identified as:

Any other conditions for agreement:

I agree to take part in this research:

Name:

Organisation/Position:

Signature:

Date:

Contact details (for transcript and final report): 
Appendix C: Organisation research agreement

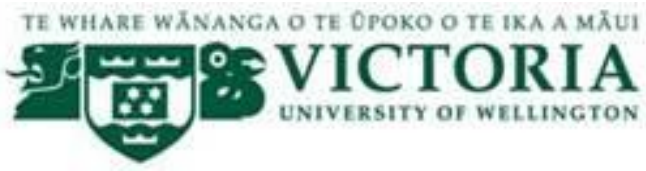

Identity as a catalyst for change: Theorising identity in the nonprofit sector

\section{FIELD STUDY: ORGANISATION RESEARCH AGREEMENT}

I have read the "Field study- about the research" handout and understand the nature of the research and why this organisation has been selected. I have had the opportunity to ask any questions and have them answered to my satisfaction. I understand that I can ask further questions at any time.

I understand that:

- Participation by this organisation is completely voluntary and participation by individual members is voluntary.

- Members of the organisation will also be invited to participate in a series of interviews. Consent for these will be obtained on an individual basis, and participation by organisational members in these interviews is completely voluntary.

- Any information provided by the organisation will be kept confidential to the researcher and the supervisors. I understand that the results will be used for a $\mathrm{PhD}$ thesis and a summary of the results may be used in academic publications, conference presentations, and public reports.

- The name of this organisation will not be used in any publications, nor will any information that would make it easy to identify the organisation.

- This research involves the negotiated participation of the researcher in the organisation for a period of 6-9 months during which time the researcher will make observations, record day-to-day activities and conversations, and attend meetings, training sessions, and participate in organisational activities.

- The data will be securely kept for a period of up to five years after the completion of this project December 2023 and then destroyed. 
- A final written report of findings will be provided to the organisation and there will be the opportunity for ongoing of the research to the organisation at key points throughout the project.

Any other conditions for agreement:

I agree to let the researcher work voluntarily in the organisation, and I agree for members of this organisation to be invited by the researcher to participate in this research:

Organisation/ Position:

Name:

Signature:

Date:

Contact information (for final report): 
Appendix D: Information sheet provided for field research

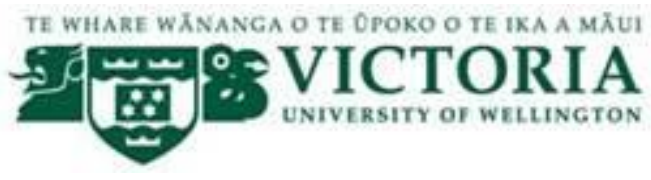

Identity as a catalyst for change: Theorising identity in the nonprofit sector FIELD STUDY: ABOUT THE RESEARCH

This research project aims to get a sense of how people experience and construct their sense of self on a day-to-day basis in nonprofit organisations and how this is related to social change. This handout aims to give you information about the project, and your rights to confidentiality, so that you can decide whether you are willing to participate in a long-term (6-9 months) field study. I have already carried out an initial phase of the research. This involved talking to experts in the nonprofit sector about the 'big picture' of the nonprofit sector and nonprofit work that aims to achieve social change. This field study is part of a second phase of the research which looks at the day-to-day practices of identities and social change by nonprofit workers themselves.

The aim of the field study is to get a sense of how people experience and construct their sense of self on a day-to-day basis in nonprofit organisations. I am interested in how these day-today experiences and the identities of individuals can be understood to catalyse social change. Participating in this research will give you and your organisation an opportunity to reflect on the meanings of your identities in relation to your nonprofit work and your nonprofit organisation in relation to social change.

The research will involve the researcher participating in your nonprofit organisation by working voluntarily in the organisation on a part-time basis over a period of 6-9 months. The nature of this participation will be negotiated with you and your organisation. With permission the researcher will:

- Record day-to-day activities and conservations

- Attend meetings, participate in any training sessions, and in any regular organisational activities (such as fundraising)

- Keep a detailed personal research journal of experiences

- Make observations of objects and the physical space 
Additionally, members of the organisation will be invited to participate in a series of interviews about their identities. Consent for these interviews will be obtained on an individual basis and participation is completely voluntary.

This research is intended to be used as part of a $\mathrm{PhD}$ thesis which will be submitted to Victoria University of Wellington. The research may also be used for academic publications, conference presentations, and public reports. Feedback on the findings as they develop is intended to be presented to you and your organisation over at several points of the course of the project. Such presentations will give you an opportunity to ask any questions, provide feedback, and make suggestions. This will also give your organisation a chance to reflect on your identities and social change.

\section{Confidentiality}

All information will be kept confidential to the researcher and the supervisors of the project. At no time will any day-to-day conversations, activities, observations, content of meetings, or material from training sessions and organisational activities be repeated to anyone else outside the organisation other than the supervisors of the project, or be repeated to anyone within the organisation. Any recordings, observations, and personal research notes will be used only for purposes of the research.

The name of your organisation, will not be used in any publications. I will use any quotations in such a way that individuals cannot be publically identified. Additionally, all information will be used in such a way that the organisation cannot be easily identified. The field notes and any other information will be destroyed five years after the completion of this project [December 2023]. A summary of findings will be made available to participants. You can withdraw from the project before the data is analysed September 2017 without having to give reasons.

\section{What am I asking of your organisation?}

- Your organisation will be asked to participate in a field study in which the researcher will work voluntarily in your organisation over a period of 6-9 months

- After negotiating the exact form of researcher participation, I will be making observations of day-to-day life, attending organisational events such as meetings, and working voluntarily in the organisation two half-days a week 
Appendices

- You will sign a consent agreement

Please do not hesitate to contact the researcher or the supervisors of this project if you have any questions.

Approval for the research has been granted by the Victoria University of Wellington Human Ethics Committee with approval number 0000023194 
Appendix E: Ethnographic interview research agreement

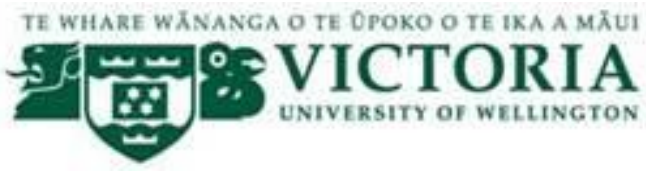

\section{Identity as a catalyst for change: Theorising identity in the nonprofit sector}

\section{IDENTITY INTERVIEWS: RESEARCH AGREEMENT}

I have read the "Identity Interviews - about the research" handout and understand the nature of the research. I have had the opportunity to ask any questions and have them answered to my satisfaction. I understand that I can ask further questions at any time.

I understand that:

- My participation is completely voluntary. I understand that the results will be used for a $\mathrm{PhD}$ thesis and the research may be used in academic publications, presented at conferences, and in public reports.

- No-one will have access to the recordings or any notes expect the researcher and supervisors.

- This research involves three interviews over period of 9 months. I understand that I can withdraw from this study up to four weeks after data analysis has commenced September 2017, or at any time during the period of interviews.

- The data will be securely kept for a period of up to five years after the completion of this project December 2023 and then destroyed.

- I will receive copies of my interview summaries and a copy of the final report which summarises the findings.

- I understand that I am free to decline to answer any question during the interview if I prefer not to provide an answer.

In publications, presentations, and any public media, if any quotations are used, I would like to be identified as:

Any other conditions for agreement:

I agree to take part in 3 audio recorded interviews:

Name/Position: 
Signature:

Date:

Contact information (for transcripts and final summary): 
Appendix F: Information sheet about ethnographic interviews

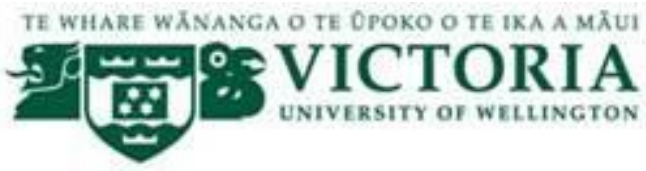

\section{Identity as a catalyst for change: Theorising identity in the nonprofit sector}

\section{IDENTITY INTERVIEWS: ABOUT THE RESEARCH}

This research project aims to get a sense of how people experience and construct their sense of self on a day-to-day basis in nonprofit organisations and how this is related to social change. This handout aims to give you information about the project, and your rights to confidentiality, so that you can decide whether you are willing to participate in a series of interviews. I have already carried out an initial phase of the research. This involved talking to experts about the 'big picture' of the nonprofit sector and nonprofit work that aims to achieve social change. These interviews are part of a second phase of the research which looks at the day-to-day practices of identities and social change by nonprofit workers themselves.

The aim of the interviews will be to share and discuss life experiences, your relationship with your nonprofit work, and your plans and aspirations for the future. I am interested in your experiences, thoughts, and opinions about nonprofit workplace experiences and how these interact with how you understand yourself. Participating in this research will give you the opportunity to reflect on the meanings of your identity and can give you a number of ways of thinking about your nonprofit work in relation to social change.

If you agree there will be three interviews over a period of nine months. Each interview will have a different focus. Interviewing you over a period of time will give a better sense of how your ideas about yourself and the organisation shift and change over time, and will allow for a more in-depth understanding and reflection of you as an individual. These interviews will each take approximately an hour and will be audio recorded. You can be interviewed in your place of choosing, such as your place of work, a public place such as a café, or at the university. Should the line of questioning progress in a way that makes you uncomfortable you can decline to answer any question(s).

This research is intended to be used as part of a $\mathrm{PhD}$ thesis which will be submitted to Victoria University of Wellington. The research may also be used for academic publications, conference presentations, and public reports. 


\section{Confidentiality}

All information from the interviews will be keep confidential to the researcher and the supervisors of the project. You will be provided with a copy of the interview transcripts and can give comments and feedback if you wish. Your name, and the name of your organisation, will not be used in any publications. I will use any quotations in such a way that individuals cannot be publically identified. The transcripts and any other information will be destroyed five years after the completion of this project December 2023. A summary of findings will be made available to participants. You can withdraw from the project before the interview data is analysed; about four weeks after the conclusion of the interviews September 2017, without having to give reasons.

\section{What does this mean for you?}

- I am asking you to participate in three one-hour interviews over a period of nine months

- I will be asking you about your life experiences, relationship with the organisation, and your plans and aspirations for the future

- You will sign a consent form

Please do not hesitate to contact the researcher or supervisor if you have any questions.

Approval for the research has been granted by the Victoria University of Wellington Human Ethics Committee with approval number 0000023194 
Appendix G: Interview schedule for first phase interviews

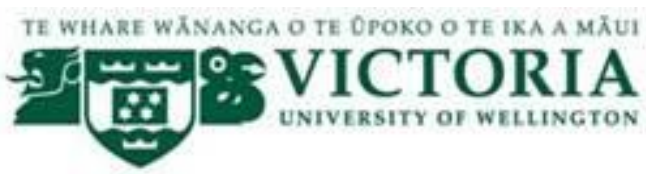

\section{$\underline{\text { Interview questions (panel interview) }}$}

This interview schedule (panel interviews) outlines a list of likely questions which will be asked of participants. The format of all interviews will be semi-structured, however this schedule will be used as a guide. The exact form of any questions to be asked in any given interview may change, depending on the focus of the interview and the information obtained during the interview. Core research questions are in bold.

\section{List of questions:}

Can you give me an overview of your current role and the relationship of this role to the nonprofit sector?

- How long have you been involved with the nonprofit sector/ in your current role?

- How would you describe your relationship with the nonprofit sector?

How would you describe the nonprofit sector? What are its key characteristics?

- What (if anything) makes the nonprofit sector different from other sectors (such as the government or the private sector)?

What role do you see the nonprofit sector playing in Aotearoa New Zealand?

- How do nonprofit organisations shape the identity of Aotearoa New Zealand?

- Do you see there as being overarching values/ideologies in the nonprofit sector? How would you characterise these?

What do you see as being the overarching goals of the nonprofit sector?

- How successful do you think the nonprofit sector is at achieving these goals?

- What do you think contributes to this success/lack of success?

- What limitations face nonprofit organisations in attempting to achieve these goals?

How do nonprofit organisations respond to the Treaty of Waitangi?

- How well do you see the sector as engaging with Māori \& Māori-led organisations?

- What do kaupapa Māori organisations contribute to the sector?

What sorts of characteristics do nonprofits need in order to be successful?

- How would you describe the attitudes of the government toward the nonprofit sector? 
- How would you characterise the relationship between the nonprofit sector and the community?

- Do you think attitudes toward the nonprofit sector have shifted in the last 30 years? If yes, how?

\section{What are the key challenges facing the nonprofit sector?}

- What else do you think is important to understand about the Aotearoa New Zealand nonprofit sector? 
Appendix H: Ethnographic interview schedules

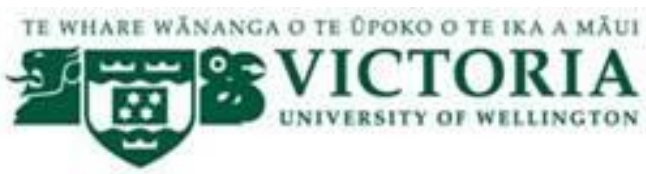

Interview schedule (ethnographic interviews)

Round 1: Life history

This interview schedule (ethnographic interviews: round 1) outlines a list of likely questions which will be asked of participants. The format of all interviews will be semi-structured, however this schedule will be used as a guide. The exact form of any questions to be asked in any given interview may change, depending on the focus of the interview and the information obtained during the interview. The aim of the interview is to have the participant narrate their life history as they see fit. Prompt questions are designed as potential points of interest but will only be used if the participant requires guidance.

\section{List of questions:}

In this interview, I'm interested in getting an overall picture of you as a person, and how you feel you've developed over the course of your life. I'm interested in hearing your 'lifehistory'. A life-history is the story of your life and contains material in your own life that you believe to be important in some fundamental way - information about yourself and your life which you feel is significant about you and who you are. I will ask questions along the way if I feel guidance is needed.

Can you recount/narrate your life history for me?

\section{Prompt questions:}

Are there any moments in your life that stand out to you as being particularly significant for influencing who you are as a person? (Describe)

Are there any specific events/experiences that stand out from your childhood years as being important for your sense of self?

Are there any specific events/experiences that stand out from your teen-aged years as being important for your sense of self?

What significant relationships have influenced you?

Are there any particular fictional stories/characters (such as from a favourite movie/book) that influenced you as a person? 
Are there any people, groups of people, or organisations/institutions that have had an impact of your sense of self? In what ways did they influence you?

What non-work activities do you engage in? What role do these leisure activities play in shaping your sense of self?

How do you approach political and social issues? Do you have a particular political point of view? What do you think has influenced your political/social position?

Are there any world events that had a significant impact on the way you thought about yourself?

Do you have any fundamental beliefs and/or values that you believe have shaped your life and sense of self?

Have you ever experienced a 'turning point' in our understanding of yourself? If yes, what was it and how did you see it?

What sort of challenges have you faced in being 'yourself'?

\section{Concluding questions:}

How does working for this organisation fit into your life-history?

Is there anything else that you see as significant to your life history?

Is there anything else that you see as significant to your identity? 
$\underline{\text { Interview schedule (ethnographic interviews) }}$

Round 2: Sense of self and the organisation

This interview schedule (ethnographic interviews: round 2) outlines a list of likely questions which will be asked of participants. The format of all interviews will be semi-structured, however this schedule will be used as a guide. The exact form of any questions to be asked in any given interview may change, depending on the focus of the interview and the information obtained during the interview.

\section{$\underline{\text { List of questions }}$}

In this interview I am interested in getting a sense of your relationship to the organisation and how it shapes you (and you shape it). The interview will start with a review of the previous interview; asking you to consider your experiences over the past 3 months. The main section of the interview will involve discussing how your identity fits into the organisation.

\section{In the previous 3 months since the interview:}

Have you had any experiences that altered or confirmed the way you think about yourself? How has your work affected you emotionally or personally over the last 3 months?

Have you had any challenges to your sense of self? Have any challenges 'resolved' or you've come to terms with them?

Are there any new influences in your life?

Have you had any strong emotional experiences?

Since having reflected on your life-history, have any other significant experiences come to light?

\section{Identity and the organisation:}

How did you first become involved with this organisation?

Why did you become involved?

What role do you play in the organisation?

What do you see as the key goals of the organisation?

How would you describe your relationship with the goals of the organisation?

What role do you see yourself as having in achieving these goals? 
What unites the organisation? Are there any similar or shared characteristics, values, or ideologies which unite people? Which do you share/not share?

Has involvement in the organisation affected you emotionally and personally?

What are the most difficult aspects of your work for you as a person?

What role do you see the organisation as having in your identity?

At work/within working relationships have you ever felt like you couldn't 'be yourself'?

Are there parts of yourself that you don't express/bring to work?

What does working for a nonprofit organisation mean is expected of you as a person? Do you feel like you are expected to act in a particular way (in your immediate working environment or by others outside the organisation)?

Has involvement in the organisation changed the way you think about yourself?

Is there any way in which you would like to see the organisation change? Why/why not?

Is there anything else you think is important to understand about your relationship with the organisation? 
Interview schedule (ethnographic interviews)

Round 3: Future self/reflection

This interview schedule (ethnographic interviews: round 3) outlines a list of likely questions which will be asked of participants. The format of all interviews will be semi-structured, however this schedule will be used as a guide. The exact form of any questions to be asked in any given interview may change, depending on the focus of the interview and the information obtained during the interview.

\section{List of questions:}

In this interview I am interested in getting a sense of how you understand yourself over time, and how you feel your identity might shift/change/be the same in the future. We will begin the interview by reflecting on the previous two interviews. The main part of the interview will involve questions about your 'future self' and a 'reflection' on the interviews and your sense of self over time.

\section{In the previous 3 months since the interview:}

Have you had any experiences that altered or confirmed the way you think about yourself? How has your work affected you emotionally or personally over the last 3 months?

Have you had any challenges to your sense of self? Have any challenges 'resolved' or you've come to terms with them?

Are there any new influences in your life?

Have you had any strong emotional experiences?

Since having reflected on your relationship with the organisation, have any other significant experiences come to light?

\section{Future self/Reflection:}

What goals and dreams do you have for the future?

Is there any way in which you'd like to see yourself change?

What parts of yourself would you like to see stay the same?

What new experiences/changes do you see yourself as pursuing in the future?

Are there are future limitations/challenges that you see as preventing you from?

How would you like to see your relationship with your work change? 
What would you like to see change in Aotearoa New Zealand? What role do you think you play in achieving this sort of change? What role do you think your organisation plays in achieving this sort of change?

How do you see the organisation's goals/mission as shifting over time? What direction would you like it to develop in (ideally)?

What could prevent it from developing in this direction?

How do you see yourself as having changed over the last 9 months? How do you see your identity as having changed over a longer period of time?

Is there anything you would like to change or rethink about yourself as a result of the experience of reflecting on your life history and relationship with the organisation? 
References

\section{REFERENCES}


Acker, J. (1990). Hierarchies, jobs, bodies: A theory of gendered organizations. Gender and Society, 4(2), 139-158. doi:abs/10.1177/089124390004002002

Ahmed, S. (2014). The cultural politics of emotion (2nd ed.). Edinburgh, UK: Edinburgh University Press.

Albert, S., Ashforth, B., \& Dutton, J. (2000). Organizational identity and identification: Charting new waters and building new bridges. Academy of Management review, 25(1), 13-17. doi:10.5465/AMR.2000.2791600

Ali, P. A., \& Naylor, P. B. (2013). Intimate partner violence: A narrative review of the feminist, social and ecological explanations for its causation. Aggression and Violent Behavior, 18(6), 611-619. doi:10.1016/j.avb.2013.07.009

Alvesson, M. (2010). Self-doubters, strugglers, storytellers, surfers and others: Images of self-identities in organization studies. Human Relations, 63(2), 193-217. doi:10.1177/0018726709350372

Alvesson, M., Bridgman, T., \& Willmott, H. (2011). The Oxford handbook of Critical Management Studies. Oxford, UK: Oxford University Press.

Alvesson, M., Lee Ashcraft, K., \& Thomas, R. (2008). Identity matters: Reflections on the construction of identity scholarship in organization studies. Organization, 15(1), 5-28. doi:10.1177/1350508407084426

Alvesson, M., \& Spicer, A. (2012). Critical leadership studies: The case for critical performativity. Human Relations, 65(3), 367-390. doi:10.1177/0018726711430555

Alvesson, M., \& Willmott, H. (1992). Critical Management Studies. London, UK: SAGE Publications.

Alvesson, M., \& Willmott, H. (2002). Identity regulation as organizational control: Producing the appropriate individual. Journal of Management Studies, 39(5), 619-644. doi:10.1111/1467-6486.00305

Andrews, M., Squire, C., \& Tamboukou, M. (Eds.). (2013). Doing narrative research (2nd ed.). Los Angeles, CA: SAGE Publications.

Antonacopoulou, E. P., \& Gabriel, Y. (2001). Emotion, learning and organizational change. Journal of Organizational Change Management, 14(5), 435-451. doi:10.1108/EUM0000000005874

Applebaum, B. (2010). Being white, being good: White complicity, white moral responsibility, and social justice pedagogy. Lanham, UK: Lexington Books.

Arnold, G., \& Ake, J. (2013). Reframing the narrative of the battered women's movement. Violence Against Women, 19(5), 557-578. doi:10.1177/1077801213490508 
Ashcraft, K. L. (2015). Fringe benefits? Revisi(ti)ng the relationship between feminism and Critical Management Studies. In A. Prasad, P. Prasad, A. J. Mills, \& J. H. Mills (Eds.), The Routledge Companion to Critical Management Studies (pp. 93-106). London, UK: Routledge.

Ashcraft, K. L., \& Ashcraft, C. S. (2014). Motifs in the methods section: Representing the qualitative research process. In E. Jeanes \& T. Huzzard (Eds.), Critical management research: Reflections from the field (pp. 155-172). London, UK: SAGE Publications.

Ashforth, B., Harrison, S., \& Corley, K. (2008). Identification in organizations: An examination of four fundamental questions. Journal of Management, 34(3), 325-374. doi:10.1177/01492063083609

Ashforth, B., Rogers, K. M., \& Corley, K. (2011). Identity in organizations: Exploring crosslevel dynamics. Organization Science, 22(5), 1144-1156. doi:10.1287/orsc.1100.0591

Ashforth, B., Schinoff, B. S., \& Rogers, K. M. (2016). "I identify with her," "I identify with him": Unpacking the dynamics of personal identification in organizations. Academy of Management review, 41(1), 28-60. doi:10.5465/amr.2014.0033

Ashkanasy, N., \& Cooper, C. (Eds.). (2008). Research companion to emotion in organizations. Cheltenham, UK: Edward Elgar Publishing.

Atkinson, P. (1992). Understanding ethnographic texts. London, UK: SAGE Publications. Atkinson, P., \& Delamont, S. (2008). Analytic perspectives. In N. Denzin \& Y. Lincoln (Eds.), Collecting and interpreting qualitative materials (3rd ed., pp. 285-311). London, UK: SAGE Publications.

Attwood, F. (2007). Sluts and Riot Grrrls: Female identity and sexual agency. Journal of Gender Studies, 16(3), 233-247. doi:10.1080/09589230701562921

Bailey, B., Buchbinder, E., \& Eisikovits, Z. (2011). Male social workers working with men who batter: Dilemmas in gender identity. Journal of Interpersonal Violence, 26(9), 1741-1762. doi:10.1177/0886260510372939

Beasley, C. (1999). What is feminism? An introduction to feminist theory. London, UK: SAGE Publications.

Behar, R. (1996). The vulnerable observer: Anthropology that breaks your heart. Boston, MA: Beacon Press.

Behar, R., \& Gordon, D. A. (1995). Women writing culture. Berkeley, CA: University of California Press.

Bell, A. (2006). Bifurcation or entanglement? Settler identity and biculturalism in Aotearoa New Zealand. Continuum, 20(2), 253-268. doi:10.1080/10304310600641786 
Bell, E., \& King, D. (2010). The elephant in the room: Critical Management Studies conferences as a site of body pedagogics. Management Learning, 41(4), 429-442. doi:10.1177/1350507609348851

Bell, E., \& Thorpe, R. (2013). A very short, fairly interesting and reasonably cheap book about management research. London, UK: SAGE Publications.

Ben-Ari, A. (2008). Splitting and integrating: The enabling narratives of mental health professionals who lived with domestic and intimate violence. Qualitative Inquiry, 14(8), 1425-1443. doi:10.1177/1077800408322581

Benhabib, S. (1995). Feminist contentions: A philosophical exchange. New York, NY: Routledge.

Bergin, J., \& Westwood, R. (2003). The necessities of violence. Culture and Organization, 9(4), 211-223. doi:10.1080/1475955042000195454

Berlant, L., \& Warner, M. (1998). Sex in public. Critical Inquiry, 24(2), 547-566. doi:10.1086/448884

Bernal, V., \& Grewal, I. (Eds.). (2014). Theorizing NGOs: States, feminisms, and neoliberalism. Durham, UK: Duke University Press.

Boje, D. (1991). The storytelling organization: A study of story performance in an officesupply firm. Administrative Science Quarterly, 36(1), 106-126. doi:10.2307/2393432

Boje, D. (1995). Stories of the storytelling organization: A postmodern analysis of Disney as "tamara-land". Academy of Management Journal, 38(4), 997-1035. doi:10.2307/256618

Borgerson, J. (2005). Judith Butler: On organizing subjectivities. Sociological Review, 53(1), 63-79. doi:10.1111/j.1467-954X.2005.00541.x

Bornstein, D. R., Fawcett, J., Sullivan, M., Senturia, K. D., \& Shiu-Thornton, S. (2006). Understanding the experiences of lesbian, bisexual and trans survivors of domestic violence: A qualitative study. Journal of Homosexuality, 51(1), 159-181. doi:10.1300/J082v51n01_08

Bourdieu, P. (1991). Language and symbolic power (J. Thompson Ed.). USA: Harvard University Press.

Bourdieu, P. (1992). An invitation to reflexive sociology. Chicago, IL: University of Chicago Press.

Bourdieu, P. (2002). Distinction: A social critique of the judgement of taste. USA: Harvard University Press. 
Bourdieu, P., Loic, J. D. W., \& Farage, S. (1994). Rethinking the state: Genesis and structure of the bureaucratic field. Sociological Theory, 12(1), 1-18. doi:10.2307/202032

Bowes, M. (2009, 27 Aug). Chris Brown to get domestic-violence counselling. McClatchy Tribune Business News.

Bowring, M., \& Brewis, J. (2009). Truth and consequences: Managing lesbian and gay identity in the Canadian workplace. Equal Opportunities International, 28(5), 361377. doi:10.1108/02610150910964231

Boylorn, R. M., \& Orbe, M. P. (Eds.). (2013). Critical autoethnography: Intersecting cultural identities in everyday life. USA: Routledge.

Brannan, M. (2011). Researching emotions and the emotions of researching: The strange case of Alexithymia in reflexive research. International Journal of Work Organisation and Emotion, 4(3-4), 322-339. doi:10.1504/ijwoe.2011.045969

Brannan, M., Rowe, M., \& Nocker, M. (Eds.). (2014). From the ethnographic turn to new forms of organizational ethnography. Bradford, UK: Emerald.

Brewis, D. N. (2017). Social justice 'lite'? Using emotion for moral reasoning in diversity practice. Gender, Work \& Organization, 24(5), 519-532. doi:10.1111/gwao.12171

Bridgman, T., \& Stephens, M. (2008). Institutionalizing critique: A problem of Critical Management Studies. ephemera, 8(3), 258-270.

Brown, A. D. (2006). A narrative approach to collective identities. Journal of Management Studies, 43(4), 731-753. doi:10.1111/j.1467-6486.2006.00609.x

Brown, A. D. (2015). Identities and identity work in organizations. International Journal of Management Reviews, 17(1), 1468-2370. doi:10.1111/ijmr.12035

Burke, P. J., \& Stets, J. E. (2009). Identity theory. Oxford, UK: Oxford University Press.

Burstow, B. (1992). Radical feminist therapy: Working in the context of violence. Newbury Park, CA: SAGE Publications.

Butler, J. (1990). Gender trouble: Feminism and the subversion of identity. New York, NY: Routledge.

Butler, J. (1993). Bodies that matter: On the discursive limits of "sex". New York, NY: Routledge.

Butler, J. (1997). The psychic life of power: Theories in subjection. USA: Stanford University Press.

Butler, J. (2001). Giving an account of oneself. Diacritics, 31(4), 22-40.

doi:10.1353/dia.2004.0002

Butler, J. (2004). Undoing gender. New York, NY: Routledge. 
Butler, J. (2005). Giving an account of oneself. New York, NY: Fordham University Press.

Butler, J. (2006a). Gender trouble: Feminism and the subversion of identity. New York, NY: Routledge.

Butler, J. (2006b). Precarious Life: The powers of mourning and violence. London, UK: Verso.

Butler, J. (2010). Performative agency. Journal of Cultural Economy, 3(2), 147-161. doi:10.1080/17530350.2010.494117

Butler, J. (2011a). Bodies in alliance and the politics of the street. In G. Sholette \& O. Ressler (Eds.), It's the political economy, stupid: The global financial crisis in art and theory (pp. 118-124). London, UK: Pluto Press.

Butler, J. (2011b) "Confessing a passionate state..." - Judith Butler im Interview/Interviewer: S. Hark \& P.-I. Villa. Feministische Studien (Vol 29: 2).

Butler, J. (2011c). Remarks on "Queer Bonds". GLQ: A Journal of Lesbian and Gay Studies, 17(2), 381-387. doi:10.1215/10642684-1163472

Butler, J. (2015). Notes toward a performative theory of assembly. USA: Harvard University Press.

Butler, J. (2017) We are wordless without one another: An interview with Judith Butler/Interviewer: S. Berbec. The Seattle school of theology \& psychology, The Other Journal: An intersection of theology \& culture.

Cabantous, L., Gond, J.-P., Harding, N., \& Learmonth, M. (2016). Critical essay: Reconsidering critical performativity. Human Relations, 69(2), 197-213. doi:10.1177/0018726715584690

Calàs, M., \& Smircich, L. (2009). Feminist perspectives on gender in organizational research: What is and is yet to be. In D. A. Buchanan \& P. Bunyan (Eds.), The SAGE handbook of organizational research methods (pp. 246-269). London, UK: SAGE Publications.

Came, H. A. (2012). Institutional racism and the dynamics of privilege in public health. (Doctoral Thesis), University of Waikato.

Campbell, R. (2013). Emotionally involved: The impact of researching rape. Milton Park, UK: Taylor and Francis.

Carey, G. (2008). Conceptualising the third sector: Foucauldian insights into the relations between the third sector, civil society and the state. Third Sector Review, 14(1), 9-22.

Casey, C. (1999). “Come, join our family”: Discipline and integration in corporate organizational culture. Human Relations, 52(2), 155-178. doi:10.1023/A:1016980602039 
Cassell, C. (2009). Interviews in organizational research. In D. A. Buchanan \& A. Bryman (Eds.), The SAGE handbook of organizational research methods (pp. 500-515). London, UK: SAGE Publications.

Cheney, G., Santa Cruz, I., Peredo, A. M., \& Nazareno, E. (2014). Worker cooperatives as an organizational alternative: Challenges, achievements and promise in business governance and ownership. Organization, 21(5), 591-603. doi:10.1177/1350508414539784

Clifford, J., \& Marcus, G. E. (2011). Writing culture: The poetics and politics of ethnography (25th anniversary ed.). Berkeley, CA: University of California Press.

Coffey, A. (1999). The ethnographic self. USA: SAGE Publications.

Colgan, F., \& Rumens, N. (Eds.). (2015). Sexual orientation at work: Contemporary issues and perspectives. New York, NY: Routledge.

Community Sector Task Force. (2006). A new way of working for the Tangata Whenua, community and voluntary sector in Aotearoa/New Zealand. Retrieved from Wellington: http://www.communityresearch.org.nz/research/a-new-way-of-working/

Connolly, M. (2004). Violence in society: New Zealand perspectives. Christchurch, NZ: Te Awatea Press.

Connor, M., \& Yerbury, H. (2017). Small worlds and active citizenship: Interactions between an NGO and its Facebook community. Third Sector Review, 23(2), 109-129.

Contu, A. (2017). '... The point is to change it' - Yes, but in what direction and how? Intellectual activism as a way of 'walking the talk' of critical work in business schools. Organization, 25(2), 282-293. doi:10.1177/1350508417740589

Corry, O. (2010). Defining and theorizing the third sector. In R. Taylor (Ed.), Third sector research (pp. 11-20). New York, NY: Springer.

Creed, W. E. D., DeJordy, R., \& Lok, J. (2010). Being the change: Resolving institutional contradiction through identity work. The Academy of Management Journal, 53(6), 1336-1364. doi:10.5465/AMJ.2010.57318357

Crocker, T. (2014). History and the Treaty of Waitangi settlement process. Journal of New Zealand Studies, 18(1), 106-117.

Cunliffe, A. L., \& Alcadipani, R. (2016). The politics of access in fieldwork. Organizational Research Methods, 19(4), 535-561. doi:10.1177/1094428116639134

Czarniawska-Joerges, B. (2003). Narratives we organize by. Amsterdam, The Netherlands: John Benjamins Publishing. 
Czarniawska, B. (1998). A narrative approach to organization studies. Thousand Oaks, CA: SAGE Publications.

D’Enbeau, S., \& Buzzanell, P. M. (2013). Constructing a feminist organization's identity in a competitive marketplace: The intersection of ideology, image, and culture. Human Relations, 66(11), 1447-1470. doi:10.1177/0018726713479621

Davids, T., \& Willemse, K. (2014). Embodied engagements: Feminist ethnography at the crossing of knowledge production and representation. Women's Studies International Forum, 43, 1-4. doi:10.1016/j.wsif.2014.02.001

Davies, A., \& Thomas, R. (2004). Gendered identities and micro-political resistance in public service organsiations. In R. Thomas, A. J. Mills, \& J. H. Mills (Eds.), Identity politics at work: Resisting gender, gendering resistance (pp. 105-122). London, UK:

Routledge.

de Souza, E. M., Brewis, J., \& Rumens, N. (2016). Gender, the body and organization studies: Que(e)rying empirical research. Gender, Work \& Organization, 23(6), 600613. doi:10.1111/gwao.12145

Deleuze, G., \& Guattari, F. 1. (1987). A thousand plateaus capitalism and schizophrenia. Minneapolis, MN: University of Minnesota Press.

Dempsey, S. E. (2009). NGOs, communicative labor, and the work of grassroots representation. Communication and Critical/Cultural Studies, 6(4), 328-345. doi:10.1080/14791420903348625

Denzin, N. (2002). Confronting ethnography's crisis of representation. Journal of Contemporary Ethnography, 31(4), 482-489.

Denzin, N., \& Lincoln, Y. (Eds.). (2005). The SAGE handbook of qualitative research (3rd ed.). Thousand Oaks, CA: SAGE Publications.

DeWalt, K. M. (2011). Participant observation: A guide for fieldworkers (2nd ed.). Lanham, MD: AltaMira Press.

Dey, P., \& Teasdale, S. (2016). The tactical mimicry of social enterprise strategies: Acting 'as if' in the everyday life of third sector organizations. Organization, 23(4), 485-504. doi:10.1177/1350508415570689

Dickson, S. (2016). Hohou Te Rongo Kahukura - Outing Violence: Building Rainbow communities free of partner and sexual violence. Retrieved from Wellington, NZ: http://www.kahukura.co.nz/uncategorized/reportandfindings/

Dodge, J., \& Ospina, S. M. (2016). Nonprofits as "schools of democracy". Nonprofit and Voluntary Sector Quarterly, 45(3), 478-499. doi:10.1177/0899764015584063 
Douglas, H. (2015). Embracing hybridity: A review of social entrepreneurship and enterprise in Australia and New Zealand. Third Sector Review, 21(1), 5-30.

Eikenberry, A. M. (2009). Refusing the market. Nonprofit and Voluntary Sector Quarterly, 38(4), 582-596. doi:10.1177/0899764009333686

Elliott, M. (2016, August 16). Unravelling charities' ability to do good. New Zealand Herald. Retrieved from https://www.nzherald.co.nz/nz/news/article.cfm?c_id=1\&objectid=11694323

Elliott, S., \& Haigh, D. (2013). Advocacy in the New Zealand not-for-profit sector: 'Nothing stands by itself'. Third Sector Review, 18(2), 157-178.

Ellsworth, E. (1989). Why doesn't this feel empowering? Working through the repressive myths of critical pedagogy. Harvard Educational Review, 59(3), 297-324. doi:10.17763/haer59.3.058342114k266250

Else, A. (Ed.) (1993). Women together: A history of women's organisations in New Zealand/Nga ropu wahine o te motu. Wellington, NZ: Historical Branch, Dept. of Internal Affairs and Daphne Brasell Associates Press.

Erakovic, L., \& McMorland, J. (2009). Perceptions of 'good governance' in New Zealand non-profit organisations. Third Sector Review, 15(2), 125-147.

Evans, E. (2015). The politics of third wave feminisms neoliberalism, intersectionality, and the state in Britain and the US. London, UK: Palgrave Macmillan.

Eweje, G., \& Palakshappa, N. (2009). Business partnerships with nonprofits: Working to solve mutual problems in New Zealand. Corporate Social Responsibility and Environmental Management, 16(6), 337-351. doi:10.1002/csr.192

Eweje, G., \& Palakshappa, N. (2011). Stakeholder collaboration in New Zealand: Adding value and legitimacy. The Journal of Corporate Citizenship, 43, 79-102.

Fahs, B. (2014). 'Freedom to' and 'freedom from': A new vision for sex-positive politics. Sexualities, 17(3), 267-290. doi:10.1177/1363460713516334

Fanslow, J. L., \& Robinson, E. M. (2011). Sticks, stones, or words? Counting the prevalence of different types of intimate partner violence reported by New Zealand women. Journal of Aggression, Maltreatment \& Trauma, 20(7), 741-759. doi:10.1080/10926771.2011.608221

Farh, C. I. C. C., Seo, M.-G., \& Tesluk, P. E. (2012). Emotional intelligence, teamwork effectiveness, and job performance: The moderating role of job context. Journal of Applied Psychology, 97(4), 890-900. doi:10.1037/a0027377 
Fine, G. A., Morrill, C., \& Surianarain, S. (2009). Ethnography in organizational settings. In D. A. Buchanan \& A. Bryman (Eds.), The SAGE handbook of organizational research methods (pp. 602-619). London, UK: SAGE Publications.

Fineman, S. (2000a). Emotional arenas revisited. In S. Fineman (Ed.), Emotion in organizations (2nd ed.). London, UK: SAGE Publications.

Fineman, S. (2004). Getting the measure of emotion - and the cautionary tale of emotional intelligence. Human Relations, 57(6), 719-740. doi:10.1177/0018726704044953

Fineman, S. (Ed.) (2000b). Emotion in organizations (2nd ed.). London, UK: SAGE Publications.

Fleming, P., \& Banerjee, S. B. (2016). When performativity fails: Implications for Critical Management Studies. Human Relations, 69(2), 257-276. doi:10.1177/0018726715599241

Fleming, P., \& Sewell, G. (2002). Looking for The Good Soldier, Svejk: Alternative modalities of resistance in the contemporary workplace. Sociology, 36(4), 857. doi:10.1177/003803850203600404

Fleming, P., \& Spicer, A. (2004). 'You can checkout anytime, but you can never leave': Spatial boundaries in a high commitment organization. Human Relations, 57(1), 7594. doi:10.1177/0018726704042715

Fotaki, M., Kenny, K., \& Vachhani, S. J. (2017). Thinking critically about affect in organization studies: Why it matters. Organization, 24(1), 3-17. doi:10.1177/1350508416668192

Foucault, M. (1977). Language, counter-memory, practice: Selected essays and interviews by Michel Foucault. New York, NY: Cornell University Press.

Foucault, M. (1981). The History of Sexuality (Vol. 1). Harmondsworth, UK: Penguin.

Freeman, J. (2013). The tyranny of structurelessness. WSQ: Women's Studies Quarterly, 41(3), 231-246. doi:10.1353/wsq.2013.0072

Fung, A. (2003). Associations and democracy: Between theories, hopes, and realities. Annual Review of Sociology, 29(1), 515-539. doi:10.1146/annurev.soc.29.010202.100134

Gabriel, Y. (1998). Psychoanalytic contributions to the study of the emotional life of organizations. Administration \& Society, 30(3), 292-315. doi:10.1177/0095399798303004

Gabriel, Y. (2000). Storytelling in organizations: Facts, fictions, and fantasies. Oxford, UK: Oxford University Press. 
Garthwaite, K. (2016). The perfect fit? Being both volunteer and ethnographer in a UK foodbank. Journal of Organizational Ethnography, 5(1), 60-71. doi:10.1108/JOE-012015-0009

Gatrell, C. (2011a). Managing the maternal body: A comprehensive review and transdisciplinary analysis. International Journal of Management Reviews, 13(1), 97112. doi:10.1111/j.1468-2370.2010.00286.x

Gatrell, C. (2011b). Policy and the pregnant body at work: Strategies of secrecy, silence and supra-performance. Gender, Work \& Organization, 18(2), 158-181. doi:10.1111/j.1468-0432.2009.00485.x

George, J., \& Stith, S. M. (2014). An updated feminist view of intimate partner violence. Family Process, 53(2), 179-193. doi:10.1111/famp.12073

Gherardi, S. (1995). Gender, symbolism and organizational cultures. Thousand Oaks, CA: SAGE Publications.

Gherardi, S., \& Poggio, B. (2007). Gendertelling in organizations: Narratives from maledominated environments. Frederiksberg, Denmark: Samfundslitteratur.

Giddings, L. S., \& Pringle, J. K. (2011). Heteronormativity at work: Stories from two lesbian academics. Women's Studies Journal, 25(2), 91-100.

Gilmore, S., \& Kenny, K. (2015). Work-worlds colliding: Self-reflexivity, power and emotion in organizational ethnography. Human Relations, 68(1), 55-78. doi:10.1177/0018726714531998

Gilpin, D. R., \& Miller, N. K. (2013). Identity brokerage and nonprofit community building. Journal of Nonprofit \& Public Sector Marketing, 25(4), 354-373. doi:10.1080/10495142.2013.830546

Glynn, M. (2000). When cymbals become symbols: Conflict over organizational identity within a symphony orchestra. Organization Science, 11(3), 285-298. doi:10.1287/orsc.11.3.285.12496

Goldblatt, H. (2009). Caring for abused women: Impact on nurses' professional and personal life experiences. Journal of Advanced Nursing, 65(8), 1645-1654. doi:10.1111/j.13652648.2009.05019.x

Goldblatt, H., \& Buchbinder, E. (2003). Challenging gender roles: The impact on female social work students of working with abused women. Journal of Social Work Education, 39(2), 255-275. doi:10.1080/10437797.2003.10779135 
Goldblatt, H., Buchbinder, E., Eisikovits, Z., \& Arizon-Mesinger, I. (2009). Between the professional and the private. Violence Against Women, 15(3), 362-384. doi:10.1177/1077801208330436

Goodwin, J., Jasper, J. M., \& Polletta, F. (Eds.). (2001). Passionate politics, emotions, and social movements. Chicago, IL: University of Chicago Press.

Grey, C., \& Sinclair, A. (2006). Writing differently. Organization, 13(3), 443-453. doi:10.1177/1350508406063492

Grey, S., \& Sedgwick, C. (2013a). The contract state and constrained democracy: The community and voluntary sector under threat. Policy Quarterly, 9(3), 3-10.

Grey, S., \& Sedgwick, C. (2013b). Fears, constraints and contracts: The democratic reality for New Zealand's community and voluntary sector. Retrieved from Wellington, NZ: https://www.victoria.ac.nz/sacs/pdf-files/Fears-constraints-and-contracts-Grey-and-

\section{$\underline{\text { Sedgwick-2014.pdf }}$}

Grey, S., \& Sedgwick, C. (2015). Constraining the community voice: The impact of the neoliberal contract state on democracy. New Zealand Sociology, 30(1), 88-110.

Grey, S., Sedgwick, C., \& Commerer, J. (2015). The declining state of New Zealand democracy: Community and voluntary sector perceptions of public debate under two governments. New Zealand Sociology, 30(4), 102-125.

Gueta, K., Peled, E., \& Sander-Almoznino, N. (2016). "I used to be an ordinary mom”: The maternal identity of mothers of women abused by an intimate partner. American Journal of Orthopsychiatry, 86(4), 456-466. doi:10.1037/ort0000128

Hall, S. (1996). Who needs 'identity'. In S. Hall \& P. du Gay (Eds.), Identity: A reader (pp. 117). London, UK: SAGE Publications.

Hancock, P., \& Tyler, M. (2007). Un/doing gender and the aesthetics of organizational performance. Gender, Work \& Organization, 14(6), 512-533. doi:10.1111/j.14680432.2007.00369.x

Hanisch, C. (1970). The personal is political. Notes from the Second Year: Women's Liberation 1970.

Harding, N., Ford, J., \& Fotaki, M. (2013). Is the 'F'-word still dirty? A past, present and future of/for feminist and gender studies in organization. Organization, 20(1), 51-65. doi:10.1177/1350508412460993

Harding, N., Lee, H., \& Ford, J. (2014). Who is 'the middle manager'? Human Relations, 67(10), 1213-1237. doi:10.1177/0018726713516654 
Haugh, H., Branzei, O., Gibbon, J., \& Hull, R. (2011). Cases, configurations, critiques and contributions: Editorial introduction. In R. Hull, J. Gibbon, O. Branzei, \& H. Haugh (Eds.), The Third Sector (pp. xiii-xxxv). Bingley, UK: Emerald.

Hemmings, C. (2012). Affective solidarity: Feminist reflexivity and political transformation. Feminist Theory, 13(2), 147-161. doi:10.1177/1464700112442643

Henry, E., \& Pene, H. (2001). Kaupapa Māori: Locating indigenous ontology, epistemology and methodology in the academy. Organization, 8(2), 234-242. doi:10.1177/1350508401082009

Herrmann, A. (2011). Narrative as an organizing process: Identity and story in a new nonprofit. Qualitative Research in Organizations and Management: An International Journal, 6(3), 246-264. doi:10.1108/17465641111188411

Hesse-Biber, S. N., \& Leavy, P. (2007). Feminist research practice: A primer. London, UK: SAGE Publications.

Hesse-Biber, S. N., \& Leavy, P. (2011). The practice of qualitative research (2nd ed.). Los Angeles, CA: SAGE Publications.

Hochschild, A. R. (1979). Emotion work, feeling rules, and social structure. American Journal of Sociology, 85(3), 551-575. doi:10.1086/227049

Hochschild, A. R. (2012 - originally 1983). The managed heart: Commercialization of human feeling (2nd ed.). Berkerley, CA: University of California Press.

Honan, E., \& Bright, D. (2016). Writing a thesis differently. International Journal of Qualitative Studies in Education, 29(5), 731-743. doi:10.1080/09518398.2016.1145280

hooks, b. (1986). Sisterhood: Political solidarity between women. Feminist Review, 23(1), 293-315.

Hope, A. (2011). The Body: A review and a theoretical perspective. In E. Jeanes, D. Knights, \& P. Yancey Martin (Eds.), Handbook of gender, work and organization. Chichester, UK: Wiley.

Hughes, J. (2017). Women's advocates and shelter residents: Describing experiences of working and living in domestic violence shelters. Journal of Interpersonal Violence, $O(0)$, 1-20. doi:10.1177/0886260517707307

Hull, R. (2011). Introduction to section 1: Overviews and angles. In R. Hull, J. Gibbon, O. Branzei, \& H. Haugh (Eds.), The Third Sector (pp. 3-6). Bingley, UK: Emerald. Hull, R., Gibbon, J., Branzei, O., \& Haugh, H. (Eds.). (2011). The third sector. Bingley, UK: Emerald. 
Hülsheger, U. R., Alberts, H. J. E. M., Feinholdt, A., \& Lang, J. W. B. (2013). Benefits of mindfulness at work: The role of mindfulness in emotion regulation, emotional exhaustion, and job satisfaction. Journal of Applied Psychology, 98(2), 310-325. doi:10.1037/a0031313

Humphreys, M., \& Brown, A. D. (2002). Narratives of organizational identity and identification: A case study of hegemony and resistance. Organization Studies, 23(3), 421-447. doi:10.1177/0170840602233005

Huygens, I. (2001). Feminist attempts at power sharing in Aotearoa: Embracing herstory or significant learning towards treaty-based structures. Feminism \& Psychology, 11(3), 393-400. doi:10.1177/0959353501011003010

Huygens, I. (2011). Developing a decolonisation practice for settler colonisers: A case study from Aotearoa New Zealand. Settler Colonial Studies, 1(2), 53-81. doi:10.1080/2201473X.2011.10648812

Hyvärinen, M. (2010). Revisiting the narrative turns. Life Writing, 7(1), 69-82. doi:10.1080/14484520903342957

Iliffe, G., \& Steed, L. G. (2000). Exploring the counselor's experience of working with perpetrators and survivors of domestic violence. Journal of Interpersonal Violence, 15(4), 393-412. doi:10.1177/088626000015004004

Jacobs, L. (2016, February 10). The face of the modern feminist: Kim Kardashian. UWIRE Text, p. 1. Retrieved from http://go.galegroup.com/ps/i.do?p=AONE\&sw=w\&u=vuw\&v=2.1\&it=r\&id=GALE\% $\underline{\text { 7CA442908981\&asid=b4b0ffd871caba7441042f1cd19133e6 }}$

James, E. (1989). Nonprofit sector in international perspective: Studies in comparitive cultural and policy. Cary, NC: Oxford University Press.

Jeanes, E. (2007). The doing and undoing of gender: The importance of being a credible female victim. Gender, Work \& Organization, 14(6), 552-571. doi:10.1111/j.14680432.2007.00371.x

Jeanes, E., Knights, D., \& Martin, P. Y. (Eds.). (2011). Handbook of gender, work and organization. Chichester, UK: Wiley.

Jensen, P. R. (2017). 'People can’t believe we exist!': Social sustainability and alternative nonprofit organizing. Critical Sociology, 44(2), 1-14. doi:10.1177/0896920517691106 
Jensen, P. R., \& Meisenbach, R. J. (2015). Alternative organizing and (in)visibility. Management Communication Quarterly, 29(4), 564-589. doi:10.1177/0893318915600577

Johansson, J., Tienari, J., \& Valtonen, A. (2017). The body, identity and gender in managerial athleticism. Human Relations, 70(9), 1141-1167. doi:10.1177/0018726716685161

Johnson, L., Todd, M., \& Subramanian, G. (2005). Violence in police families: Work-family spillover. Journal of Family Violence, 20(1), 3-12. doi:10.1007/s10896-005-1504-4

Jones, A. (2014, November 15). In an age when a woman's bottom can break the internet, feminism is a term we cannot do without. The Independent (London, England), p. 37. Retrieved from http://go.galegroup.com/ps/i.do?p=ITOF\&sw=w\&u=vuw\&v=2.1\&it=r\&id=GALE\%7 CA390117926\&asid=49b7cebaaa1ea7b7bb72bbad81f50a4d

Jones, C. (2011). Poststructuralism in Critical Management Studies. In M. Alvesson, T. Bridgman, \& H. Willmott (Eds.), The Oxford handbook of Critical Management Studies (pp. 76-99). Oxford, UK: Oxford University Press.

Just, S. N., Muhr, S. L., \& Burø, T. (2017). Queer matters: Reflections on the critical potential of affective organizing. In A. Pullen, N. Harding, \& M. Phillips (Eds.), Feminists and queer theorists debate the future of Critical Management Studies (pp. 203-226). London, UK: Emerald.

Kafetsios, K., Athanasiadou, M., \& Dimou, N. (2014). Leaders' and subordinates' attachment orientations, emotion regulation capabilities and affect at work: A multilevel analysis. Leadership Quarterly, 25(3), 512-527. doi:10.1016/j.leaqua.2013.11.010

Kamler, B., \& Thomson, P. (2006). Helping doctoral students write: Pedagogies for supervision. London, UK: Taylor and Francis.

Kelan, E. K. (2010). Gender logic and (un)doing gender at work. Gender, Work \& Organization, 17(2), 174-194. doi:10.1111/j.1468-0432.2009.00459.x

Kelemen, M., \& Rumens, N. (2008). An introduction to critical management research. London, UK: SAGE Publications.

Kenny, K. (2010). Beyond ourselves: Passion and the dark side of identification in an ethical organization. Human Relations, 63(6), 857-873. doi:10.1177/0018726709345042

Kenny, K. (2012). 'Someone big and important': Identification and affect in an international development organization. Organization Studies, 33(9), 1175-1193. doi:10.1177/0170840612448156 
Kenny, K., \& Bell, E. (2011). Representing the successful managerial body. In E. Jeanes, D. Knights, \& P. Martin (Eds.), Handbook of gender, work \& organization (pp. 163177). Chichester, UK: Wiley.

Kenny, K., \& Fotaki, M. (Eds.). (2014). The psychosocial and organization studies: Affect at work. Basingstoke, UK: Pallgrave Macmillan.

Kensinger, L. (1997). (In)quest of liberal feminism. Hypatia, 12(4), 178-197. doi:10.1111/j.1527-2001.1997.tb00303.x

Kent, J. (2012). Third-sector organisations and climate change: A case study of Australian climate-action groups. Third Sector Review, 18(1), 53-77.

Kerekere, E. (2015). Takatāpui: Part of the whānau. Auckland, NZ: Tiwhanawhana Trust and Mental Health Foundation.

Killermann, S. (2018). The social justice advocate's handbook: A guide to gender (2nd ed.). Austin, TX: Impetus Books.

King, D. (2017). Becoming business-like. Nonprofit and Voluntary Sector Quarterly, 46(2), 241-260. doi:10.1177/0899764016663321

King, D., \& Learmonth, M. (2015). Can Critical Management Studies ever be 'practical'? A case study in engaged scholarship. Human Relations, 68(3), 353-375. doi:10.1177/0018726714528254

Kirby, E. L., Koschmann, M. A., \& Dempsey, S. E. (2012). Nonprofits as political actors. Management Communication Quarterly, 26(1), 147-151. doi:10.1177/0893318911424375

Kirby, J. (2011). An aleatory experience using the spontaneous playing with words that led to a chance encounter with self and with writing poetry as a valid form of inquiry. Tamara Journal of Critical Organisation Inquiry, 9(1/2), 29-36.

Knights, D. (1992). Changing spaces: The disruptive impact of a new epistemological location for the study of management. The Academy of Management Review, 17(3), 514-530. doi:10.2307/258721

Knights, D. (1997). Organization theory in the age of deconstruction: Dualism, gender and postmodernism revisted. Organization Studies, 18(1), 1-19. doi:10.1177/017084069701800102

Knights, D., \& Clarke, C. A. (2014). It's a bittersweet symphony, this life: Fragile academic selves and insecure identities at work. Organization Studies, 35(3), 335-357. doi:10.1177/0170840613508396 
Knights, D., \& Surman, E. (2008). Editorial: Addressing the gender gap in studies of emotion. Gender, Work \& Organization, 15(1), 1-8. doi:10.1111/j.14680432.2007.00382.x

Knights, D., \& Willmott, H. (1989). Power and subjectivity at work: From degradation to subjugation in social relations. Sociology, 23(4), 535-558. doi:10.1177/0038038589023004003

Knutsen, W. L. (2013). Value as a self-sustaining mechanism. Nonprofit and Voluntary Sector Quarterly, 42(5), 985-1005. doi:10.1177/0899764012457244

Köllen, T. (2013). Bisexuality and diversity management: Addressing the 'B' in LGBT as a relevant 'sexual orientation' in the workplace. Journal of Bisexuality, 13(1), 122-137. doi:10.1080/15299716.2013.755728

Kondo, D. (1990). Crafting Selves: Power, gender, and discourses of identity in a Japanese workplace. London, UK: The University of Chicago Press.

Kostera, M. (1997). Personal performatives: Collecting poetical definitions of management. Organization, 4(3), 345-353. doi:10.1177/135050849743003

Kreutzer, K., \& Jaeger, U. (2011). Volunteering versus managerialism: Conflict over organizational identity in voluntary associations. Nonprofit and Voluntary Sector Quarterly, 40(4), 634-661. doi:10.1177/0899764010369386

Krumer-Nevo, M., \& Sidi, M. (2012). Writing against othering. Qualitative Inquiry, 18(4), 299-309. doi:10.1177/1077800411433546

Land, C., \& King, D. (2014). Organizing otherwise: Translating anarchism in a voluntary sector organization. ephemera, 14(4), 923-950.

Lapointe, K. (2013). Heroic career changers? Gendered identity work in career transitions. Gender, Work \& Organization, 20(2), 133-146. doi:10.1111/j.14680432.2012.00601.x

Larner, W., \& Butler, M. (2005). Governmentalities of local partnerships: The rise of a 'partnering' state in New Zealand. Studies in Political Economy, 75(1), 79-102.

Larner, W., \& Craig, D. (2005). After neoliberalism? Community activism and local partnerships in Aotearoa New Zealand. Antipode, 37(3), 402-424.

Lather, P. (2001). Postbook: Working in the ruins of feminist ethnography. Signs: Journal of Women in Culture \& Society, 27(1), 199-227. doi:10.1086/495677

Laurie, N., \& Bondi, L. (Eds.). (2005). Working the spaces of neoliberalism: Activism, professionalisation and incorporation. Oxford, UK: Blackwell. 
Leavy, P. (2007). Feminist postmodernism and poststructuralism. In S. N. Hesse-Biber \& P. Leavy (Eds.), Feminist research practice: A primer (pp. 83-108). London, UK: SAGE Publications.

Lee, R. (2017). Breastfeeding bodies: Intimacies at work. Gender, Work \& Organization, 25(1), 77-90. doi:10.1111/gwao.12170

Lindgren, M., Packendorff, J., \& Sergi, V. (2014). Thrilled by the discourse, suffering through the experience: Emotions in project-based work. Human Relations, 67(11), 1383-1412. doi:10.1177/0018726713520022

Lloyd, M. (2015). The ethics and politics of vulnerable bodies. In M. Lloyd (Ed.), Butler and Ethics (pp. 167-192). Edinburgh, UK: Edinburgh University Press.

Lofland, J., \& Lofland, L. H. (1995). Analyzing social settings: A guide to qualitative observation and analysis (3rd ed.). Belmont, CA: Wadsworth.

Lorde, A. (2007). Sister outsider: Essays and speeches. Berkeley, CA: Crossing Press.

Lorentzen, H. (2010). Sector labels. In R. Taylor (Ed.), Third sector research. New York, NY: Springer.

Mackey, J. D., \& Perrewé, P. L. (2014). The AAA (appraisals, attributions, adaptation) model of job stress. Organizational Psychology Review, 4(3), 258-278. doi: $10.1177 / 2041386614525072$

Maclean, M., Harvey, C., Gordon, J., \& Shaw, E. (2015). Identity, storytelling and the philanthropic journey. Human Relations, 68(10), 1623-1652. doi:10.1177/0018726714564199

Macy, R. J., Giattina, M. C., Parish, S. L., \& Crosby, C. (2010). Domestic violence and sexual assault services. Journal of Interpersonal Violence, 25(1), 3-32. doi:10.1177/0886260508329128

Madison, D. S. (2005). Critical ethnography: Method, ethics, and performance. Thousand Oaks, CA: SAGE Publications.

Maier, F., Meyer, M., \& Steinbereithner, M. (2016). Nonprofit organizations becoming business-like: A systematic review. Nonprofit and Voluntary Sector Quarterly, 45(1), 64-86. doi:10.1177/0899764014561796

Malin, V., Murphy, J., \& Siltaoja, M. (Eds.). (2013). Getting things done. Bingley, UK: Emerald.

Manning, J. (2016). Constructing a postcolonial feminist ethnography. Journal of Organizational Ethnography, 5(2), 90-105. doi:10.1108/JOE-01-2016-0002 
Margaret, J. (2016). Ngā Reregna o Te Tirity: Community organisations engaging with the Treaty of Waitangi. Retrieved from Auckland, NZ: https://nzfvc.org.nz/news/newresource-community-organisations-engaging-treaty

Martin, A. (2017, September 5). Sharon Osbourne on Kim Kardashian's sexy selfies: 'That's not feminism!'. UPI News Current. Retrieved from http://go.galegroup.com/ps/i.do?p=ITOF\&sw=w\&u=vuw\&v=2.1\&it=r\&id=GALE\%7 $\underline{\text { CA503528971\&asid }=1723133 \text { b9db940de1d8c653eadb43ac5 }}$

Martin, P. (2005). Rape work: Victims, gender, and emotions in organization and community context. New York, NY: Routledge.

Mason, D. E. (1996). Leading and managing the expressive dimension: Harnessing the hidden power source of the nonprofit sector (1st ed.). San Francisco, CA: Jossey-Bass Publishers.

McDonald, J. (2013a). Coming out in the field: A queer reflexive account of shifting researcher identity. Management Learning, 44(2), 127-143. doi:doi:10.1177/1350507612473711

McDonald, J. (2013b). Conforming to and resisting dominant gender norms: How male and female nursing students do and undo gender. Gender, Work \& Organization, 20(5), 561-579. doi:10.1111/j.1468-0432.2012.00604.x

McDonald, J. (2016). Expanding queer reflexivity: The closet as a guiding metaphor for reflexive practice. Management Learning, 47(4), 391-406. doi:10.1177/1350507615610029

McGovern, P. (2017). Small voluntary organisations in the 'age of austerity': Funding challenges and opportunities. London, UK: Palgrave Macmillan.

McLeod, J. (2017). The New Zealand cause report: Shape of the charity sector. Retrieved from https://www.jbwere.co.nz/assets/Uploads/JBWereNZ-CauseReport-March2017DigitalVersion.pdf:

McNay, L. (2000). Gender and agency: Reconfiguring the subject in feminist and social theory. Cambridge, UK: Polity Press.

Meyerson, D. E., \& Scully, M. A. (1995). Tempered radicalism and the politics of ambivalence and change. Organization Science, 6(5), 585-600. doi:10.1287/orsc.6.5.585

Michels, C., \& Steyaert, C. (2017). By accident and by design: Composing affective atmospheres in an urban art intervention. Organization, 24(1), 79-104. doi:10.1177/1350508416668190 
Mikaere, A. (1994). Māori women: Caught in the contradictions of a colonised reality. Waikato Law Review, 2(1), 125-149.

Milbourne, L. (2013). Voluntary sector in transition: Hard times or new opportunities? London, UK: Polity Press.

Ministry of Justice. (2016). Safer sooner: Strengthening New Zealand's Family Violence Laws. Retrieved from Wellington, NZ:

https://www.justice.govt.nz/assets/Documents/Publications/safer-sooner-report.pdf

Moraga, C. e., \& Anzaldúa, G. (Eds.). (2015). This bridge called my back: Writings by radical women of color (4th ed.). Albany, NY: SUNY Press.

Morison, T., \& Macleod, C. (2013). A performative-performance analytical approach: Infusing Butlerian theory into the narrative-discursive method. Qualitative Inquiry, 19(8), 566-577. doi:10.1177/1077800413494344

Morris, S. (2000). Defining the nonprofit sector: Some lessons from history. Voluntas: International Journal of Voluntary \& Nonprofit Organizations, 11(1), 25-43. doi:10.1023/A:1008950915555

Murgia, A., \& Poggio, B. (2009). Challenging hegemonic masculinities: Men's stories on gender culture in organizations. Organization, 16(3), 407-423. doi:10.1177/1350508409102303

Murphy, E., \& Dingwall, R. (2001). The ethics of ethnography. In P. Atkinson, A. Coffey, S. Delamont, J. Loftland, \& L. Loftland (Eds.), The handbook of ethnography (pp. 339351). London, UK: SAGE Publications.

Naples, N. A. (2003). Feminism and method: Ethnography, discourse analysis, and activist research. New York, NY: Taylor and Francis.

Neilson, B., Sedgwick, C., \& Grey, S. (2015). Outcomes plus: The added value provided by community social services. Retrieved from Wellington, NZ: http://www.communityresearch.org.nz/research/outcomes-plus/

Nentwich, J. C., Ozbilgin, M. F., \& Tatli, A. (2015). Change agency as performance and embeddedness: Exploring the possibilities and limits of Butler and Bourdieu. Culture and Organization, 21(3), 235-250. doi:10.1080/14759551.2013.851080

Neyland, D. (2008a). Organizational ethnography. London, UK: SAGE Publications.

Neyland, D. (2008b). Sensibility seven: Supplementing. In D. Neyland (Ed.), Organizational ethnography (pp. 112-125). London, UK: SAGE Publications. 
Ng, E. S., \& Rumens, N. (2017). Diversity and inclusion for LGBT workers: Current issues and new horizons for research. Canadian Journal of Administrative Sciences / Revue Canadienne des Sciences de l'Administration, 34(2), 109-120. doi:10.1002/cjas.1443

Nichols, A. J. (2011). Gendered organizations: Challenges for domestic violence victim advocates and feminist advocacy. Feminist Criminology, 6(2), 111-131. doi:10.1177/1557085111398117

Nichols, A. J. (2013). Meaning-making and domestic violence victim advocacy. Feminist Criminology, 8(3), 177-201. doi:10.1177/1557085113482727

Nichols, A. J. (2014). Feminist advocacy: Gendered organizations in community-based responses to domestic violence. Lanham, MD: Lexington Books.

Nowland-Foreman, G. (2016a). Crushed or just bruised?: Voluntary organisations - 25 years under the bear hug of government funding in Aotearoa New Zealand. Third Sector Review, 22(2), 53-69.

Nowland-Foreman, G. (2016b). Outcomes, acctounability and community \& voluntary organisations in New Zealand: Holy grail, black hole or wholly possible? Retrieved from Auckland, NZ: http://www.communityresearch.org.nz/research/outcomesaccountability-and-community-voluntary-organisations-in-new-zealand-holy-grailblack-hole-or-wholly-possible/

O'Connor, C. H., \& Baker, R. (2017). Working with and for social enterprises: The role of the volunteer ethnographer. Social Enterprise Journal, 12(2), 180-193. doi:10.1108/SEJ07-2016-0033

Ozturk, M. B., \& Rumens, N. (2014). Gay male academics in UK business and management schools: Negotiating heteronormativities in everyday work life. British Journal of Management, 25(3), 503-517. doi:10.1111/1467-8551.12061

Parker, M. (2002). Queering management and organization. Gender, Work \& Organization, 9(2), 146-166. doi:10.1111/1468-0432.00153

Parker, M. (2013). 'What is to be done?' CMS as a political party. In V. Malin, J. Murphy, \& M. Siltaoja (Eds.), Getting things done (pp. 165-181). London, UK: Emerald.

Parker, M., Cheney, G., Fournier, V., \& Land, C. (2014a). The question of organization: A manifesto for alternatives. ephemera, 14(4), 623-638.

Parker, M., Cheney, G., Fournier, V., \& Land, C. (Eds.). (2014b). The Routledge companion to alternative organization. Abingdon, UK: Routledge. 
Parker, S., \& Parker, M. (2017). Antagonism, accommodation and agonism in Critical Management Studies: Alternative organizations as allies. Human Relations, 70(11), 1366-1387. doi:10.1177/0018726717696135

Parsons, E., \& Priola, V. (2013). Agents for change and changed agents: The micro-politics of change and feminism in the academy. Gender, Work \& Organization, 20(5), 580598. doi:10.1111/j.1468-0432.2012.00605.x

Pedwell, C. (2012). Affective (self-) transformations: Empathy, neoliberalism and international development. Feminist Theory, 13(2), 163-179. doi:10.1177/1464700112442644

Pedwell, C. (2013). Affect at the margins: Alternative empathies in a small place. Emotion, Space and Society, 8, 18-26. doi:10.1016/j.emospa.2012.07.001

Peled, E., \& Dekel, R. (2010). Excusable deficiency: Staff perceptions of mothering at shelters for abused women. Violence Against Women, 16(11), 1224-1241. doi:10.1177/1077801210386775

Pence, E., \& Paymar, M. (1993). Education groups for men who batter: The Duluth model. New York, NY: Springer Publishing.

Perrewe, P. L., Halbesleben, J. R. B., \& Rosen, C. C. (Eds.). (2013). The role of emotion and emotion regulation in job stress and well being. Bingley, UK: Emerald.

Phipps, A. (2016). Whose personal is more political? Experience in contemporary feminist politics. Feminist Theory, 17(3), 303-321. doi:10.1177/1464700116663831

Poirer, D. (2013). Charity law in New Zealand. Wellington, N.Z.: The Charities Commission. Porschitz, E. T., \& Siler, E. A. (2017). Miscarriage in the workplace: An authoethnography. Gender, Work \& Organization, 24(6), 565-578. doi:10.1111/gwao.12181

Powell, W. W., \& Steinberg, R. (Eds.). (2006). The nonprofit sector: A research handbook (2nd ed.). New Haven, CT: Yale University Press.

Prasad, A., \& Prasad, P. (2002). The coming of age of interpretive organizational research. Organizational Research Methods, 5(1), 4-11. doi:10.1177/1094428102051002

Prasad, A., Prasad, P., Mills, A. J., \& Mills, J. H. (Eds.). (2015). The Routledge companion to Critical Management Studies. London, UK: Routledge.

Prasad, P. (2005). Crafting qualitative research: Working in the postpositivist traditions. Armonk, NY: M.E. Sharpe.

Pullen, A. (2018). Writing as labiaplasty. Organization, 25(1), 123-130. doi:10.1177/1350508417735537 
Pullen, A., Harding, N., \& Phillips, M. (2017a). Introduction: Feminist and queer politics in Critical Management Studies. In A. Pullen, N. Harding, \& M. Phillips (Eds.), Feminists and queer theorists debate the future of Critical Management Studies (pp. 1-11): Emerald.

Pullen, A., Harding, N., \& Phillips, M. (Eds.). (2017b). Feminist and queer theorists debate the future of Critical Management Studies: Emerald.

Pullen, A., \& Rhodes, C. (2008). Dirty writing. Culture and Organization, 14(3), 241-259. doi:10.1080/14759550802270684

Pullen, A., \& Rhodes, C. (2015). Writing, the feminine and organization. Gender, Work \& Organization, 22(2), 87-93. doi:10.1111/gwao.12084

Pullen, A., Rhodes, C., \& Thanem, T. (2017). Affective politics in gendered organizations: Affirmative notes on becoming-woman. Organization, 24(1), 105-123. doi:10.1177/1350508416668367

Pullen, A., \& Thanem, T. (2010). Sexual spaces. Gender, Work and Organization, 17(1), 1-6. doi:10.1111/j.1468-0432.2009.00497.x

Ramarajan, L., Berger, I. E., \& Greenspan, I. (2017). Multiple identity configurations: The benefits of focused enhancement for prosocial behavior. Organization Science, 28(3), 495-513. doi:10.1287/orsc.2017.1129

Rawiri Waretini, K. (2012). Takitoru: From parallel to partnership - A ritual of engagement based on Te Tiriti o Waitangi for implementing safe cultural practice in Māori counselling and social science. MAI Journal (Online), 1(1), 61-75.

Reedy, P. (2014). Impossible organisations: Anarchism and organisational praxis. ephemera, 14(4), 639-658.

Reedy, P., King, D., \& Coupland, C. (2016). Organizing for individuation: Alternative organizing, politics and new identities. Organization Studies, 37(11), 1553-1573. doi:10.1177/0170840616641983

Reedy, P., \& Learmonth, M. (2009). Other possibilities? The contribution to management education of alternative organizations. Management Learning, 40(3), 241-258. doi:10.1177/1350507609104338

Reinelt, C. (1994). Fostering empowerment, building community: The challenge for statefunded feminist organizations. Human Relations, 47(6), 685-705. doi:10.1177/001872679404700606

Rhodes, C. (2015). Writing organization/romancing fictocriticism. Culture and Organization, 21(4), 289-303. doi:10.1080/14759551.2014.882923 
Rhodes, C. (2017). Ethical praxis and the business case for LGBT diversity: Political insights from Judith Butler and Emmanuel Levinas. Gender, Work \& Organization, 24(5), 533-546. doi:10.1111/gwao.12168

Rhodes, C., \& Brown, A. D. (2005). Narrative, organizations and research. International Journal of Management Reviews, 7(3), 167-188. doi:10.1111/j.14682370.2005.00112.x

Riach, K., Rumens, N., \& Tyler, M. (2016). Towards a Butlerian methodology: Undoing organizational performativity through anti-narrative research. Human Relations, 69(11), 2069-2089. doi:10.1177/0018726716632050

Riach, K., \& Warren, S. (2015). Smell organization: Bodies and corporeal porosity in office work. Human Relations, 68(5), 789-809. doi:10.1177/0018726714545387

Riad, S. (2007). Under the desk: On becoming a mother in the workplace. Culture and Organization, 13(3), 205-222. doi:10.1080/14759550701486522

Richardson, L., \& St. Pierre, E. A. (2017). Writing: A method of inquiry. In N. K. Denzin \& Y. Lincoln, S. (Eds.), The SAGE Handbook of Qualitative research. Thousand Oaks, CA: SAGE Publications.

Ricœur, P. (1988). Time and narrative. Vol. 3 (K. Blamey \& D. Pellauer, Trans.). London, UK: University of Chicago Press.

Riessman, C. K. (2008). Narrative methods for the human sciences (2nd ed.). Los Angeles, CA: SAGE Publications.

Ristock, J. L. (2011). Intimate partner violence in LGBTQ lives. Florence, SC: Taylor and Francis.

Rodriguez, N. M. (1988). Transcending bureaucracy: Feminist politics at a shelter for battered women. Gender \& Society, 2(2), 214-227. doi:10.1177/089124388002002006

Rosaldo, R. (1989). Culture \& Truth: The remaking of social analysis. Boston, MA: Beacon Press.

Ruekgauer, A. (2017, March 16). Kim Kardashian and feminism. UWIRE Text, p. 1.

Retrieved from

http://go.galegroup.com/ps/i.do?p=ITOF\&sw=w\&u=vuw\&v=2.1\&it=r\&id=GALE\%7 CA486563412\&asid=79bd5ebd904ec0540e420da72a95277d

Rumens, N. (2015). Is your workplace 'gay-friendly'? Current issues and controversies. In F. Colgan \& N. Rumens (Eds.), Sexual orientation at work: Contemporary issues and perspectives (pp. 181-196). London, UK: Taylor and Francis. 
Rumens, N. (2016a). On the violence of heteronormativity within business schools. In T. Köllen (Ed.), Sexual orientation and transgender issues in organizations: Global perspectives on LGBT workforce diversity (pp. 389-404). Cham, Switzerland: Springer International Publishing.

Rumens, N. (2016b). Towards queering the business school: A research agenda for advancing Lesbian, Gay, Bisexual and Trans perspectives and issues. Gender, Work \& Organization, 23(1), 36-51. doi:10.1111/gwao.12077

Rumens, N. (2017). Queering lesbian, gay, bisexual and transgender identities in human resource development and management education contexts. Management Learning, 48(2), 227-242. doi:10.1177/1350507616672737

Rumens, N., \& Kerfoot, D. (2009). Gay men at work: (Re)constructing the self as professional. Human Relations, 62(5), 763-786. doi:10.1177/0018726709103457

Ryan, S. (2015). 'Not enough evidence' to show Chris Brown reformed, September 30. New Zealand Herald. Retrieved from https://www.nzherald.co.nz/entertainment/news/article.cfm?c_id=1501119\&objectid= $\underline{11521285}$

Said, E. W. (1993). Culture and imperialism (1st ed.). New York, NY: Knopf.

Said, E. W. (2003). Orientalism. London, UK: Penguin.

Salamon, L. M., \& Anheier, H. K. (1997). Defining the nonprofit sector: A cross-national analysis. New York, NY: Manchester University Press.

Sama, T. B. (2010). Conceptualizing non-governmentals: Still searching for conceptual clarity. Journal of Social and Psychological Sciences, 3, 32-54.

Sanders, J., O'Brien, M., Sokolowiski, S., \& Salamon, L. M. (2008). The New Zealand nonprofit sector in comparative perspective. Retrieved from Wellington, NZ: http://www.communityresearch.org.nz/research/the-new-zealand-non-profit-sector-incomparative-perspective/

Sanders, M. L. (2015). Being nonprofit-like in a market economy. Nonprofit and Voluntary Sector Quarterly, 44(2), 205-222. doi:10.1177/0899764013508606

Sanders, M. L., \& McClellan, J. G. (2014). Being business-like while pursuing a social mission: Acknowledging the inherent tensions in US nonprofit organizing. Organization, 21(1), 68-89. doi:10.1177/1350508412464894

Sarkar, S. (2016, April 12). Why I hate the term 'SJW'. Huffington Post. Retrieved from https://www.huffingtonpost.com/samita-sarkar/why-i-hate-the-termsjw_b_9651022.html 
Sayers, J. G., \& Jones, D. (2015). Truth scribbled in blood: Women's work, menstruation and poetry. Gender, Work \& Organization, 22(2), 94-111. doi:10.1111/gwao.12059

Schilt, K., \& Connell, C. (2007). Do workplace gender transitions make gender trouble? Gender, Work \& Organization, 14(6), 596-618. doi:10.1111/j.14680432.2007.00373.x

Schrock, R. D. (2013). The methodological imperatives of feminist ethnography. Journal of Feminist Scholarship, 5(1), 48-60.

Seigworth, G., \& Gregg, M. (2010). An inventory of shimmers. The affect theory reader (pp. 1-28). London, UK: Duke University Press.

Seymour, K. (2009). Women, gendered work and gendered violence: So much more than a job. Gender, Work \& Organization, 16(2), 238-265. doi:10.1111/j.14680432.2009.00437.x

Shaw, S., \& Allen, J. B. (2006). "We actually trust the community:" Examining the dynamics of a nonprofit funding relationship in New Zealand. VOLUNTAS: International Journal of Voluntary and Nonprofit Organizations, 17(3), 211-220. doi:10.1007/s11266-006-9018-0

Shelton, S. Z. (2017). A queer theorist's critique of online domestic violence advocacy: Critically responding to the National Coalition Against Domestic Violence website. Journal of Homosexuality, 1-24. doi:10.1080/00918369.2017.1374060

Sieben, B., \& Wettergren, ̊.. (2010). Emotionalizing organizations and organizing emotions: Our research agenda. In B. Sieben \& A. Wettergren (Eds.), Emotionalizing organizations and organizing emotions. London, UK: Palgrave Macmillan.

Sieweke, J. (2014). Pierre Bourdieu in management and organization studie: A citation context analysis and discussion of contributions. Scandinavian Journal of Management, 30(4), 532-543. doi:10.1016/j.scaman.2014.04.004

Simmonds, N. (2011). Mana wahine: Decolonising politics. Women's Studies Journal, 25(2), $11-25$.

Sinclair, A. (2011). Leading with body. In E. Jeanes, D. Knights, \& P. Martin (Eds.), Handbook of gender, work \& organization (pp. 117-130). Chichester, UK: Wiley.

Skeggs, B. (2001). Feminist ethnography. In P. Atkinson, A. Coffey, S. Delamont, J. Loftland, \& L. Loftland (Eds.), Handbook of ethnography (pp. 426-442). London, UK: SAGE Publications.

Smith, L. T. (2012). Decolonizing methodologies: Research and indigenous peoples (2nd ed.). London, UK: Zed Books. 
Spelman, A. C. (2013). A relationships framework for organisational responsiveness to Te Tiriti/Treaty of Waitangi in the work groups and organisations in the community and the public sector of Aotearoa New Zealand. (Masters thesis), University of Waikato.

Spicer, A., Alvesson, M., \& Kärreman, D. (2009). Critical performativity: The unfinished business of Critical Management Studies. Human Relations, 62(4), 537-560. doi:10.1177/0018726708101984

Spicer, A., Alvesson, M., \& Kärreman, D. (2016). Extending critical performativity. Human Relations, 69(2), 225-249. doi:10.1177/0018726715614073

Stacey, J. (1988). Can there be a feminist ethnography? Women's Studies International Forum, 11(1), 21-27. doi:10.1016/0277-5395(88)90004-0

Statistics New Zealand. (2015). Non-profit institutions satellite account: 2013. Retrieved from Wellington, NZ: http://archive.stats.govt.nz/browse_for_stats/economic_indicators/NationalAccounts/n on-profit-institutions-2013.aspx

Steyaert, C. (2015). Three women. A kiss. A life. On the queer writing of time in organization. Gender, Work \& Organization, 22(2), 163-178. doi:10.1111/gwao.12075

Suárez-Ortega, M. (2013). Performance, reflexivity, and learning through biographicalnarrative research. Qualitative Inquiry, 19(3), 189-200. doi:10.1177/1077800412466223

Sutherland, N., Land, C., \& Böhm, S. (2014). Anti-leaders(hip) in social movement organizations: The case of autonomous grassroots groups. Organization, 21(6), 759781. doi:10.1177/1350508413480254

Sveningsson, S., \& Alvesson, M. (2003). Managing managerial identities: Organizational fragmentation, discourse and identity struggle. Human Relations, 56(10), 1163-1193. doi:10.1177/00187267035610001

Swan, E. (2017a). Manifesto for feminist critical race killjoys in CMS. In A. Pullen, N. Harding, \& M. Phillips (Eds.), Feminists and queer theorists debate the future of Critical Management Studies (pp. 13-37): Emerald.

Swan, E. (2017b). What are white people to do? Listening, challenging ignorance, generous encounters and the 'not yet' as diversity research praxis. Gender, Work \& Organization, 24(5), 547-563. doi:10.1111/gwao.12165 
Swan, E., \& Fox, S. (2010). Playing the game: Strategies of resistance and co-optation in diversity work. Gender, Work \& Organization, 17(5), 567-589. doi:10.1111/j.14680432.2010.00524.x

Szabo, C. (2010). The not-for-profit Chief Executive: An insider view. (Masters Thesis), Victoria University of Wellington.

Tajfel, H., \& Turner, J. C. (1979). An integrative theory of intergroup conflict. In W. G. Austin \& S. Worchel (Eds.), The social psychology of intergroup relations (pp. 3347). Monterey, CA: Brooks/Coles.

Tamboukou, M. (2013). A Foucauldian approach to narratives. In M. Andrews, C. Squire, \& M. Tamboukou (Eds.), Doing narrative research (2nd ed., pp. 88-107). London, UK: SAGE Publications.

Tangata Whenua: Community and Voluntary Sector Research Centre. (2007). Code of Practice. Retrieved from http://www.communityresearch.org.nz/wpcontent/uploads/2011/01/COP-v2.1.pdf

Tatli, A., Ozbilgin, M., \& Karatas-Ozkan, M. (2015). Pierre Bourdieu, organization, and management. London, UK: Taylor and Francis.

Tauri, J., \& Webb, R. (2011). The Waitangi Tribunal and the regulation of Māori protest. New Zealand Sociology, 26(3), 21-41.

Te Puni Kōkiri. (2010). Arotake tūkino whānau: Literature review on family violence.

Retrieved from Te Puni Kōkiri: http://www.tpk.govt.nz/en/a-matoumohiotanga/health

Tennant, M. (1989). Paupers \& providers: Charitable aid in New Zealand. Wellington, NZ: Allen \& Unwin New Zealand Ltd.

Tennant, M. (2005). Welfare interactions: Māori, government and the voluntary sector in New Zealand. History Australia, 2(3), 1-15. doi:10.2104/ha050080

Tennant, M. (2006). Defining the nonprofit sector: New Zealand. Baltimore, MD: Johns Hopkins University Center for Civil Society Studies.

Tennant, M., O'Brien, M., \& Sanders, J. (2008). The history of the non-profit sector in New Zealand. Retrieved from Wellington, New Zealand:

http://www.communityresearch.org.nz/wp-content/uploads/formidable/sanders4.pdf

Tennant, M., Sanders, J., O'Brien, M., \& Castle, C. (2006). Defining the nonprofit sector: New Zealand. Retrieved from Office for the Community \& Voluntary Sector: https://www.parliament.nz/resource/0000115088 
Thanem, T., \& Wallenberg, L. (2015). What can bodies do? Reading Spinoza for an affective ethics of organizational life. Organization, 22(2), 235-250. doi: $10.1177 / 1350508414558725$

The Trapese Collective. (2014). Education: By the people, for the people. In M. Parker, G. Cheney, V. Fourneir, \& C. Land (Eds.), The Routledge companion to alternative organization (pp. 329-344). Abingdon, UK: Routledge.

Thedvall, R. (2017). Affective atmospheres of hope: Management model training in public reforms. Journal of Organizational Ethnography, 6(2), 87-99. doi:10.1108/JOE-012017-0003

Thiem, A. (2008). Unbecoming subjects: Judith Butler, moral philosophy, and critical responsibility. Bronx, NY: Fordham University Press.

Thomas, N. (1994). Colonialism's culture: Anthropology, travel and government. Cambridge, UK: Polity Press in association with Blackwell Publishers.

Thomas, R. (2011). Critical Management Studies on identity: Mapping the terrain. In M. Alvesson, T. Bridgman, \& H. Willmott (Eds.), Oxford handbook of Critical Management Studies: Oxford University Press.

Thomas, R., \& Davies, A. (2005a). Theorizing the micro-politics of resistance: New public management and managerial identities in the UK public services. Organization Studies, 26(5), 683-706. doi:10.1177/0170840605051821

Thomas, R., \& Davies, A. (2005b). What have the feminists done for us? Feminist theory and organizational resistance. Organization, 12(5), 711-740. doi:10.1177/1350508405055945

Thomas, R., Mills, A. J., \& Helms-Mills, J. (2004). Identity politics at work: Resisting gender, gendering resistance. London, UK: Routledge.

Thompson, M., \& Willmott, H. (2016). The social potency of affect: Identification and power in the immanent structuring of practice. Human Relations, 69(2), 483-506. doi:10.1177/0018726715593161

Tinney, J. (2008). Negotiating boundaries and roles: Challenges faced by the nursing home ethnographer. Journal of Contemporary Ethnography, 37(2), 202-225. doi:10.1177/0891241607312487

Tolich, M. (Ed.) (2001). Research ethics in Aotearoa New Zealand: Concepts, practice, critique. Auckland, NZ: Longman. 
Tomlinson, F., \& Schwabenland, C. (2010). Reconciling competing discourses of diversity? The UK non-profit sector between social justice and the business case. Organization, 17(1), 101-121. doi:10.1177/1350508409350237

Trethewey, A. (1999). Disciplined bodies: Women's embodied identities at work. Organization Studies, 20(3), 423-450. doi:10.1177/0170840699203003

Troth, A. C., Lawrence, S. A., Jordan, P. J., \& Ashkanasy, N. M. (2017). Interpersonal emotion regulation in the workplace: A conceptual and operational review and future research agenda. International Journal of Management Reviews, 20(2), 523-543. doi:10.1111/ijmr.12144

Tushman, M. L., \& Scanlan, T. J. (1981). Characteristics and external orientations of boundary spanning individuals. Academy of Management Journal, 24(1), 83-98. doi: $10.2307 / 255825$

Tyagi, S. V. (2006). Female counselors and male perpetrators of violence against women. Women \& Therapy, 29(1-2), 1-22. doi:10.1300/J015v29n01_01

Tyler, M., \& Cohen, L. (2010). Spaces that matter: Gender performativity and organizational space. Organization Studies, 31(2), 175-198. doi:10.1177/0170840609357381

Ulus, E. (2014). Workplace emotions in postcolonial spaces: Enduring legacies, ambivalence, and subversion. Organization, 22(6), 890-908. doi:10.1177/1350508414522316

Ulus, E., \& Gabriel, Y. (2018). Bridging the contradictions of social constructionism and psychoanalysis in a study of workplace emotions in India. Culture and Organization, 24(3), 221-243. doi:10.1080/14759551.2015.1131688

Vachhani, S. J. (2014). Always different? Exploring the monstrous-feminine and maternal embodiment in organisation. Equality, Diversity and Inclusion: An International Journal, 33(7), 648-661. doi:10.1108/EDI-05-2012-0047

Van Maanen, J. (1988). Tales of the field: On writing ethnography. Chicago, IL: University of Chicago Press.

Van Maanen, J. (2006). Ethnography then and now. Qualitative Research in Organizations and Management: An International Journal, 1(1), 13-21. doi:10.1108/17465640610666615

Van Maanen, J. (2010). You gotta have a grievance: Locating heartbreak in ethnography. Journal of Management Inquiry, 19(4), 338-341. doi:10.1177/1056492610370284

Waldegrave, C. (2009). Cultural, gender, and socioeconomic contexts in therapeutic and social policy work. Family Process, 48(1), 85-101. 
Walker, R. (2004). Ka whawhai tonu mātou: Struggle without end (Revised ed.). Auckland, NZ: Penguin.

Warhol, R. R., \& Lanser, S. S. (Eds.). (2015). Narrative theory unbound: Queer and feminist interventions. Colombus, OH: The Ohio State University Press.

Watson, T. J. (2009). Narrative, life story and manager identity: A case study in autobiographical identity work. Human Relations, 62(3), 425-452. doi:10.1177/0018726708101044

Wesely, J. K., Allison, M. T., \& Schneider, I. E. (2000). The lived body experience of domestic violence survivors: An interrogation of female identity. Women's Studies International Forum, 23(2), 211-222. doi:10.1016/S0277-5395(00)00073-X

Whiteman, G. (2010). Management studies that break your heart. Journal of Management Inquiry, 19(4), 328-337. doi:10.1177/1056492610370282

Wickert, C., \& Schaefer, S. M. (2015). Towards a progressive understanding of performativity in Critical Management Studies. Human Relations, 68(1), 107-130. doi:10.1177/0018726713519279

Wilson, D., Jackson, D., \& Herd, R. (2016). Confidence and connectedness: Indigenous Māori women's views on personal safety in the context of intimate partner violence. Health Care for Women International, 37(7), 707-720. doi:10.1080/07399332.2015.1107069

Wolgemuth, J. R., \& Donohue, R. (2006). Toward an inquiry of discomfort. Qualitative Inquiry, 12(5), 1012-1021. doi:10.1177/1077800406288629

Wong, Y.-L. R. (2002). Reclaiming Chinese women's subjectivities: Indigenizing "social work with women" in China through postcolonial ethnography. Women's Studies International Forum, 25(1), 67-77. doi:10.1016/S0277-5395(02)00222-4

Woolford, A., \& Curran, A. (2013). Community positions, neoliberal dispositions: Managing nonprofit social services within the bureaucratic field. Critical Sociology, 39(1), 4563. doi:10.1177/0896920512439728

Wright, C., Nyberg, D., \& Grant, D. (2012). "Hippies on the third floor": Climate change, narrative identity and the micro-politics of corporate environmentalism. Organization Studies, 33(11), 1451-1475. doi:10.1177/0170840612463316

Yanow, D. (2009). Organizational ethnography and methodological angst: Myths and challenges in the field. Qualitative Research in Organizations and Management: An International Journal, 4(2), 186-199. doi:10.1108/17465640910978427 
Yanow, D. (2012). Organizational ethnography between toolbox and world-making. Journal of Organizational Ethnography, 1(1), 31-42. doi:10.1108/202466741211220633

Young, C. (2016, February 2). The totalitarian doctrine of 'Social Justice 'Warriors'. The Observer. Retrieved from observer.com/2016/02/the-totalitarian-doctrine-of-socialjustice-warriors/ 
